\title{
The impact of post translational modification on the aggregation of the ß-amyloid peptide in the presence or absence of lipids
}

\author{
Albert Walton Pilkington IV \\ West Virginia University, apilkin1@mix.wvu.edu
}

Follow this and additional works at: https://researchrepository.wvu.edu/etd

Part of the Neurosciences Commons, and the Physical Chemistry Commons

\section{Recommended Citation}

Pilkington, Albert Walton IV, "The impact of post translational modification on the aggregation of the ßamyloid peptide in the presence or absence of lipids" (2019). Graduate Theses, Dissertations, and Problem Reports. 7479.

https://researchrepository.wvu.edu/etd/7479

This Dissertation is protected by copyright and/or related rights. It has been brought to you by the The Research Repository @ WVU with permission from the rights-holder(s). You are free to use this Dissertation in any way that is permitted by the copyright and related rights legislation that applies to your use. For other uses you must obtain permission from the rights-holder(s) directly, unless additional rights are indicated by a Creative Commons license in the record and/ or on the work itself. This Dissertation has been accepted for inclusion in WVU Graduate Theses, Dissertations, and Problem Reports collection by an authorized administrator of The Research Repository @ WVU.

For more information, please contact researchrepository@mail.wvu.edu. 
The impact of post translational modification on the aggregation of the $\boldsymbol{B}$-amyloid peptide in the presence or absence of lipids

\author{
Albert Walton Pilkington IV \\ Dissertation submitted to the \\ Eberly College of Arts and Science \\ at West Virginia University \\ in partial fulfillment of the requirements for the degree of \\ Doctor of Philosophy \\ in \\ Chemistry
}

\author{
Justin Legleiter, Ph.D., Committee Chairperson \\ Johnathan Boyd, Ph.D. \\ Terry Gullion, Ph.D. \\ Blake Mertz, Ph.D. \\ Peng Li, Ph.D. \\ C. Eugene Bennett Department of Chemistry
}

\author{
Morgantown, West Virginia \\ 2019
}

Keywords: amyloid formation, annular aggregates lipid peroxidation, lysine acetylation, methionine oxidation, oligomers, polymorphic fibrils, 


\title{
ABSTRACT \\ The impact of post translational modification on the aggregation of the $B$-amyloid peptide in the presence or absence of lipids
}

\author{
Albert Walton Pilkington IV
}

\begin{abstract}
Alzheimer's disease (AD) is a neurodegenerative condition afflicting 5.7 million Americans with no effective treatments. The pathology of $\mathrm{AD}$ is described by the formation of neurotoxic oligomers formed by the self-assembly of amyloid- $\beta(A \beta)$. The affinity of oligomers for cellular membranes disrupts calcium homeostasis and is believed to be the underlying cause of neurotoxicity; however, due to the metastability of oligomers, it has been difficult to understand their role in membrane interactions and self-assembly. Here we utilize post translational modifications (PTM) to understand the role of specific amino acids on $\mathrm{A} \beta_{40^{-}}$ membrane interactions and self-assembly. We employ ThT, AFM, CD, and polydiacetylene assays (PDA) to determine how PTMs of Met35, Lys28, and Lys16 affect the aggregation rates, population distributions, morphologies, and secondary structure of $A \beta_{40}$ in the presence or absence of a model membrane system, total brain lipid extract (TBLE). Our results show that oxidative environments promote the selective oxidation of Met35 (Met35[O]). Decreases in the magnitude of $A \beta_{40}$ aggregation was observed along with an inhibition of oligomer structural transitions to fibrils. In the presence of total brain lipid extracts (TBLE), Met35[O] showed increased aggregation rates relative to $A \beta_{40}$ and reduced peptide-membrane interactions. Isolation of oxidative effects on TBLE and $A \beta_{40}$ showed that the oxidation of the membrane was responsible for reductions in peptide-membrane interactions. Subsequent studies chemically acetylated Lys16 and Lys 28 to understand how the removal of lysine's cationic properties alters $\mathrm{A} \beta$ self-assembly and membrane-binding. Here we report that lower levels of acetylation, predominantly affecting Lys16, reduced fibrilization and oligomerization of $\mathrm{A} \beta_{40}$ while higher levels of acetylation affecting both Lys16 and Lys28 dramatically inhibited fibril formation and reduced oligomerization. In the presence of TBLE, aggregation of $A \beta_{40}$ was observed even under higher levels of acetylation. Under the influence of the membrane, fibril aggregates of $A \beta_{40}$ were observed with higher levels of acetylation producing annular aggregates suggesting the promotion of secondary aggregation pathways. Additionally, the magnitude of the peptidemembrane interactions of acetylated $\mathrm{A} \beta$ and PDA/TBLE vesicles were reduced but not absent. Collectively, these results highlight the role specific amino acids play in the assembly of $A \beta$, and how the presence of membranes modulates peptide-membrane interactions and influence aggregation pathways
\end{abstract}




\section{Dedication}

I dedicate this Ph.D. dissertation to my family

Albert Walton Pilkington III

Michelle Lynn Plumlee-Herold

Aaron Michel Pilkington

Austin Lynn Pilkington

Jenna Marie Pilkington

Emmaline Elizabeth Pilkington

Joseph Lynn Pilkington

Milena Grace Pilkington

and to the memory of...

Albert Walton Pilkington II

Gwen Dean Pilkington

with a special dedication to the love of my life

Alissa Lauren Gulette

It is only with all your love, kindness, and patience that I can achieve my dreams...

Now Thus Now Thus 


\section{Acknowledgments}

I want to say a warm-hearted thank you to everyone that has been instrumental in helping me to achieve my goals as a graduate student. It hasn't been easy, but you believed in me when I didn't believe in myself. Thank you!

Dr. Justin Legleiter, I am forever grateful for the time, effort, and patience that you have invested in me. You always supported my scientific curiosity, and for that, I'm so grateful. I will miss the times that we spent in your office talking about research and the excitement that surrounded our ideas and hypotheses even if they didn't work out. You allowed my passion for science to flourish while trying to keep me focused, which I'm sure was not an easy job. At times when I was stuck, dumbfounded, and confused, you took the time to help me understand, and if my scientific work is of any value, it is truly because of your investments in me. Justin, you have been a great mentor to me throughout my graduate career, and I only hope that I made you proud during my time here as a graduate student. I am genuinely grateful for the opportunity to have been a member of your research laboratory, and I wish you all the best in the years to come.

I would also like to thank my committee members Dr. Blake Mertz, Dr. Jonathan Boyd, Dr. Terry Gullion, and Dr. Peng Li. Thank you for your advice, guidance, and time throughout my graduate career.

I would like to personally thank Marcella Yaremchuk for taking me into her home early in my graduate career. I had no place to live and not a dime to my name, but you opened your home to me, and for that, I am grateful. Marcella, you are like a grandmother to me. You are 
kind, warmhearted, and I don't call you nearly as much as I should. I will always have a place in my heart for you, and I will genuinely miss our Sunday lunches together as a family.

To my lab mates, I have enjoyed our time together in the lab. Thank you for the positive words of encouragement and support over the years. Adewale, you are by far the hardest working individual that I have ever met, and I know you will accomplish great things. Faezeh, you have the most powerful and insightful scientific mind, and even though you doubt yourself at times, you truly are brilliant. To Sharon, sorry you had to share an office with me. Also I think that pudding is probably bad by now.

Lastly, I would like to say thank you to my best friend Kacee Caster, the dark and mysterious woman that plays with lasers all day. You have been my best friend through this experience and asked for nothing in return. You listen to me talk about my day, my pains, and my crazy ramblings. We have been through thick and thin together, and your friendship and loyalty never waver. Thank you, Kacee for being you and thank you for continuing to be my friend. 
Table of Contents

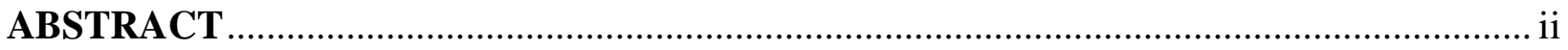

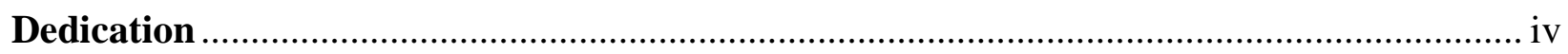

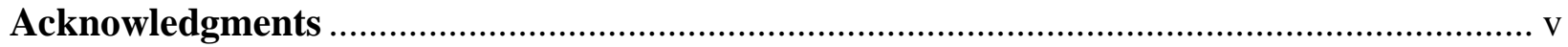

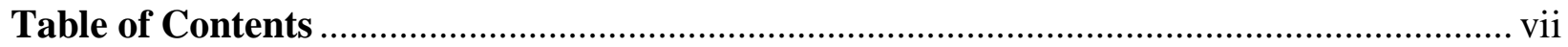

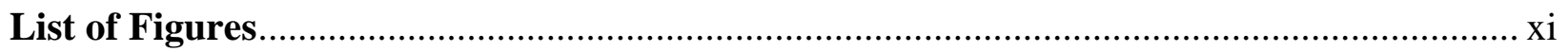

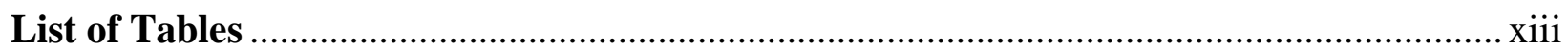

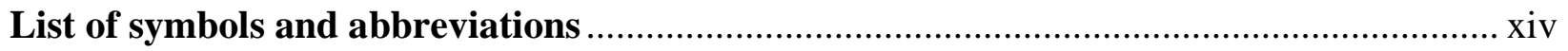

1. Introduction: Mutations, modifications, and the membrane's role in the aggregation of

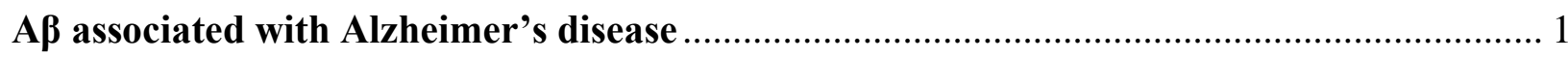

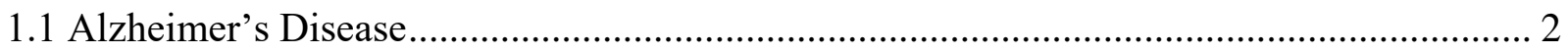

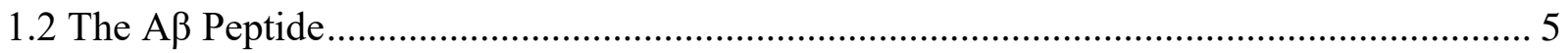

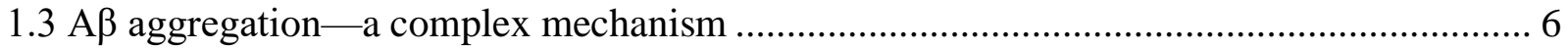

1.4 Familial Mutations and Post-Translational Modification of A $\beta$.................................. 14

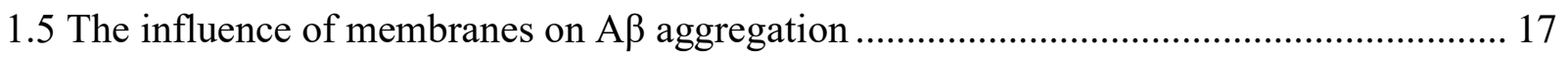

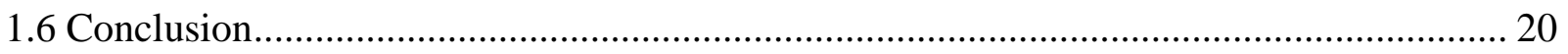

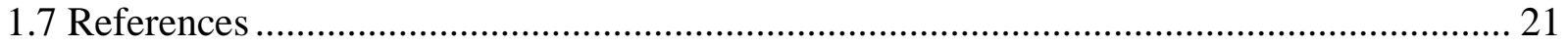

2. Hydrogen peroxide modifies A $\beta$-membrane interactions with implications for $\mathbf{A} \boldsymbol{\beta}_{40}$

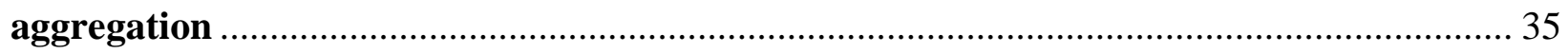

2.1 Introduction: The role of oxidation in Alzheimer's disease ....................................... 35

Table of Contents vii 
2.2 Materials and Methods 38

2.2.1 A $\beta_{40}$ Preparation ................................................................................................ 38

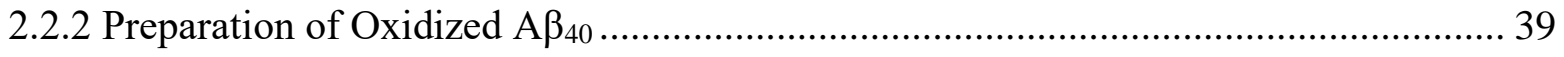

2.2.3 Liquid Chromatography Mass Spectrometry (LC-MS)............................................... 39

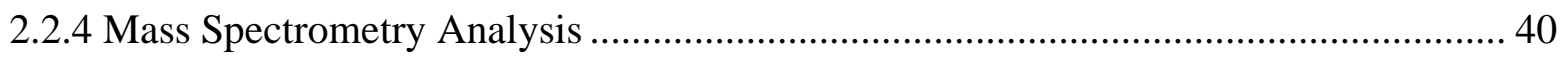

2.2.5 Sample preparation for $1 \mathrm{H}$ NMR and analysis of measurements ............................... 40

2.2.6 Thioflavin-T Fluorescence Assay (ThT) …………..................................................... 41

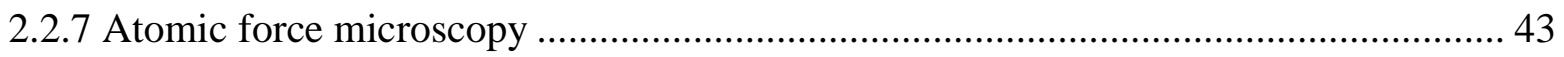

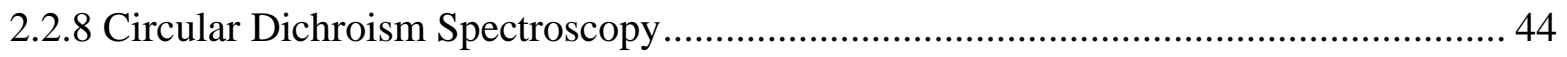

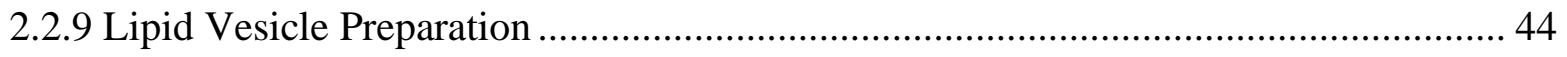

2.2.10 Preparation of TBLE/Polydiacetylene Vesicles (PDA) .............................................. 45

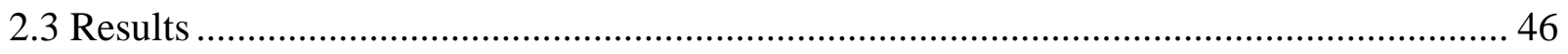

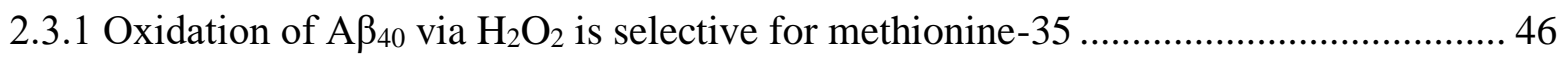

2.3.2 Methionine oxidation decreases total fibril content associated with $\mathrm{A} \beta_{40}$ aggregation 49

2.3.3 Increased oxidation modifies the distribution of $A \beta_{40}$ aggregate species .................... 52

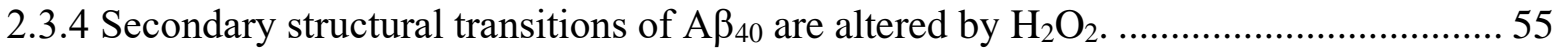

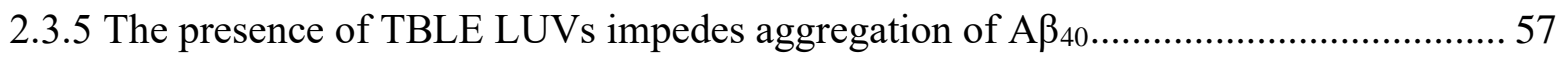

2.3.6 Oxidation reduces $A \beta /$ lipid interaction and lipid oxidation plays a large role.............. 61

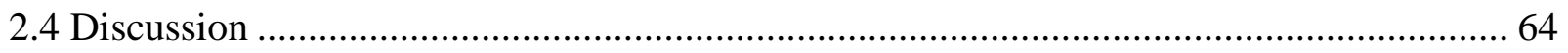

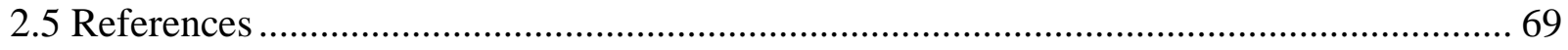

Table of Contents viii 
3. Acetylation of $\mathbf{A} \boldsymbol{\beta}_{40}$ alters aggregation in the presence and absence of lipid membranes 76

3.1 Introduction: The importance of lysine in the aggregation and membrane binding of $A \beta .77$

3.2 Materials and Methods 79

3.2.1 Peptide Preparation 79

3.2.2 Mass Spectrometry 80

3.2.3 Thioflavin-T Fluorescence Assay (ThT)..... 81

3.2.4 Lipid Vesicle Preparation 83

3.2.5 Ex situ Tapping Mode Atomic force microscopy (TMAFM) 83

3.2.6 TMAFM Image Analysis. 84

3.2.7 Preparation of TBLE/Polydiacetylene Vesicles (PDA. 84

3.3 Results 85

3.3.1 Lysine-16 is preferentially acetylated over lysine- 28 85

3.3.2 Acetylation of $A \beta_{40}$ extends the lag phase and extent of aggregation 87

3.3.3 Acetylation of $A \beta_{40}$ inhibits fibril formation and oligomerization 89

3.3.4 Exposure to TBLE membranes promotes fibrillization of acetylated $A \beta_{40}$ 97

3.3.5 TBLE promotes unique aggregate morphologies of acetylated $A \beta_{40}$ 99

3.3.6 Acetylation reduces the affinity of $A \beta_{40}$ for TBLE membranes 103

3.4 Discussion 105

References 3.5 109 
4. Outlook: Future directions for advancing the understanding of A $\beta$ aggregation in Alzheimer's disease

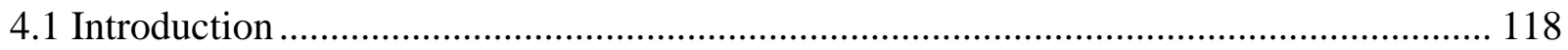

4.2 Meta-analysis of $A \beta$ sample preparation and experimental outcomes........................... 121

4.3 Real-Time tracking of $\mathrm{A} \beta$ oligomerization ........................................................ 123

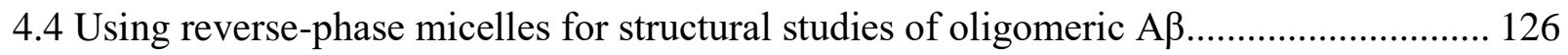

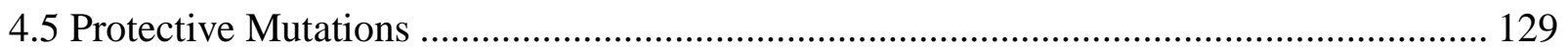

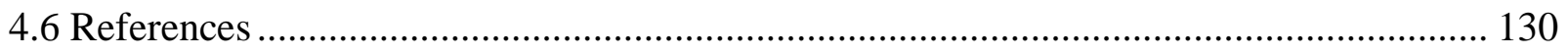




\section{List of Figures}

1.1 APP processing and subsequent $\mathrm{A} \beta$ amino acid sequence with......................................6 specific domains of interest specified.

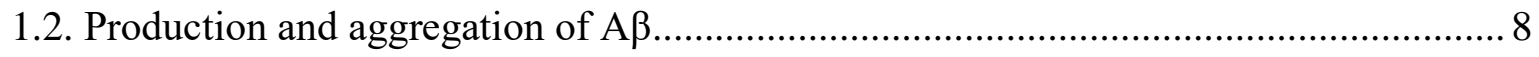

1.3. Aggregation of $A \beta$ via nucleation-dependent polymerization......................................

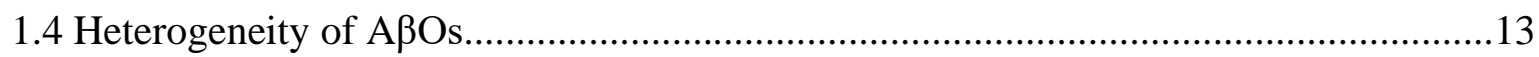

1.5. Genetic mutations and post translational modifications of the $A \beta$ sequence.................15

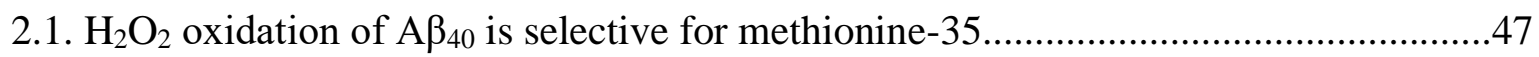

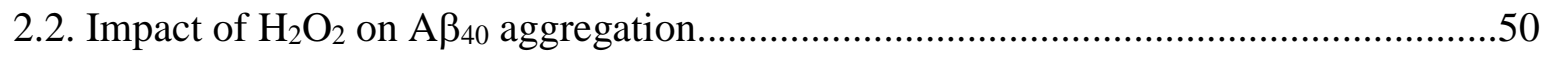

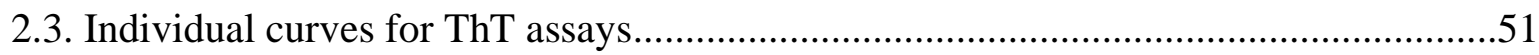

2.4. Atomic force microscopy analysis of $\mathrm{A} \beta_{40}$ aggregation..............................................53 as a function of $\mathrm{H}_{2} \mathrm{O}_{2}$ concentration.

2.5. Comparison of $\mathrm{A} \beta_{40}$ fibrils formed in the presence of varying ....................................55 concentrations of $\mathrm{H}_{2} \mathrm{O}_{2}$.

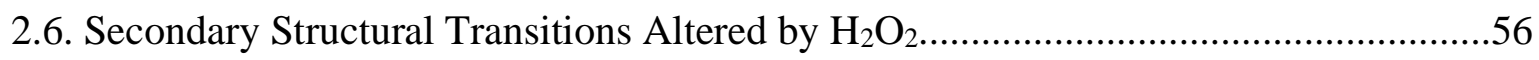

2.7. Presence of TBLE extends lag-phase of $A \beta_{40}$ aggregation.........................................58

2.8. Impact of $\mathrm{H}_{2} \mathrm{O}_{2}$ on $\mathrm{A} \beta_{40}$ aggregation in the presence of TBLE vesicles.....................60

2.9. $A \beta_{40}$ binding assays performed with TBLE/PDA vesicles...........................................62

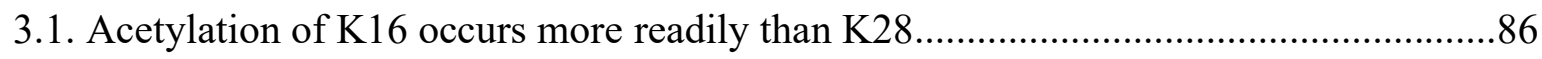


3.2. ThT assays investigating the impact or acetylation on $A \beta_{40}$ aggregation......................88

3.3. Atomic force microscopy images of $A \beta_{40}$ aggregates as a function...............................91 of increasing acetylation and time.

3.4. AFM image analysis of the impact of acetylation on $A \beta_{40}$ aggregate...........................92 populations and morphologies.

3.5. Comparison of fibril aggregates of $A \beta_{40}$ as a function of acetylation...........................96

3.6. ThT assays investigating the impact or acetylation on $A \beta_{40}$ aggregation.....................98 in the presence of TBLE LUVs.

3.7 Comparison of fibril morphologies of $A \beta_{40}$ as a function of acetylation.....................100

3.8 Acetylation of $A \beta_{40}$ in presence of TBLE produces annular aggregates......................102

3.9. Fibrils and annular aggregates often colocalize.......................................................103

3.10. Polydiacetylene binding assay of $A \beta_{40}$ at increasing states of acetylation................103

List of Figures $\quad$ xii 


\section{List of Tables}

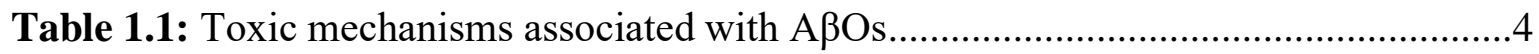

Table 1.2 Representative disaggregation, reconstitution, and miscellaneous.....................12 protocols for the preparation of $A \beta$ and observed $A \beta O$ s.

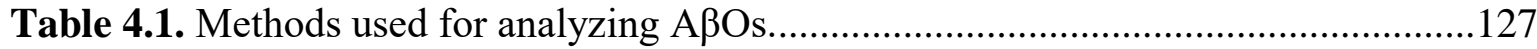

List of Tables $\quad$ xiii 


\section{List of symbols and abbreviations}

AcK16

AcK28

AD

ADDL

AFM

AOT

APP

$\mathrm{A} \beta$

$\mathrm{A} \beta 40 \mathrm{Met} 35[\mathrm{O}]$

$\mathrm{A} \beta 400 \mathrm{x}$

$\mathrm{A} \beta \mathrm{O}$

BODIPY

CD

$\mathrm{CHC}$

CSF

DMSO

EM

EPR

FAD

$\mathrm{H}_{2} \mathrm{O}_{2}$

HFIP acetylated K16

acetylated K28

Alzheimer's disease

amyloid-beta derived diffusible ligands

atomic force microscopy

sodium bis(2-ethylhexyl) sulfosuccinate

amyloid precursor protein

$\beta$-amyloid

sulfoxide $\beta$-amyloid 1-40

oxidized $\beta$-amyloid 1-40

$\mathrm{A} \beta$ oligomers

boron-dipyrromethene

circular dichroism

central hydrophobic core

cerebrospinal fluid

dimethyl sulfoxide

electron microscopy

electron paramagnetic resonance

familial Alzheimer's disease

hydrogen peroxide

hexafluoroisopropanol 
HMW

HNE

IM-MS

K16

K28

$\mathrm{L}: \mathrm{P}$

LC-MS

LMW

LPO

LUV

Met35

MS

NHSA

NMR

PDA

PICUP

PTM

PXRD

RFss

RM

ROS

$\mathrm{R}_{\text {slope }}\left(\mathrm{h}^{-1}\right)$ high molecular weight

4-hydroxy-2-nonenal

ion-mobility mass spectrometry

lysine-16

lysine-28

lipid-to-peptide

liquid chromatography mass spectrometry

low molecular weight

lipid hydroperoxide

large unilamellar vesicles

methionine-35

mass spectrometry

sulfo-N-hydroxysulfosuccinimide acetate

nuclear magnetic resonance

polydiacetylene assays

photo-induced cross-linking of unmodified proteins

post-translational modification

Powder X-ray diffraction

relative fluorescence at steady state

reverse micelles

reactive oxygen species

relative slope of growth phase 
sAD

SAXS

SCXD

SDS

SEC

SEM

TBLE

TBLE $_{O x}$

TFA

ThT

TIC

tlag

TMAFM sporadic Alzheimer's disease

small angle X-ray scattering single crystal X-ray diffraction

sodium dodecyl sulfate

size-exclusion chromatography

standard error mean

total brain lipid extract bilayers

oxidized total brain lipid extract

trifluoroacetic acid

thioflavin-T

total ion chromatogram

lag-phase time

tapping mode atomic force microscopy 


\section{Introduction: Mutations, modifications, and the membrane's role in the aggregation of $\mathrm{A} \beta$ associated with Alzheimer's disease}

Alzheimer's disease (AD) is characterized by the accumulation and deposition of fibrillar aggregates of the amyloid- $\beta$ (A $\beta$ ) peptide into neuritic plaques. These amyloid deposits were thought to play a central role in $\mathrm{AD}$; however, the correlation between plaque load and disease is weak. Increasing evidence supports the notion that a variety of small, globular aggregates of $A \beta$, referred to broadly as $A \beta$ oligomers $(A \beta O)$, may in fact be the primary culprits associated with neurotoxicity. The aggregation of $\mathrm{A} \beta$ proceeds via a nucleationdependent polymerization mechanism that is heavily influenced by changes in peptide sequence, environmental conditions, and preparatory steps. Familial point mutations of $A \beta$ produce the early onset of Alzheimer's disease but only account for a small fraction of the number of $\mathrm{AD}$ cases. Recently, the analysis of sporadic $\mathrm{AD}$ patient's cerebrospinal fluid revealed the presence of post-translationally modified forms of $A \beta$ and may represent changes to the physiochemical properties of $A \beta$ that promote secondary aggregation pathways and toxic mechanisms. Experimental evidence shows AD patients exhibit altered membrane compositions. The presence of membrane surfaces also possesses the ability to modulate the aggregation of $A \beta$, stabilize toxic intermediates such as $\mathrm{A} \beta \mathrm{O}$, and are themselves targets of $\mathrm{A} \beta$ 's toxicity. Ultimately, understanding the interplay between $A \beta$ and membranes, with respect to direct effects on $A \beta$ sequence, modification, and environmental factors is important in elucidating the underlying causes of Alzheimer's disease.

1. Introduction: Mutations, modifications, and the membrane's role in the aggregation of $A \beta$ associated with Alzheimer's disease 


\subsection{Alzheimer's Disease}

Alzheimer's disease (AD) is a fatal neurodegenerative disorder that is the most prevalent form of dementia. Neuropathological and neurochemical hallmarks of AD include: synaptic loss and selective neuronal cell death; decreases in markers for certain neurotransmitters; and abnormalities in neurons and their processes as well as in the extracellular space. Two of the main features associated with $\mathrm{AD}$ are neurofibrillary tangles comprised of the protein tau and cerebrovascular, diffuse, and neuritic plaques composed predominantly of the amyloidogenic peptide amyloid- $\beta(A \beta)$. These proteinaceous deposits of tau and $A \beta$ consist of stable amyloid fibrils, which are $\beta$-sheet rich fibrous protein aggregates. Similar deposition of amyloid is associated with numerous other diseases. ${ }^{1}$

In the early 90's, the amyloid cascade hypothesis was introduced, which postulated that A $\beta$ aggregation and deposition directly lead to neuronal death, resulting in $\mathrm{AD} .{ }^{2}$ Yet, the correlation between plaques and cognitive dysfunction in $\mathrm{AD}$ has been questionable for years, ${ }^{3-7}$ and with $A \beta$-directed therapeutic strategies failing in numerous clinical trials, the role of $A \beta$ in $A D$ progression is being re-evaluated. ${ }^{8-11}$ This has led to an enhanced research focus on diffuse, soluble aggregates of $A \beta$. Various small, globular aggregates of $A \beta$, referred to broadly as $A \beta$ oligomers $(\mathrm{A} \beta \mathrm{O})$, were detected in $\mathrm{AD}$ patients a few decades ago, ${ }^{12-14}$ and these $\mathrm{A} \beta \mathrm{O}$ were originally classified as being intermediates toward the formation of amyloid fibrils. Over the years, increasing evidence points toward $\mathrm{A} \beta \mathrm{O}$ s playing a central role in $\mathrm{AD}$, as $\mathrm{A} \beta \mathrm{O}$ s correlate

more strongly with $\mathrm{AD}$ progression in patients and animal models. ${ }^{15-19}$ For example, $\mathrm{A} \beta \mathrm{O}$ formation and buildup occurs early compared with plaque buildup (much earlier than plaque

1. Introduction: Mutations, modifications, and the membrane's role in the aggregation of $A \beta$ associated with Alzheimer's disease 
deposition) in the $\mathrm{AD}$ brain ${ }^{20-22}$ and $\mathrm{CSF},{ }^{23}$ which has led to extensive efforts to develop assays to detect $\mathrm{A} \beta \mathrm{O}$ s for potential application as biomarkers. ${ }^{24-31}$

An extensive body of evidence has linked high levels of $\mathrm{A} \beta \mathrm{O}$ s in the brain to a variety of pathogenic consequences associated with $\mathrm{AD}$ (summarized in Table 1). As such, there has been significant effort made to characterize $\mathrm{A} \beta \mathrm{O}$ formation, structure, and biochemical/biophysical characteristics (such as interactions with other proteins and lipids) in the hope that underlying modes of A $\beta O$-related toxicity could be revealed. ${ }^{32-37}$ 
Table 1.1: Toxic mechanisms associated with A $\beta O s$.

\begin{tabular}{|c|c|c|}
\hline Toxic effects of $\mathrm{A} \beta \mathrm{Os}$ & Model System & References \\
\hline Reduction in neural plasticity & mice, rat & $37-40$ \\
\hline Stimulation of tau phosphorylation & $\begin{array}{l}\text { cortical neurons (rat), hippocampal neurons, } \\
\text { neuroblastoma, primary neurons, Tg-Mice }\end{array}$ & $41-45$ \\
\hline Choline acetyltransferase Inhibition & cholinergic cell lines & 46,47 \\
\hline Oxidative stress & $\begin{array}{l}\text { cortical neurons, hippocampal neurons, in vitro, } \\
\text { neuroblastoma, }\end{array}$ & $48-51$ \\
\hline Endoplasmic reticulum stress & $\begin{array}{l}\text { cortical astrocytes, cortical neurons (rat), } \\
\text { fibroblasts, Tg-mice }\end{array}$ & $45,52,53$ \\
\hline Receptor disturbance & cortical neurons, hippocampal neurons & $54-57$ \\
\hline Insulin resistance & cortical neurons, hippocampal neurons, rat & $42,57-59$ \\
\hline Synapse deterioration & $\begin{array}{l}\text { hippocampal neurons, pyramidal neurons (rat), Tg- } \\
\text { mice, }\end{array}$ & $21,35,56,60$ \\
\hline Axonal transport & cortical neurons, hippocampal, in vitro, Tg-mice & $61-64$ \\
\hline Astrocytes/microglia effects & cortical astrocytes, Tg-mice & $43,53,65,66$ \\
\hline Cell cycle disruption & cortical neurons, Tg-mice, & 67,68 \\
\hline Selective neuron death & mice & 39,69 \\
\hline Inhibition of long-term potentiation & mice & 37,40 \\
\hline Calcium dysregulation & $\begin{array}{l}\text { cortical neurons (rat), hippocampal neurons, } \\
\text { primary neurons }\end{array}$ & $44,45,51,53$ \\
\hline Modulation of metal toxicity & neuroblastoma & 48 \\
\hline Cytoskeleton disruption & primary neurons & 49 \\
\hline $\begin{array}{l}\text { Modulation of Receptor/Channel } \\
\text { Activity }\end{array}$ & hippocampal neurons & 51 \\
\hline
\end{tabular}

1. Introduction: Mutations, modifications, and the membrane's role in the aggregation of $A \beta$ associated with Alzheimer's disease 


\subsection{The A $\beta$ Peptide}

$\mathrm{A} \beta$ is an approximately $4 \mathrm{kDA}$ peptide (typically $40-42$ amino acids long) that is derived from the transmembrane portion of the amyloid precursor protein (APP; Figure 1). The production of $A \beta$ is achieved by the sequential cleavage of APP by two membrane-bound endoprotease activities, $\beta$ - and $\gamma$-secretase. The two predominant $\mathrm{A} \beta$ peptides produced are 40 and 42 amino acids in length, and these peptides are referred to as $A \beta_{40}$ and $A \beta_{42}$ respectively. $\mathrm{A} \beta$ is amphipathic in nature (having a predominately hydrophilic $\mathrm{N}$-terminus and a predominately hydrophobic C-terminus), which is thought to drive its aggregation. As the Cterminal end of $A \beta$ coincides with the transmembrane portion of APP, $A \beta_{42}$ has a larger hydrophobic domain, making it more fibrillogenic compared to $A \beta_{40}$ and deposits to a much greater extent in the brain. ${ }^{70-72}$ Only about $10 \%$ of APP is processed via this A $\beta$ producing pathway. Most APP is cleaved by the $\alpha$-secretase, generating a series of much more benign peptide fragments.

The hydrophilic $\mathrm{N}$-terminal region of $\mathrm{A} \beta$ can adopt both an $\alpha$-helical or $\beta$-sheet structure dependent on solution conditions, for example $\mathrm{pH} .{ }^{73,74}$ The hydrophobic C-terminal end of $\mathrm{A} \beta$ has a propensity to adopt $\beta$-sheet structure upon aggregation independent of solvent conditions. ${ }^{73,74}$ Beyond its amphipathic nature, several other domains have been identified in $A \beta$. The different polymorphic fibril structures of $A \beta$ are comprised of bundled $\beta$-sheets with backbones orthogonal to the fiber axis creating a cross- $\beta$ structure, ${ }^{75}$ and two $\beta$-strand forming domains (residues 11-21 and 29-39 respectively) that are separated by a turn/bend region (around residues $23-26$ ) identified through various experimental and computational studies. ${ }^{76-79}$ The central 
region of $A \beta$ (residues 16-21), contained within one of the $\beta$-strands, has enhanced amyloidogenic properties and represents a hydrophobic core. ${ }^{80}$

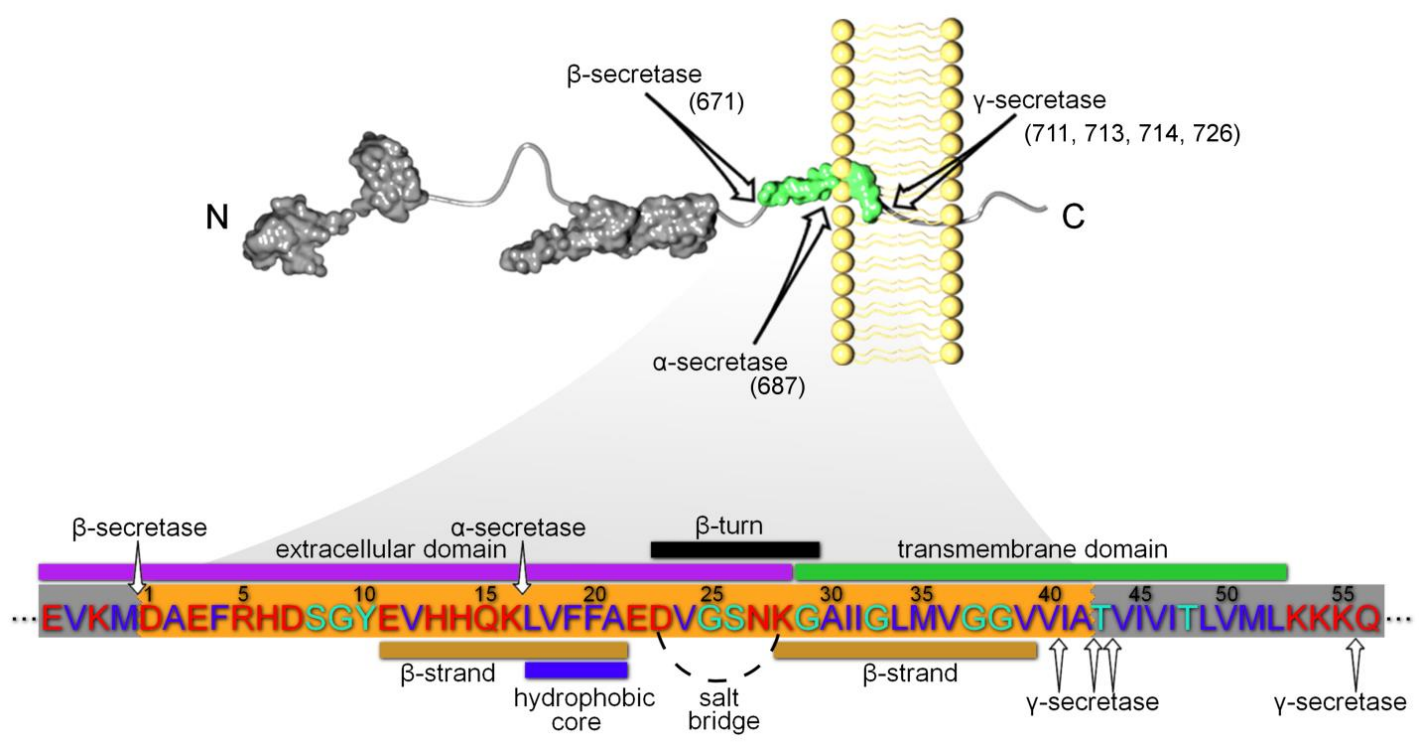

Figure 1.1 APP processing and subsequent $A \beta$ amino acid sequence with specific domains of interest specified. Proteolytic cleavage of APP is initiated at residue 671 by $\beta$-secretase followed by either non-amyloidogenic processing, cleavage at residue 687 by $\alpha$-secretase, or amyloidogenic processing, cleavage at residue 711, 713, 714, or 726 by $\gamma$ - secretase. The amino acid sequence below highlights the region of APP from which $A \beta$ is produced with the numbering referring the residues in $A \beta$. The orange highlighted region represents the intact $A \beta_{42}$ sequence. Hydropathy indexes of individual residues are color coded according to hydrophobic (blue), slightly hydrophobic (light green), and hydrophilic (red). Regions of interest and cites of secretase activity within the APP and A $\beta$ are indicated.

\subsection{A $\beta$ aggregation-a complex mechanism}

The aggregation of $\mathrm{A} \beta$ (and other amyloid-forming proteins) is typically characterized in terms of fibril formation (Figure 1.2). A $\beta$ fibril formation occurs via a complex aggregation pathway. Fundamentally, AßOs can be subdivided into species that are intermediates in fibrils formation (referred to as being on pathway) or species that do not directly lead to fibrils (referred to as being off pathway). This is a contributing factor to the immense heterogeneity observed in 
$\mathrm{A} \beta \mathrm{O}$ populations as will be discussed in more detail later. In general, amyloid formation proceeds via a nucleation dependent polymerization mechanism (Figure 1.3) ${ }^{81-83}$ With this mechanism, aggregation initially occurs via a slow nucleation phase (often called the lag phase) that involves the formation of a thermodynamically unfavorable critical nucleus that is associated with a transition from a native to non-native protein conformation. For $\mathrm{A} \beta$, the critical nucleus is likely a multimeric species. ${ }^{84-86}$ Once the critical nucleus has formed, an elongation or growth phase (characterized by a relatively rapid extension of fibril aggregates) occurs. While numerical models can extract important parameters (lag phase times, elongation rates, critical nucleus size) from experimental data, ${ }^{87}$ the actual aggregation pathway toward fibrils can be complicated. For example, other on pathway intermediates, like protofibrils, are also observed in $A \beta$ aggregation. Protofibrils are amyloid-like, elongated aggregates with filament-like morphologies and are latestage intermediate precursors on the aggregation pathway to fibrils. A key aspect that facilitates on and off pathway aggregation routes and complicates investigations of $\mathrm{A} \beta \mathrm{Os}$ is that they possess structural plasticity and are metastable and transient in nature.

1. Introduction: Mutations, modifications, and the membrane's role in the aggregation of $A \beta$ associated with Alzheimer's disease 


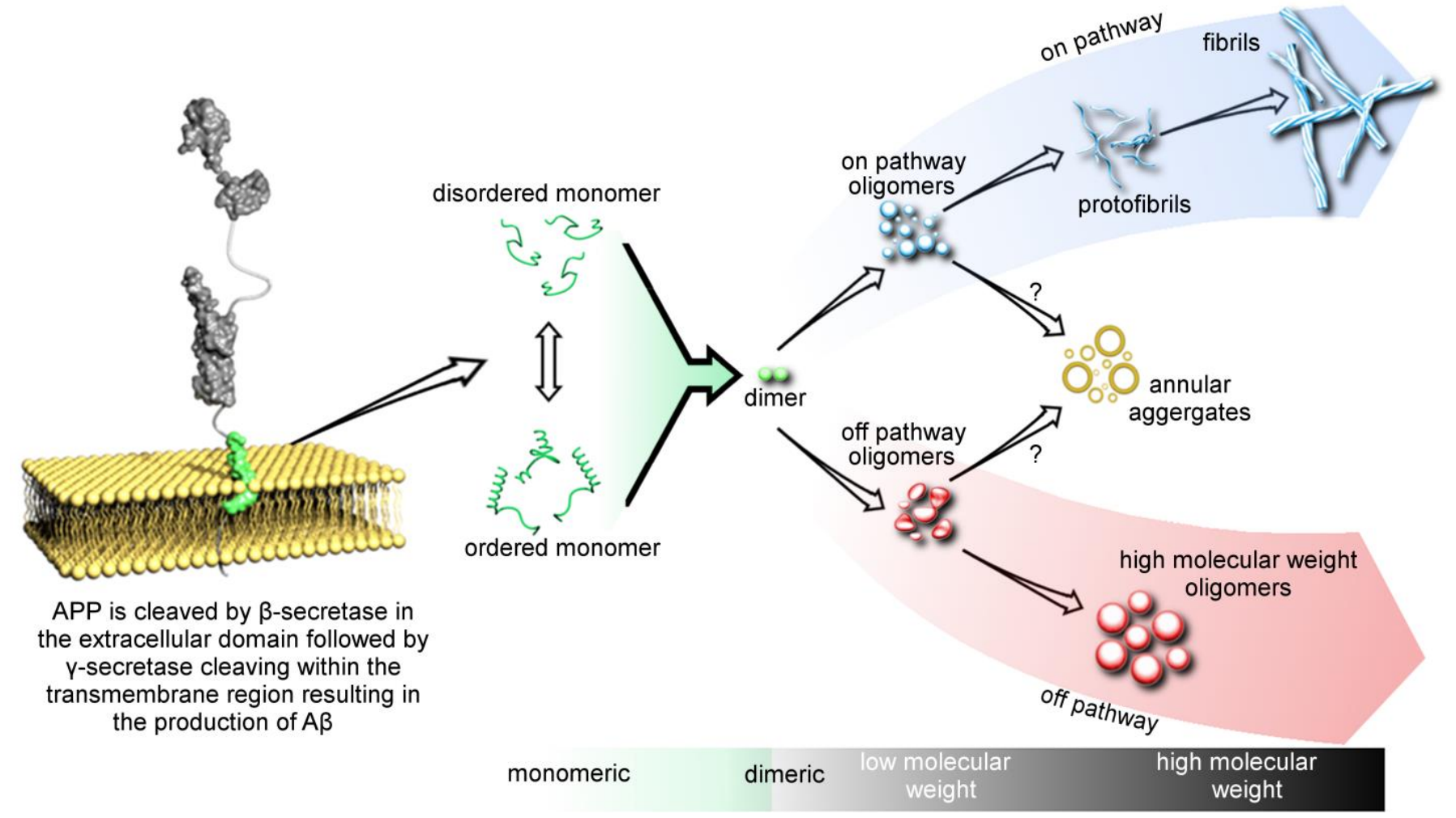

Figure 1.2. Production and aggregation of Aß. $A \beta$ is a cleavage product of $A P P, a$ transmembrane protein. Monomeric A $\beta$ transitions between ordered and disordered states. Once dimerization occurs, subsequent aggregation occurs either on pathway or off pathway with respect to fibril formation. The aggregates associated with these different pathways increase in molecular weight from the left to the right of the schematic. Fibrillization can proceed via several potential pathways that can populate various intermediate aggregate states, including oligomers and protofibrils. Off-pathway oligomers of various size may also form. Annular aggregates of A $\beta$ can also form and are thought to potentially be associated with forming pore-like structures.

1. Introduction: Mutations, modifications, and the membrane's role in the aggregation of $A \beta$ associated with Alzheimer's disease 


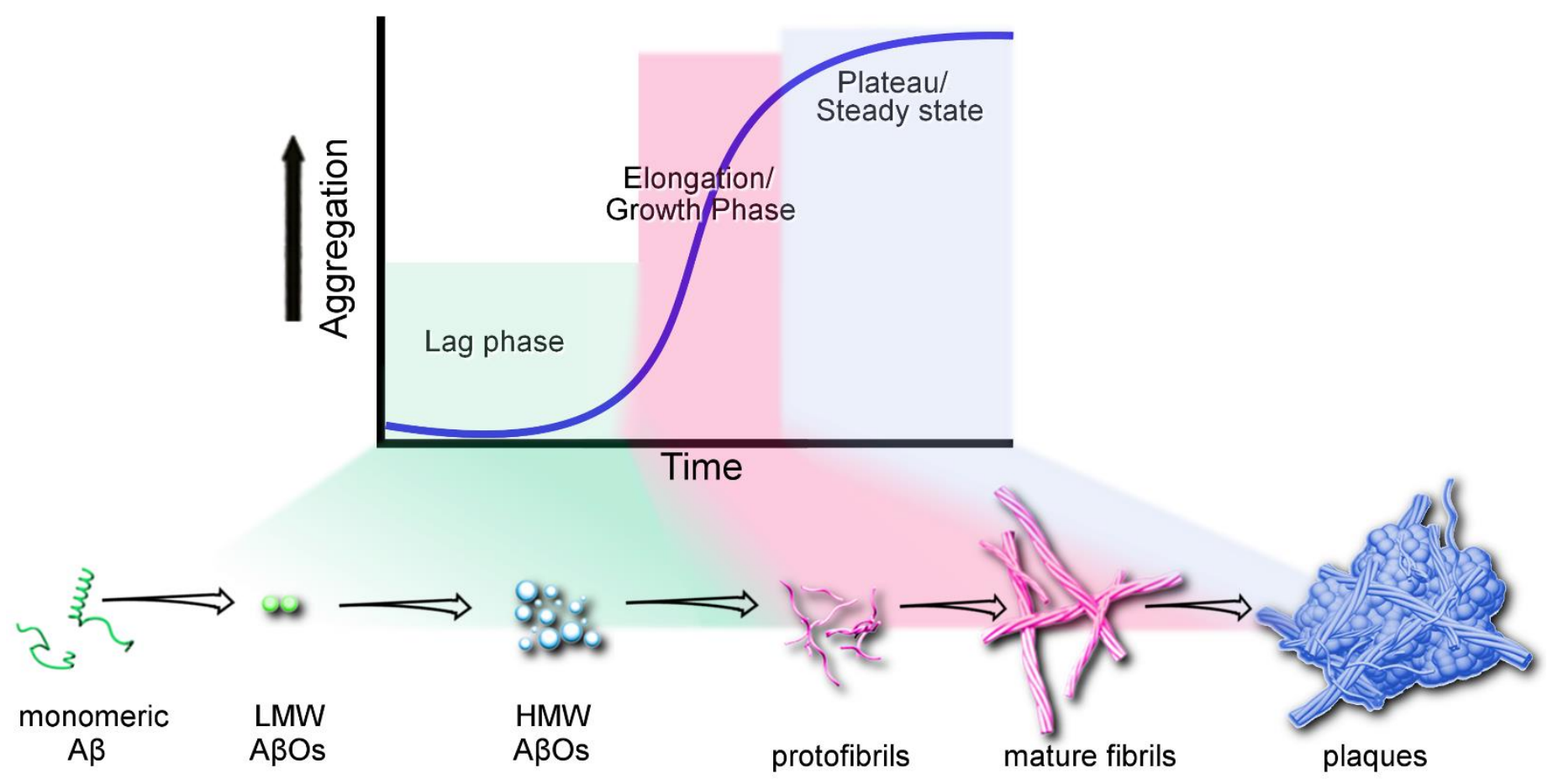

Figure 1.3. Aggregation of $\mathbf{A} \boldsymbol{\beta}$ via nucleation-dependent polymerization. The thioflavin- $T$ (ThT) curve is representative of the aggregation of $A \beta$ toward fibril aggregates. This sigmoidal curve is defined by three distinct regions First, the initial lag-phase (green) is defined by the formation of LMW A $\beta O s$ and HMW A $\beta O s$ as $A \beta$ forms the critical nucleus necessary for fibrillization. Aggerate species generated during the lag-phase are ThT-negative. Second, upon formation of the critical nucleus fibril formation is initiated and the elongation phase of the curve begins. This elongation/growth phase (pink) is dominated by a mixture of HMWABOs which are ThT-negative, and to a greater extent small ThT-positive protofibril structures. Third, as the protofibrils increase in size and associate to form mature fibrils and plaques the ThT signal ultimately reaches a plateau (blue).

Further complicating the issue is the observation that $\mathrm{A} \beta$ can aggregate into a variety of morphologically distinct fibril structures, referred to as polymorphs. ${ }^{88-92}$ This phenomenon is predicated on subtle changes of environmental conditions associated with aggregation, and as a result, preparatory protocols employed in experiments determines the resulting A $\beta$ fibril morphology. ${ }^{89}$ While polymorphic aggregates are readily observed within in vitro studies using synthetic $A \beta$, polymorphic structures have been observed in amyloids derived from tissue, and it

1. Introduction: Mutations, modifications, and the membrane's role in the aggregation of $A \beta$ associated with Alzheimer's disease 
is thought that variations in $\mathrm{A} \beta$ aggregate morphologies may play an important role in $\mathrm{AD} .{ }^{93,94}$ For example, polymorphic aggregates and fibrils may result in distinct biological activities and levels of toxicity that could underlie variations in $\mathrm{AD},{ }^{78}$ and distinct fibril structures can be directly associated with individual $\mathrm{AD}$ patients and clinical phenotype. ${ }^{95,96}$

A complicating factor in evaluating and comparing studies aimed at elucidating $A \beta$ formation, structure, and physiological impact is divergent experimental conditions, such as $A \beta$ preparation protocols, heavily influences experimental outcomes. In terms of oligomers, the emergence of distinct fibril structure strongly suggests that there would also be distinct oligomeric precursors associated with their formation. Indeed, distinct $\mathrm{A} \beta \mathrm{O}$ species can be observed within in vitro aggregation assays under conditions that result in fibril polymorphs (Figure 1.4) ${ }^{97}$ For studies conducted with synthetic peptide, there are a variety of protocols used to solubilize $\mathrm{A} \beta$ (Table 1.2). Typically, these protocols consist of a disaggregation step and a reconstitution step. The disaggregation steps usually involve the use of hydrogen bond disrupting solvents, i.e., hexafluoroisopropanol (HFIP) or trifluoroacetic acid (TFA), that break down preexisting aggregates within lyophilized stocks of $\mathrm{A} \beta$. These solvents are often removed under vacuum, leaving a peptide film. The reconstitution step involves dissolving these peptide films into a solvent that facilitates dilution into an appropriate buffer. Dimethyl sulfoxide (DMSO) is often used, creating a concentrated stock that is diluted into the desired buffer. Disaggregation and reconstitution can also be facilitated by changes in $\mathrm{pH}$. Sometimes reconstitution is performed directly into the final buffer. Importantly, variations in preparatory protocols indeed result in different populations of oligomers (Table 1.2 and Figure 1.4), and these variations can complicate direct comparisons between different reports within the literature. Further

\section{Introduction: Mutations, modifications, and the membrane's role in the} aggregation of $A \beta$ associated with Alzheimer's disease 
complicating the issue, there are often distinctions observed between studies performed with synthetic $A \beta$ and naturally derived $A \beta .{ }^{98}$ In many studies aimed at elucidating activity of $A \beta O$, specific preparations are used to obtain a particular population of oligomer species. These are then directly applied to different model systems, ranging from cell culture to animal models. However, there is often a lack of effort to verify that once added to the model system (which can often be a pronounced change in chemical environment) that these $\mathrm{A} \beta \mathrm{O}$ species do not dissociate or aggregate into a different $A \beta O$ or $A \beta$ aggregates. To truly relate specific $A \beta O$ s to a neurotoxic activity, effort should be invoked to attempt additional controls of this type. 
Table 1.2. Representative disaggregation, reconstitution, and miscellaneous protocols for the preparation of $A \beta$ and observed $A \beta O$ s.

\begin{tabular}{|c|c|c|c|c|c|}
\hline Classification & Disaggregation & Reconstitution & Miscellaneous & Result & References \\
\hline ADDLs & None & $\begin{array}{l}\text { F12 Media } 4 \\
{ }^{\circ} \mathrm{C}\end{array}$ & $\begin{array}{l}\text { Centrifuged } 14,000 \\
\times \mathrm{g} \text { for } 10 \mathrm{mins}\end{array}$ & $\begin{array}{l}\text { 5-6 nm by } \\
\text { AFM } \\
\text { (height) }\end{array}$ & 39 \\
\hline ADDLs & HFIP & $\begin{array}{l}\mathrm{DMSO} \text { at } 5 \\
\mathrm{mMA} \beta\end{array}$ & $\begin{array}{l}\text { Sonicate } 5 \text { mins, } \\
\text { dilute with } \\
\text { DMEM/F12 Media }\end{array}$ & A11+ & 99 \\
\hline Globulomers & HFIP & $\begin{array}{l}\mathrm{DMSO} \text { at } 5 \\
\mathrm{mMA} \beta\end{array}$ & $\begin{array}{l}\text { Sonicate } 10 \text { mins, } \\
\text { dilute PBS }+0.05 \% \\
\text { SDS }\end{array}$ & $\begin{array}{l}16-56 \mathrm{kDa} \\
\text { by SDS- } \\
\text { PAGE }\end{array}$ & 100 \\
\hline Globulomers & HFIP & $\begin{array}{l}\mathrm{DMSO} \text { at } 5 \\
\mathrm{mMA} \beta\end{array}$ & $\begin{array}{l}\text { Dilute PBS + 0.05\% } \\
\text { SDS, Dialyze }\end{array}$ & $\begin{array}{l}38-48 \mathrm{kDa} \\
\text { by SDS- } \\
\text { PAGE }\end{array}$ & 101 \\
\hline $\mathrm{A} \beta * 56$ & HFIP & $\begin{array}{l}\text { DMSO at } 5 \\
\mathrm{mMA} \beta\end{array}$ & $\begin{array}{l}\text { Sonicate } 20 \mathrm{~min} \text {, } \\
\text { PBS }+0.2 \% \mathrm{SDS} \\
\text { incubate } 6 \mathrm{~h} \text {, dilute } \\
\text { and incubated } 18 \mathrm{~h} \text {; } \\
\text { centrifuge } 3000 \times \mathrm{g} \text {, } \\
\text { dialysis }\end{array}$ & $\begin{array}{l}56 \mathrm{kDa} \text { by } \\
\text { Native- } \\
\text { PAGE }\end{array}$ & 102 \\
\hline $\mathrm{A} \beta \mathrm{Os}$ & HFIP & DMSO & $\begin{array}{l}\text { F12 Media incubated } \\
\text { at } 4{ }^{\circ} \mathrm{C} \text { for } 24 \mathrm{~h}\end{array}$ & $\begin{array}{l}1-4 \mathrm{~nm} \text { by } \\
\text { AFM }\end{array}$ & 103,104 \\
\hline $\mathrm{A} \beta \mathrm{Os}$ & $\mathrm{HFIP} / \mathrm{NH}_{4} \mathrm{OH}$ & $\begin{array}{l}10 \mathrm{mM} \text { Tris- } \\
\mathrm{HCl}\end{array}$ & Addition of $\mathrm{Zn}^{2+}$ & $\begin{array}{l}10-12 \mathrm{~nm} \\
\text { by AFM }\end{array}$ & 99 \\
\hline $\mathrm{A} \beta \mathrm{Os}$ & $\begin{array}{l}\text { TFA/HFIP } \\
(2 \mathrm{Xs})\end{array}$ & $2 \mathrm{mM} \mathrm{NaOH}$ & $\begin{array}{l}\text { PBS Centrifuge } \\
386,000 \times \mathrm{g}\end{array}$ & $\begin{array}{l}2.5 \mathrm{~nm} \text { by } \\
\text { AFM }\end{array}$ & 89,97 \\
\hline $\mathrm{A} \beta \mathrm{Os}$ & $\begin{array}{l}\text { TFA salt/2 } \\
\mathrm{mM} \mathrm{NaOH}, \\
\mathrm{pH} \sim 10.5,1 \\
\text { min sonication }\end{array}$ & PBS & - & $\begin{array}{l}3-12 \mathrm{~nm} \text { by } \\
\text { AFM }\end{array}$ & 105 \\
\hline $\mathrm{A} \beta \mathrm{Os}$ & $\begin{array}{l}10 \% \mathrm{NH}_{4} \mathrm{OH} \\
(\mathrm{w} / \mathrm{v}) \\
\text { sonicated } 5 \\
\text { mins, } \\
\text { lyophilized }\end{array}$ & $60 \mathrm{mM} \mathrm{NaOH}$ & - & $\begin{array}{l}1-10 \mathrm{~nm} \text { by } \\
\text { DLS }\end{array}$ & 106 \\
\hline A $\beta$ Os LMW & - & DMSO & $\begin{array}{l}\text { Sonicate } 1 \mathrm{~min}, \\
\text { centrifuge } 16,000 \times \mathrm{g} \text {, } \\
\text { SEC, PBS, PICUP } \\
\text { crosslinking }\end{array}$ & $\begin{array}{l}4-26 \mathrm{kDa} \\
\text { by SDS- } \\
\text { PAGE }\end{array}$ & 107 \\
\hline
\end{tabular}

1. Introduction: Mutations, modifications, and the membrane's role in the aggregation of $A \beta$ associated with Alzheimer's disease 

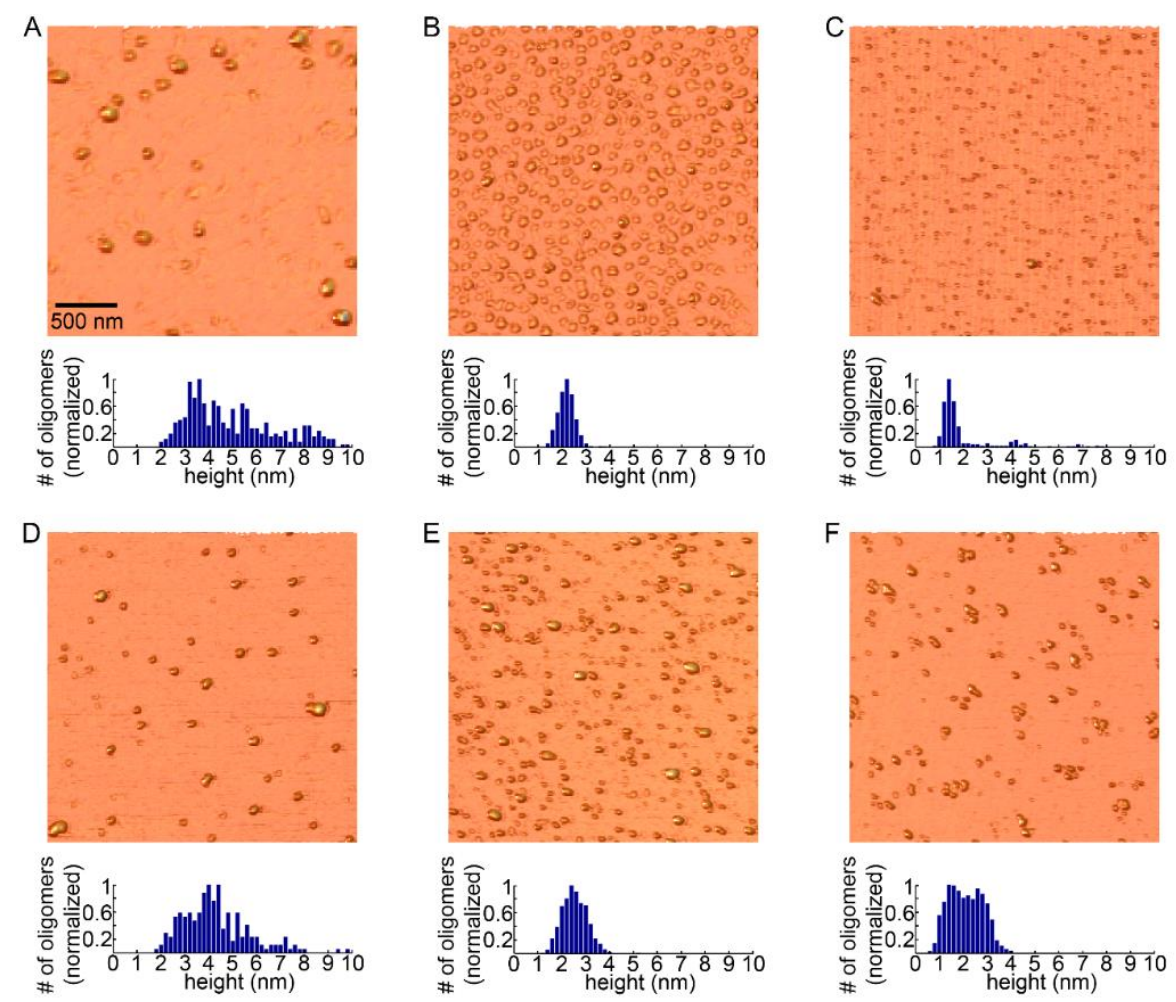

Figure 1.4. Heterogeneity of AßOs. A series of atomic force microscopy images and size analysis, i.e. height histograms, of ABOs formed from synthetic $A \beta$ that had been prepared by some of the protocols described in Table 2. The ABOs were prepared in the following way: (A) protocol provided in the AggreSure $\beta$-amyloid kits available from AnaSpec which consists of a reconstitution step directly into Tris buffer with bath sonication; (B) $10 \% \mathrm{NH}_{4} \mathrm{OH}$ disaggregation buffer, followed by additional treatment with HFIP, and reconstitution in $2 \mathrm{mM} \mathrm{NaOH}(\mathrm{pH}>11)$ with subsequent dilution into Tris buffer; (C) $10 \% \quad \mathrm{NH}_{4} \mathrm{OH}$ disaggregation buffer, and reconstitution in $60 \mathrm{mM} \mathrm{NaOH}(\mathrm{pH}>11)$ with subsequent dilution into HEPES buffer; (D) HFIP disaggregation, reconstitution in DMSO, followed by dilution into PBS; (E) TFA disaggregation with sonication, an additional HFIP disaggregation step, reconstitution with $\mathrm{NaOH}$, and dilution into PBS; $(F)$ No disaggregation step and direct reconstitution in to phosphate buffer.

1. Introduction: Mutations, modifications, and the membrane's role in the aggregation of $A \beta$ associated with Alzheimer's disease 


\subsection{Familial Mutations and Post-Translational Modification of A}

A number of mutations within $A \beta$ are associated with Familial forms of Alzheimer's disease (FAD), which are often characterized by early onset or other variations in disease progression. FAD mutations consist of single point mutations in the amino acid sequence of $A \beta$ and produced a variety of $\mathrm{AD}$ symptoms including seizures, cardiovascular degradation, and cerebral amyloid angiopathy. ${ }^{108}$ Primarily, FAD mutations of $\mathrm{A} \beta$ are located within the turn region and central hydrophobic core of A $\beta$ (E22Q Dutch, E22K Italian, D23N Iowa, E22G Arctic,) which promote increased aggregation and stabilization of unique aggregate species (Figure 1.5). Additionally FAD mutations within the N-terminal region (English H6R, Tottori $\mathrm{D} 7 \mathrm{~N}$ ) or C-terminal region (Piedmont L34V) also promote the accelerated fibril formation of $A \beta .{ }^{108}$ For the FAD mutations mentioned above, the disease outcomes are principally associated with increased A $\beta$ aggregation as APP processing remains unchanged. Additionally, some point mutations within $A \beta$ slow $A \beta$ aggregation (A21G Flemish and $\mathrm{K} 16 \mathrm{~N}$ ) and instead promote increased secretion of $A \beta$ resulting in early onset of $A D .{ }^{108}$ Some FADs are associated with altered APP processing, such as increased production of $A \beta$ or promoting $A \beta 42$ over $A \beta 40$. FADs, however, only make up 5\% of the total cases of $\mathrm{AD}$ and do not explain the other $95 \%$ of sporadic Alzheimer's disease (sAD) cases. ${ }^{109}$ Collectively, the ability of single point mutations to modify the $A \beta$ aggregation process and resulting aggregate structures demonstrates that single amino acids within the peptide can heavily influence aggregation. 


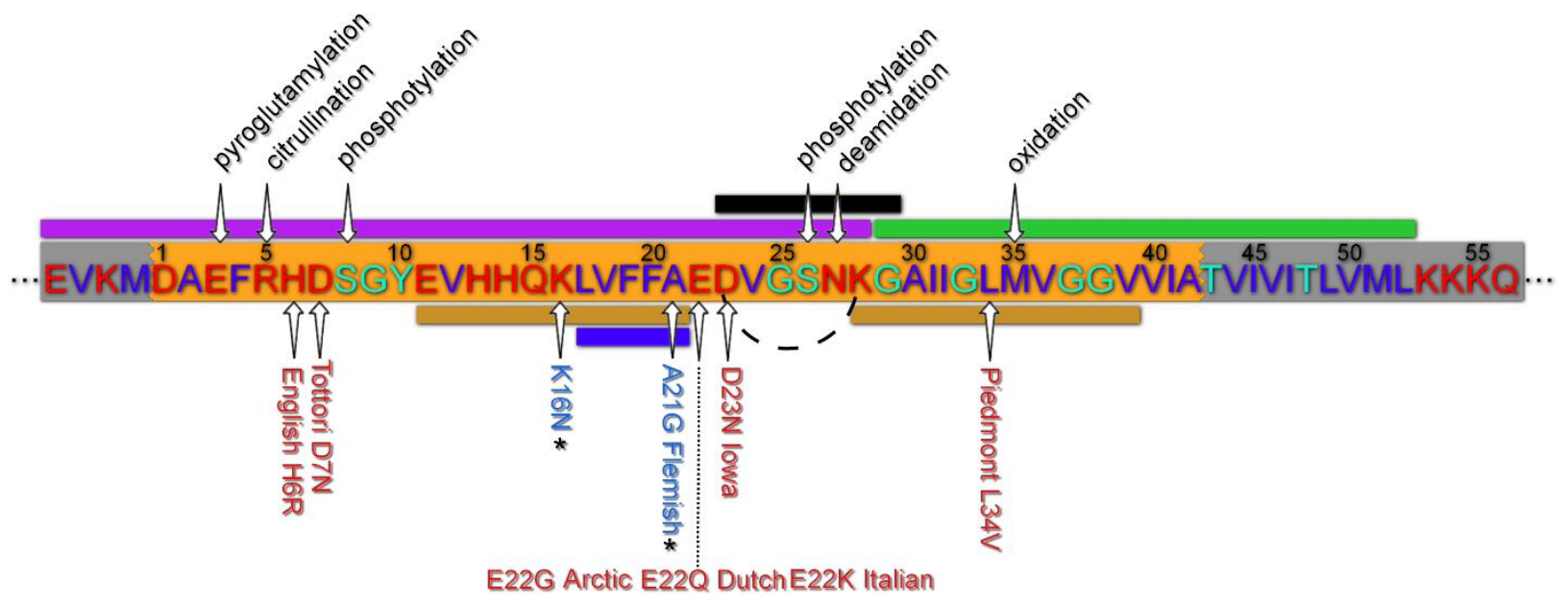

Figure 1.5. Genetic mutations and post translational modifications of the $A \beta$ sequence. Familial mutations and post translation modifications of the $A \beta$ amino acid sequence, highlighted in orange, within APP. Familial mutations are represented below the A $\beta$ sequence with mutations that increase aggregation of $A \beta$ colored red and mutations that slow aggregation highlighted in blue. Familial mutations that are responsible for increased production of $A \beta$ are denoted with an asterisk. Located above the $A \beta$ sequence are the post-translational modifications of $A \beta$ with arrows denoting the location and type of modification. Hydropathy indexes of individual residues are color coded according to hydrophobic (blue), slightly hydrophobic (light green), and hydrophilic (red). Familial and post translational modifications of $A \beta$ shown here are not inclusive.

Aging is known to be the largest risk factor of Alzheimer's disease. The deregulation of cellular mechanisms governing post-translationally modified (PTMs) is also modified with increases in age. ${ }^{110-112}$ Analysis of sAD patient's senile plaques and cerebrospinal fluid (CSF) shows that $A \beta$ is post-translationally modified. ${ }^{113}$ Whether PTMs of $A \beta$ are directly responsible for the initiation of the amyloid cascade is still unclear; however, aggregation of tau has been directly linked its hyperphosphorylation. Post translational modifications of $A \beta$ involve phosphorylation, oxidation, pyroglutamination, deamidation, and citrullination. A number of these modifications directly influence the $\mathrm{A} \beta$ aggregation process and resulting aggregate species.

1. Introduction: Mutations, modifications, and the membrane's role in the aggregation of $A \beta$ associated with Alzheimer's disease 
Phosphorylation of $A \beta$ in vivo occurs primarily at serine- 8 and $26 .{ }^{114-116}$ Specifically, phosphorylation of $A \beta$ at serine-8 is known to accelerate aggregation and promote oligomerization. ${ }^{114}$ Phosphorylated $\mathrm{A} \beta$ also exhibits increased toxicity in Drosophila models, and is found within the core of senile plaques suggesting its involvement in the early stages of aggregation. ${ }^{114}$ Pyroglutamination of $A \beta\left(A \beta_{p} E 3-40 / 42\right)$ involves the removal of two N-terminal amino acids, aspartic acid- 1 and alanine- 2 , in the $A \beta$ sequence. This truncation is followed by the dehydration and cyclization of the new N-terminus of $A \beta$ by the enzyme glutaminyl cyclase. ${ }^{117}$ This change in the $\mathrm{N}$-terminal charge state of $\mathrm{A} \beta$ creates a peptide that is more hydrophobic and therefore $A \beta_{p} E 3-40 / 42$ produces persistent oligomeric aggregates with increased rates of fibril formation. ${ }^{118,119}$ Furthermore, analysis of CSF in sAD patients revealed that the ratio of $\mathrm{A} \beta_{\mathrm{p}} \mathrm{E}$ $40 / 42$ to $A \beta_{40} / A \beta_{42}$ is increased suggesting pyroglutamination plays a role in late onset Alzheimer's disease. ${ }^{113}$ These observations further indicate that changes in the $\mathrm{A} \beta$ peptide at the single amino acid level can have a profound impact on the aggregation process, and hence AD.

$\mathrm{A} \beta$ can also undergo PTMs that are more frequently associated with the aging process. ${ }^{120,121}$ Oxidation of $A \beta$ via reactive oxygen species (ROS) occurs primarily at metionine35 , in the absence of metals, ${ }^{122-125}$ and the modification of the hydrophobic methionine to a hydrophilic residue within the C-terminus region is suggested to reduce toxicity. ${ }^{126-128}$ Interestingly, further oxidation from the sulfoxide to sulfone derivative of methionine restores toxicity, providing evidence of the fine line between toxic and nontoxic forms of $A \beta .{ }^{127}$ Additional evidence has implicated methionine in initiating radical chain reactions within cellular membranes leading to increased lipid peroxidation and the formation of ion-channel-like structures within the membrane. ${ }^{129-131}$ The increased lipid peroxidation appears to create a 
feedback loop in which lipid peroxidation products like 4-hydroxy-2-nonenal (HNE) can PTM $\mathrm{A} \beta$ forming $\mathrm{A} \beta$-HNE adduct which have an increased affinity for cellular membranes. ${ }^{132}$

Deamidation and citrullination are PTMs that have also been suggested to be affected by the aging process. ${ }^{120}$ Deamidation, involving the transition of an amide to a carboxylic acid, within $A \beta$ results in the generation of a negative charge upon replacing asparagine- 27 with aspartic acid via chemical modification. This deamidation significantly reduces the rate of fibril formation and promotes stable oligomeric intermediates of $A \beta_{40 / 42}$ with an antiparallel $\beta$-sheet structure which has been postulated to be a toxic conformation of $\mathrm{A} \beta \mathrm{O} .{ }^{133}$ Citrullination of $\mathrm{A} \beta$, involving the conversion of arginine-3 to an amide functional group, showed a marked reduction in fibrillization of $A \beta_{40}$ but not for $A \beta_{42 .}{ }^{133}$ Citrullinated $A \beta$ forms oligomeric and fibril structures, but was suggested to have alter $\beta$-sheet characteristic associated with fibril formation. Further analysis of $\mathrm{AD}$ brains reveals that citrullinated forms of $\mathrm{A} \beta$ are also localized within amyloid plaques. ${ }^{134,135}$ Collectively, point mutations of FADs and the PTM of A $\beta$ found in SAD patients helps to illustrate the significant role that individual amino acids can play in aggregation, structure, and toxicity of $A \beta$.

\subsection{The influence of membranes on A $\beta$ aggregation}

As previously discussed, $A \beta$ aggregation is highly susceptible to sample preparation and environmental factors. While variations in sample preparation produce distinct polymorphs, ${ }^{89}$ the presence of surfaces also modulates aggregate morphology. For example, A $\beta$ aggregates into linear nanowires along the underlying lattice structure of graphite, and aggregation on mica

yields $\mathrm{A} \beta \mathrm{O}$ s that coalesce into protofibrils. ${ }^{136}$ In a physiological context, protein structure and dynamics are altered in the presence of a two-dimensional liquid environment provided by the 
presence of lipid bilayers. The importance of studying the relationship between $\mathrm{A} \beta$ and membranes lies in the fact that the membrane compositions are altered in AD patients, ${ }^{137,138}$ plasma membrane damage occurs in $\mathrm{AD},{ }^{139-141}$ and the binding of $\mathrm{A} \beta$ to the plasma membrane is highly correlated with cell death. ${ }^{41,142}$

The interaction of $A \beta$ with lipid membranes has been well established; ${ }^{143,144}$ however, the nature of the peptide-membrane interactions is complex, as subtle changes in physiochemical properties of the peptide or membrane can greatly influence their interactions. The initial interaction of $A \beta$ with membranes involves the insertion of $A \beta$ into the hydrophobic region of the membrane or the adhesion of $A \beta$ to the membrane surface. Numerous research efforts suggest that the mechanism by which $\mathrm{A} \beta$ binds to membranes is driven by electrostatic and hydrophobic interactions between the peptide and membrane (see review). ${ }^{145}$ Moreover, the importance of lipid headgroup charges has been established with $\mathrm{A} \beta$ preferentially binding to anionic lipid headgroups ${ }^{146-148}$ more favorably over purely zwitterionic lipids. ${ }^{146-148}$ The charge of the membranes and the peptide to lipid ratio also have profound effects on the secondary structure of $A \beta .{ }^{145,149}$ Previous finding show that under low peptide to lipid ratios $A \beta$ is primarily $\alpha$-helical in nature with high peptide to lipid ratios favoring a $\beta$-sheet structure of $A \beta .{ }^{150}$ Specific chemical modifications of a membrane's extent of unsaturation, conformational changes, variation in lipid headgroups, and acyl chains will also have an effect on the hydrophobic and electrostatic matching taking place at the protein-lipid interface of membranes. ${ }^{151,152}$ This is noteworthy as the plasma membrane of neurons are highly heterogenous in nature, and changes in the composition or charge of lipids can result in differences of fibril elongation rates, nucleation times, and aggregate morphology. ${ }^{153,154}$

\section{Introduction: Mutations, modifications, and the membrane's role in the} aggregation of $A \beta$ associated with Alzheimer's disease 
Once bound, $A \beta$ can then further migrate and aggregate along the membrane surface. Monomeric A $\beta$ exhibits significant lateral mobility, but $\mathrm{A} \beta$ becomes increasingly immobile following oligomerization. ${ }^{155}$ This lateral mobility of $\mathrm{A} \beta$ has also been related to the properties of the surface with highly hydrophilic surfaces inhibiting adhesion of $A \beta$ and highly hydrophobic surfaces significantly slowing diffusion rates and inhibiting fibril formation. ${ }^{156}$ It is hypothesized that the regulation of $A \beta$ diffusion to a two-dimensional surface is the primary cause for increased rates of fibril formation in the presence of membrane surfaces. In this regard, surface density of $\mathrm{A} \beta$ on a lipid membrane also plays a role, making the peptide to lipid ratio an important parameter to control. Under high peptide to lipid ratios concentrations of $A \beta$ on a single vesicle are increased effectively increasing the local concentration of $A \beta$ at the surface and prompting accelerated oligomerization of $A \beta$ and fibrillization. Low peptide to lipid ratios exert the opposite effect; wherein, the concentration of $\mathrm{A} \beta$ at the lipid surface is lower and the time it takes for $\mathrm{A} \beta$ to diffuse and aggregate significantly increased. ${ }^{149}$

While membrane properties can influence the aggregation of $A \beta,{ }^{153,157,158}$ features of the A $\beta$ peptide also play a role in its interaction with the plasma membrane. For example, the aggregation of $A \beta 40$ and $A \beta 42$ on total brain lipid extract bilayers (TBLE) is different. ${ }^{159,160}$ Several point mutations with FADs promoted unique aggregate species on TBLE bilayers as well. ${ }^{161}$ This demonstrates that single amino acids within $\mathrm{A} \beta$ can play an important role in regulating the interaction of $A \beta$ with the plasma membrane. Specifically, lysine in $A \beta$ may be responsible for facilitating the electrostatic interactions between the peptide and anionic lipid headgroups. Lysine in other protein systems is known to play a role in membrane protein anchoring, ${ }^{162}$ cell-penetrating peptides, ${ }^{163}$ and antimicrobial peptides. ${ }^{164}$ These results suggest 
that the peptide sequence and modification of $A \beta$ are of equal importance in evaluating the interactions of $\mathrm{A} \beta$ and the membrane.

\subsection{Conclusion}

$\mathrm{A} \beta$ aggregation and deposition has long been associated with $\mathrm{AD}$. The aggregation process and resulting aggregate species are highly dependent on the chemical properties of specific amino acids within $A \beta$. In addition, the interaction of $A \beta$ with plasma membranes is also influenced by specific amino acids. Understanding the of each amino acid in these phenomena can provide novel therapeutic targets and strategies. Here, we explore how targeting specific amino acids with $\mathrm{A} \beta$ by chemically induced post-translational modifications alters the aggregation process, aggregate morphology, and interactions with model lipid membranes. In Chapter 2, we examine how increasing the concentration of $\mathrm{H}_{2} \mathrm{O}_{2}$, at physiologically relevant levels, post translationally modifies $A \beta$ to its sulfoxide derivative Met35[O]. We go on to elucidate that oxidation of $A \beta$ alters aggregation, secondary structural transitions, morphologies of aggregates, and oligomerization of $\mathrm{A} \beta$ in the absence of lipids. In addition, ThT assays are performed in the presence of TBLE and polydiacetylene assays (PDA; a lipid binding assay) are utilized to clarify the role of an oxidative environment on the $A \beta$-membrane interactions. Finally, we isolated the oxidative effects on $A \beta$ and TBLE to determine the individual roles of oxidation on the peptide and membrane and determine the oxidation state of the membrane modulates the $A \beta$-membrane interaction. In Chapter 3 , we chemically acetylate $A \beta$ via the addition of sulfo-Nhydroxysulfosuccinimide acetate (NHSA) with the aim of understanding how the removal of lysines cationic charge through acetylation modifies the aggregation of $\mathrm{A} \beta$ in the presence and absence of TBLE. We observe the inhibition of fibril formation and oligomerization in the 
absence of lipids with no observations of polymorphic structures. However, ThT assays performed in the presence of TBLE restore fibril formation in addition to producing polymorphic structures, annular aggregates, at higher acetylation concentrations. Finally, we conclude Chapter 3 by performing PDA assays to illustrate that acetylation of $\mathrm{A} \beta$ reduces membrane binding.

\subsection{References}

(1) Knowles, T. P. J., Vendruscolo, M., and Dobson, C. M. (2014) The amyloid state and its association with protein misfolding diseases, Nat Rev Mol Cell Biol 15, 384-396.

(2) Hardy, J. A., Higgins, G. A., Hardy, J. A., and Higgins, G. A. (1992) Alzheimer 's Disease : The Amyloid Cascade Hypothesis Published by : American Association for the Advancement of Science Alzheimer's Disease : The Amyloid Cascade Hypothesis, Science (80-. ). 256, 184185.

(3) Arriagada, P. V, Growdon, J. H., Hedleywhyte, E. T., and Hyman, B. T. (1992) NEUROFIBRILLARY TANGLES BUT NOT SENILE PLAQUES PARALLEL DURATION AND SEVERITY OF ALZHEIMERS-DISEASE, Neurology 42, 631-639.

(4) Terry RD, Masliah E, Salmon DP, Butters N, DeTeresa R, Hill R, H. LA, and R, K. (1991) Physical basis of cognitive alterations in Alzheimer's disease: synapse loss is the major correlate of cognitive impairment., Ann. Neurol. 30, 572-580.

(5) Viola, K. L., Sbarboro, J., Sureka, R., De, M., Bicca, M. A., Wang, J., Vasavada, S., Satpathy, S., Wu, S., Joshi, H., Velasco, P. T., MacRenaris, K., Waters, E. A., Lu, C., Phan, J., Lacor, P., Prasad, P., Dravid, V. P., and Klein, W. L. (2015) Towards non-invasive diagnostic imaging of early-stage Alzheimer's disease, Nat. Nanotechnol. 10, 91-98.

(6) Hyman, B. T., and Tanzi, R. E. (1992) Amyloid, dementia and Alzheimer's disease, Curr Opin Neurol Neurosurg 5, 88-93.

(7) Cummings, B. J., Pike, C. J., R, D., and CW, C. (1996) b-Amyloid deposition and other measures of neuropathology predict cognitive status in Alzheimer's disease 17, 921-933.

(8) Cummings, J. L., Morstorf, T., and Zhong, K. (2014) Alzheimer's disease drug-development pipeline: few candidates, frequent failures, Alzheimers Res. Ther. 6.

(9) Goure, W. F., Krafft, G. A., Jerecic, J., and Hefti, F. (2014) Targeting the proper amyloidbeta neuronal toxins: a path forward for Alzheimer's disease immunotherapeutics, Alzheimers Res. Ther. 6.

(10) Karran, E., and Hardy, J. (2014) A Critique of the Drug Discovery and Phase 3 Clinical Programs Targeting the Amyloid Hypothesis for Alzheimer Disease, Ann. Neurol. 76, 185-205.

1. Introduction: Mutations, modifications, and the membrane's role in the aggregation of $A \beta$ associated with Alzheimer's disease 
(11) Karran, E., and Hardy, J. (2014) Antiamyloid Therapy for Alzheimer's Disease - Are We on the Right Road?, N. Engl. J. Med. 370, 377-378.

(12) Frackowiak, J., Zoltowska, A., and Wisniewski, H. M. (1994) NONFIBRILLAR BETAAMYLOID PROTEIN IS ASSOCIATED WITH SMOOTH-MUSCLE CELLS OF VESSEL WALLS IN ALZHEIMER-DISEASE, J. Neuropathol. Exp. Neurol. 53, 637-645.

(13) Oda, T., Pasinetti, G. M., Osterburg, H. H., Anderson, C., Johnson, S. A., and Finch, C. E. (1994) PURIFICATION AND CHARACTERIZATION OF BRAIN CLUSTERIN, Biochem. Biophys. Res. Commun. 204, 1131-1136.

(14) Oda, T., Wals, P., Osterburg, H. H., Johnson, S. A., Pasinetti, G. M., Morgan, T. E., Rozovsky, I., Stine, W. B., Snyder, S. W., Holzman, T. F., Krafft, G. A., and Finch, C. E. (1995) CLUSTERIN (APOJ) ALTERS THE AGGREGATION OF AMYLOID BETA-PEPTIDE (ABETA(1-42)) AND FORMS SLOWLY SEDIMENTING A-BETA COMPLEXES THAT CAUSE OXIDATIVE STRESS, Exp. Neurol. 136, 22-31.

(15) Esparza, T. J., Zhao, H., Cirrito, J. R., Cairns, N. J., Bateman, R. J., Holtzman, D. M., and Brody, D. L. (2013) Amyloid-Beta Oligomerization in Alzheimer Dementia versus HighPathology Controls, Ann. Neurol. 73, 104-119.

(16) Gong, Y. S., Chang, L., Viola, K. L., Lacor, P. N., Lambert, M. P., Finch, C. E., Krafft, G. A., and Klein, W. L. (2003) Alzheimer's disease-affected brain: Presence of oligomeric A beta ligands (ADDLs) suggests a molecular basis for reversible memory loss, Proc. Natl. Acad. Sci. U. S. A. 100, 10417-10422.

(17) Kayed, R., Head, E., Thompson, J. L., McIntire, T. M., Milton, S. C., Cotman, C. W., and Glabe, C. G. (2003) Common structure of soluble amyloid oligomers implies common mechanism of pathogenesis, Science (80-. ). 300, 486-489.

(18) Noguchi, A., Matsumura, S., Dezawa, M., Tada, M., Yanazawa, M., Ito, A., Akioka, M., Kikuchi, S., Sato, M., Ideno, S., Noda, M., Fukunari, A., Muramatsu, S., Itokazu, Y., Sato, K., Takahashi, H., Teplow, D. B., Nabeshima, Y., Kakita, A., Imahori, K., and Hoshi, M. (2009) Isolation and Characterization of Patient-derived, Toxic, High Mass Amyloid beta-Protein (A beta) Assembly from Alzheimer Disease Brains, J. Biol. Chem. 284, 32895-32905.

(19) Pham, E., Crews, L., Ubhi, K., Hansen, L., Adame, A., Cartier, A., Salmon, D., Galasko, D., Michael, S., Savas, J. N., Yates, J. R., Glabe, C., and Masliah, E. (2010) Progressive accumulation of amyloid-beta oligomers in Alzheimer's disease and in amyloid precursor protein transgenic mice is accompanied by selective alterations in synaptic scaffold proteins, Febs $J$. 277, 3051-3067.

(20) Gyure, K. A., Durham, R., Stewart, W. F., Smialek, J. E., and Troncoso, J. C. (2001) Intraneuronal A beta-amyloid precedes development of amyloid plaques in Down syndrome, Arch. Pathol. Lab. Med. 125, 489-492.

(21) Lacor, P. N. (2004) Synaptic targeting by Alzheimer's-Related Amyloid $\beta$ oligomers, $J$. Neurosci. 24, 10191-10200.

1. Introduction: Mutations, modifications, and the membrane's role in the aggregation of $A \beta$ associated with Alzheimer's disease 
(22) Lesne, S. E., Sherman, M. A., Grant, M., Kuskowski, M., Schneider, J. A., Bennett, D. A., and Ashe, K. H. (2013) Brain amyloid-beta oligomers in ageing and Alzheimer's disease, Brain $136,1383-1398$.

(23) Georganopoulou, D. G., Chang, L., Nam, J. M., Thaxton, C. S., Mufson, E. J., Klein, W. L., and Mirkin, C. A. (2005) Nanoparticle-based detection in cerebral spinal fluid of a soluble pathogenic biomarker for Alzheimer's disease, Proc. Natl. Acad. Sci. U. S. A. 102, 2273-2276.

(24) Bruggink, K. A., Jongbloed, W., Biemans, E. A. L. M., Veerhuis, R., Claassen, J. A. H. R., Kuiperij, H. B., and Verbeek, M. M. (2013) Amyloid-beta oligomer detection by ELISA in cerebrospinal fluid and brain tissue, Anal. Biochem. 433, 112-120.

(25) Englund, H., Gunnarsson, M. D., Brundin, R. M., Hedlund, M., Kilander, L., Lannfelt, L., and Pettersson, F. E. (2009) Oligomerization Partially Explains the Lowering of A beta 42 in Alzheimer's Disease Cerebrospinal Fluid, Neurodegener. Dis. 6, 139-147.

(26) Fukumoto, H., Tokuda, T., Kasai, T., Ishigami, N., Hidaka, H., Kondo, M., Allsop, D., and Nakagawa, M. (2010) High-molecular-weight beta-amyloid oligomers are elevated in cerebrospinal fluid of Alzheimer patients, Faseb J. 24, 2716-2726.

(27) Gao, C. M., Yam, A. Y., Wang, X., Magdangal, E., Salisbury, C., Peretz, D., Zuckermann, R. N., Connolly, M. D., Hansson, O., Minthon, L., Zetterberg, H., Blennow, K., Fedynyshyn, J. P., and Allauzen, S. (2010) A beta 40 Oligomers Identified as a Potential Biomarker for the Diagnosis of Alzheimer's Disease, PLoS One 5.

(28) Herskovits, A. Z., Locascio, J. J., Peskind, E. R., Li, G., and Hyman, B. T. (2013) A Luminex Assay Detects Amyloid beta Oligomers in Alzheimer's Disease Cerebrospinal Fluid, PLoS One 8.

(29) Holtta, M., Hansson, O., Andreasson, U., Hertze, J., Minthon, L., Nagga, K., Andreasen, N., Zetterberg, H., and Blennow, K. (2013) Evaluating Amyloid-beta Oligomers in Cerebrospinal Fluid as a Biomarker for Alzheimer's Disease, PLoS One 8.

(30) Jongbloed, W., Bruggink, K. A., Kester, M. I., Visser, P.-J., Scheltens, P., Blankenstein, M. A., Verbeek, M. M., Teunissen, C. E., and Veerhuis, R. (2015) Amyloid-beta Oligomers Relate to Cognitive Decline in Alzheimer's Disease, J. Alzheimers Dis. 45, 35-43.

(31) Santos, A. N., Ewers, M., Minthon, L., Simm, A., Silber, R.-E., Blennow, K., Prvulovic, D., Hansson, O., and Hampel, H. (2012) Amyloid-beta Oligomers in Cerebrospinal Fluid are Associated with Cognitive Decline in Patients with Alzheimer's Disease, J. Alzheimers Dis. 29, 171-176.

(32) Lesné, S., Ming, T. K., Kotilinek, L., Kayed, R., Glabe, C. G., Yang, A., Gallagher, M., and Ashe, K. H. (2006) A specific amyloid- $\beta$ protein assembly in the brain impairs memory, Nature $440,352-357$.

(33) Ono, K., Condron, M. M., and Teplow, D. B. (2009) Structure-neurotoxicity relationships of amyloid -protein oligomers, Proc. Natl. Acad. Sci.

1. Introduction: Mutations, modifications, and the membrane's role in the aggregation of $A \beta$ associated with Alzheimer's disease 
(34) Quist, A., Doudevski, I., Lin, H., Azimova, R., Ng, D., Frangione, B., Kagan, B., Ghiso, J., and Lal, R. (2005) Amyloid ion channels: a common structural link for protein-misfolding disease., Proc. Natl. Acad. Sci. U. S. A. 102, 10427-10432.

(35) Shankar, G. M., Bloodgood, B. L., Townsend, M., Walsh, D. M., Selkoe, D. J., and Sabatini, B. L. (2007) Natural Oligomers of the Alzheimer Amyloid- Protein Induce Reversible Synapse Loss by Modulating an NMDA-Type Glutamate Receptor-Dependent Signaling Pathway, J. Neurosci. 27, 2866-2875.

(36) Shankar, G. M., Li, S., Mehta, T. H., Garcia-Munoz, A., Shepardson, N. E., Smith, I., Brett, F. M., Farrell, M. A., Rowan, M. J., Lemere, C. A., Regan, C. M., Walsh, D. M., Sabatini, B. L., and Selkoe, D. J. (2008) Amyloid-beta protein dimers isolated directly from Alzheimer's brains impair synaptic plasticity and memory, Nat. Med. 14, 837-842.

(37) Townsend, M., Shankar, G. M., Mehta, T., Walsh, D. M., and Selkoe, D. J. (2006) Effects of secreted oligomers of amyloid beta-protein on hippocampal synaptic plasticity: a potent role for trimers, J. Physiol. 572, 477-492.

(38) Walsh, D. M., Klyubin, I., Fadeeva, J. V., Cullen, W. K., Anwyl, R., Wolfe, M. S., Rowan, M. J., and Selkoe, D. J. (2002) Naturally secreted oligomers of amyloid $\beta$ protein potently inhibit hippocampal long-term potentiation in vivo, Nature 416, 535-539.

(39) Lambert, M. P., Barlow, A. K., Chromy, B. A., Edwards, C., Freed, R., Liosatos, M., Morgan, T. E., Rozovsky, I., Trommer, B., Viola, K. L., Wals, P., Zhang, C., Finch, C. E., Krafft, G. A., and Klein, W. L. (1998) Diffusible, nonfibrillar ligands derived from A $\beta$ 1-42 are potent central nervous system neurotoxins, Proc. Natl. Acad. Sci. 95, 6448-6453.

(40) Zhao, J., Li, A., Rajsombath, M., Dang, Y., Selkoe, D. J., and Li, S. (2018) Soluble A $\beta$ Oligomers Impair Dipolar Heterodendritic Plasticity by Activation of mGluR in the Hippocampal CA1 Region, iScience 6, 138-150.

(41) De Felice, F. G., Wu, D., Lambert, M. P., Fernandez, S. J., Velasco, P. T., Lacor, P. N., Bigio, E. H., Jerecic, J., Acton, P. J., Shughrue, P. J., Chen-Dodson, E., Kinney, G. G., Klein, W. L., Paul, J., Shughrue, P. J., Chen-Dodson, E., Kinney, G. G., and Klein, W. L. (2008) Alzheimer's disease-type neuronal tau hyperphosphorylation induced by A $\beta$ oligomers, Neurobiol. Aging 29, 1334-1347.

(42) Ma QL, Yang F, Rosario ER, Ubeda OJ, Beech W, G., DJ, Chen PP, Hudspeth B, Chen C, Zhao Y, V. H., and Frautschy SA, C. G. (2009) $\beta$-Amyloid Oligomers Induce Phosphorylation ofTau and Inactivation ofInsulin Receptor Substrate via c-Jun N-Terminal Kinase Signaling: Suppression by Omega-3 Fatty Acids and Curcumin, J. Neurosci. 29, 9078-9089.

(43) Tomiyama, T., Matsuyama, S., Iso, H., Umeda, T., Takuma, H., Ohnishi, K., Ishibashi, K., Teraoka, R., Sakama, N., Yamashita, T., Nishitsuji, K., Ito, K., Shimada, H., Lambert, M. P., Klein, W. L., and Mori, H. (2010) A Mouse Model of Amyloid Oligomers: Their Contribution to Synaptic Alteration, Abnormal Tau Phosphorylation, Glial Activation, and Neuronal Loss In Vivo, J. Neurosci. 30, 4845-4856.

1. Introduction: Mutations, modifications, and the membrane's role in the aggregation of $A \beta$ associated with Alzheimer's disease 
(44) Zempel, H., Thies, E., Mandelkow, E.-M. M., and Mandelkow, E.-M. M. (2010) A Oligomers Cause Localized Ca2+ Elevation, Missorting of Endogenous Tau into Dendrites, Tau Phosphorylation, and Destruction of Microtubules and Spines, J. Neurosci. 30, 1193811950.

(45) Resende, R., Ferreiro, E., Pereira, C., and Oliveira, C. R. (2008) ER stress is involved in A $\beta$-induced GSK-3 $\beta$ activation and tau phosphorylation, J. Neurosci. Res. 86, 2091-2099.

(46) Heinitz, K., Beck, M., Schliebs, R., and Perez-Polo, J. R. (2006) Toxicity mediated by soluble oligomers of ??-amyloid(1-42) on cholinergic SN56.B5.G4 cells, J. Neurochem. 98, 1930-1945.

(47) Nunes-Tavares, N., Santos, L. E., Stutz, B., Brito-Moreira, J., Klein, W. L., Ferreira, S. T., and de Mello, F. G. (2012) Inhibition of choline acetyltransferase as a mechanism for cholinergic dysfunction induced by amyloid-beta peptide oligomers, J Biol Chem 287, 19377-19385.

(48) Longo, V. D., Viola, K. L., Klein, W. L., and Finch, C. E. (2000) Reversible inactivation of superoxide-sensitive aconitase in A $\beta 1$-42-treated neuronal cell lines, J. Neurochem. 75, 19771985.

(49) Sponne, I., Fifre, A., Drouet, B., Klein, C., Koziel, V., Pinçon-Raymond, M., Olivier, J. L., Chambaz, J., and Pillot, T. (2003) Apoptotic neuronal cell death induced by the non-fibrillar amyloid- $\beta$ peptide proceeds through an early reactive oxygen species-dependent cytoskeleton perturbation, J. Biol. Chem. 278, 3437-3445.

(50) Tabner, B. J., El-Agnaf, O. M. A. a, Turnbull, S., German, M. J., Paleologou, K. E., Hayashi, Y., Cooper, L. J., Fullwood, N. J., and Allsop, D. (2005) Hydrogen peroxide is generated during the very early stages of aggregation of the amyloid peptides implicated in Alzheimer disease and familial British dementia, J. Biol. Chem. 280, 35789-35792.

(51) De Felice, F. G., Velasco, P. T., Lambert, M. P., Viola, K., Fernandez, S. J., Ferreira, S. T., and Klein, W. L. (2007) A $\beta$ oligomers induce neuronal oxidative stress through an N-methyl-Daspartate receptor-dependent mechanism that is blocked by the Alzheimer drug memantine, $J$. Biol. Chem. 282, 11590-11601.

(52) Nishitsuji, K., Tomiyama, T., Ishibashi, K., Ito, K., Teraoka, R., Lambert, M. P., Klein, W. L., and Mori, H. (2009) The E693 $\Delta$ mutation in amyloid precursor protein increases intracellular accumulation of amyloid $\beta$ oligomers and causes endoplasmic reticulum stress-induced apoptosis in cultured cells, Am. J. Pathol. 174, 957-969.

(53) Alberdi, E., Wyssenbach, A., Alberdi, M., Sánchez-Gómez, M. V., Cavaliere, F., Rodríguez, J. J., Verkhratsky, A., and Matute, C. (2013) Ca2+-dependent endoplasmic reticulum stress correlates with astrogliosis in oligomeric amyloid $\beta$-treated astrocytes and in a model of Alzheimer's disease, Aging Cell 12, 292-302.

(54) Snyder, E. M., Nong, Y., Almeida, C. G., Paul, S., Moran, T., Choi, E. Y., Nairn, A. C., Salter, M. W., Lombroso, P. J., Gouras, G. K., and Greengard, P. (2005) Regulation of NMDA receptor trafficking by amyloid- $\beta$, Nat. Neurosci. $8,1051-1058$.

1. Introduction: Mutations, modifications, and the membrane's role in the aggregation of $A \beta$ associated with Alzheimer's disease 
(55) Roselli, F. (2005) Soluble -Amyloid1-40 Induces NMDA-Dependent Degradation of Postsynaptic Density-95 at Glutamatergic Synapses, J. Neurosci. 25, 11061-11070.

(56) Pascale N. Lacor, Maria C. Buniel, Paul W. Furlow, Antonio Sanz Clemente, Pauline T. Velasco, Margaret Wood, Kirsten L. Viola, and W. L. K. (2007) A $\beta$ Oligomer-Induced Aberrations in Synapse Composition, Shape, and Density Provide a Molecular Basis for Loss of Connectivity in Alzheimer's Disease, J. Neurosci. 27, 796-807.

(57) Zhao, W.-Q. Q., De Felice, F. G., Fernandez, S., Chen, H., Lambert, M. P., Quon, M. J., Krafft, G. A., and Klein, W. L. (2007) Amyloid beta oligomers induce impairment of neuronal insulin receptors, FASEB J. 22, 246-260.

(58) Zhao, W. Q., Lacor, P. N., Chen, H., Lambert, M. P., Quon, M. J., Krafft, G. A., and Klein, W. L. (2009) Insulin receptor dysfunction impairs cellular clearance of neurotoxic oligomeric A $\beta$, J. Biol. Chem. 284, 18742-18753.

(59) De Felice FG, Vieira MN, Bomfim TR, Decker H, V., PT, Lambert MP, Viola KL, Zhao WQ, Ferreira ST, K., and WL. (2009) Protection of synapses against Alzheimer's-linked toxins: Insulin signaling prevents the pathogenic binding of A $\beta$ oligomers, Proc. Natl. Acad. Sci. 106, 1971-1976.

(60) Koffie, R. M., Meyer-Luehmann, M., Hashimoto, T., Adams, K. W., Mielke, M. L., GarciaAlloza, M., Micheva, K. D., Smith, S. J., Kim, M. L., Lee, V. M., Hyman, B. T., and SpiresJones, T. L. (2009) Oligomeric amyloid associates with postsynaptic densities and correlates with excitatory synapse loss near senile plaques, Proc. Natl. Acad. Sci. 106, 4012-4017.

(61) Poon, W. W., Blurton-Jones, M., Tu, C. H., Feinberg, L. M., Chabrier, M. A., Harris, J. W., Jeon, N. L., and Cotman, C. W. (2011) $\beta$-Amyloid impairs axonal BDNF retrograde trafficking, Neurobiol. Aging 32, 821-833.

(62) Poon, W. W., Carlos, A. J., Aguilar, B. L., Berchtold, N. C., Kawano, C. K., Zograbyan, V., Yaopruke, T., Shelanski, M., and Cotman, C. W. (2013) $\beta$-Amyloid (A $\beta$ ) oligomers impair brain-derived neurotrophic factor retrograde trafficking by down-regulating ubiquitin C-terminal hydrolase, UCH-L1, J. Biol. Chem. 288, 16937-16948.

(63) Pigino, G., Morfini, G., Atagi, Y., Deshpande, A., Yu, C., Jungbauer, L., LaDu, M., Busciglio, J., and Brady, S. (2009) Disruption of fast axonal transport is a pathogenic mechanism for intraneuronal amyloid beta, Proc. Natl. Acad. Sci. 106, 5907-5912.

(64) Decker, H., Lo, K. Y., Unger, S. M., Ferreira, S. T., and Silverman, M. A. (2010) AmyloidPeptide Oligomers Disrupt Axonal Transport through an NMDA Receptor-Dependent Mechanism That Is Mediated by Glycogen Synthase Kinase 3 in Primary Cultured Hippocampal Neurons, J. Neurosci. 30, 9166-9171.

(65) Hu, J., Akama, K. T., Krafft, G. A., Chromy, B. A., and Van Eldik, L. J. (1998) Amyloid- $\beta$ peptide activates cultured astrocytes: Morphological alterations, cytokine induction and nitric oxide release, Brain Res. 785, 195-206.

1. Introduction: Mutations, modifications, and the membrane's role in the aggregation of $A \beta$ associated with Alzheimer's disease 
(66) Jimenez, S., Baglietto-Vargas, D., Caballero, C., Moreno-Gonzalez, I., Torres, M., SanchezVaro, R., Ruano, D., Vizuete, M., Gutierrez, A., and Vitorica, J. (2008) Inflammatory Response in the Hippocampus of PS1M146L/APP751SL Mouse Model of Alzheimer's Disease: AgeDependent Switch in the Microglial Phenotype from Alternative to Classic, J. Neurosci. 28, $11650-11661$.

(67) Varvel, N. H., Bhaskar, K., Patil, A. R., Pimplikar, S. W., Herrup, K., and Lamb, B. T. (2008) A Oligomers Induce Neuronal Cell Cycle Events in Alzheimer's Disease, J. Neurosci. 28, 10786-10793.

(68) Bhaskar, K., Miller, M., Chludzinski, A., Herrup, K., Zagorski, M., and Lamb, B. T. (2009) The PI3K-Akt-mTOR pathway regulates a oligomer induced neuronal cell cycle events, Mol. Neurodegener. 4, 1-18.

(69) Kim, H. J., Chae, S. C., Lee, D. K., Chromy, B., Lee, S. C., Park, Y. C., Klein, W. L., Krafft, G. A., and Hong, S. T. (2003) Selective neuronal degeneration induced by soluble oligomeric amyloid beta protein., FASEB J. 17, 118-120.

(70) Roher, A. E., Lowenson, J. D., Clarke, S., Woods, A. S., Cotter, R. J., Gowing, E., and Ball, M. J. (1993) beta-Amyloid-(1-42) is a major component of cerebrovascular amyloid deposits: implications for the pathology of Alzheimer disease, Proc. Natl. Acad. Sci. 90, 10836.

(71) Naslund, J., Schierhorn, A., Hellman, U., Lannfelt, L., Roses, A. D., Tjernberg, L. O., Silberring, J., Gandy, S. E., Winblad, B., and Greengard, P. (1994) Relative abundance of Alzheimer $\mathrm{A} \beta$ amyloid peptide variants in Alzheimer disease and normal aging, Proc.Natl.Acad.Sci.U.S.A 91, 8378-8382.

(72) Vandersteen, A., Hubin, E., Sarroukh, R., De Baets, G., Schymkowitz, J., Rousseau, F., Subramaniam, V., Raussens, V., Wenschuh, H., Wildemann, D., and Broersen, K. (2012) A comparative analysis of the aggregation behavior of amyloid-?? peptide variants, FEBS Lett. 586, 4088-4093.

(73) Barrow, C. J., Yasuda, A., Kenny, P. T., and Zagorski, M. G. (1992) Solution conformations and aggregational properties of synthetic amyloid $\beta$-peptides of Alzheimer's disease. Analysis of circular dichroism spectra, J. Mol. Biol. 225, 1075-1093.

(74) Barrow, C. J., and Zagorski, M. G. (1991) Solution structures of beta peptide and its constituent fragments: relation to amyloid deposition, Science (80-. ). 253, 179-182.

(75) Inouye, H., Fraser, P. E., and Kirschner, D. A. (1993) STRUCTURE OF BETACRYSTALLITE ASSEMBLIES FORMED BY ALZHEIMER BETA-AMYLOID PROTEIN ANALOGS - ANALYSIS BY X-RAY-DIFFRACTION, Biophys. J. 64, 502-519.

(76) Török, M., Milton, S., Kayed, R., Wu, P., McIntire, T., Glabe, C. G., and Langen, R. (2002) Structural and dynamic features of Alzheimer's A $\beta$ peptide in amyloid fibrils studied by sitedirected spin labeling, J. Biol. Chem. 277, 40810-40815.

(77) Antzutkin, O. N., Balbach, J. J., Leapman, R. D., Rizzo, N. W., Reed, J., and Tycko, R.

1. Introduction: Mutations, modifications, and the membrane's role in the aggregation of $A \beta$ associated with Alzheimer's disease 
(2000) Multiple quantum solid-state NMR indicates a parallel, not antiparallel, organization of beta -sheets in Alzheimer's beta -amyloid fibrils, Proc. Natl. Acad. Sci. 97, 13045-13050.

(78) Petkova, A. T., Leapman, R. D., Guo, Z. H., Yau, W.-M. M., Mattson, M. P., and Tycko, R. (2005) Self-propagating, molecular-level polymorphism in Alzheimer's beta-amyloid fibrils, Science (80-. ). 307, 262-265.

(79) Tycko, R. (2006) Solid-state NMR as a probe of amyloid structure, Protein Pept. Lett. 13, 229-234.

(80) Pastor, M. T., Kuemmerer, N., Schubert, V., Esteras-Chopo, A., Dotti, C. G., de la Paz, M. L., and Serrano, L. (2008) Amyloid toxicity is independent of polypeptide sequence, length and chirality, J. Mol. Biol. 375, 695-707.

(81) Chiti, F., and Dobson, C. M. (2006) Protein misfolding, functional amyloid, and human disease, in ,Annual Review of Biochemistry, pp 333-366.

(82) Xue, W.-F., Homans, S. W., and Radford, S. E. (2008) Systematic analysis of nucleationdependent polymerization reveals new insights into the mechanism of amyloid self-assembly, Proc. Natl. Acad. Sci. U. S. A. 105, 8926-8931.

(83) Murphy, R. M. (2007) Kinetics of amyloid formation and membrane interaction with amyloidogenic proteins, Biochim. Biophys. Acta - Biomembr. 1768, 1923-1934.

(84) Ghosh, P., Vaidya, A., Kumar, A., and Rangachari, V. (2016) Determination of critical nucleation number for a single nucleation amyloid- $\beta$ aggregation model, Math. Biosci. 273, 7079.

(85) Garai, K., Sahoo, B., Sengupta, P., and Maiti, S. (2008) Quasihomogeneous nucleation of amyloid beta yields numerical bounds for the critical radius, the surface tension, and the free energy barrier for nucleus formation, J. Chem. Phys. 128, 45102.

(86) Novo, M., Freire, S., and Al-Soufi, W. (2018) Critical aggregation concentration for the formation of early Amyloid- $\beta$ (1-42) oligomers, Sci. Rep. 8, 1783.

(87) Xue, C., Lin, T. Y., Chang, D., and Guo, Z. (2017) Thioflavin T as an amyloid dye: Fibril quantification, optimal concentration and effect on aggregation, R. Soc. Open Sci.

(88) Kodali, R., and Wetzel, R. (2007) Polymorphism in the intermediates and products of amyloid assembly, Curr. Opin. Struct. Biol. 17, 48-57.

(89) Kodali, R., Williams, A. D., Chemuru, S., and Wetzel, R. (2010) A $\beta(1-40)$ forms five distinct amyloid structures whose $\beta$-sheet contents and fibril stabilities are correlated, J. Mol. Biol. 401, 503-517.

(90) Meinhardt, J., Sachse, C., Hortschansky, P., Grigorieff, N., Fandrich, M., and Fändrich, M. (2009) A $\beta(1-40)$ Fibril Polymorphism Implies Diverse Interaction Patterns in Amyloid Fibrils, $J$. Mol. Biol. 386, 869-877.

1. Introduction: Mutations, modifications, and the membrane's role in the aggregation of $A \beta$ associated with Alzheimer's disease 
(91) Tycko, R. (2015) Amyloid Polymorphism: Structural Basis and Neurobiological Relevance, Neuron 86, 632-645.

(92) Colletier, J. P., Laganowsky, A., Landau, M., Zhao, M., Soriaga, A. B., Goldschmidt, L., Flot, D., Cascio, D., Sawaya, M. R., and Eisenberg, D. (2011) Molecular basis for amyloid- $\beta$ polymorphism, Proc. Natl. Acad. Sci. U. S. A. 108, 16938-16943.

(93) Crowther, R. A., and Goedert, M. (2000) Abnormal Tau- Containing Filaments in Neurodegenerative Diseases, J. Struct. Biol. 130, 271-279.

(94) Lu, J.-X., Qiang, W., Yau, W.-M., Schwieters, C. D., Meredith, S. C., and Tycko, R. (2013) Molecular structure of $\beta$-amyloid fibrils in Alzheimer's disease brain tissue., Cell 154, 1257-68.

(95) Qiang, W., Yau, W. M., Lu, J. X., Collinge, J., and Tycko, R. (2017) Structural variation in amyloid-beta fibrils from Alzheimer's disease clinical subtypes, Nature 541, 217-221.

(96) Paravastu, A. K., Qahwash, I., Leapman, R. D., Meredith, S. C., and Tycko, R. (2009) Seeded growth of $\beta$-amyloid fibrils from Alzheimer's brain-derived fibrils produces a distinct fibril structure, Proc. Natl. Acad. Sci. 106, 7443-7448.

(97) Yates, E. A., and Legleiter, J. (2014) Preparation Protocols of A beta(1-40) Promote the Formation of Polymorphic Aggregates and Altered Interactions with Lipid Bilayers, Biochemistry 53, 7038-7050.

(98) Teplow, D. B. (2013) On the subject of rigor in the study of amyloid beta-protein assembly, Alzheimers Res. Ther. 5.

(99) Lee, M. C., Yu, W. C., Shih, Y. H., Chen, C. Y., Guo, Z. H., Huang, S. J., Chan, J. C. C. C., and Chen, Y. R. (2018) Zinc ion rapidly induces toxic, off-pathway amyloid- $\beta$ oligomers distinct from amyloid- $\beta$ derived diffusible ligands in Alzheimer's disease, Sci. Rep. 8, 1-16.

(100) Deborah, A, Ryan Wade, C. Narrow, Howard J. Federoff, W. J. B., Ryan, D. A., Narrow, W. C., Federoff, H. J., and Bowers, W. J. (2010) An Improved Method for Generating Consistent Soluble Amyloid-beta Oligomer Preparations for In Vitro Neurotoxicity Studies, J Neurosci Methods 190, 171-179.

(101) Barghorn, S., Nimmrich, V., Striebinger, A., Krantz, G., Keller, P., Janson, B., Bahr, M., Schmidt, M., Bitner, R. S., Harlan, J., Barlow, E., Ebert, U., and Hillen, H. (2005) Globular amyloid $\beta$-peptide1-42 oligomer - A homogenous and stable neuropathological protein in Alzheimer's disease, J. Neurochem. 95, 834-847.

(102) Thibaudeau, T. A., Anderson, R. T., and Smith, D. M. (2018) A common mechanism of proteasome impairment by neurodegenerative disease-associated oligomers, Nat. Commun. 9.

(103) Stine, W. B., Dahlgren, K. N., Krafft, G. a., and LaDu, M. J. (2003) In vitro characterization of conditions for amyloid- $\beta$ peptide oligomerization and fibrillogenesis, J. Biol. Chem. 278, 11612-11622.

(104) Stine, W. B., Jungbauer, L., Yu, C., and LaDu, M. J. (2011) Preparing Synthetic A $\beta$ in

1. Introduction: Mutations, modifications, and the membrane's role in the aggregation of $A \beta$ associated with Alzheimer's disease 
Different Aggregation States, in ,Alzheimer's Disease and Frontotemporal Dementia: Methods and Protocols (Roberson, E. D., Ed.), pp 13-32.Humana Press, Totowa, NJ.

(105) Benninger, R. J. ;Davi. T., and David, T. (1983) An improved method of preparing the amyloid $\beta$-protein for fibrillogenesis and neurotoxicity experiments, Brain Res. Rev. 287, 173196.

(106) Ryan, T. M., Caine, J., Mertens, H. D. T., Kirby, N., Nigro, J., Breheney, K., Waddington, L. J., Streltsov, V. a, Curtain, C., Masters, C. L., and Roberts, B. R. (2013) Ammonium hydroxide treatment of $\mathrm{A} \beta$ produces an aggregate free solution suitable for biophysical and cell culture characterization., PeerJ 1, e73.

(107) Bitan, G., Lomakin, A., and Teplow, D. B. (2001) Amyloid $\beta$-protein oligomerization: Prenucleation interactions revealed by photo-induced cross-linking of unmodified proteins, $J$. Biol. Chem. 276, 35176-35184.

(108) Hatami, A., Monjazeb, S., Milton, S., and Glabe, C. G. (2017) Familial Alzheimer's disease mutations within the amyloid precursor protein alter the aggregation and conformation of the amyloid- $\beta$ peptide, J. Biol. Chem. 292, 3172-3185.

(109) Alzheimer's Association. (2017) 2017 Alzheimer's disease facts and figures, Alzheimer's Dement. 13, 325-373.

(110) Harding, J. J., Beswick, H. T., Ajiboye, R., Huby, R., Blakytny, R., and Rixon, K. C. (1989) Non-enzymic post-translational modification of proteins in aging. A review, Mech. Ageing Dev. 50, 7-16.

(111) Cloos, P. A. C., Christgau, S., S, N. B. A., Hovedgade, H., and Herlev, D.-. (2004) Posttranslational modifications of proteins: implications for aging, antigen recognition, and autoimmunity 139-158.

(112) Labbadia, J., and Morimoto, R. I. (2015) The Biology of Proteostasis in Aging and Disease, Annu. Rev. Biochem. 84, 435-464.

(113) Kummer, M. P., and Heneka, M. T. (2014) Truncated and modified amyloid-beta species, Alzheimer's Res. Ther. 6, 1-9.

(114) Kumar, S., Rezaei-Ghaleh, N., Terwel, D., Thal, D. R., Richard, M., Hoch, M., Mc Donald, J. M., Wüllner, U., Glebov, K., Heneka, M. T., Walsh, D. M., Zweckstetter, M., and Walter, J. (2011) Extracellular phosphorylation of the amyloid $\beta$ 2-peptide promotes formation of toxic aggregates during the pathogenesis of Alzheimer's disease, EMBO J. 30, 2255-2265.

(115) Milton, N. G. N. (2005) Phosphorylated Amyloid- $\beta$ : the Toxic Intermediate in Alzheimer's Disease Neurodegeneration BT - Alzheimer's Disease: Cellular and Molecular Aspects of Amyloid $\beta$ (Harris, J. R., and Fahrenholz, F., Eds.), pp 381-402.Springer US, Boston, MA.

(116) Milton, N. G. (2001) Phosphorylation of amyloid-beta at the serine 26 residue by human cdc2 kinase., Neuroreport 12, 3839-44.

1. Introduction: Mutations, modifications, and the membrane's role in the aggregation of $A \beta$ associated with Alzheimer's disease 
(117) Jawhar, S., Wirths, O., and Bayer, T. A. (2011) Pyroglutamate amyloid- $\beta$ (A $\beta$ ): A hatchet man in alzheimer disease, J. Biol. Chem. 286, 38825-38832.

(118) Bouter, Y., Dietrich, K., Wittnam, J. L., Rezaei-Ghaleh, N., Pillot, T., Papot-Couturier, S., Lefebvre, T., Sprenger, F., Wirths, O., Zweckstetter, M., and Bayer, T. A. (2013) N-truncated amyloid $\beta$ (A $\beta$ ) 4-42 forms stable aggregates and induces acute and long-lasting behavioral deficits, Acta Neuropathol.

(119) Wirths, O., Erck, C., Martens, H., Harmeier, A., Geumann, C., Jawhar, S., Kumar, S., Multhaup, G., Walter, J., Ingelsson, M., Degerman-Gunnarsson, M., Kalimo, H., Huitinga, I., Lannfelt, L., and Bayer, T. A. (2010) Identification of low molecular weight pyroglutamate A $\beta$ oligomers in Alzheimer disease: A novel tool for therapy and diagnosis, J. Biol. Chem. 285, $41517-41524$.

(120) Stadtman, E. R. (1988) Protein Modification in Aging, J. Gerontol. 43, B112-B120.

(121) Stadtman, E. R. (1992) Protein oxidation and aging. Free Radical Research, Science (80-. ). 40257, 1220-1224.

(122) Hou, L., Kang, I., Marchant, R. E., and Zagorski, M. G. (2002) Methionine 35 oxidation reduces fibril assembly of the amyloid A $\beta-(1-42)$ peptide of Alzheimer's disease, J. Biol. Chem. 277, 40173-40176.

(123) Friedemann, M., Helk, E., Tiiman, A., Zovo, K., Palumaa, P., and Tõugu, V. (2015) Effect of methionine-35 oxidation on the aggregation of amyloid- $\beta$ peptide, Biochem. Biophys. Reports 3, 94-99.

(124) Palmblad, M., Westlind-Danielsson, A., and Bergquist, J. (2002) Oxidation of methionine 35 attenuates formation of amyloid $\beta$-peptide 1-40 oligomers, J. Biol. Chem. 277, 19506-19510.

(125) Gu, M., and Viles, J. H. (2016) Methionine oxidation reduces lag-times for amyloid- $\beta$ (140) fiber formation but generates highly fragmented fibers, Biochim. Biophys. Acta-Proteins Proteomics 1864, 1260-1269.

(126) Misiti, F., Clementi, M. E., and Giardina, B. (2010) Oxidation of methionine 35 reduces toxicity of the amyloid beta-peptide(1-42) in neuroblastoma cells (IMR-32) via enzyme methionine sulfoxide reductase A expression and function, Neurochem. Int. 56, 597-602.

(127) Maiti, P., Piacentini, R., Ripoli, C., Grassi, C., and Bitan, G. (2011) Surprising toxicity and assembly behaviour of amyloid $\beta$-protein oxidized to sulfone., Biochem. J. 433, 323-332.

(128) Ripoli, C., Piacentini, R., Riccardi, E., Leone, L., Li Puma, D. D., Bitan, G., and Grassi, C. (2013) Effects of different amyloid $\beta$-protein analogues on synaptic function, Neurobiol. Aging $34,1032-1044$.

(129) Butterfield, D. A., and Boyd-Kimball, D. (2005) The critical role of methionine 35 in Alzheimer's amyloid $\beta$-peptide (1-42)-induced oxidative stress and neurotoxicity, Biochim. Biophys. Acta - Proteins Proteomics 1703, 149-156.

1. Introduction: Mutations, modifications, and the membrane's role in the aggregation of $A \beta$ associated with Alzheimer's disease 
(130) Barnham, K. J., Ciccotosto, G. D., Tickler, A. K., Ali, F. E., Smith, D. G., Williamson, N. A., Lam, Y. H., Carrington, D., Tew, D., Kocak, G., Volitakis, I., Separovic, F., Barrow, C. J., Wade, J. D., Masters, C. L., Cherny, R. A., Curtain, C. C., Bush, A. I., and Cappai, R. (2003) Neurotoxic, Redox-competent Alzheimer's $\beta$-Amyloid Is Released from Lipid Membrane by Methionine Oxidation, J. Biol. Chem. 278, 42959-42965.

(131) Butterfield, D. A., and Sultana, R. (2011) Methionine-35 of A $\beta(1-42)$ : importance for oxidative stress in Alzheimer disease., J. Amino Acids 2011, 1-10.

(132) Liu, L., Komatsu, H., Murray, I. V. J., and Axelsen, P. H. (2008) Promotion of Amyloid $\beta$ Protein Misfolding and Fibrillogenesis by a Lipid Oxidation Product, J. Mol. Biol.

(133) Gu, L., Liu, C., and Guo, Z. (2013) Structural Insights into A 42 Oligomers Using Sitedirected Spin Labeling, J. Biol. Chem. 288, 18673-18683.

(134) Nicholas, A. P. (2013) Dual immunofluorescence study of citrullinated proteins in Alzheimer diseased frontal cortex, Neurosci. Lett. 545, 107-111.

(135) Acharya, N. K., Nagele, E. P., Han, M., Coretti, N. J., DeMarshall, C., Kosciuk, M. C., Boulos, P. A., and Nagele, R. G. (2012) Neuronal PAD4 expression and protein citrullination: Possible role in production of autoantibodies associated with neurodegenerative disease, $J$. Autoimmun. 38, 369-380.

(136) Kowalewski, T., and Holtzman, D. M. (1999) In situ atomic force microscopy study of Alzheimer's beta-amyloid peptide on different substrates: new insights into mechanism of betasheet formation., Proc. Natl. Acad. Sci. U. S. A. 96, 3688-3693.

(137) Wallin A, Gottfries CG, Karlsson I, S. (1989) Decreased myelin lipids in Alzheimer's disease and vascular dementia., Acta Neurol Scand 80, 319-323.

(138) Roth, G. S., Joseph, J. A., and Preston Mason, R. (1995) Membrane alterations as causes of impaired signal transduction in Alzheimer's disease and aging, Trends Neurosci. 18, 203-206.

(139) Lukiw, W. J. (2013) Alzheimer's disease (AD) as a disorder of the plasma membrane, Front. Physiol. 4, 24.

(140) Evangelisti, Elisaa; Zampagni, Mariagioiaa; Cascella, Robertaa; Becatti, Matteoa; Fiorillo, Claudiaa; Caselli, Annaa; Bagnoli, Silviab; Nacmias, Benedettab; Cecchi, C. (2014) Plasma membrane injury depends on bilayer lipid composition in Alzheimer's disease, J. Alzheimer's Dis. 41, 289-300.

(141) Drolle, E., Negoda, A., Hammond, K., Pavlov, E., and Leonenko, Z. (2017) Changes in lipid membranes may trigger amyloid toxicity in Alzheimer's disease, PLoS One.

(142) Lacor, P. N., Buniel, M. C., Chang, L., Fernandez, S. J., Gong, Y. S., Viola, K. L., Lambert, M. P., Velasco, P. T., Bigio, E. H., Finch, C. E., Krafft, G. A., and Klein, W. L. (2004) Synaptic targeting by Alzheimer's-related amyloid beta oligomers, J. Neurosci. 24, 1019110200.

1. Introduction: Mutations, modifications, and the membrane's role in the aggregation of $A \beta$ associated with Alzheimer's disease 
(143) Niu, Z., Zhang, Z., Zhao, W., and Yang, J. (2018) Interactions between amyloid $\beta$ peptide and lipid membranes, Biochim. Biophys. Acta - Biomembr. 1860, 1663-1669.

(144) Butterfield, S. M., and Lashuel, H. A. (2010) Amyloidogenic protein-membrane interactions: Mechanistic insight from model systems, Angew. Chemie - Int. Ed. 49, 5628-5654.

(145) Bokvist, M., Lindström, F., Watts, A., and Gröbner, G. (2004) Two Types of Alzheimer's $\beta$-Amyloid (1-40) Peptide Membrane Interactions: Aggregation Preventing Transmembrane Anchoring Versus Accelerated Surface Fibril Formation, J. Mol. Biol. 335, 1039-1049.

(146) Chi, E. Y., Ege, C., Winans, A., Majewski, J., Wu, G., Kjaer, K., and Lee, K. Y. C. (2008) Lipid membrane templates the ordering and induces the fibrillogenesis of Alzheimer's disease amyloid- $\beta$ peptide, Proteins Struct. Funct. Genet. 72, 1-24.

(147) Bokvist, M., and Gröbner, G. (2007) Misfolding of amyloidogenic proteins at membrane surfaces: The impact of macromolecular crowding, J. Am. Chem. Soc. 129, 14848-14849.

(148) Matsuzaki, K. (2007) Physicochemical interactions of amyloid $\beta$-peptide with lipid bilayers, Biochim. Biophys. Acta - Biomembr. 1768, 1935-1942.

(149) Wong, P. T., Schauerte, J. A., Wisser, K. C., Ding, H., Lee, E. L., Steel, D. G., and Gafni, A. (2009) Amyloid- $\beta$ Membrane Binding and Permeabilization are Distinct Processes Influenced Separately by Membrane Charge and Fluidity, J. Mol. Biol. 386, 81-96.

(150) Mandal, P. K., and Pettegrew, J. W. (2004) Alzheimer's disease: Soluble oligomeric A $\beta(1$ 40) peptide in membrane mimic environment from solution NMR and circular dichroism studies, Neurochem. Res. 29, 2267-2272.

(151) Jensen, M., and Mouritsen, O. G. (2004) Lipids do influence protein function - The hydrophobic matching hypothesis revisited, Biochim. Biophys. Acta-Biomembr. 1666, 205-226.

(152) Sciacca, M. F. M., Kotler, S. A., Brender, J. R., Chen, J., Lee, D. K., and Ramamoorthy, A. (2012) Two-step mechanism of membrane disruption by A $\beta$ through membrane fragmentation and pore formation, Biophys. J. 103, 702-710.

(153) Sani, M. A., Gehman, J. D., and Separovic, F. (2011) Lipid matrix plays a role in Abeta fibril kinetics and morphology, FEBS Lett. 585, 749-754.

(154) Sabaté, R., Espargaró, A., Barbosa-Barros, L., Ventura, S., and Estelrich, J. (2012) Effect of the surface charge of artificial model membranes on the aggregation of amyloid $\beta$-peptide, Biochimie 94, 1730-1738.

(155) Chang, C. C., Edwald, E., Veatch, S., Steel, D. G., and Gafni, A. (2018) Interactions of amyloid- $\beta$ peptides on lipid bilayer studied by single molecule imaging and tracking, Biochim. Biophys. Acta - Biomembr. 1860, 1616-1624.

(156) Shen, L., Adachi, T., Vanden Bout, D., and Zhu, X. Y. (2012) A mobile precursor determines amyloid- $\beta$ peptide fibril formation at interfaces, J. Am. Chem. Soc. 134, 1417214178 .

1. Introduction: Mutations, modifications, and the membrane's role in the aggregation of $A \beta$ associated with Alzheimer's disease 
(157) Yip, C. M., Elton, E. A., Darabie, A. A., Morrison, M. R., and Mclaurin, J. (2001) Cholesterol, a modulator of membrane-associated A $\beta$-fibrillogenesis and neurotoxicity, J. Mol. Biol. 311, 723-734.

(158) Sparr, E., Chia, S., Kumita, J. R., Sanguanini, M., Vendruscolo, M., Idini, I., Bellaiche, M. M. J., Michaels, T. C. T., Dobson, C. M., Knowles, T. P. J., Galvagnion, C., Linse, S., Ruggeri, F. S., and Habchi, J. (2018) Cholesterol catalyses A $\beta 42$ aggregation through a heterogeneous nucleation pathway in the presence of lipid membranes, Nat. Chem. 10, 673-683.

(159) Yip, C. M., Darabie, A. A., and McLaurin, J. A. (2002) Aß42-peptide assembly on lipid bilayers, J. Mol. Biol. 318, 97-107.

(160) Yip, C. M., and McLaurin, J. (2001) Amyloid-beta peptide assembly: a critical step in fibrillogenesis and membrane disruption., Biophys. J. 80, 1359-1371.

(161) Pifer, P. M., Yates, E. a., and Legleiter, J. (2011) Point mutations in A $\beta$ result in the formation of distinct polymorphic aggregates in the presence of lipid bilayers, PLoS One 6 .

(162) Liu, A., Wenzel, N., and Qi, X. (2005) Role of lysine residues in membrane anchoring of saposin C, Arch. Biochem. Biophys. 443, 101-112.

(163) Herce, H. D., and Garcia, A. E. (2007) Cell penetrating peptides: how do they do it?, $J$. Biol. Phys. 33, 345-356.

(164) Yount, N. Y., Bayer, A. S., Xiong, Y. Q., and Yeaman, M. R. (2006) Advances in Antimicrobial Peptide Immunobiology, Pept. Sci. 84, 435-458.

1. Introduction: Mutations, modifications, and the membrane's role in the aggregation of $A \beta$ associated with Alzheimer's disease 


\section{Hydrogen peroxide modifies $A \beta$-membrane interactions with implications for $A \beta_{40}$ aggregation}

Alzheimer's disease (AD) is pathologically characterized by the formation of extracellular senile plaques, predominately comprised of aggregated $\beta$-amyloid $(A \beta)$, deposited in the brain. $\mathrm{A} \beta$ aggregation can result in a myriad of distinct aggregate species, from soluble oligomers to insoluble fibrils. $A \beta$ strongly interacts with membranes, which can be linked to a variety of potential toxic mechanism associated with $\mathrm{AD}$. Oxidative damage accompanies the formation of $A \beta$ aggregates, with a $10-50 \%$ proportion of $A \beta$ aggregates being oxidized in vivo. Hydrogen peroxide $\left(\mathrm{H}_{2} \mathrm{O}_{2}\right)$ is a reactive oxygen species implicated in several neurodegenerative diseases. Recent evidence has demonstrated that $\mathrm{H}_{2} \mathrm{O}_{2}$ concentration fluctuates rapidly in the brain, resulting in large concentration spikes, especially in the synaptic cleft. Here, the impact of environmental $\mathrm{H}_{2} \mathrm{O}_{2}$ on $A \beta$ aggregation in the presence and absence of lipid membranes is investigated. $A \beta_{40}$ was exposed to $\mathrm{H}_{2} \mathrm{O}_{2}$, resulting in the selective oxidation of methionine-35 (Met35) to produce $A \beta_{40} \mathrm{Met} 35[\mathrm{O}]$. While oxidation mildly reduced the rate of $\mathrm{A} \beta$ aggregation and produced a distinct fibril morphology at large $\mathrm{H}_{2} \mathrm{O}_{2}$ concentrations, $\mathrm{H}_{2} \mathrm{O}_{2}$ had a much more pronounced impact on $A \beta$ aggregation in the presence of total brain lipid extract vesicles (TBLE). The impact of $\mathrm{H}_{2} \mathrm{O}_{2}$ on $\mathrm{A} \beta$ aggregation in the presence of lipids was associated with a reduced affinity of $\mathrm{A} \beta$ for the vesicle surface. However, this reduced vesicle affinity was predominately associated with lipid peroxidation rather than $A \beta$ oxidation.

\subsection{Introduction: The role of oxidation in Alzheimer's disease}

A key pathological feature in Alzheimer's disease $(\mathrm{AD})$ is the formation of senile plaques composed of the amyloid- $\beta$ peptide $(A \beta)$. A $\beta$ is formed by the successive cleavage of the 
transmembrane amyloid precursor protein (APP), resulting in varied lengths of $A \beta$, the most common being 40-42 residues long. Aggregation of $A \beta$ results in the formation of insoluble plaques, fibrils, protofibrils, and soluble oligomeric intermediates; the latter of which is considered to be the dominant neurotoxic species. ${ }^{1-3}$ Ninety-five percent of $\mathrm{AD}$ cases are sporadic, with aging being highly associated with developing AD. ${ }^{4}$

A contributing factor in aging is the continuous production of reactive oxygen species $(\mathrm{ROS})^{5}$, which can lead to cellular and molecular damage ${ }^{6,7}$ and several enzymes function to counteract ROS. ${ }^{8}$ Oxidative modifications of polyunsaturated fatty acids play a role in agedependent reduction of membrane fluidity by increasing the rigidity of lipid bilayer membranes due to steric hindrance restricting the movement of lipid acyl chains. ${ }^{9,10} \mathrm{~A} \beta$ oligomers preferentially accumulate near the plasma membrane of oxidatively damaged cells ${ }^{11}$ and enhanced oxidative damage is observed in $\mathrm{AD}$ brains. ${ }^{12}$ The $\mathrm{A} \beta$-induced oxidative stress hypothesis states that the principle toxic mechanism underlying $\mathrm{AD}$ results from $\mathrm{A} \beta$ inducing oxidative stress within the brain. ${ }^{13,14}$ Numerous studies have provided evidence that implicates methionine-35 (Met35) in ROS generation, which can be associated with neurotoxicity. ${ }^{15}$

Oxidized variants of $A \beta$ have been detected in mass spectrometry studies of transgenic mice, ${ }^{16}$ Raman spectroscopy of intact senile plaques from $\mathrm{AD}$ patients, ${ }^{17}$ and post-mortem analysis of $\mathrm{AD}$ patient's cerebral spinal fluid with $10-50 \%$ of $\mathrm{A} \beta$ being oxidized. ${ }^{16,18} \mathrm{~A} \beta$ oxidation occurs at several residues, e.g. histidine and tyrosine, but these require transition metals. ${ }^{19}$ However, Met35 is the only residue susceptible to oxidation directly by hydrogen peroxide $\left(\mathrm{H}_{2} \mathrm{O}_{2}\right){ }^{20-23}$ The oxidation of Met35 occurs via a hydroxyl radical addition to the thioether of methionine in aqueous media to its sulfoxide derivative. ${ }^{24}$ The impact of oxidation on $\mathrm{A} \beta$ aggregation varies greatly in the literature (depending on experimental conditions) as 
oxidation of $\mathrm{A} \beta$ has been observed to increase, ${ }^{25,26}$ decrease, ${ }^{21,23,27-29}$ or have no impact on aggregation. ${ }^{30-32}$ In some instances, $A \beta$ oxidation inhibited the formation of intermediate aggregates associated with fibril formation. For example, oxidation of Met35 abolished the formation of critical nuclei associated with fibril formation, ${ }^{33}$ and oxidized $\mathrm{A} \beta_{40}$ was limited to the formation of dimers. ${ }^{22}$ Yet other studies have reported the formation of higher ordered fibrils from Met35[O] substituted forms of $A \beta .^{21,32,34,35}$

The oxidation state of $A \beta$ influences its toxic properties. Modification of Met35 to its sulfoxide derivative, A $\beta 42-M e t 35[\mathrm{O}]$, abolished cellular toxicity in 9 to 11-day-old rat embryonic hippocampal neuronal cultures. ${ }^{36}$ Further studies supported the notion that $A \beta$ Met35[O] reduced toxicity. ${ }^{32,37,38}$ Interestingly, Met35Val substitution enhances toxicity, illustrating that Met35 is not required for toxicity of $A \beta$; however, the increased flexibility gained by the $\mathrm{C}$-terminus upon this substitution allowed for a higher affinity of $\mathrm{A} \beta$ to lipid bilayers. ${ }^{39}$

The interaction of $A \beta$ and the plasma membrane has been associated with a variety of toxic mechanisms. ${ }^{40-42}$ Membrane surfaces can (i) modify peptide structure, ${ }^{43}$ (ii) alter rates of amyloid nucleation and growth, ${ }^{44}$ (iii) promote polymorphic aggregate structures, ${ }^{45,46}$ and (iv) stabilize intermediate aggregate species. ${ }^{47-49}$ ROS can also cause lipid peroxidation. ${ }^{50}$ As oxidation of Met35 alters the chemical properties of $A \beta$, the ability of $A \beta$ to bind and insert into lipid membranes would be altered with implications for the aggregation process occurring on the membrane surface. A potential phenomenon associated with $A \beta /$ lipid interactions under oxidative conditions is the localization of $A \beta$ to synapses ${ }^{51}$ and synaptotoxicity of $A \beta$ oligomers, underlying neuronal loss in $\mathrm{AD} .{ }^{51,52}$ Oxidation of Met35 reduces synaptotoxicity and dendrite retraction. ${ }^{32}$ Fast-scan cyclic voltammograms have measured, in real time, $\mathrm{H}_{2} \mathrm{O}_{2}$ dynamics in 
vivo, suggesting that $\mathrm{H}_{2} \mathrm{O}_{2}$ fluctuations within the brain and synaptic regions occur $\sim 4-11$ times per minute ${ }^{53}$ creating an opportunity for acute oxidative damage of synaptic $A \beta$ in the presence of the plasma membrane.

Here, we investigate how oxidative environments, produced by $\mathrm{H}_{2} \mathrm{O}_{2}$, influence $\mathrm{A} \beta_{40}$ aggregation in the presence and absence of model lipid membranes of total brain lipid extract (TBLE). TBLE is an excellent model system as it is comprised of a physiologically relevant ratio of lipids, i.e. acidic and neutral phospholipids, gangliosides, cholesterol, sphingolipids, and isoprenoids. We demonstrate that $\mathrm{H}_{2} \mathrm{O}_{2}$ reduces the total fibril load of $\mathrm{A} \beta_{40}$ in the absence of lipid until the $\mathrm{H}_{2} \mathrm{O}_{2}$ concentration reaches $6.0 \mathrm{mM}$. At this concentration, a polymorphic fibril structure is observed. With the introduction of TBLE vesicles, $A \beta_{40}$ aggregation is delayed; however, the introduction of $\mathrm{H}_{2} \mathrm{O}_{2}$ begins to restore $\mathrm{A} \beta$ aggregation rates. This correlates with a reduced interaction between $A \beta_{40}$ and the lipid bilayer caused by the presence of $\mathrm{H}_{2} \mathrm{O}_{2}$. The reduced affinity of $A \beta_{40}$ for TBLE membranes is more strongly associated with the oxidation of lipids rather than the peptide.

\subsection{Materials and Methods}

2.2.1 A $\beta_{40}$ Preparation - Synthetic $\beta$-Amyloid 1-40 (from AnaSpec Inc., San Jose, CA and Alfa Aesar, Tewksbury, MA) was equilibrated to room temperature for $30 \mathrm{~min}$. Disaggregation of $\mathrm{A} \beta_{40}$ was achieved by adding $10 \% \mathrm{NH}_{4} \mathrm{OH}(\mathrm{w} / \mathrm{v})$ to $\mathrm{A} \beta_{40}$ to obtain a concentration of $0.5 \mathrm{mg} / \mathrm{mL}$. After $10 \mathrm{~min}$ of incubation and $5 \mathrm{~min}$ of bath sonication at room temperature, $A \beta$ was aliquoted and snap frozen. Aliquots were lyophilized overnight and stored at $-80^{\circ} \mathrm{C}$. On the day of experiments, $\mathrm{A} \beta$ was equilibrated to room temperature and dissolved in a $60 \mathrm{mM} \mathrm{NaOH}$ solution, $\mathrm{pH} \geq 11.23$. The solution was gently pipette mixed and incubated for 10 mins at room temperature. Concentrations of the $A \beta_{40}$ stock solutions, $1.5 \mathrm{mg} / \mathrm{mL}$, was 2. Hydrogen peroxide modifies A $\beta$-membrane interactions with implications for $A \beta_{40}$ aggregation 
confirmed using a NanoDrop2000 (Thermo Scientific) at an absorbance of $280 \mathrm{~nm}$ with an extinction coefficient of $1440 \mathrm{M}^{-1} \mathrm{~cm}^{-1}$. A litmus test verified the $\mathrm{pH}$ of the reconstituted $\mathrm{A} \beta$ to be $\geq 11.0$. Immediately, $A \beta_{40}$ was used in experiments or other preparatory methods.

2.2.2 Preparation of Oxidized $A \beta_{40}$ - Oxidized derivatives of $\mathrm{A} \beta_{40}$ were prepared by solubilizing lyophilized aliquots with a $60 \mathrm{mM} \mathrm{NaOH}$ solution and diluted to a final concentration of $20 \mu \mathrm{M}$ in a $20 \mathrm{mM}$ HEPES $150 \mathrm{mM} \mathrm{NaCl}$ buffer ( $\mathrm{pH}=7.23$ ) containing $3 \%$ (w/v) $\mathrm{H}_{2} \mathrm{O}_{2}, 980 \mathrm{mM}$. Samples were incubated for $3 \mathrm{~h}$ before being dialyzed against $18 \mathrm{M} \Omega$ water overnight in a Slide-A-Lyzer MINI Dialysis Device (Thermo Scientific, Waltham, MA) with a $3.5 \mathrm{kDa}$ molecular weight cut off. Samples were alkalified for extraction by the addition of a $10 \% \mathrm{NH}_{4} \mathrm{OH}(\mathrm{w} / \mathrm{v})$ solution. Extracts were lyophilized, re-disaggregated, and lyophilized again before storage at $-80^{\circ} \mathrm{C}$.

2.2.3 Liquid Chromatography Mass Spectrometry (LC-MS) — Lyophilized aliquots of $\mathrm{A} \beta_{40}$ were removed from $-80^{\circ} \mathrm{C}$ and allowed to reach $\mathrm{RT}$ over the course of $30 \mathrm{~min}$ before being solublized in $60 \mathrm{mM} \mathrm{NaOH}(\mathrm{pH} \geq 11.23)$ and incubated for $10 \mathrm{~min}$ at RT without agitation. Finally, the stock $\mathrm{A} \beta_{40} \bullet \mathrm{NaOH}$ solution was bath sonicated for 5 min. $\mathrm{A} \beta_{40}(20 \mu \mathrm{M})$ was incubated at $37^{\circ} \mathrm{C}$ in a HEPES buffering solution (20mM HEPES, $150 \mathrm{mM} \mathrm{NaCl} \mathrm{pH}=7.23$ ) with varying amounts of $\mathrm{H}_{2} \mathrm{O}_{2}(0,0.1,1.0,3.0,6.0 \mathrm{mM})$. Solutions were aliquoted for each oxidation condition and incubated without agitation. At specific time points $(0,15,30,45,60,120,180$, 240, and $300 \mathrm{~min}$ ) aliquots of each oxidation condition were snap frozen and lyophilized overnight to remove $\mathrm{H}_{2} \mathrm{O}_{2}$. The following day, samples were diluted in $1 \%$ formic acid/water (v/v) right before being introduced to the LC-MS.

Chromatography was performed on a C18 column (ZORBAX RRHD Eclipse XDB $80 \AA$ C18, 2.1 x $100 \mathrm{~mm}, 1.8 \mu \mathrm{m}$; Agilent, Santa Clara, CA) utilizing a mobile phase of 0.1\% 
formic/water (v/v) (\%A) and $0.1 \%$ formic acid/acetonitrile $(\mathrm{v} / \mathrm{v})(\% \mathrm{~B})$ with a gradient of $5 \% \mathrm{~B}$ to $60 \% \mathrm{~B}$ over 4.5 min with a flowrate of $300 \mu \mathrm{L} / \mathrm{min}$. A Q Exactive (Thermo Scientific) mass spectrometer was operated in positive ion mode and scanned over a mass-to-charge $(\mathrm{m} / \mathrm{z})$ range of 500-2000 at a 70,000 resolution.

2.2.4 Mass Spectrometry Analysis - Percent oxidation was calculated by determining the area (total ion chromatogram, TIC) of the oxidized peak, retention time of 5.5-5.7 min, and unoxidized peak, retention time of 5.9-6.0 min, and dividing by the summation of the total peak area. Peak areas encompassed all charge states from $\mathrm{m} / \mathrm{z}$ 500-2000. Unoxidized and oxidized $\mathrm{A} \beta_{40}$ ions were clearly resolved in the TIC as observed in the different mass spectra. However, the oxidized peak did contain minor contributions from the doubly oxidized sulfone peptide, but its contribution was consistently less than $1 \%$ and was considered negligible.

2.2.5 Sample preparation for $1 H$ NMR and analysis of measurements $-{ }^{1} \mathrm{H}$ NMR experiments were run on an INOVA ${ }^{\text {Unity }} 600 \mathrm{MHz}$ spectrometer (proton frequency, $599.67 \mathrm{MHz}$ ) equipped with a triple-resonance z-axis pulsed field gradient $5 \mathrm{~mm}$ probe. $\mathrm{A} \beta_{40}$ samples where oxidized, as mentioned above, for $3 \mathrm{~h}$ or $24 \mathrm{~h}$ at ambient temperature without agitation. Lyophilized aliquots of $A \beta_{40}$ or oxidized $A \beta_{40}$ were solubilized in $60 \mathrm{mM} \mathrm{NaOD}$ in $\mathrm{D}_{2} \mathrm{O}$ and diluted to $10 \mu \mathrm{M}$ with a $100 \mathrm{mM} \mathrm{Na} 3 \mathrm{PO}_{4}$ deuterated buffer. Then a $700 \mu \mathrm{L}$ solution was placed in $5 \mathrm{~mm}$ NMR tube and the ${ }^{1} \mathrm{H}$ NMR spectra with a PRESAT sequence were acquired for $30 \mathrm{~min}$ to $1 \mathrm{~h}$. The FIDs of the ${ }^{1} \mathrm{H}$ NMR spectra were processed using the commercially available NMR software package ACD/Spectrus Processor 2017.2 (Advanced Chemistry Development, Inc; http://, File Version S70S41, Build 98721, 19 Dec 2017). ${ }^{1} \mathrm{H}$ NMR chemical shifts were referenced to a residual proton peak (HDO) of water at $4.63 \mathrm{ppm}$, and the FID's of ${ }^{1} \mathrm{H}$ NMR were processed with a line broadening function of $2 \mathrm{~Hz}$. 
2.2.6 Thioflavin-T Fluorescence Assay (ThT) - Lyophilized aliquots of $\mathrm{A} \beta_{40}$ were removed from $-80^{\circ} \mathrm{C}$ storage and allowed to reach $\mathrm{RT}$ over the course of $30 \mathrm{~min}$. $\mathrm{A} \beta_{40}$ was solubilized with $60 \mathrm{mM} \mathrm{NaOH}$ ( $\mathrm{pH} \geq 11.23$ ), incubated, and sonicated for $5 \mathrm{~min}$ before being diluted into a HEPES buffer $\left(20 \mathrm{mM}\right.$ HEPES, $150 \mathrm{mM} \mathrm{NaCl} \mathrm{pH} \mathrm{=7.23)} \mathrm{at} 20 \mu \mathrm{M} \mathrm{A} \beta_{40}$, as previously mentioned. The formation of higher ordered $\beta$-sheet aggregates was monitored via a thioflavin-T (ThT; Sigma Aldrich, St. Louis, MO) assay. In a 96-well plate $\mathrm{A} \beta_{40}$ was aggregated in a HEPES buffering ( $20 \mathrm{mM}$ HEPES $150 \mathrm{mM} \mathrm{NaCl} \mathrm{pH}=7.23$ ) solution containing ThT at a 1.5 molar ratio to $A \beta_{40}$, with varying final concentrations of $\mathrm{H}_{2} \mathrm{O}_{2}(0,0.1,1.0,3.0,6.0 \mathrm{mM})$ relative to A $\beta$ 's final concentration. Additionally, to facilitate homogenous mixing across the 96well plate and enhance the reproducibility of aggregation kinetics $3 \mathrm{~mm}$ borosilicate beads were added to each well. Well plates were sealed and reactions were performed at $37^{\circ} \mathrm{C}$. Fluorescence intensities were measured at excitation and emission wavelengths of $440 \mathrm{~nm}$ and $484 \mathrm{~nm}$, respectively, utilizing a SpectraMax M5 or M2 Multi-Mode plate reader (Molecular Devices, Sunnyvale, CA) to measure in 5 min interval readings with $10 \mathrm{~s}$ shaking between intervals. Assays preformed in the presence of TBLE were carried out using the same procedure (see Lipid Vesicle Preparation). The ThT signal in the presence of TBLE exhibited only a slight increase in fluorescence in the background signal which was constant across all variables and subtracted out during baseline correction.

Data analysis was performed employing GraphPad Prism 6 to average across triplicates, baseline correct, and perform error analysis reported as a standard error mean (SEM). Kinetic parameters of aggregation such as nucleation lag-phase time $\left(t_{\text {lag }}\right)$ were obtained empirically by fitting the ThT traces for each experiment to a Boltzmann sigmodal function, Equation $1 .^{54,55}$ 


$$
Y=\left(y_{i}+m_{i} x\right)+\frac{y_{f}+m_{f} x}{1+e^{-\left(\frac{x-x_{0}}{\tau}\right)}}
$$

Utilizing GraphPad Prism 6 the initial lag-phase and plateau regions of the curves are defined by linear fits where the initial fluorescence and slope are defined by, $y_{i}$ and $m_{i}$, and the final fluorescence and slope as, $y_{f}$ and $m_{f}$, respectively. The time to reach the half maximum of the curve is defined by $x_{o}$ and the elongation time constant of the growth phase is defined as $\tau$. As a nonideal sigmodal function, no constraints were applied. A least squares fitting operation was then performed for a maximum iteration limit of 1000. The lag-phase time was calculated from the kinetic parameters, $t_{\text {lag }}=x_{o}-2 \tau$. The slope of the growth phase is associated with the growth of fibrils. The slope was calculated by normalizing the ThT traces to the mean maximum response of control group (no $\mathrm{H}_{2} \mathrm{O}_{2}$ added) within each independent experiment for comparison across experiments. To obtain the relative slope of the growth phase, $\mathrm{R}_{\text {slope }}\left(\mathrm{h}^{-1}\right)$ the linear fits of the growth phase were performed by defining the boundaries of the fit to only include the linear region between the lag-phase and the plateau region as visually determined for each ThT curve. The maximum signal of fluorescence at steady state was calculate using a linear fit over the plateau region of the sigmodal curve. This was accomplished by adjusting the starting point of the data to be fit and moving it further back to optimize the $r^{2}$ value. Initial starting point points were visually determined to be near the inflection point where the sigmoidal curve enters the plateau region. The fits were performed from these starting points to the end of the data set. Once the boundaries were defined, the average fluorescence signal within this plateau region was determined. For comparison between trials, these were converted to the relative fluorescence at steady state $\left(\mathrm{RF}_{\mathrm{ss}}\right)$ by dividing each value by the control experiment (no $\mathrm{H}_{2} \mathrm{O}_{2}$ for that experiment). All kinetic parameters were then averaged from triplicates of independent experiments to determine the mean \pm SEM. Significance was reported as greater than $95 \%$ 
confidence calculated using a standard Student's T-test to determine variations in parameters across varied $\mathrm{H}_{2} \mathrm{O}_{2}$ concentrations.

2.2.7 Atomic force microscopy - $\mathrm{A} \beta_{40}$ was prepared in the same manner as the ThT assays. Samples were incubated using a Spectra Max M5 plater reader's shaker and incubator, $37^{\circ} \mathrm{C}$, to maintain the same experimental conditions as used in the ThT assays. At $1 \mathrm{~h}$ intervals. 2 $\mu \mathrm{L}$ samples were taken and deposited on freshly cleaved mica. Samples were allowed to incubate for 1 min before being washed with $200 \mu \mathrm{L}$ of $18 \mathrm{M} \Omega$ water and dried immediately with compressed air. Imaging of samples was performed on a Nanoscope V Multimode Atomic Force Microscope (AFM) (Veeco, Santa Barbara, CA) with a closed-loop vertical engage J-scanner. All images were obtained in tapping mode under $e x$-situ conditions utilizing a diving-boardshaped silicon oxide cantilever with a spring constant of $40 \mathrm{~N} / \mathrm{m}$ and the resonance frequency of $\sim 300 \mathrm{kHz}$.

AFM image processing and analysis was performed in Matlab (MathWorks, Natick, MA) by utilizing the imaging processing toolbox. ${ }^{56} \mathrm{~A} 3^{\text {rd }}$ order polynomial flattening algorithm was used to correct for background curvature. Binary maps were created by using an established height threshold $(\mathrm{z}=0.99 \mathrm{~nm})$, and discrete aggregates were selected by implementing recognition algorithms to the binary maps. Physical features of individual aggregates (e.g., height, volume, diameter, shape factor, length, aspect ratio, length, and area covered) were measured. A minimum of five $5 \times 5 \mu \mathrm{m}$ AFM images for each time point was analyzed, resulting in a minimum of $125 \mu \mathrm{m}^{2}$ of surface area analyzed.

The number of oligomeric aggregates per unit area was determined through a filtering algorithm. Thresholds for filtering oligomeric aggregates were defined as heights between 1.0 and $10 \mathrm{~nm}$ with an aspect ratio between 1.0-2.5. Fibril aggregates per unit area were counted 
individually by hand and divided by total area of the image ${ }^{56,57}$ The percent of the mica surface covered by fibrils was determined by filtering out non-fibrillar aggregates (based on aspect ratio) from the above mentioned binary map. The remaining number of pixels in the binary map associated with fibril aggregates were summed and divided by the total number of pixels in the AFM image. Populations of oligomers and fibrils, along with the percent area covered by fibrils, were plotted using GraphPad Prism 6 to average across replicates and perform error analysis reported as a standard error mean (SEM).

2.2.8 Circular Dichroism Spectroscopy — Samples containing $20 \mu \mathrm{M} A \beta_{40}$ and different concentrations of $\mathrm{H}_{2} \mathrm{O}_{2}(0,1.0,6.0 \mathrm{mM})$ in a $10 \mathrm{mM} \mathrm{K}_{2} \mathrm{HPO}_{4} 50 \mathrm{mM} \mathrm{Na}_{2} \mathrm{SO}_{4}(\mathrm{pH}=7.23)$ buffer, were prepared in a 96-well plate and incubated on a Spectra Max M5 plate reader, as described previously here. Samples were taken in $1 \mathrm{~h}$ intervals and transferred to a 1-mm quartz cell. A Jasco-810 spectropolarimeter (Japan Spectroscopic Company, Tokyo, Japan) was used to record spectra from 190-260 $\mathrm{nm}$ at $0.5 \mathrm{~nm}$ resolution at ambient temperature. An average of five spectra were collected, averaged, and repeated three more times over the course of $1 \mathrm{~h}$ to ensure that any continued aggregation had not significantly changed spectra between the initial and final reading. Deconvolution of spectra was performed using BeStSel (http://bestsel.elte.hu/ $)^{58,59}$ and plotted using GraphPad Prism 6. Experiments were performed alongside their equivalent ThT assay experiment to ensure the accuracy of aggregation kinetics.

2.2.9 Lipid Vesicle Preparation - Lyophilized total brain lipid extracts (TBLE; Avanti Polar Lipids, Alabaster, AL) were dissolved in chloroform at $25 \mathrm{mg} / \mathrm{mL}$, aliquoted into $5 \mathrm{mg}$ amounts, dried in vacuo producing a transparent film, and stored at $-20^{\circ} \mathrm{C}$. Oxidation of TBLE samples was performed by hydrating the lipid film with a $3 \%(w / v) \mathrm{H}_{2} \mathrm{O}_{2}$ solution and incubating at $60^{\circ} \mathrm{C}$ and $1400 \mathrm{rpm}$ for $3 \mathrm{~h}$ on an Eppendorf Thermomixer. Unoxidized and oxidized TBLE 
samples were hydrated with a HEPES buffer (20 mM HEPES $150 \mathrm{mM} \mathrm{NaCl}$ buffer $\mathrm{pH}=7.23$ ) and incubated for $30 \mathrm{~min}$ at $60^{\circ} \mathrm{C}$ and $1400 \mathrm{rpm}$ in a Thermomixer. Lipid samples were subjected to 7 freeze-thaw cycles followed by 30 mins of bath sonication. Lipid stocks were heated and kept at $60^{\circ} \mathrm{C}$ during extrusion through $100 \mathrm{~nm}$ polycarbonate membrane filter. Extruded lipids were kept at $37^{\circ} \mathrm{C}$ before being added to a 96 -well plate for a final concentration of 0.432 $\mathrm{mg} / \mathrm{mL}$. To determine the extent of lipid peroxidation for pre-oxidized lipid experiments, a Lipid Hydroperoxide (LPO) Assay Kit (Abnova) was used.

2.2.10 Preparation of TBLE/Polydiacetylene Vesicles (PDA) - Five-milligram aliquots of TBLE or TBLE ${ }_{\mathrm{Ox}}$ were dissolved in a 1:1 chloroform: ethanol solution. Separately $8.4 \mathrm{mg}$ of 10,12-tricosadiynoic acid (GFS Chemicals, Columbus, OH) was also dissolved in a 1:1 chloroform: ethanol solution. The two were combined in a glass vial at a 60:40 mass ratio of PDA to TBLE and solvent was removed in vacuo to produce a TBLE/PDA film. Eight milliliters of a HEPES buffer (20 mM HEPES $150 \mathrm{mM} \mathrm{NaCl}$ buffer $\mathrm{pH}=7.23$ ) was heated to $75^{\circ} \mathrm{C}$ and used to hydrate the TBLE/PDA film. The solution was probe sonicated for 10 mins at $180 \mathrm{~W}$ then stored at $4^{\circ} \mathrm{C}$, protected from light, overnight. The following day the TBLE/PDA or TBLE $_{O x} /$ PDA vesicles are transferred to a $100-\mathrm{mL}$ beaker and stirred under a black box while being irradiated at $254 \mathrm{~nm}$ for 10 mins through the utilization of a TLC lamp. Experiments were conducted in a Costar 96 black clear flat bottom well plate with the addition of $3 \mathrm{~mm}$ borosilicate glass beads. Utilizing a SpectraMax M2 or M5 Multi-Mode plate reader (Molecular Devices, Sunnyvale, CA), the rates of peptide-lipid interactions were observed fluorescently under ambient temperature and at excitation and emission wavelengths of $485 \mathrm{~nm}$ and $560 \mathrm{~nm}$, respectively. Data analysis was performed using the software suite GraphPad Prism 6. Briefly, 
mean triplicates were baseline corrected with the matching vehicle controls and adjusted relative to the minimum and maximum experimental variable.

\subsection{Results}

2.3.1 Oxidation of $\mathrm{A}_{40}$ via $\mathrm{H}_{2} \mathrm{O}_{2}$ is selective for methionine-35. To determine the extent and selectivity of $A \beta_{40}$ oxidation in the presence of $\mathrm{H}_{2} \mathrm{O}_{2}, 20 \mu \mathrm{M}$ solutions of $\mathrm{A} \beta_{40}$ were exposed to $\mathrm{H}_{2} \mathrm{O}_{2}$ at concentrations ranging from $0.1 \mathrm{mM}$ to $6.0 \mathrm{mM}$. The resulting solutions were incubated at room temperature without agitation. Aliquots were taken at various time points ranging from 0 min to $300 \mathrm{~min}$ and accurate protein masses were determined from charge state envolopes within high-resolution MS spectra (Figure. 2.1). 

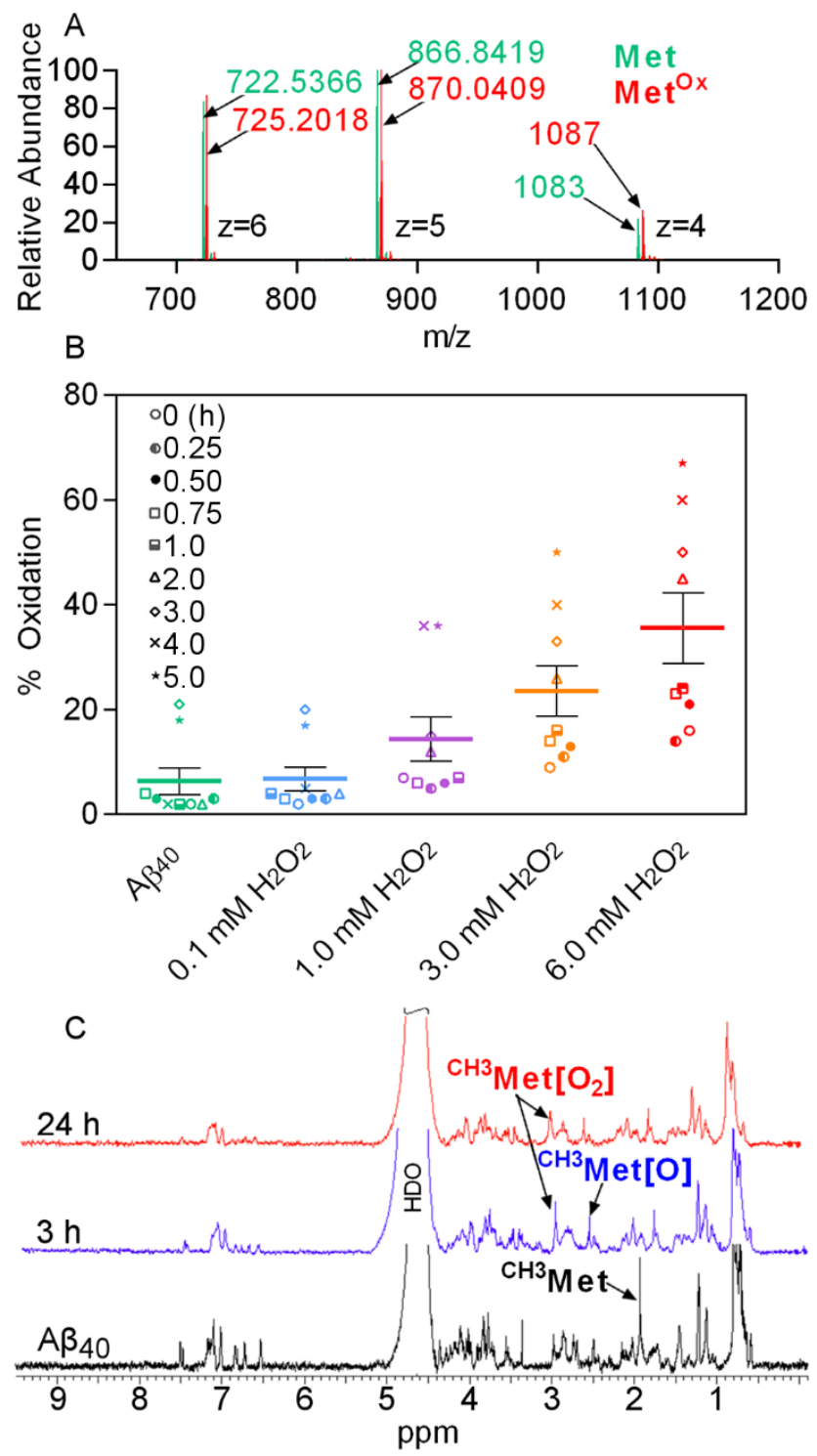

Figure 2.1. $\mathrm{H}_{2} \mathrm{O}_{2}$ oxidation of $\mathbf{A} \boldsymbol{\beta}_{40}$ is selective for methionine-35. (A) Mass spectrum from $600-1200 \mathrm{~m} / z$ illustrating that the $+4,+5,+6 \mathrm{~m} / \mathrm{z}$ charge states exhibit a 16 Da mass shift when unoxidized $A \beta_{40}$, Met (green), is exposed to $\mathrm{H}_{2} \mathrm{O}_{2}$ producing a singly-oxidized $A \beta_{40}$ variant, MetOx (red). (B) Percent oxidation of $A \beta_{40}$ as determined from the oxidized peak area (TIC) of $A \beta_{40}$ relative to the total $A \beta_{40}$ peak area. $A \beta_{40}$ was incubation under varied $\mathrm{H}_{2} \mathrm{O}_{2}$ concentrations $0.0 \mathrm{mM}$ (green), $0.1 \mathrm{mM}$ (blue), $1.0 \mathrm{mM}$ (purple), $3.0 \mathrm{mM}$ (orange), $6.0 \mathrm{mM}$ (red), and varied lengths of time indicated by symbols (see key). Lines represent the mean \pm SEM percent oxidation over the time course of the experiments. $(C)$ The ${ }^{1} \mathrm{H} N \mathrm{NR}$ spectrum of $A \beta_{40}$ dissolved in $60 \mathrm{mM} \mathrm{NaOD}$ and diluted to $10 \mu \mathrm{M}$ in $100 \mathrm{mM} \mathrm{Na}_{3} \mathrm{PO}_{4}$ deuterated buffer at pH 7.23. Total acquisition time was over 30-60 min. The $1 \mathrm{H}$ NMR spectrum was referenced to the residual proton peak of $H D O$ at $4.63 \mathrm{ppm}$. In the $1 \mathrm{H} N \mathrm{NR}$ spectrum of unoxidized $A \beta_{40}$ (black) the singlet peak $1.99 \mathrm{ppm}$ belongs to $\varepsilon \mathrm{CH}_{3}$ of Met. Oxidation of $\mathrm{A} \beta_{40}$ was achieved by addition of $3 \% \mathrm{H}_{2} \mathrm{O}_{2}$ $(w / v)$ for $3 h$ and $24 h$ before its removal via lyophilization. The ${ }^{1} H$ NMR spectra (blue and red) exhibited downfield shits indicated by arrows at $2.55 \mathrm{ppm}$ and $2.95 \mathrm{ppm}$ which were assigned to $\varepsilon \mathrm{CH}_{3}$ of Met-sulfoxide and Met-sulfone, respectively.

2. Hydrogen peroxide modifies Aß-membrane interactions with implications for $A \beta_{40}$ aggregation 
The mass spectra showed a single oxidation event consistent with the oxidation of Met35 to a sulfoxide derivative under all conditions from the analysis of the $+4,+5$, and +6 charge state ions. Oxidation of $\mathrm{A} \beta_{40}$ with $\mathrm{H}_{2} \mathrm{O}_{2}$ concentrations up to $6.0 \mathrm{mM}$ predominatley resulted in the sulfoxide rather than the sulfone. By comparing the spectral peaks for the unoxidized states $(+4$ ion at $\mathrm{m} / \mathrm{z} 1083,+5$ ion at $\mathrm{m} / \mathrm{z} 866.8,+6$ ion at $\mathrm{m} / \mathrm{z} 722.5)$ to the respective oxidized peaks $(+4$ ion at $\mathrm{m} / \mathrm{z} 1087,+5$ ion at $\mathrm{m} / \mathrm{z} 870.0,+6$ ion at $\mathrm{m} / \mathrm{z} 725.2$ ), the extent of oxidation at different $\mathrm{H}_{2} \mathrm{O}_{2}$ concentrations was determined as a function of time. Without the addition of $\mathrm{H}_{2} \mathrm{O}_{2}$, a small amount of oxidized $A \beta_{40}$ was present $(6.3 \%$ on average over all time points with $18 \%$ of $A \beta$ being oxidized by $5 \mathrm{~h}$ of incubation), which is inherent to the peptide preparation and disaggregation procedure (Figure. 2.1B). The addition of $\mathrm{H}_{2} \mathrm{O}_{2}$ at 5:1 molar ratio $\left(0.1 \mathrm{mM} \mathrm{H}_{2} \mathrm{O}_{2}\right)$ did not significantly increase the extent of Met35 oxidation (6.8\% on average over all time points with $17 \%$ of $\mathrm{A} \beta$ being oxidized by $5 \mathrm{~h}$ of incubation). At $50: 1$ molar ratio of $\mathrm{H}_{2} \mathrm{O}_{2}(1.0 \mathrm{mM}$ $\mathrm{H}_{2} \mathrm{O}_{2}$ ) a significant increase in Met35 oxidation is observed (14\% on average over all time points with $36 \%$ of $\mathrm{A} \beta$ being oxidized by $5 \mathrm{~h}$ of incubation). Additional increases in $\mathrm{H}_{2} \mathrm{O}_{2}$ (150:1 and 300:1) yielded increases in Met35 oxidation (24\% and 36\% on average over all time points with $50 \%$ and $67 \%$ of $A \beta$ being oxidized by $5 \mathrm{~h}$ of incubation, respectively). The observed selective oxidation of Met35 by treatment with $\mathrm{H}_{2} \mathrm{O}_{2}$ is consistent with previous reports, ${ }^{20-23}$ but it was essential to establish reliable reaction parameters for further experimentation. Note, the oxidation of other residues within $A \beta$ has been observed; however, these oxidation events require transition state metals. ${ }^{19,21}$

To verify the selectivity of oxidation at Met35 under experimental conditions, $20 \mu \mathrm{M}$ samples of $\mathrm{A} \beta_{40}$ were incubated with an excess of $\mathrm{H}_{2} \mathrm{O}_{2}(980 \mathrm{mM})$ for $3 \mathrm{~h}$ and $24 \mathrm{~h}$. After a disaggregation step, these $A \beta_{40}$ samples were analyzed by ${ }^{1} \mathrm{H}$ NMR spectroscopy (Figure. 2.1C). 
The ${ }^{1} \mathrm{H}$ NMR spectrum of unoxidized $\mathrm{A} \beta_{40}$ shows a singlet peak at $1.99 \mathrm{ppm}$ which belongs to $\varepsilon \mathrm{CH}_{3}$ of Met. The ${ }^{1} \mathrm{H}$ NMR spectra reveal two relatively downfield singlet peaks at $2.55 \mathrm{ppm}$ and $2.95 \mathrm{ppm}$, respectively and were assigned directly to the oxidized species of Met35 (Metsulfoxide and Met-sulfone). Oxidation of other residues was not observed at these harsher conditions.

\subsubsection{Methionine oxidation decreases total fibril content associated with $A \beta_{40}$} aggregation. To establish if the presence of $\mathrm{H}_{2} \mathrm{O}_{2}$ would alter the aggregation process of $\mathrm{A} \beta 40$, the rate of fibril formation was monitored with a ThT assay, which detects $\beta$-sheet formation associated with fibrils (Figure 2.2A). Amyloid formation occurs via a characteristic two-step process consisting of a lag phase and growth phase. The lag phase is associated with the slow formation of a critical nucleus that triggers fibrillization. The growth phase is associated with fibril elongation. For all concentrations of $\mathrm{H}_{2} \mathrm{O}_{2}$, the lag-phase of $\mathrm{A} \beta_{40}$ aggregation was similar (Figure. 2.2B). The relative slope of the growth phase, $\mathrm{R}_{\text {slope }}\left(\mathrm{h}^{-1}\right)$, were similar at lower $\mathrm{H}_{2} \mathrm{O}_{2}$ concentrations, but interestingly, the increase of oxidation conditions to that of $3.0 \mathrm{mM}$ and 6.0 $\mathrm{mM} \mathrm{H}_{2} \mathrm{O}_{2}$ significantly reduced slopes of the growth phase, from $0.62 \pm 0.041 \mathrm{~h}^{-1}$ and $0.24 \pm$ $0.018 \mathrm{~h}^{-1}$ respectively, when compared to the control $0.85 \pm 0.032 \mathrm{~h}^{-1}$ (Figure 2.2C). However, once steady state was achieved (see Figure 2.3 for all individual ThT curves), the magnitude of total fibril content (as measured by the relative fluorescence at steady state) was reduced as the amount of $\mathrm{H}_{2} \mathrm{O}_{2}$ present was increased with a statistical significance starting at $1.0 \mathrm{mM} \mathrm{H}_{2} \mathrm{O}_{2}$ compared to control (Figure 2.2D). 

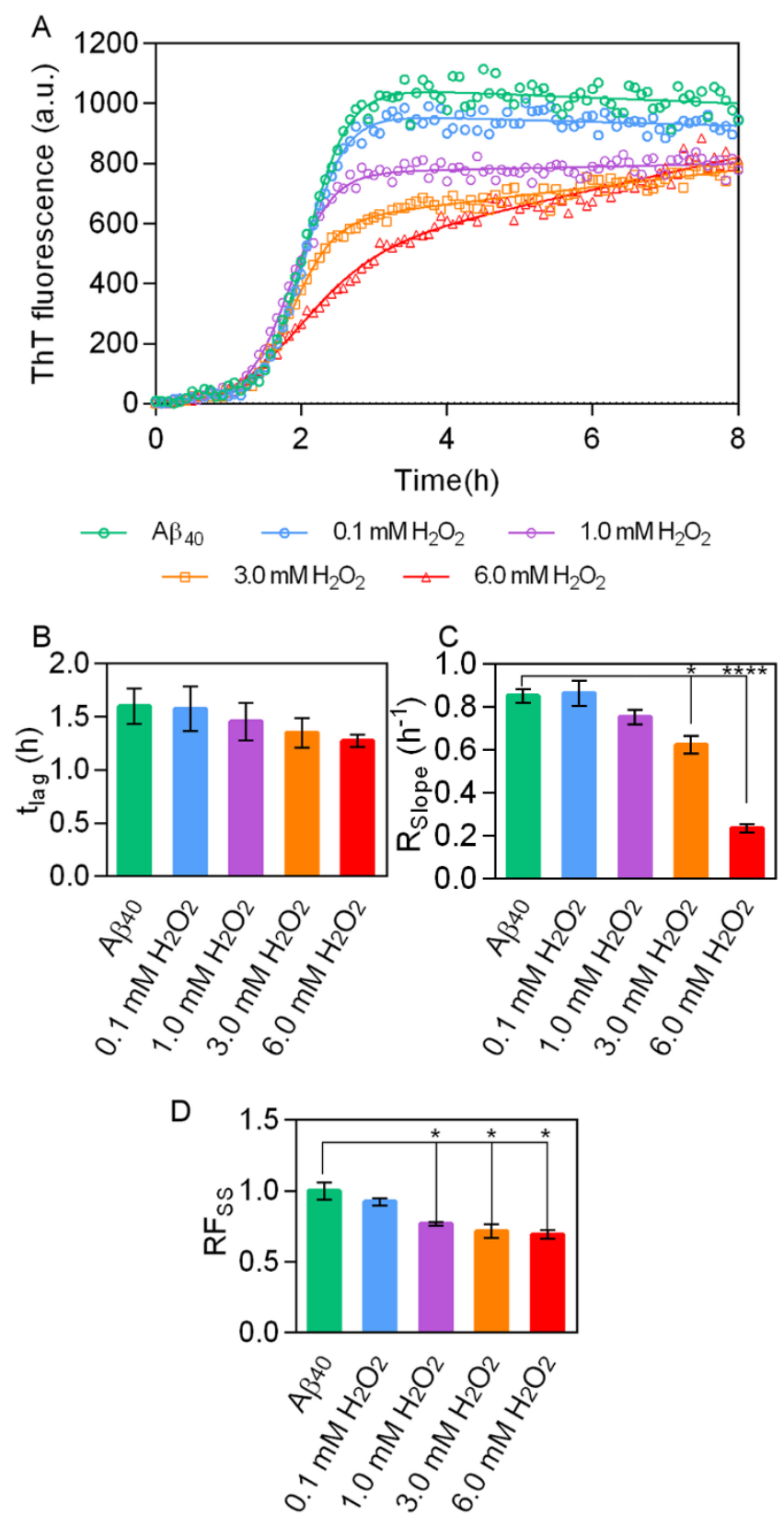

Figure 2.2. Impact of $\mathrm{H}_{2} \mathrm{O}_{2}$ on $\mathbf{A} \boldsymbol{\beta}_{40}$ aggregation (A) Average ThT assays of 20 $\mu M A \beta_{40}$ (green) aggregation performed at $37{ }^{\circ} \mathrm{C}$ with the addition of $0.1 \mathrm{mM}$ (blue), 1.0 $\mathrm{mM}$ (purple), $3.0 \mathrm{mM}$ (orange), and $6.0 \mathrm{mM}$ $\mathrm{H}_{2} \mathrm{O}_{2}$ (red). Continuous lines represent nonlinear best fits (Equation 1) to the average experimental traces. The lag-phase was calculated from non-linear fits of three independent experiments represented by bar-graphs as the mean \pm SEM. Kinetic parameters include the (B) lag-phase, tag, (C) relative slope of the normalized ThT curves, $R_{\text {slope }}\left(h^{-1}\right)$, and $(D)$ normalized steady-state maximum fluorescent response, and relative fluorescence at steady state. $P$ values are indicated as follows (*) $P \leq 0.05$, (**) $P \leq 0.01,(* * *) P \leq 0.001$, and $(* * * *) P$ $\leq 0.0001$. 

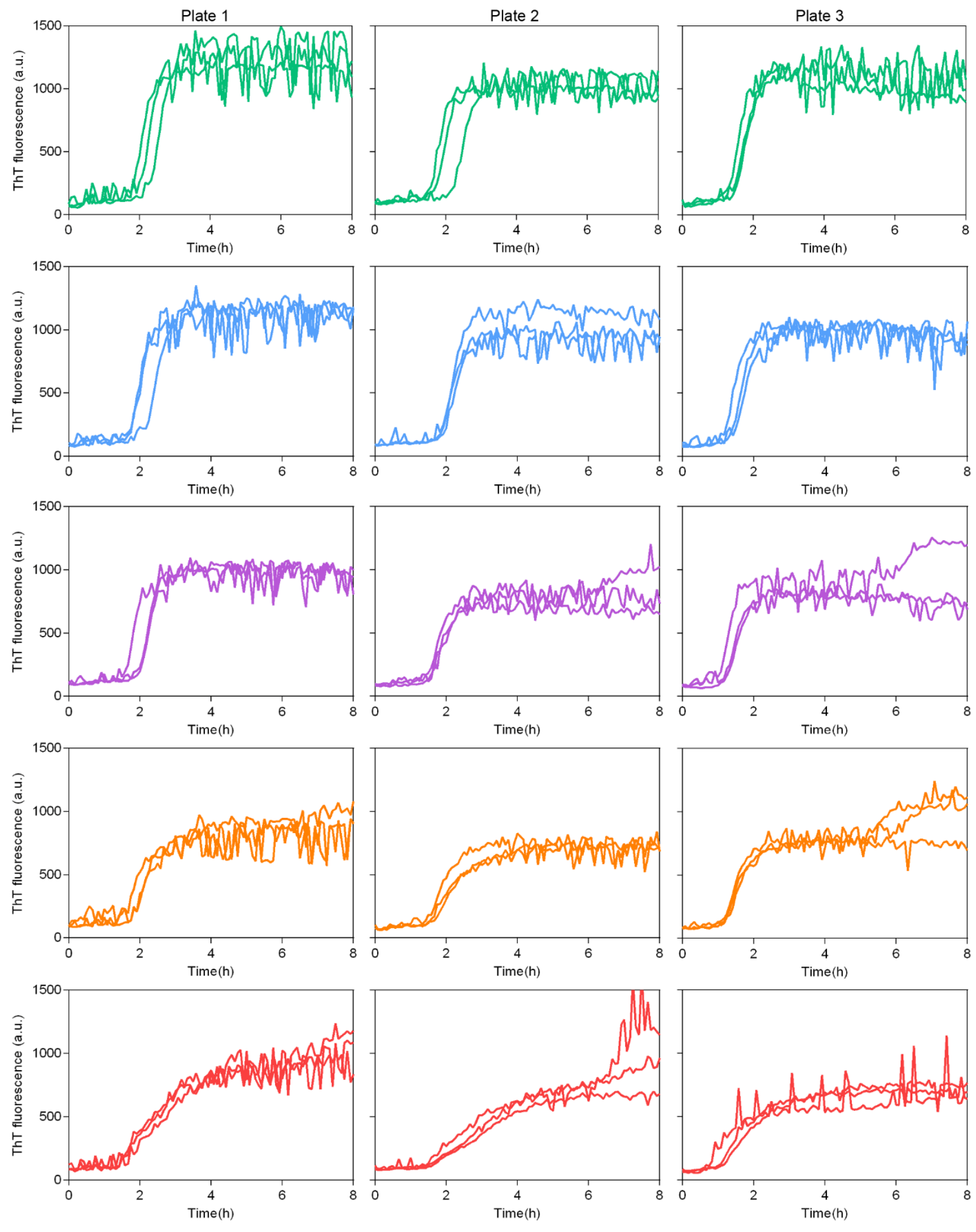

$-A \beta_{40}$

$0.1 \mathrm{mM} \mathrm{H}_{2} \mathrm{O}_{2}$

$1.0 \mathrm{mM} \mathrm{H}_{2} \mathrm{O}_{2}$

$3.0 \mathrm{mMH}_{2} \mathrm{O}_{2}-6.0 \mathrm{mMH}_{2} \mathrm{O}_{2}$ 
Figure 2.3. Individual curves for ThT assays. Assays performed at a concentration of $20 \mu \mathrm{M}$ $A \beta_{40}$ (green) aggregation performed at $37^{\circ} \mathrm{C}$ in the absence of $\mathrm{H}_{2} \mathrm{O}_{2}$ (green) or with the addition of $0.1 \mathrm{mM}$ (blue), $1.0 \mathrm{mM}$ (purple), $3.0 \mathrm{mM}$ (orange), and $6.0 \mathrm{mM} \mathrm{H}_{2} \mathrm{O}_{2}$ (red). Three independent plates were run.

2.3.3 Increased oxidation modifies the distribution of $A \beta_{40}$ aggregate species. It is wellknown that variations in the chemical environment can induce polymorphic aggregates in $A \beta,{ }^{60-}$ ${ }^{64}$ that is, fibrils of unique morphology and structure. To determine if oxidation could result in polymorphic $A \beta$ aggregates, incubations of $A \beta$ with various concentrations of $\mathrm{H}_{2} \mathrm{O}_{2}$ were sampled every hour for analysis by atomic force microscopy (AFM) to determine the impact of oxidative environments on aggregate species and morphology (Figure 2.4). To determine populations of different aggregate species, oligomers were defined as particles larger than $1 \mathrm{~nm}$ in height with an aspect ratio (defined as long axis/short axis) of less than 2.5 , indicating a globular morphology. Due to the high density of crossing fibrils in some images, the number of fibrils were manually counted. To prevent bias due to overcounting, individual fibrils were marked by tracing along the contour of each fibril in Photoshop. As fibril length can vary greatly, the total fibril load at any given time point was also determined by percent area of the mica surface covered by fibril aggregates (Figure 2.4B). At time point $0 \mathrm{~h}$, no observable oligomer or fibrils were observed for every condition $\left(\mathrm{H}_{2} \mathrm{O}_{2}\right.$ concentration). Within the first-hour, the number of oligomeric aggregates grew similarly for all conditions to higher than $\sim 20$ oligomers per $\mu \mathrm{m}^{2}$; however, these oligomer populations dramatically dropped after $2 \mathrm{~h}$ (a 2 to 4 -fold reduction). This decrease in oligomers under each condition coincided with the appearance of fibrils. The appearance of fibril after $2 \mathrm{~h}$ is consistent with the lag phases determined from the ThT assays (Figure 2.2A). The number of oligomers continued to decrease as the fibril load increased for each condition. With that being stated, the decrease in oligomers (and subsequent increase in 
fibrils) for the $6.0 \mathrm{mM} \mathrm{H} \mathrm{O}_{2}$ condition was significantly less pronounced compared with the other conditions, with a noticeable oligomer population still observed into the $3^{\text {rd }} \mathrm{h}$ of incubation. The number of fibrils observed at any given time point as a function of $\mathrm{H}_{2} \mathrm{O}_{2}$ concentration was consistent with the total fibril load associated with the ThT assays, that is, the number of fibrils and the surface area covered by fibrils decreases as the concentration of $\mathrm{H}_{2} \mathrm{O}_{2}$ increases.
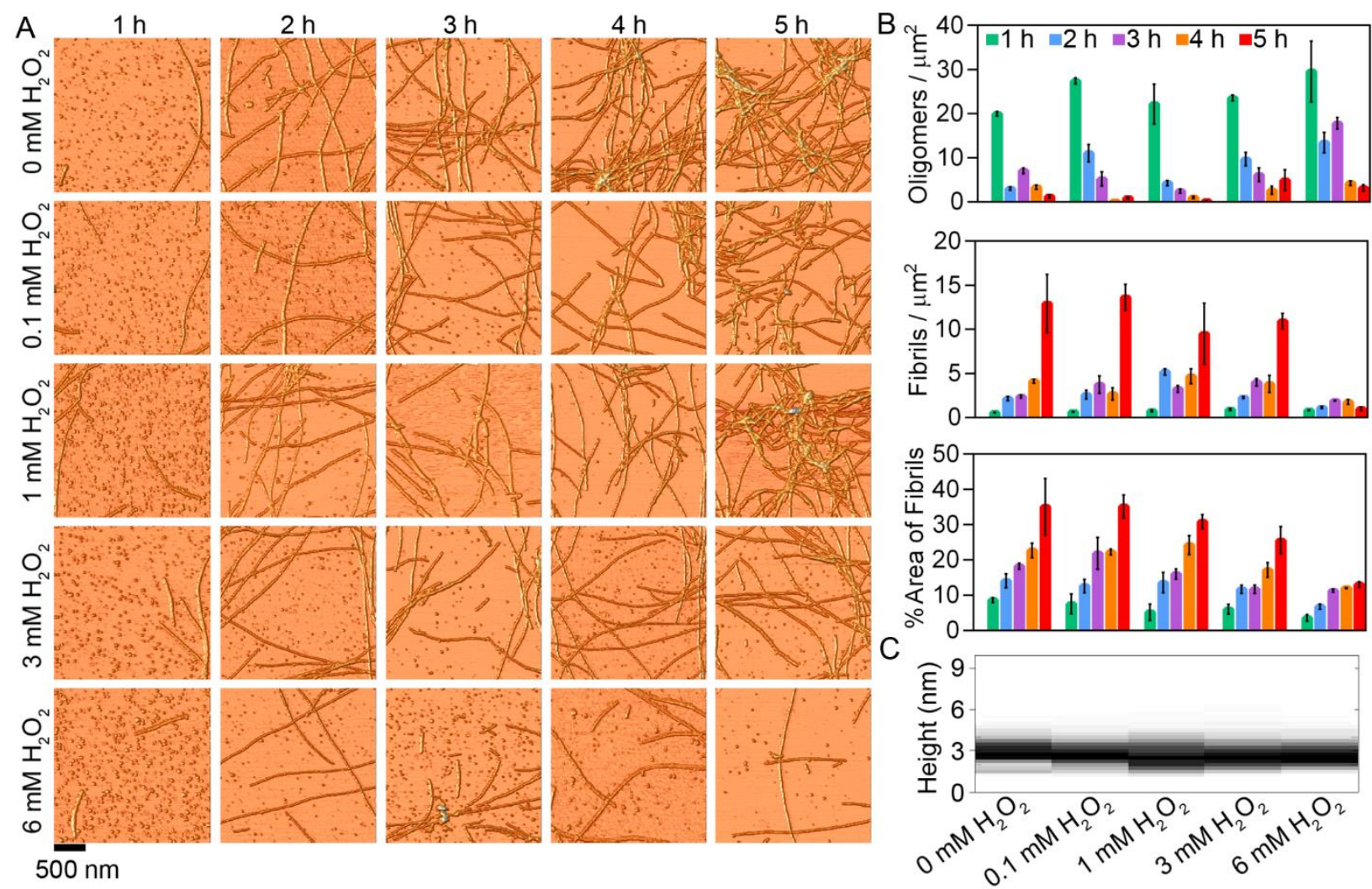

Figure 2.4. Atomic force microscopy analysis of $A \beta_{40}$ aggregation as a function of $\mathrm{H}_{2} \mathrm{O}_{2}$ concentration. (A) Representative AFM images of $20 \mu \mathrm{M} A \beta_{40}$ incubated at $37{ }^{\circ} \mathrm{C}$ with the

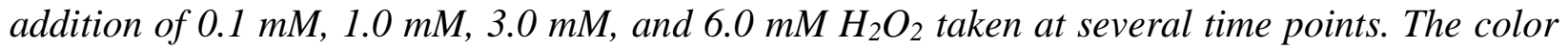
scale is the same for each image. (B) Determination of the number of oligomers and fibrils per unit area and the percent area of the mica surface covered by fibrils as observed in AFM images as a function of time. (C) Height histograms of oligomers observed in AFM images. 
Under all conditions, the distribution of oligomer size was consistent with a mode of oligomer size of 2.8-3.2 $\mathrm{nm}$ in height (Figure 2.4C). In contrast, there was a distinct polymorphic fibril structure formed in the presence of $6.0 \mathrm{mM} \mathrm{H} \mathrm{H}_{2} \mathrm{O}_{2}$ (Figure 2.5). With no $\mathrm{H}_{2} \mathrm{O}_{2}$ and $\mathrm{H}_{2} \mathrm{O}_{2}$ concentrations up to $3.0 \mathrm{mM}$, the average height along the contour of the fibril was $\sim 3 \mathrm{~nm}$. At these conditions, there were often regions where fibrils were bundled or crisscrossed, and these regions were thicker. When $\mathrm{H}_{2} \mathrm{O}_{2}$ concentration was $6.0 \mathrm{mM}$, the height along the contour of the fibrils was only $\sim 2 \mathrm{~nm}$, suggesting that the fibrils formed under this condition were structurally different. Interestingly, this is also the condition for which the elongation rate was significantly different and that the amount of Met35 oxidation can reach 50\% within 2 hours of incubation. 

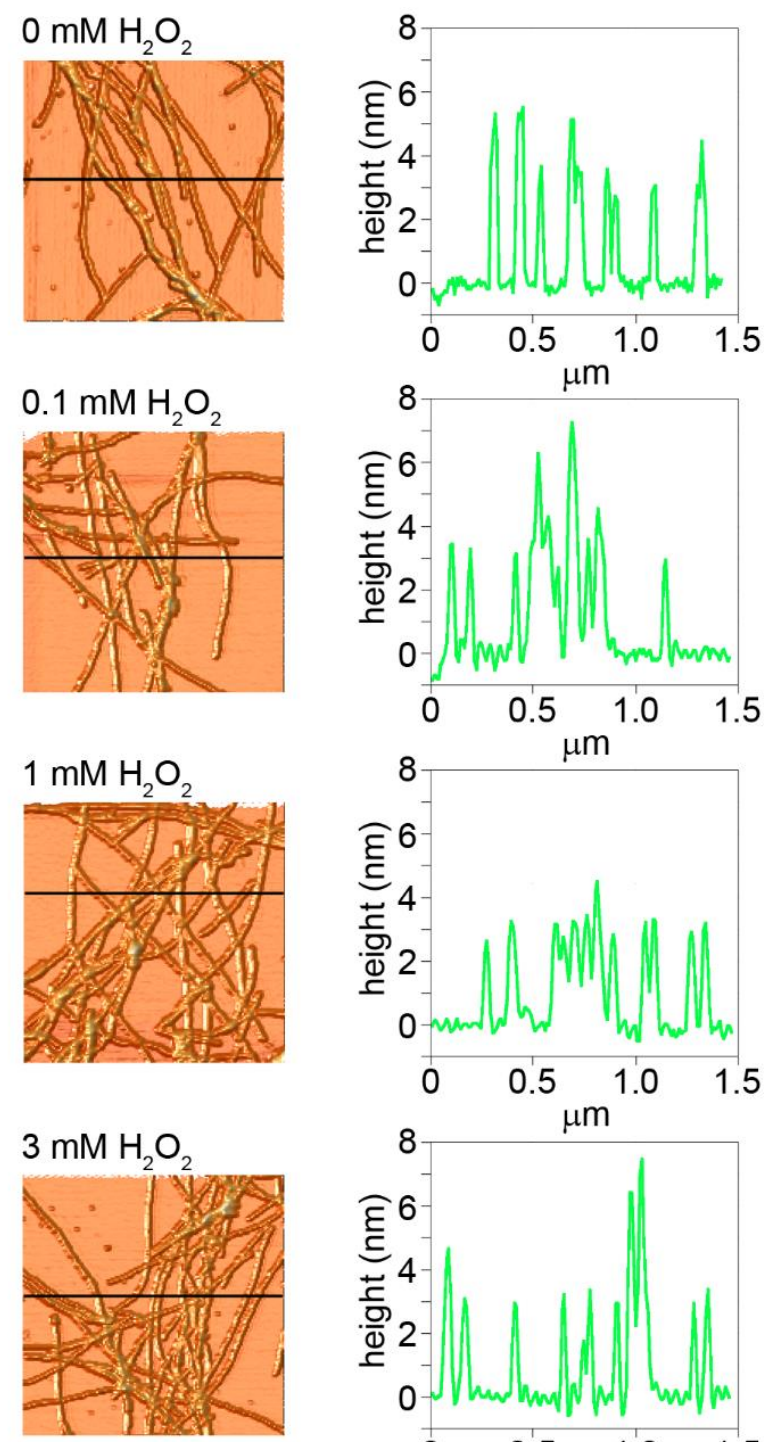

$6 \mathrm{mM} \mathrm{H}_{2} \mathrm{O}_{2}$

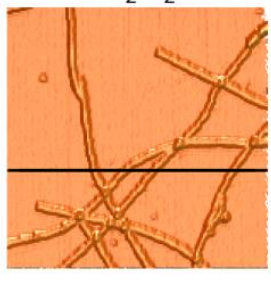

Figure 2.5. Comparison of $A \beta_{40}$ fibrils formed in the presence of varying concentrations of $\mathrm{H}_{2} \mathrm{O}_{2}$. (A) AFM images of fibrils formed by $A \beta_{40}$ in the presence of $\mathrm{H}_{2} \mathrm{O}_{2}$ concentrations ranging from 0-6.0 $m M$. The color scale is the same for each image. The black lines in each image corresponds to the height profile to the right of the image. In the height profile, a red dashed line is provided at a height of $3 \mathrm{~nm}$ for visual reference. (B) Histograms of the average height along the contour of fibrils observed in AFM images.

2.3.4 Secondary structural transitions of $\mathrm{A}_{40}$ are altered by $\mathrm{H}_{2} \mathrm{O}_{2}$. To determine if oxidative environments altered secondary structural changes in $A \beta_{40}$ associated with aggregation, circular dichroism (CD) spectra were collected of $A \beta_{40}$ exposed to various concentrations of 
$\mathrm{H}_{2} \mathrm{O}_{2}$ as a function of time (Figure 2.6). In the absence of $\mathrm{H}_{2} \mathrm{O}_{2}, A \beta_{40}$ underwent a clear structural transition between 2 and $3 \mathrm{~h}$ of incubation. Specifically, during the first $2 \mathrm{~h}$ of incubation, $A \beta_{40}$ was predominately random coil. At $3 \mathrm{~h}$, there was a significant increase in $\alpha$ helical content, suggesting the appearance of an $\alpha$-helical intermediate that has been proposed. ${ }^{29,65-67}$ After $3 \mathrm{~h}$, the parallel $\beta$-sheet content of $A \beta_{40}$ increased, consistent with extensive fibril formation.
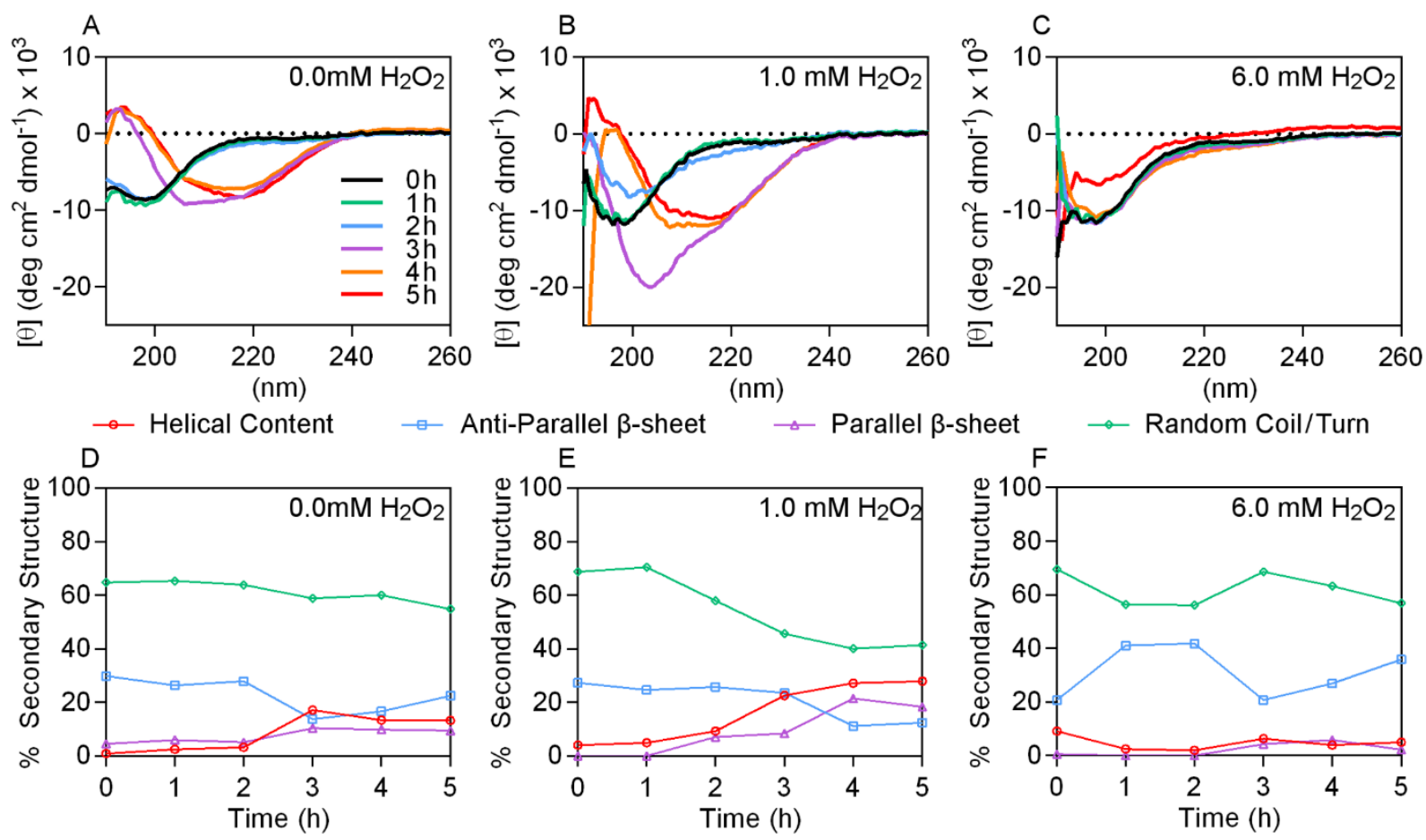

Figure 2.6. Secondary Structural Transitions Altered by $\mathbf{H}_{2} \mathrm{O}_{2}$. Time-dependent changes in $C D$ spectra recorded from 190-260 $\mathrm{nm}$ over $5 \mathrm{~h}$, discontinuously, at $25^{\circ} \mathrm{C}$ from $20 \mu \mathrm{M} \mathrm{A} \beta_{40}$ samples incubated continuously at $37{ }^{\circ} \mathrm{C}$ in a $10 \mathrm{mM} \mathrm{K} \mathrm{K}_{2} \mathrm{HPO}_{4} 50 \mathrm{mM} \mathrm{Na}_{2} \mathrm{SO}_{4}$ buffer (pH 7.23) containing (A) $0.0 \mathrm{mM} \mathrm{H}_{2} \mathrm{O}_{2}$, (B) $1.0 \mathrm{mM} \mathrm{H}_{2} \mathrm{O}_{2}$, and (C) $6.0 \mathrm{mM} \mathrm{H}_{2} \mathrm{O}_{2}$. Changes in secondary structure as a function of time from $C D$ deconvolution presented as percent contribution of helical content (red), antiparallel $\beta$-sheet (blue), parallel $\beta$-sheet (purple), and turn/random coil regions (green) for $\mathrm{A}_{40}$ in the presence of (D) $0.0 \mathrm{mM} \mathrm{H}_{2} \mathrm{O}_{2}$, (E) $1.0 \mathrm{mM} \mathrm{H}_{2} \mathrm{O}_{2}$, and (F) $6.0 \mathrm{mM}$ $\mathrm{H}_{2} \mathrm{O}_{2}$. Each spectra was deconvoluted using the online program BeStSel (Beta Structure Selection, http://bestsel.elte.hu/).

Adding $\mathrm{H}_{2} \mathrm{O}_{2}$ to the $\mathrm{A} \beta_{40}$ incubations at concentration of $1.0 \mathrm{mM}$ and $6.0 \mathrm{mM}$ altered the development of secondary structural elements as a function of time. Neither condition caused a 2. Hydrogen peroxide modifies A $\beta$-membrane interactions with implications for $A \beta_{40}$ aggregation 
significant change in secondary structure of $A \beta_{40}$ for the first $2 \mathrm{~h}$ of incubation, that is, random coil was the dominant structural element. At $3 \mathrm{~h}$, the rise of $\alpha$-helical structure in $A \beta_{40}$ was still apparent with $1.0 \mathrm{mM} \mathrm{H}_{2} \mathrm{O}_{2}$. The transition from the $\alpha$-helical intermediate to $\beta$-sheet structure associated with fibrillization still occurred in the presence of $1.0 \mathrm{mM} \mathrm{H}_{2} \mathrm{O}_{2}$ after $3 \mathrm{~h}$ of incubation, but this $\alpha$-helical content persisted at the 4 and $5 \mathrm{~h}$ time points. Similar to aggregation in the absence of $\mathrm{H}_{2} \mathrm{O}_{2}$, there was an increase in parallel $\beta$-sheet content. At the 6.0 $\mathrm{mM}$ concentration of $\mathrm{H}_{2} \mathrm{O}_{2}$, the transition away from random coil structure was not apparent over the time course of the experiment, which is consistent with previously published results for $A \beta_{42}$ and $\mathrm{A} \beta_{42}-\mathrm{Met} 35[\mathrm{O}]^{20}$ and further supports the notion that fibrils observed under this condition represent a polymorph when compared to $A \beta$ fibrils formed in the absence of $\mathrm{H}_{2} \mathrm{O}_{2}$.

2.3.5 The presence of TBLE LUVS impedes aggregation of $A \beta_{40}$. To understand how the presence of lipid membranes alter $A \beta_{40}$ aggregation, and how oxidation may modulate that interaction, we evaluated $A \beta_{40}$ aggregation in the presence of large unilamellar vesicles (LUV) of TBLE with ThT assays. Due to inconsistent results in the literature demonstrating the increase $^{68,69}$ or decreases ${ }^{70,71}$ of lag-phase behavior for $A \beta$ aggregation in the presence of lipids, first performed to understand how $A \beta$ aggregates as a function of lipid mass for the specific lipid system and $A \beta$ preparation protocols used here (Figure 2.7). These experiments were performed in the absence of $\mathrm{H}_{2} \mathrm{O}_{2}$ and at an $\mathrm{A} \beta_{40}$ concentration of $20 \mu \mathrm{M}$. As the lipid to peptide ratio was increased, the lag phase associated with $A \beta_{40}$ aggregation (in the absence of $\mathrm{H}_{2} \mathrm{O}_{2}$ ) extended, increasing by $\sim 3.5 \mathrm{~h}$ when the lipid to peptide ratio exceeded 50:1 (Figure 2.7B). These extended lag phases are attributable to the effect of interactions between $A \beta_{40}$ and the LUVs. The slope of the growth phase and extent of $\beta$-sheet formation at steady state varied extensively without a clear trend in the presence of TBLE. 

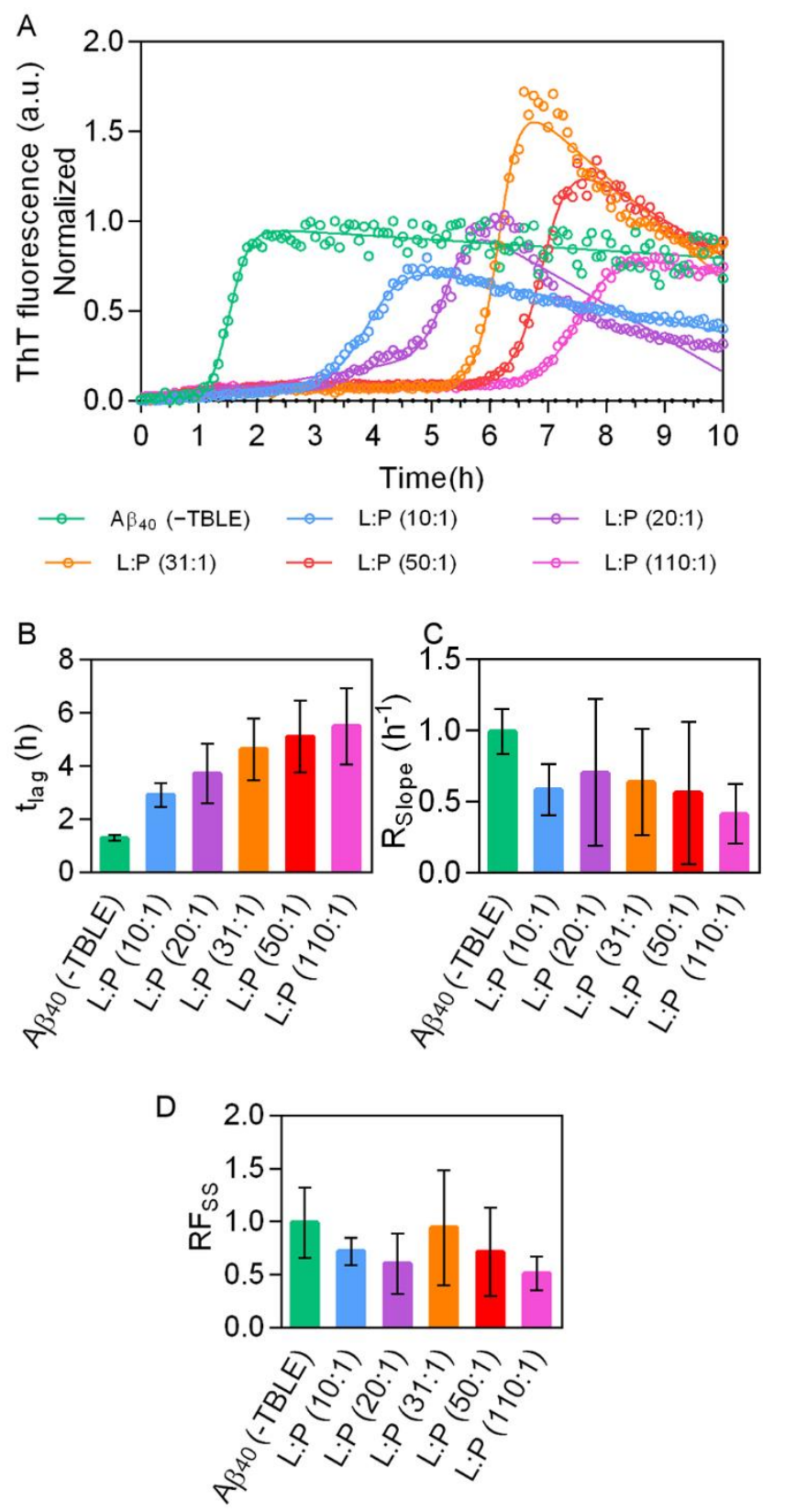

Figure 2.7. Presence of TBLE extends lag-phase of $\mathbf{A \beta}_{40}$ aggregation $(A)$ Average ThT assays of $20 \mu M \quad A \beta_{40}$ performed at $37^{\circ} \mathrm{C}$ in the absence (green) and presence of TBLE vesicles various lipid-to-peptide (L:P) ratios; 10:1 (blue), 20:1 (purple), 30:1 (orange), 50:1 (red), and 110:1 (pink). Equation 1 was utilized to provide a non-linear best fit to the average of triplicate traces represented as continuous lines. (B) The lag-phase, tlag, was calculated from non-linear fits of experiments represented by bar-graphs as the mean $\pm S E M .(C)$ The relative slope of the normalized ThT curves, $R_{\text {slope }}\left(h^{-1}\right)$, and $(D)$ relative fluorescence at steady state, $R F_{s s}$, were calculated of the linear fits of the growth phase and plateau region of the ThT curves, respectively. 
Having established how TBLE alters $A \beta_{40}$ aggregation in the absence of $\mathrm{H}_{2} \mathrm{O}_{2}$, a series of ThT assays were run with increasing amounts of $\mathrm{H}_{2} \mathrm{O}_{2}$ (from $0.1 \mathrm{mM}$ to $6.0 \mathrm{mM}$ ) and a lipid to peptide ratio of 30:1 (Figure 2.8). At the 30:1 lipid to peptide ratio, the lag phase was $3.61 \pm 0.39$ $h$ in the absence of $\mathrm{H}_{2} \mathrm{O}_{2}$. Increasing $\mathrm{H}_{2} \mathrm{O}_{2}$ concentration systematically reduced the lag phase associated with $A \beta$ aggregation. The effect was significant enough that at the highest concentration of $\mathrm{H}_{2} \mathrm{O}_{2}, 6.0 \mathrm{mM}$, the lag-phase was roughly equivalent to the lag-phases of $\mathrm{A} \beta_{40}$ observed in Figure 2.2 in which no lipid was present $(1.10 \pm 0.51 \mathrm{~h}$ and $1.27 \pm 0.06 \mathrm{~h}$, respectively), suggesting that increased $\mathrm{H}_{2} \mathrm{O}_{2}$ concentration decreases the interaction between $\mathrm{A} \beta_{40}$ and lipids. Once nucleation occurred, the slope of the growth phase, associated with fibril elongation, remained unchanged as $\mathrm{H}_{2} \mathrm{O}_{2}$ concentration was increased up to a concentration of $3.0 \mathrm{mM}$. At $6.0 \mathrm{mM} \mathrm{H} \mathrm{H}_{2} \mathrm{O}_{2}$ the slope of the growth phase abruptly dropped to $0.21 \pm 0.015 \mathrm{~h}^{-1}$. The magnitude of ThT signal once steady state $A \beta$ aggregation was reached also diminished with increased exposure to $\mathrm{H}_{2} \mathrm{O}_{2}$. Collectively, these observations suggest that the oxidative environment provided by $\mathrm{H}_{2} \mathrm{O}_{2}$ reduced the affinity of $\mathrm{A} \beta$ for the lipid bilayer surface, causing the characteristics of $A \beta$ aggregation to shift toward those associated with the absence of lipids. 

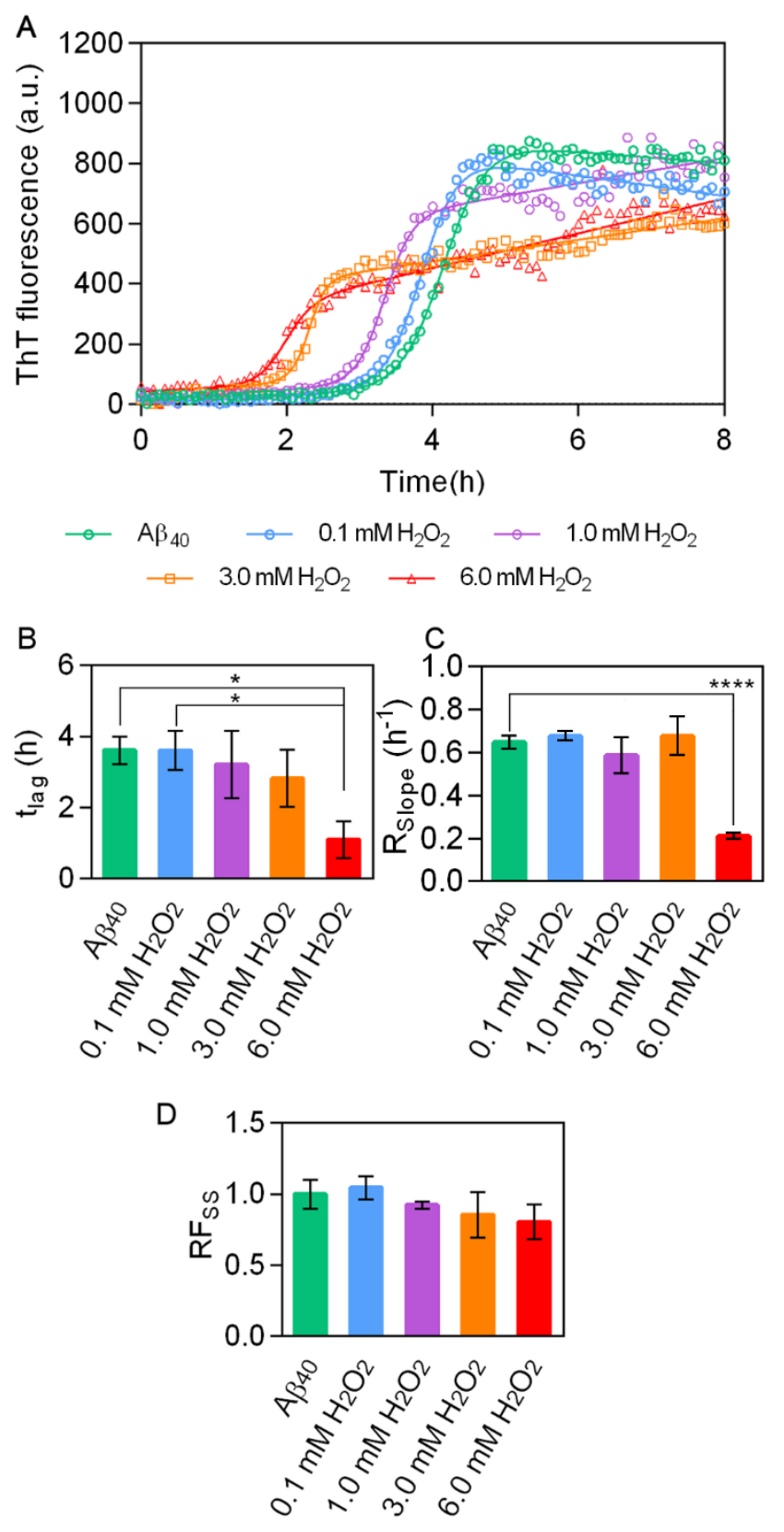

Figure 2.8. Impact of $\mathrm{H}_{2} \mathrm{O}_{2}$ on $\mathrm{A} \boldsymbol{\beta}_{40}$ aggregation in the presence of TBLE vesicles (A) Average ThT assays of $20 \mu \mathrm{M}$ $A \beta_{40}$ (green) aggregation in the presence of TBLE vesicles (30:1 lipid to peptide ratio) performed at $37{ }^{\circ} \mathrm{C}$ with the addition of 0.1 $\mathrm{mM}$ (blue), $1.0 \mathrm{mM}$ (purple), $3.0 \mathrm{mM}$ (orange), and $6.0 \quad \mathrm{mM} \quad \mathrm{H}_{2} \mathrm{O}_{2}$ (red). Continuous lines represent non-linear best fits (Equation 1) to the average experimental traces. The lag-phase was calculated from non-linear fits of three independent experiments represented by bar-graphs as the mean $\pm S E M$. Kinetic parameters include the $(B)$ lag-phase, $t_{\text {lag }},(C)$ relative slope of the normalized ThT curves, $R_{\text {slope }}\left(h^{-1}\right)$, and (D) normalized steady-state maximum fluorescent response, and relative fluorescence at steady state. $P$-values are indicated as follows (*) $P \leq 0.05$, (**) $P \leq^{*}$ $0.01,(* * *) \quad P \leq 0.001$, and $(* * * *) P \leq$ 0.0001 . 
2.3.6 Oxidation reduces AB/lipid interaction and lipid oxidation plays a large role. As the ThT assays suggested a reduced interaction between the lipid vesicles and $A \beta_{40}$, a polydiacetylene (PDA) lipid binding assay was performed to measure the total interaction between $A \beta_{40}$ and lipid membranes (Figure 2.9A). Polydiacetylene is a lipid moiety that can be incorporated into vesicles and photo-crosslinked to create vesicles that are sensitive to mechanical perturbations associated with peptide binding and aggregation, resulting in both a color change (blue to red) and enhanced fluorescence. Here, the PDA was incorporated into TBLE vesicles, and the response upon exposure to $A \beta_{40}$ was measured fluorescently. Controls were performed demonstrating that exposure to various concentration of $\mathrm{H}_{2} \mathrm{O}_{2}$ did not invoke a fluorescent response in the PDA assay in the absence of $A \beta$ and used for background correction. Upon exposure of TBLE/PDA vesicles to $A \beta_{40}$, the fluorescent signal steadily increases as the peptide binds and aggregates on vesicles. While the presence of $0.1 \mathrm{mM}$ and $1.0 \mathrm{mM} \mathrm{H}_{2} \mathrm{O}_{2}$ did not significantly alter the interaction between $\mathrm{A} \beta_{40}$ and the vesicles, $\mathrm{H}_{2} \mathrm{O}_{2}$ concentrations of 3.0 $\mathrm{mM}$ and higher resulted in a significant decrease in peptide/lipid interaction, which correlates with the ThT data presented in Figure 2.8. 

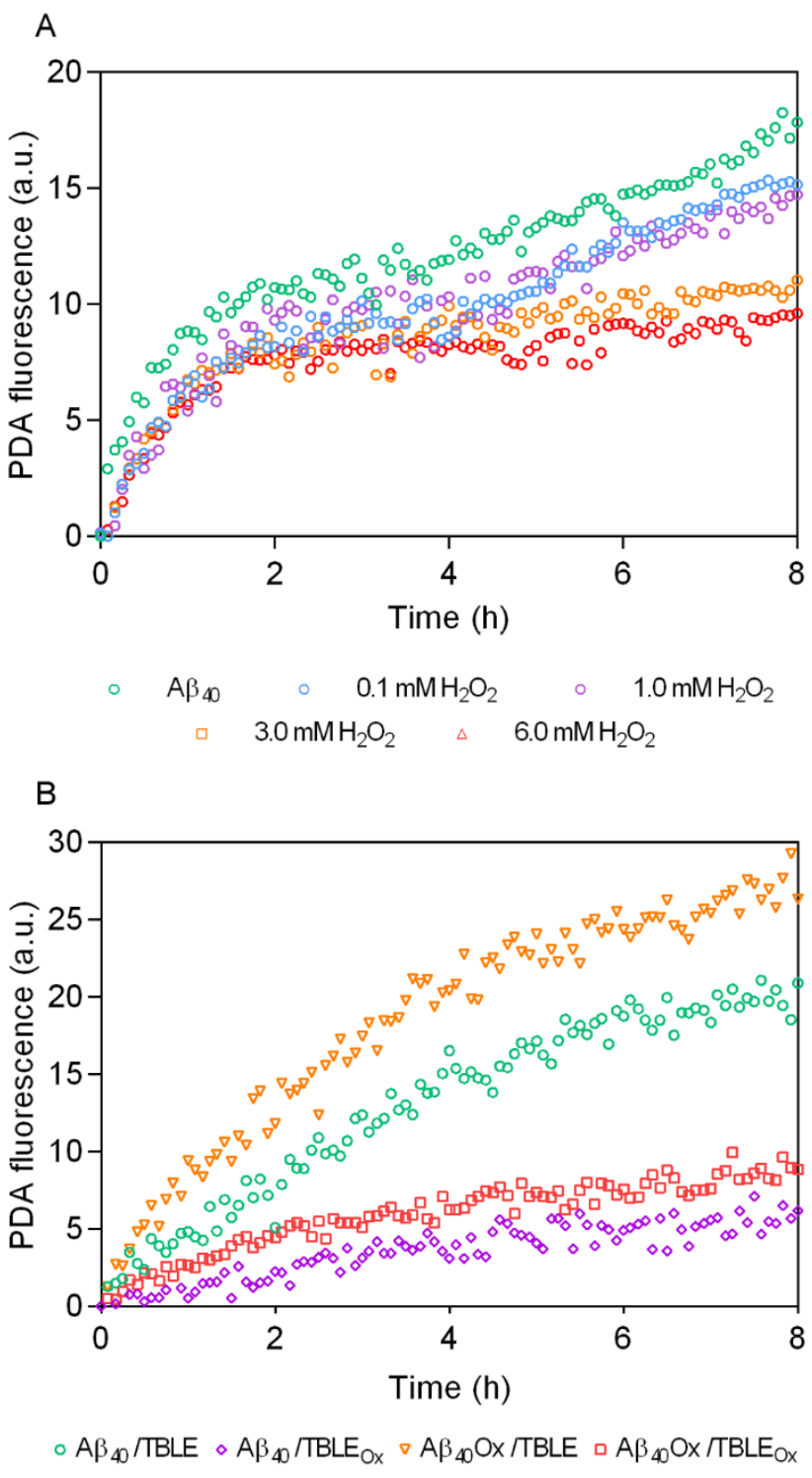

Figure 2.9. $A \beta_{40}$ binding assays performed with TBLE/PDA vesicles. (A) PDA fluorescence response $\left(\lambda_{E x} 485 \mathrm{~nm}, \lambda_{E m} 560\right.$ $\mathrm{nm})$ as a function of time when exposed to 20 $\mu M A \beta_{40}$ (green) incubated at $25^{\circ} \mathrm{C}$ and in the presence of $0.1 \mathrm{mM}$ (blue), $1.0 \mathrm{mM}$ (purple), $3.0 \mathrm{mM}$ (orange), and $6.0 \mathrm{mM}$ $\mathrm{H}_{2} \mathrm{O}_{2}$ (red). (B) Isolated effects of varied oxidation states of TBLE and $A \beta_{40}$ on peptide-membrane interactions measured by PDA fluorescence incubated at $25^{\circ} \mathrm{C}$. PDA assays were performed with the following combinations; unoxidized TBLE/PDA and $A \beta_{40}$ (green, circle), TBLE/PDA and $A \beta_{40}$ oxidized (orange, triangle), TBLE ${ }_{0 X} / P D A$ and $A \beta_{40}$ (purple, diamond), lastly $T B L E_{O x} / P D A$ and $A \beta_{40}$ oxidized (red, square).

$\mathrm{H}_{2} \mathrm{O}_{2}$ can oxidize not only $\mathrm{A} \beta$ but also lipids. To elucidate if oxidation of $\mathrm{A} \beta_{40}$, TBLE LUVs, or both was the modulator of the observed decreased peptide/lipid interaction, additional lipid binding assays were performed in which the oxidation of the varying components was controlled. Briefly, $A \beta_{40}$ and TBLE were oxidized separately and lyophilized to remove residual $\mathrm{H}_{2} \mathrm{O}_{2}$. These pre-oxidized materials were then used for a series of TBLE/PDA assays. The preoxidized stock of $A \beta_{40}$ was $76 \%$ oxidized (as measured by MS), and the pre-oxidized stock of 
TBLE was $62 \%$ oxidized (as determined by an LPO Assay Kit). The oxidized form of TBLE was used in conjunction with PDA to create an oxidized-TBLE/PDA vesicles (TBLE $\left.{ }_{O x}\right)$. Due to concerns about changes in solubility upon oxidation of the lipids, it was necessary that the total lipid mass delivered to each sample be standardized. Standardization was carried out through the use of optical density measurements at $470 \mathrm{~nm}$ conducted before photoactivation of TBLE/PDA vesicles. Maximum responses of positive controls were also compared and used to standardize the responses across different TBLE/PDA batches; maximum fluorescent intensities were found to be directly comparable even before normalizing across batches.

When both oxidized TBLE (TBLE $0 x)$ and $A \beta_{40}\left(A \beta_{40} \mathrm{Ox}\right)$ were used in the PDA assay, a significant decrease in peptide/lipid interaction was observed compared with using un-oxidized TBLE and $A \beta_{40}$, which is consistent with the PDA assay results from Figure 2.9B. However, when only $A \beta_{40}$ was oxidized, the interaction of the peptide with un-oxidized TBLE vesicles increased in comparison with un-oxidized $\mathrm{A} \beta_{40}$ (Figure 2.9B), which is the opposite effect that was observed when $\mathrm{H}_{2} \mathrm{O}_{2}$ was just added directly to the interaction. When TBLE 0 was used in the PDA assay, exposure to un-oxidized $A \beta_{40}$ resulted in an even greater decrease in the measured peptide/lipid interaction compared with oxidized $A \beta_{40}$. These observations suggest that oxidation of $\mathrm{A} \beta$ and lipid both play a role in their co-interaction, but with opposite effects. That is, oxidation of $A \beta$ enhances the affinity for TBLE based membranes, while lipid oxidation inhibits the binding of $A \beta$ to membranes. Of the two, lipid oxidation appears to have a larger impact on the peptide/lipid interaction. 


\subsection{Discussion}

A number of studies have investigated the impact of Met35 oxidation on A $\beta$ aggregation in the absence of lipids with varying results. Some studies suggest that Met35 oxidation enhances aggregation to fibrils: ${ }^{26}$ meanwhile, others suggest it impedes aggregation. ${ }^{23,25,72} \mathrm{~A}$ complicating factor in evaluating studies of $\mathrm{A} \beta$ aggregation and structure is divergent preparatory conditions greatly influence experimental outcomes. ${ }^{73}$ Of these reports, the study by $\mathrm{Gu}$ and Viles is most directly comparable to our results, as the same $\mathrm{A} \beta$ preparation protocol was used, oxidation was performed with a similar range of $\mathrm{H}_{2} \mathrm{O}_{2}$, and the aggregation occurs with mixtures of oxidized and unoxidized $A \beta \cdot{ }^{23}$ In fact, the extent of oxidation in their study and ours under similar concentrations of $\mathrm{H}_{2} \mathrm{O}_{2}$ were comparable. While $\mathrm{Gu}$ and Viles observed a $\mathrm{H}_{2} \mathrm{O}_{2}$ concentration dependent reduction in the lag phase, ${ }^{23}$ we observed no statistically significant effect on the lag phase. A key difference between the two studies is that we elected to use small borosilicate beads in each well to mix our aggregation reactions during the ThT assays. This is

known to enhance $A \beta$ aggregation and provide more reproducible aggregation rates. ${ }^{74}$ As a result, our aggregation reactions proceeded much more rapidly in comparison with Gu and Viles. We elected to use this protocol as without the beads our rates of aggregation were too variable to perform a statistical analysis of kinetic parameters, even without the addition of $\mathrm{H}_{2} \mathrm{O}_{2}$.

In these studies, the similarities in the lag-phase associated with the presence of up to 3.0 $\mathrm{mM} \mathrm{H}_{2} \mathrm{O}_{2}$ suggest that oxidation of Met35 is not pivotal in the initial formation of the critical nucleus associated with fibril formation under our experimental conditions. The critical nucleus associated with $A \beta$ fibrillization is often considered to be a small oligomer. ${ }^{75-77}$ While crosslinking methods to stabilize small $A \beta$ oligomers have demonstrated that $A \beta_{40}$ forms an equilibrium distribution of monomers, dimers, trimers, and tetramer formation, isolated 
$\mathrm{A} \beta{ }_{40}$ Met35[O] only formed dimers, as determined by ESI-MS ${ }^{78,79}$ However, co-incubation of $A \beta_{40}$ and $A \beta_{40}$ Met35[O] resulted in trimer and tetramer formation with statistically random incorporation of $A \beta_{40} \mathrm{Met} 35[\mathrm{O}]$ into oligomers. This heterogenic mixing is the scenario that is applicable to our experimental setup as increasing $\mathrm{H}_{2} \mathrm{O}_{2}$ concentration resulted in a gradual increase in $A \beta_{40}$ oxidation at Met35, maxing out at $~ 50-65 \%$. Taken together, it appears that for homogenous systems of oxidized A $\beta$ Met35 plays a large role in the initial oligomerization, but under heterogenous systems of $A \beta_{40}$ and $A \beta_{40} M e t 35[O]$ oligomerization on-pathway to fibril formation can still proceed.

Despite the lag phase of aggregation being predominately unaltered in the absence of lipids, at large enough $\mathrm{H}_{2} \mathrm{O}_{2}$ concentrations (at least $6.0 \mathrm{mM}$ ) the relative slope of the growth phase, associated with fibril growth of $A \beta_{40}$, was significantly reduced indicating that the addition of monomeric $A \beta_{40}$ to the terminal ends of fibrils is altered. Since the extent of oxidized $\mathrm{A} \beta_{40}$ varies with increases in the oxidative environment, representing a higher population of $A \beta_{40}-\mathrm{Met} 35[\mathrm{O}]$ to $A \beta_{40}$, the reduction in fibril growth could reflect a lower affinity of $A \beta_{40^{-}}$ Met35[O] for fibril ends. This is consistent with experiments in which the aggregation of monomeric $A \beta_{40}$-Met35[O] was less efficiently seeded by the addition of pre-formed fibrils. ${ }^{23}$ The addition of monomeric $A \beta$ to fibril ends has been proposed before to proceed through a twostep "dock-lock" mechanism ${ }^{80-82}$ with the C-terminal hydrophobic residues having a conformational preference for the initial docking stage ${ }^{83}$ Since Met35 is the only observable modification to $\mathrm{A} \beta_{40}$ determined by MS and ${ }^{1} \mathrm{H} N M R$, it is possible that oxidation of Met35 is inhibiting the ability of $A \beta_{40}$ to dock to fibril ends successfully. However, this is difficult to ascertain as the reduction of fibril growth at $6.0 \mathrm{mM} \mathrm{H}_{2} \mathrm{O}_{2}$ may also reflect the underlying fibril structure, as our AFM and CD analysis indicated that a distinct, polymorphic fibril was observed 
under this condition. That is, the docking and locking mechanism may be distinct as the underlying fibril structure is likely different as discussed below.

The altered morphology observed by AFM and CD spectral differences associated with fibrils formed with $6.0 \mathrm{mM} \mathrm{H} \mathrm{H}_{2} \mathrm{O}_{2}$ suggest a unique fibril structure. Several lines of evidence support that oxidation of Met35 could promote a fibril polymorph. Intermolecular interactions between Met35-Met35 found in hydrophobic domains have been observed for two-fold ${ }^{84}$ and three-fold symmetric fibrils. ${ }^{85}$ Cryo-EM resolved structures demonstrating an $L S$-shaped motif placed Met35 in one of three stabilizing hydrophobic clusters. Gremer et al. proposed that these Met35-Met35 interactions occur along the fiber axis instead of across the fibril axis as previously thought. ${ }^{86}$ Therefore, $A \beta_{40}$-Met35[O] with significant alterations to its dipole moment and hydrophobicity ${ }^{72,87}$ would likely not be incorporated into these types of fibril structures as easily. NMR structures of pure $A \beta_{42}-\mathrm{Met} 35[\mathrm{O}]$ fibrils have been obtained in which Met35[O] is facing away from the hydrophobic core making it solvent exposed. ${ }^{35}$ In addition, solution state NMR studies suggest that the more solvent exposed Met35[O] of $A \beta_{40}$ or $A \beta_{42}$ reduces hydrophobic and electrostatic associations involved in fibril formation. ${ }^{29}$

The presence of a distinct fibril polymorph might suggest unique oligomeric precursors. Just as structural changes of $A \beta$ are hypothesized to be the driving force for aggregation and subtle environmental factors can result in unique fibril structures, ${ }^{84,88}$ one could envision that the ratio of $A \beta_{40}-$ Met35[O] to $A \beta_{40}$ would influence the formation of both off-pathway and onpathway oligomers. However, evaluation of oligomer morphology by AFM did not result in any observable differences at a morphological level. Time resolved CD spectroscopy did suggest that transitory secondary structural elements associated with $\mathrm{A} \beta_{40}$ aggregation was altered at $6.0 \mathrm{mM}$ $\mathrm{H}_{2} \mathrm{O}_{2}$. From the absence of $\mathrm{H}_{2} \mathrm{O}_{2}$ to $1.0 \mathrm{mM} \mathrm{H} \mathrm{O}_{2}$, evidence of an $\alpha$-helical intermediate was 
observed, but this was not apparent at $6.0 \mathrm{mM} \mathrm{H}_{2} \mathrm{O}_{2}$ despite the similarities in the lag phase. $\mathrm{A} \beta$ $\alpha$-helical intermediates on-pathway to fibril formation have been observed via $\operatorname{Raman}^{89}$ and CD spectroscopy. ${ }^{90}$ The NMR study of monomeric $A \beta_{40}$ in SDS micelles ${ }^{28}$ and aqueous ${ }^{65}$ environments suggested that the structure of monomeric $A \beta_{40}$ adopts helical conformations. Met35 oxidation specifically disrupts a helical region of $A \beta$ spanning from residues $28-36{ }^{28}$ In light of the unique fibril structure associated with fibrils formed in the presence of $6.0 \mathrm{mM} \mathrm{H}_{2} \mathrm{O}_{2}$, it is possible that the oligomers observed under these different conditions were structurally different despite being similar in size.

Lipid membranes are known to influence the aggregation of $A \beta,{ }^{71}$ and this is highly sensitive to membrane composition. ${ }^{43,71,91}$ As a result, we aimed to determine how oxidative environments influenced $A \beta$ aggregation in the presence of lipid membranes of TBLE. In the absence of $\mathrm{H}_{2} \mathrm{O}_{2}$, the addition of TBLE LUVs increased the lag-phase as a function of peptide/lipid ratio. We then introduced oxidizing environments to a standardized ratio of TBLE LUVs and $A \beta_{40}$. Our observations established that increasing $\mathrm{H}_{2} \mathrm{O}_{2}$ concentration reduced TBLE LUV's effect on $A \beta_{40}$ fibrillogenesis, resulting in similar aggregation profiles for $A \beta$ in $6.0 \mathrm{mM}$ $\mathrm{H}_{2} \mathrm{O}_{2}$ in the presence and absence of TBLE. A potential explanation is that binding of $A \beta$ to TBLE LUVs effectively retards aggregation, but the affinity of $A \beta$ is reduced as Met35 is oxidized. As the affinity of A $\beta$ for the TBLE is reduced due to oxidation, the impact of TBLE LUVs on aggregation would decrease, and aggregation would proceed in a manner similar to the condition when the LUVs are absent. To test this assertion, PDA assays were performed that confirmed that increased $\mathrm{H}_{2} \mathrm{O}_{2}$ concentration directly correlated with decreased $\mathrm{A} \beta_{40}$ interaction with TBLE LUVs. 
Due to hydrogen peroxide's ability to oxidize $A \beta_{40}$ and TBLE-LUVs simultaneously, we sought to distinguish the relative contribution of peptide and lipid oxidation on the reduced binding interaction by systematically performing PDA assays with varying combinations of oxidized and un-oxidized components. This is important as A $\beta$ binding to cellular membranes represents a key phenomenon in assessing cellular susceptibility to A $\beta$-induced toxicity. ${ }^{41}$ Interestingly, Met35 oxidation increased the affinity of $A \beta_{40}$ for TBLE membranes that were not oxidized; whereas, lipid peroxidation reduced the ability of $A \beta_{40}$ to bind lipids. There are several physicochemical possibilities as to why Met35 oxidation increased the affinity of $A \beta_{40}$ for lipid membranes. The methionine sulfoxide side chain is stiffer and more polar compared to methionine, and the hydropathy index of methionine sulfoxide is similar to that of lysine, ${ }^{92}$ which is known to play a role in membrane protein anchoring, ${ }^{93}$ cell-penetrating peptides, ${ }^{94}$ and antimicrobial peptides. ${ }^{95}$ These chemical changes could enhance the affinity of $A \beta_{40}-\mathrm{Met} 35[\mathrm{O}]$ with membranes via stronger interactions with polar and charged lipid head groups. Regarding the role of lipids, lipid peroxidation is known to rigidify membranes. Interestingly, alteration in membrane rigidity correlated with the ability of $A \beta_{40}$ to bind and damage supported TBLE bilayers. ${ }^{96,97}$ Collectively, our results suggest that the affinity of $A \beta$ for cellular membranes would depend not just on intrinsic factors associated with the peptide, but also environmental factors. 


\subsection{References}

(1) Pilkington IV, A. W., and Legleiter, J. (2019) Challenges in understanding the structure/activity relationship of A $\beta$ oligomers, AIMS Biophys. 6, 1-22.

(2) Cline, E. N., Bicca, M. A., Viola, K. L., and Klein, W. L. (2018) The Amyloid- $\beta$ Oligomer Hypothesis: Beginning of the Third Decade, J. Alzheimer's Dis. 64, S567-S610.

(3) Sakono, M., and Zako, T. (2010) Amyloid oligomers: Formation and toxicity of A $\beta$ oligomers, FEBS J. 277, 1348-1358.

(4) Alzheimer's Association. (2017) Alzheimer's Disease Facts and Figures 2017, Alzheimer's Dement. 13, 325-373.

(5) Beckmanm, K. B., and Ames, B. N. (1998) The Free Radical Theory of Aging Matures, Physiol. Rev. 78, 547-581.

(6) Harman, D. (1956) Aging: A Theory Based on Free Radical and Radiation Chemistry, $J$. Gerontol. 11, 298-300.

(7) Gerschman, R., Gilbert, D. L., Sylvanus, N. W., Dwyer, P., and O. Fenn, W. (1954) Oxygen Poisoning and X-irradiation: A Mechanism in Common, Science (80-. ). 119, 623-626.

(8) Magalhães, J. P. D., and Church, G. M. (2006) Cells discover fire: Employing reactive oxygen species in development and consequences for aging, Exp. Gerontol. 41, 1-10.

(9) Choe, M., Jackson, C., and Yu, B. P. (1995) Lipid peroxidation contributes to age-related membrane rigidity, Free Radic. Biol. Med. 18, 977-984.

(10) Choi, J.-H., and Yu, B. P. (1995) Brain Synaptosomal Aging: Free radicals and membrane fluidity, Free Radic. Biol. Med. 18, 133-139.

(11) Cecchi, C., Fiorillo, C., Baglioni, S., Pensalfini, A., Bagnoli, S., Nacmias, B., Sorbi, S., Nosi, D., Relini, A., and Liguri, G. (2007) Increased susceptibility to amyloid toxicity in familial Alzheimer's fibroblasts, Neurobiol. Aging 28, 863-876.

(12) Williamson, R., Usardi, A., Hanger, D. P., and Anderton, B. H. (2007) Membrane-bound $\beta$ amyloid oligomers are recruited into lipid rafts by a fyn-dependent mechanism, FASEB J. 22, 1552-1559.

(13) Butterfield, D. A., Drake, J., Pocernich. Chava, and Castegna, A. (2001) Evidence of oxidative damage in Alzheimer's disease brain: central role for amyloid $\beta$-peptide, Trends Mol. Med. 7, 548-554.

(14) Markesbery, W. R. (1997) Oxidative stress hypothesis in Alzheimer's disease, Free Radic. Biol. Med. 23, 134-147.

(15) Butterfield, D. A., and Sultana, R. (2011) Methionine-35 of A $\beta(1-42)$ : importance for oxidative stress in Alzheimer disease., J. Amino Acids 2011, 1-10.

(16) Kuo, Y.-M., Kokjohn, T. A., Beach, T. G., Sue, L. I., Brune, D., Lopez, J. C., Kalback, W. M., Abramowski, D., Sturchler-Pierrat, C., Staufenbiel, M., and Roher, A. E. (2001)

Comparative Analysis of Amyloid- $\beta$ Chemical Structure and Amyloid Plaque Morphology of Transgenic Mouse and Alzheimer's Disease Brains, J. Biol. Chem. 276, 12991-12998.

(17) Dong, J., Atwood, C. S., Anderson, V. E., Siedlak, S. L., Smith, M. A., Perry, G., and Carey, P. R. (2003) Metal binding and oxidation of amyloid- $\beta$ within isolated senile plaque

2. Hydrogen peroxide modifies A $\beta$-membrane interactions with implications for $A \beta_{40}$ aggregation 
cores: Raman microscopic evidence, Biochemistry 42, 2768-2773.

(18) Naslund, J., Schierhorn, A., Hellman, U., Lannfelt, L., Roses, A. D., Tjernberg, L. O., Silberring, J., Gandy, S. E., Winblad, B., and Greengard, P. (1994) Relative abundance of Alzheimer A $\beta$ amyloid peptide variants in Alzheimer disease and normal aging,

Proc.Natl.Acad.Sci.U.S.A 91, 8378-8382.

(19) Ali, F. E., Separovic, F., Barrow, C. J., Cherny, R. a, Fraser, F., Bush, A. I., Masters, C. L., and Barnham, K. J. (2005) Methionine regulates copper/hydrogen peroxide oxidation products of A $\beta$, J. Pept. Sci. 11, 353-360.

(20) Hou, L., Kang, I., Marchant, R. E., and Zagorski, M. G. (2002) Methionine 35 oxidation reduces fibril assembly of the amyloid A $\beta-(1-42)$ peptide of Alzheimer's disease, J. Biol. Chem. 277, 40173-40176.

(21) Friedemann, M., Helk, E., Tiiman, A., Zovo, K., Palumaa, P., and Tõugu, V. (2015) Effect of methionine-35 oxidation on the aggregation of amyloid- $\beta$ peptide, Biochem. Biophys. Reports 3, 94-99.

(22) Palmblad, M., Westlind-Danielsson, A., and Bergquist, J. (2002) Oxidation of methionine 35 attenuates formation of amyloid $\beta$-peptide 1-40 oligomers, J. Biol. Chem. 277, 19506-19510. (23) Gu, M., and Viles, J. H. (2016) Methionine oxidation reduces lag-times for amyloid- $\beta$ (140) fiber formation but generates highly fragmented fibers, Biochim. Biophys. Acta - Proteins Proteomics 1864, 1260-1269.

(24) Hiller, K. O., Masloch, B., Gobi, M., and Asmus, K. D. (1981) Mechanism of the OH• Radical Induced Oxidation of Methionine in Aqueous Solution, J. Am. Chem. Soc. 103, 2734 2743.

(25) Seilheimer, B., Bohrmann, B., Bondolfi, L., Müller, F., Stüber, D., and Döbeli, H. (1997) The toxicity of the Alzheimer's $\beta$-amyloid peptide correlates with a distinct fiber morphology, $J$. Struct. Biol. 119, 59-71.

(26) Snyder, S. W., Ladror, U. S., Wade, W. S., Wang, G. T., Barrett, L. W., Matayoshi, E. D., Huffaker, H. J., Krafft, G. A., and Holzman, T. F. (1994) Amyloid-beta aggregation: selective inhibition of aggregation in mixtures of amyloid with different chain lengths, Biophys. J. 67, 1216-1228.

(27) Riek, R., Güntert, P., Döbeli, H., Wipf, B., and Wüthrich, K. (2001) NMR studies in aqueous solution fail to identify significant conformational differences between the monomeric forms of two Alzheimer peptides with widely different plaque-competence, $A \beta(1-40)$ ox and A $\beta(1-42)$ ox, Eur. J. Biochem. 268, 5930-5936.

(28) Watson, A. A., Fairlie, D. P., and Craik, D. J. (1998) Solution structure of methionineoxidized amyloid $\beta$-peptide (1-40). Does oxidation affect conformational switching?, Biochemistry 37, 12700-12706.

(29) Hou, L., Shao, H., Zhang, Y., Li, H., Menon, N. K., Neuhaus, E. B., Brewer, J. M., Byeon, I. L. J. L., Ray, D. G., Vitek, M. P., Iwashita, T., Makula, R. a., Przybyla, A. B., and Zagorski, M. G. (2005) Solution NMR Studies of the A $\beta(1-40)$ and A $\beta(1-42)$ Peptides Establish that the Met35 Oxidation State Affects the Mechanism of Amyloid Formation, J. Am. Chem. Soc. 126, 
1992-2005.

(30) Varadarajan, S., Kanski, J., Aksenova, M., Lauderback, C., and Butterfield, D. A. (2001) Different mechanisms of oxidative stress and neurotoxicity for Alzheimer's A $\beta(1-42)$ and A $\beta(25-35)$, J. Am. Chem. Soc. 123, 5625-5631.

(31) Döbeli, H., Draeger, N., Huber, G., Jakob, P., Schmidt, D., Seilheimer, B., Stüber, D., Wipf, B., and Zulauf, M. (1995) A Biotechnological Method Provides Access to Aggregation Competent Monomeric Alzheimer's 1-42 Residue Amyloid Peptide, Bio/Technology 13, 988993.

(32) Maiti, P., Piacentini, R., Ripoli, C., Grassi, C., and Bitan, G. (2011) Surprising toxicity and assembly behaviour of amyloid $\beta$-protein oxidized to sulfone, Biochem. J. 433, 323-332. (33) Bitan, G., Kirkitadze, M. D., Lomakin, A., Vollers, S. S., Benedek, G. B., and Teplow, D. B. (2003) Amyloid $\beta$-protein (A $\beta$ ) assembly: A $\beta 40$ and A $\beta 42$ oligomerize through distinct pathways, Proc. Natl. Acad. Sci. U. S. A. 100, 330-335.

(34) Hou, L., Lee, H. G., Han, F., Tedesco, J. M., Perry, G., Smith, M. A., and Zagorski, M. G. (2013) Modification of amyloid- $\beta$ 1-42 fibril structure by methionine-35 oxidation, $J$. Alzheimer's Dis. 37, 9-18.

(35) Lührs, T., Ritter, C., Adrian, M., Riek-loher, D., Bohrmann, B., Döbeli, H., Schubert, D., and Riek, R. (2005) 3D structure of Alzheimer's amyloid- $\beta(1-42)$ fibrils, Proc. Natl. Acad. Sci. U. S. A. 102, 17342-17347.

(36) Butterfield, D. A., and Kanski, J. (2002) Methionine residue 35 is critical for the oxidative stress and neurotoxic properties of Alzheimer's amyloid $\beta$-peptide 1-42, Peptides 23, 12991309.

(37) Misiti, F., Clementi, M. E., and Giardina, B. (2010) Oxidation of methionine 35 reduces toxicity of the amyloid beta-peptide(1-42) in neuroblastoma cells (IMR-32) via enzyme methionine sulfoxide reductase A expression and function, Neurochem. Int. 56, 597-602.

(38) Ripoli, C., Piacentini, R., Riccardi, E., Leone, L., Li Puma, D. D., Bitan, G., and Grassi, C. (2013) Effects of different amyloid $\beta$-protein analogues on synaptic function, Neurobiol. Aging $34,1032-1044$.

(39) Ciccotosto, G. D., Tew, D., Curtain, C. C., Smith, D., Carrington, D., Masters, C. L., Bush, A. I., Cherny, R. A., Cappai, R., and Barnham, K. J. (2004) Enhanced toxicity and cellular binding of a modified amyloid $\beta$ peptide with a methionine to valine substitution, J. Biol. Chem. 279, 42528-42534.

(40) Wong, P. T., Schauerte, J. A., Wisser, K. C., Ding, H., Lee, E. L., Steel, D. G., and Gafni, A. (2009) Amyloid- $\beta$ Membrane Binding and Permeabilization are Distinct Processes Influenced Separately by Membrane Charge and Fluidity, J. Mol. Biol. 386, 81-96.

(41) Simakova, O., and Arispe, N. J. (2007) The Cell-Selective Neurotoxicity of the Alzheimer's A $\beta$ Peptide Is Determined by Surface Phosphatidylserine and Cytosolic ATP Levels. Membrane Binding Is Required for A $\beta$ Toxicity, J. Neurosci. 27, 13719-13729.

(42) Burke, K. A., Yates, E. A., and Legleiter, J. (2013) Biophysical insights into how surfaces, including lipid membranes, modulate protein aggregation related to neurodegeneration, Front. 
Neurol. 4, 1-17.

(43) Terzi, E., Hölzemann, G., and Seelig, J. (1997) Interaction of Alzheimer $\beta$-amyloid peptide(1-40) with lipid membranes., Biochemistry 36, 14845-14852.

(44) Lindberg, D. J., Wesén, E., Björkeroth, J., Rocha, S., and Esbjörner, E. K. (2017) Lipid membranes catalyse the fibril formation of the amyloid- $\beta(1-42)$ peptide through lipid-fibril interactions that reinforce secondary pathways, Biochim. Biophys. Acta - Biomembr. 1859, 19211929.

(45) Kowalewski, T., and Holtzman, D. M. (1999) In situ atomic force microscopy study of Alzheimer's beta-amyloid peptide on different substrates: new insights into mechanism of betasheet formation., Proc. Natl. Acad. Sci. U. S. A. 96, 3688-3693.

(46) Zhu, M., Souillac, P. O., Ionescu-Zanetti, C., Carter, S. A., and Fink, A. L. (2002) Surfacecatalyzed amyloid fibril formation, J. Biol. Chem. 277, 50914-50922.

(47) Burke, K. A., Yates, E. A., and Legleiter, J. (2013) Amyloid-Forming Proteins Alter the Local Mechanical Properties of Lipid Membranes, Biochemistry 52, 808-817.

(48) Yip, C. M., Darabie, A. A., and McLaurin, J. A. (2002) Aß42-peptide assembly on lipid bilayers, J. Mol. Biol. 318, 97-107.

(49) Lin, H., Bhatia, R., and Lal, R. (2001) Amyloid $\beta$ protein forms ion channels: implications for Alzheimer's disease pathophysiology, FASEB J. 15, 2433-2444.

(50) Kwiecien, S., Jasnos, K., Magierowski, M., Sliwowski, Z., Pajdo, R., Brzozowski, B., Mach, T., Wojcik, D., and Brzozowski, T. (2014) Lipid peroxidation, reactive oxygen species and antioxidative factors in the pathogenesis of gastric mucosal lesions and mechanism of protection against oxidative stress - induced gastric injury, J. Physiol. Pharmacol. 65, 613-622. (51) Lacor, P. N. (2004) Synaptic targeting by Alzheimer's-Related Amyloid $\beta$ oligomers, $J$. Neurosci. 24, 10191-10200.

(52) Selkoe, D. J. (2002) Alzheimer's Disease Is a Synaptic Failure, Science (80-. ). 298, 789791.

(53) Spanos, M., Gras-najjar, J., Letchworth, J. M., Sanford, A. L., Toups, J. V., and Sombers, L. A. (2013) Quantitation of Hydrogen Peroxide Fluctuations and Their Modulation of Dopamine Dynamics in the Rat Dorsal Striatum Using Fast-Scan Cyclic Voltammetry, ACS Chem.

Neurosci 4, 782-789.

(54) Nielsen, L., Khurana, R., Coats, A., Frokjaer, S., Brange, J., Vyas, S., Uversky, V. N., and Fink, A. L. (2001) Effect of environmental factors on the kinetics of insulin fibril formation: Elucidation of the molecular mechanism, Biochemistry 40, 6036-6046.

(55) Gade Malmos, K., Blancas-Mejia, L. M., Weber, B., Buchner, J., Ramirez-Alvarado, M., Naiki, H., and Otzen, D. (2017) ThT 101: a primer on the use of thioflavin T to investigate amyloid formation, Amyloid.

(56) Burke, K. A., Godbey, J., and Legleiter, J. (2011) Assessing mutant huntingtin fragment and polyglutamine aggregation by atomic force microscopy, Methods 53, 275-284.

(57) Legleiter, J., Czilli, D. L., Gitter, B., DeMattos, R. B., Holtzman, D. M., and Kowalewski, T. (2004) Effect of Different Anti-A $\beta$ Antibodies on A $\beta$ Fibrillogenesis as Assessed by Atomic 
Force Microscopy, J. Mol. Biol. 335, 997-1006.

(58) Micsonai, A., Wien, F., Kernya, L., Lee, Y.-H., Goto, Y., Réfrégiers, M., and Kardos, J. (2015) Accurate secondary structure prediction and fold recognition for circular dichroism spectroscopy, Proc. Natl. Acad. Sci. U. S. A. 112, 3095-3103.

(59) Rigden, D. J., and Fernández, X. M. (2018) The 2018 Nucleic Acids Research database issue and the online molecular biology database collection, Nucleic Acids Res. 46, D1-D7. (60) Kodali, R., and Wetzel, R. (2007) Polymorphism in the intermediates and products of amyloid assembly, Curr. Opin. Struct. Biol. 17, 48-57.

(61) Kodali, R., Williams, A. D., Chemuru, S., and Wetzel, R. (2010) A $\beta(1-40)$ forms five distinct amyloid structures whose $\beta$-sheet contents and fibril stabilities are correlated, J. Mol. Biol. 401, 503-517.

(62) Meinhardt, J., Sachse, C., Hortschansky, P., Grigorieff, N., and Fändrich, M. (2009) A $\beta(1-$ 40) Fibril Polymorphism Implies Diverse Interaction Patterns in Amyloid Fibrils, J. Mol. Biol. $386,869-877$.

(63) Tycko, R. (2015) Amyloid Polymorphism: Structural Basis and Neurobiological Relevance, Neuron 86, 632-645.

(64) Colletier, J. P., Laganowsky, A., Landau, M., Zhao, M., Soriaga, A. B., Goldschmidt, L., Flot, D., Cascio, D., Sawaya, M. R., and Eisenberg, D. (2011) Molecular basis for amyloid- $\beta$ polymorphism, Proc. Natl. Acad. Sci. U. S. A. 108, 16938-16943.

(65) Vivekanandan, S., Brender, J. R., Lee, S. Y., and Ramamoorthy, A. (2011) A partially folded structure of amyloid-beta(1-40) in an aqueous environment, Biochem. Biophys. Res. Commun. 411, 312-316.

(66) Kirkitadze, M. D., Condron, M. M., and Teplow, D. B. (2001) Identification and characterization of key kinetic intermediates in amyloid $\beta$-protein fibrillogenesis, J. Mol. Biol. 312, 1103-1119.

(67) Fezoui, Y., and Teplow, D. B. (2002) Kinetic studies of amyloid $\beta$-protein fibril assembly. Differential effects of $\alpha$-helix stabilization, J. Biol. Chem. 277, 36948-36954.

(68) Hellstrand, E., Sparr, E., and Linse, S. (2010) Retardation of A $\beta$ fibril formation by phospholipid vesicles depends on membrane phase behavior, Biophys. J. 98, 2206-2214.

(69) Sciacca, M. F. M., Kotler, S. A., Brender, J. R., Chen, J., Lee, D. K., and Ramamoorthy, A. (2012) Two-step mechanism of membrane disruption by A $\beta$ through membrane fragmentation and pore formation, Biophys. J. 103, 702-710.

(70) Malishev, R., Nandi, S., Kolusheva, S., Levi-Kalisman, Y., Klärner, F.-G., Schrader, T., Bitan, G., and Jelinek, R. (2015) Toxicity Inhibitors Protect Lipid Membranes from Disruption by A $\beta 42$, ACS Chem. Neurosci. 6, 1860-1869.

(71) Sani, M. A., Gehman, J. D., and Separovic, F. (2011) Lipid matrix plays a role in Abeta fibril kinetics and morphology, FEBS Lett. 585, 749-754.

(72) Bitan, G., Tarus, B., Vollers, S. S., Lashuel, H. A., Condron, M. M., Straub, J. E., and Teplow, D. B. (2003) A Molecular Switch in Amyloid Assembly: Met 35 and Amyloid $\beta$-Protein Oligomerization, J. Am. Chem. 125, 15359-15365. 
(73) Teplow, D. B. (2013) On the subject of rigor in the study of amyloid $\beta$-protein assembly, Alzheimer's Res. Ther. 5, 1-12.

(74) Abdolvahabi, A., Shi, Y., Rasouli, S., Croom, C. M., Chuprin, A., and Shaw, B. F. (2017) How Do Gyrating Beads Accelerate Amyloid Fibrillization ?, Biophysj 112, 250-264.

(75) Ghosh, P., Vaidya, A., Kumar, A., and Rangachari, V. (2016) Determination of critical nucleation number for a single nucleation amyloid- $\beta$ aggregation model, Math. Biosci. 273, 7079.

(76) Garai, K., Sahoo, B., Sengupta, P., and Maiti, S. (2008) Quasihomogeneous nucleation of amyloid beta yields numerical bounds for the critical radius, the surface tension, and the free energy barrier for nucleus formation, J. Chem. Phys. 128.

(77) Novo, M., Freire, S., and Al-Soufi, W. (2018) Critical aggregation concentration for the formation of early Amyloid- $\beta$ (1-42) oligomers, Sci. Rep. 8, 3-10.

(78) Bitan, G., Vollers, S. S., and Teplow, D. B. (2003) Elucidation of primary structure elements controlling early amyloid $\beta$-protein oligomerization, J. Biol. Chem. 278, 34882-34889.

(79) Bitan, G., Lomakin, A., and Teplow, D. B. (2001) Amyloid $\beta$-protein oligomerization: Prenucleation interactions revealed by photo-induced cross-linking of unmodified proteins, $J$. Biol. Chem. 276, 35176-35184.

(80) Cannon, M. J., Williams, A. D., Wetzel, R., and Myszka, D. G. (2004) Kinetic analysis of beta-amyloid fibril elongation, Anal. Biochem. 328, 67-75.

(81) Esler, W. P., Stimson, E. R., Jennings, J. M., Vinters, H. V., Ghilardi, J. R., Lee, J. P., Mantyh, P. W., and Maggio, J. E. (2000) Alzheimer's disease amyloid propagation by a template-dependent dock-lock mechanism, Biochemistry 39, 6288-6295.

(82) Massi, F., and Straub, J. E. (2001) Energy landscape theory for Alzheimer's amyloid $\beta$ peptide fibril elongation., Proteins 42, 217-229.

(83) Rodriguez, R. A., Chen, L. Y., Plascencia-Villa, G., and Perry, G. (2018) Thermodynamics of amyloid- $\beta$ fibril elongation: atomistic details of the transition state, ACS Chem. Neurosci. 9 , 783-789.

(84) Paravastu, A. K., Leapman, R. D., Yau, W., and Tycko, R. (2008) Molecular structural basis for polymorphism in Alzheimer's beta-amyloid fibrils, Proc. Natl. Acad. Sci. U. S. A. 105, 18349-18354.

(85) Miller, Y., Ma, B., and Nussinov, R. (2011) The unique Alzheimer's $\beta$-amyloid triangular fibril has a cavity along the fibril axis under physiological conditions, J. Am. Chem. Soc. 133, 2742-2748.

(86) Gremer, L., Schölzel, D., Schenk, C., Reinartz, E., Labahn, J., Ravelli, R. B. G., Tusche, M., Lopez-Iglesias, C., Hoyer, W., Heise, H., Willbold, D., and Schröder, G. F. (2017) Fibril structure of amyloid- $\beta(1-42)$ by cryo-electron microscopy, Science (80-. ). 358, 116-119.

(87) Brown, A. M., Lemkul, J. A., Schaum, N., and Bevan, D. R. (2014) Simulations of monomeric amyloid $\beta$-peptide (1-40) with varying solution conditions and oxidation state of Met35: Implications for aggregation, Arch. Biochem. Biophys. 545, 44-52.

(88) Fändrich, M., Meinhardt, J., and Grigorieff, N. (2009) Structural polymorphism of 
Alzheimer A $\beta$ and other amyloid fibrils., Prion 3, 89-93.

(89) Wang, Q., Wang, Y., and Lu, H. P. (2013) Revealing the secondary structural changes of amyloid $\beta$-peptide by probing the spectral fingerprint characters, J. Raman Spectrosc. 44, 670674.

(90) Bokvist, M., Lindström, F., Watts, A., and Gröbner, G. (2004) Two Types of Alzheimer's $\beta$-Amyloid (1-40) Peptide Membrane Interactions: Aggregation Preventing Transmembrane Anchoring Versus Accelerated Surface Fibril Formation, J. Mol. Biol. 335, 1039-1049.

(91) Matsuzaki, K. (2007) Physicochemical interactions of amyloid $\beta$-peptide with lipid bilayers, Biochim. Biophys. Acta - Biomembr. 1768, 1935-1942.

(92) Black, S. D., and Mould, D. R. (1991) Development of hydrophobicity parameters to analyze proteins which bear post- or cotranslational modifications, Anal. Biochem. 193, 72-82. (93) Liu, A., Wenzel, N., and Qi, X. (2005) Role of lysine residues in membrane anchoring of saposin C, Arch. Biochem. Biophys. 443, 101-112.

(94) Herce, H. D., and Garcia, A. E. (2007) Cell penetrating peptides: how do they do it?, J. Biol. Phys. 33, 345-356.

(95) Yount, N. Y., Bayer, A. S., Xiong, Y. Q., and Yeaman, M. R. (2006) Advances in Antimicrobial Peptide Immunobiology, Pept. Sci. 84, 435-458.

(96) Legleiter, J., Fryer, J. D., Holtzman, D. M., and Kowalewski, T. (2011) The Modulating Effect of Mechanical Changes in Lipid Bilayers Membrane Disruption, ACS Chem. Neurosci 2, 588-599.

(97) Yip, C. M., Elton, E. A., Darabie, A. A., Morrison, M. R., and Mclaurin, J. (2001) Cholesterol, a modulator of membrane-associated A $\beta$-fibrillogenesis and neurotoxicity, J. Mol. Biol. 311, 723-734. 


\section{Acetylation of $A \boldsymbol{\beta}_{40}$ alters aggregation in the presence and absence of lipid membranes}

One characteristic of Alzheimer's disease (AD) pathology is the formation of extracellular senile plaques comprised of the peptide $\beta$-amyloid (A $\beta)$. Aggregation of $A \beta$ is a complex nucleation-dependent polymerization process involving the creation of a variety of metastable intermediates that can be on-pathway towards fibril formation or off-pathway towards amorphous or annular aggregates. An essential feature of the aggregation of $A \beta$ to fibril aggregates is the formation of a $\beta$-sheet hairpin which is stabilized by a salt bridge between D23 and K28. Recent evidence has demonstrated that the forming of the salt bridge is a critical step in the nucleation process. Lysine-16 has also been implicated in participating in the intermolecular formation of salt bridges between fibril strands. Lysine's in general are involved in proteinmembrane interactions between the cationic lysine and anionic lipid headgroups, and it is this general interaction of $A \beta$ with membranes that is proposed to be a toxic mechanism of $A D$. In this work, we explored the role of lysine's positive charge in the aggregation of $A \beta_{40}$ in the presence and absence of membranes through its removal via acetylation. Here, we report that lower levels of acetylation, primarily affecting K16, has minor effects on the fibril formation but reduces oligomerization of $A \beta_{40}$ while higher levels of acetylation involving K16 and K28 inhibits fibril formation and further reduces oligomerization. However, in the presence of total brain lipid extract (TBLE) acetylated $\mathrm{A} \beta$ was observed to interact less with the membrane but was still able to form fibrils and under extensive levels of acetylation promoted the formation of annular aggregates. Our results suggest that in the absence of membranes the aggregation process is highly dependent on the electrostatic interactions of $\mathrm{K} 16$ and $\mathrm{K} 28$, and in the presence of 
membranes lipids promote the formation of the critical nucleus towards fibril formation in addition to promoting secondary aggregation pathways.

\subsection{Introduction: The importance of lysine in the aggregation and membrane binding of A $\beta$}

Two prominent pathological features associated with Alzheimer's disease (AD), a fatal neurodegenerative disorder, are cerebrovascular, diffuse, and neuritic plaques composed predominantly of the amyloidogenic peptide amyloid- $\beta$ (A $\beta)$ and neurofibrillary tangles comprised of the protein tau. These proteinaceous deposits of tau and $A \beta$ are predominantly comprised of $\beta$-sheet-rich fibrous aggregates termed amyloid fibrils. A $\beta$ aggregation can be a multifaceted and complex process that involves a variety of metastable, intermediate species that may or may not be directly on-pathway to fibril formation. ${ }^{1}$ The aggregate species that can be formed include a variety of soluble $\mathrm{A} \beta$ oligomers (A $\beta \mathrm{Os}$ ), insoluble protofibrils, and annular aggregates. ${ }^{1-3}$ Beyond the heterogeneity of smaller intermediate aggregate structures, $\mathrm{A} \beta$ fibrils can form a variety of distinct structure and morphologies, often termed polymorphs, as a result of preparatory and/or environmental conditions during the aggregation process. ${ }^{4-6}$

Specific domains or amino acids within the $A \beta$ peptide appear to play a prominent role in dictating the rate of aggregation and the resulting aggregate morphologies. ${ }^{7}$ For example, specific regions within the $\mathrm{A} \beta$ peptide have been implicated as being particularly amyloidogenic. ${ }^{7-10}$ Using site-directed spin labeling electron paramagnetic resonance, two $\beta$ strand forming domains in A $\beta$ were identified (residues11-21 and 29-39, respectively) that were separated by a $\beta$-turn. ${ }^{11}$ NMR studies further support the two $\beta$-strand regions separated by a $\beta$ turn motif in a number of fibril structures. ${ }^{12-14}$ Various fragments of $A \beta$ display different propensities to aggregate. ${ }^{7}$ For example, the first $\beta$-strand forming stretch of $A \beta$ also contains a 
hydrophobic core (residues 16-21) with enhanced amyloidogenic properties. ${ }^{15}$ Furthermore, a number of point mutations associated with familial forms of AD clearly alter aggregation rates and aggregate morphologies. ${ }^{16}$

Lysine is of interest as it contains a cationic charge at the end of an aliphatic chain. There are two lysines in Aß: lysine-16 (K16) and lysine-28 (K28). Electrostatic interactions facilitated by these two lysines in $A \beta$ have been suggested by many to play an essential role in $A \beta$ folding, nucleation, oligomerization, fibril formation, and toxicity. ${ }^{17,18}$ Specifically, a salt bridge forms between D23 and K28 that stabilizes a $\beta$-turn in a variety of fibril structures. ${ }^{18-20} \mathrm{~K} 16$ is the first amino acid of the previously mentioned hydrophobic core. Additionally, K16 can be involved in intermolecular salt bridge formation in some fibril structures of $A \beta ;{ }^{18,21}$ however, K16 is solvent exposed in other fibril structures. ${ }^{22}$ Beyond fibril formation, lysine residues are involved in oligomer formation, as substituting alanine for each lysine altered $A \beta$ assembly and highlighted a role of K16 in A $\beta$ toxicity. ${ }^{23}$

In addition to playing a role in $A \beta$ aggregation, lysines play a prominent role in the interaction of $A \beta$ with lipid membranes. In general, lysine plays an important role in facilitating a variety of peptide-membrane interactions, as it contains the ability to electrostatically interact with charged lipid headgroups while the alkyl chain allows for hydrophobic interactions within the lipid tails. ${ }^{24}$ Interaction with cellular membranes, comprised predominately of lipid bilayers, can heavily influence $\mathrm{A} \beta$ aggregation, ${ }^{25}$ potentially promoting unique aggregation pathways ${ }^{26-28}$ nucleating aggregation, ${ }^{29-34}$ and/or promote/stabilize specific $A \beta$ aggregate species. ${ }^{26,32,35,36}$ It is even suggested that the binding of $A \beta$ to the plasma membrane is a key step in $A \beta$ toxicity. ${ }^{37,38} \mathrm{~A}$ variety of model lipid membranes alter $A \beta$ conformation and exert enormous influence on the aggregation state, but the exact impact of lipids on $A \beta$ aggregation is specific to membrane lipid 
composition. ${ }^{39}$ In addition to influencing $\mathrm{A} \beta$ aggregation ${ }^{40,41} \mathrm{~A} \beta$ can directly damage cellular membranes, resulting in membrane dysfunction through altered mechanical properties ${ }^{42}$ and/or the formation of discrete pores. ${ }^{32,35,43}$ While lipid composition and biophysical properties of membranes play a role $A \beta /$ lipid interactions, physicochemical properties of the residues within $\mathrm{A} \beta$ also play a role in the surface interactions. ${ }^{16,44}$ For example, disease-related point mutations within $A \beta$ alter the aggregate species observed on model lipid membranes, with hydrophilicity and electrostatic properties of specific amino acids playing a key role. ${ }^{16}$

Here, our aim was to understand how acetylating lysine alters $A \beta_{40}$ aggregation in the presence and absence of lipid membranes. $A \beta_{40}$ was acetylated by exposure to sulfo-Nhydroxysulfosuccinimide acetate (NHSA) producing acetylated K16 (AcK16) and K28 (AcK28). The lipid system used was total brain lipid extract (TBLE), which contain a physiologically relevant mix of lipid components. In the absence of lipid vesicles, acetylation of $A \beta_{40}$ reduced both oligomerization and fibrillization, with extensive acetylation resulting in complete inhibition of fibril formation. However, the presence of TBLE lipid vesicles appeared to invoke a distinct aggregation mechanism, resulting in fibril formation even when $A \beta_{40}$ was extensively acetylated.

\subsection{Materials and Methods}

3.2.1 Peptide Preparation - Synthetic $\mathrm{A} \beta_{40}$ (Invitrogen, $1 \mathrm{mg}$ ) was equilibrated to room temperature for 30 mins. $\mathrm{A}_{40}$ was dissolved in $10 \% \mathrm{NH}_{4} \mathrm{OH}(\mathrm{w} / \mathrm{v})$ to acquire an alkaline stock solution of $A \beta_{40}(0.5 \mathrm{mg} / \mathrm{mL})$. The stock solution was unperturbed for 10 min followed by $5 \mathrm{~min}$

of bath sonication. The $A \beta_{40}$ stock solution was aliquoted and snap frozen. Aliquots were lyophilized overnight and stored at $-80{ }^{\circ} \mathrm{C}$ until the day of experimentation. For experiments, 
individual aliquots of $A \beta_{40}$ were equilibrated to room temperature. An alkaline solution, $60 \mathrm{mM}$ $\mathrm{NaOH}(\mathrm{aq})$, was used to solubilize $\mathrm{A} \beta_{40}$ (target concentration of $1.5 \mathrm{mg} / \mathrm{mL}$ ), creating what is referred to as the $\mathrm{A} \beta_{40}{ }^{\circ} \mathrm{NaOH}$ solution. The $\mathrm{A} \beta_{40}{ }^{\circ} \mathrm{NaOH}$ solution was incubated at room temperature for $10 \mathrm{~min}$, after which it was gently pipette mixed. The actual concentration of the $\mathrm{A} \beta_{40^{\circ}} \mathrm{NaOH}$ solution was measured (NanoDrop, ThermoScientific) via absorbance at $280 \mathrm{~nm}$ with an extinction coefficient of $1440 \mathrm{M}^{-1} \mathrm{~cm}^{-1}$. The $\mathrm{pH}$ of the $\mathrm{A} \beta_{40^{\bullet}} \mathrm{NaOH}$ solution was controlled to be $\geq 11.23$. For all experiments, the $\mathrm{A} \beta_{40}{ }^{\circ} \mathrm{NaOH}$ solution was diluted into a $20 \mathrm{mM}$ HEPES $150 \mathrm{mM} \mathrm{NaCl}$ buffer, $\mathrm{pH}=7.23$.

3.2.2 Mass Spectrometry - For the MS experiments, the $\mathrm{A} \beta_{40} \bullet \mathrm{NaOH}$ solution was divided into $10 \mu \mathrm{g}$ aliquots. These aliquots were diluted in the HEPES buffer and then treated with NHSA at increasing molar ratios of NHSA:A $\beta_{40}$. Samples were allowed to incubate at room temperature for $1 \mathrm{~h}$ before the NHSA reaction was quenched with $1 \mathrm{M}^{\text {Trizma }^{\mathrm{TM}}}$ (Sigma Aldrich, St. Louis, MO). All samples were snap-frozen and lyophilized overnight. The following day, samples were dissolved in $1 \mathrm{M}$ acetic acid containing $0.5 \mathrm{mg} / \mathrm{mL}$ of pepsin (10:1 pepsin: $A \beta_{40}$ ). Samples were left overnight protected from light and incubated at room temperature. On the 3rd day samples were analyzed via LC-MS (Thermofisher Scientific Q Exactive Mass Spectrometer, an LC-MS/MS with orbitrap). To remove residual salts, chromatography utilized a C18 column (ZORBAX RRHD Eclipse XDB 80Å C18, 2.1 x 100 mm, $1.8 \mu \mathrm{m}$; Agilent, Santa Clara, CA) and a mobile phase of $0.1 \%$ formic/water $(\mathrm{v} / \mathrm{v})(\% \mathrm{~A})$ and $0.1 \%$ formic acid/acetonitrile (v/v) (\%B) with a gradient of $5 \% \mathrm{~B}$ for $0-2 \mathrm{~min}, 40 \% \mathrm{~B}$ for $5 \mathrm{~min}, 50 \% \mathrm{~B}$ for 6 $\min , 95 \% \mathrm{~B}$ for 7-8 min, and 5\% B for $8.5-10$ min with a flowrate of $300 \mu \mathrm{L} / \mathrm{min}$. A full scan was performed for the mass charge range of $200-2000 \mathrm{~m} / \mathrm{z}$ with a resolution of 70,000 and a resolution of 17,500 for the Top 5 method that was used. Mass spectrum analysis was performed 
using Proteome Discovery ${ }^{\mathrm{TM}}$ to determine the percent abundance of AcK16 and AcK28. This was carried out by comparing lysine specific fragments of $A \beta_{40}$ to the same peptide fragments containing a 43.05 Da mass shift, for all charge states.

3.2.3 Thioflavin-T Fluorescence Assay (ThT) — Monitoring fibril formation was achieved with thioflavin T (ThT; Sigma Aldrich, St. Louis, MO) assays. Assays were carried out in a Costar 96-well black clear flat bottom plate. The $\mathrm{A} \beta_{40^{\circ}} \mathrm{NaOH}$ solution was added to $20 \mathrm{mM}$ HEPES $150 \mathrm{mM} \mathrm{NaCl}$ solutions containing 3 molar equivalents of ThT to $\mathrm{A} \beta_{40}$ and varied molar equivalents of NHSA to $A \beta_{40}$ at a $\mathrm{pH}$ of 7.23. The resulting solutions contained $20 \mu \mathrm{MA} \beta 40$ and the addition of $0.16,0.320 .501 .001 .50 \mathrm{mM}$ NHSA. Additionally, a $3 \mathrm{~mm}$ borosilicate bead was introduced to facilitate homogeneous mixing across wells. ${ }^{45}$ The assay plate was sealed with plate tape, and incubated at $37{ }^{\circ} \mathrm{C}$ for $24 \mathrm{~h}$ on a SpectraMax M2 Multi-Mode plate reader (Molecular Devices, Sunnyvale, CA). Fluorescence intensities were measured in 5 min intervals at excitation and emission wavelengths of $440 \mathrm{~nm}$ and $484 \mathrm{~nm}$, respectively, with shaking in between reads. Assays performed in the presence of TBLE were performed in the same manner with the addition of TBLE vesicles prepared as described below.

Data analysis was performed utilizing GraphPad Prism 6 was to average replicates, perform baseline corrections, and error analysis reported as the standard error mean (SEM). Additionally, through the use of a Boltzmann sigmodal function (Equation 1) kinetic parameters such as the nucleation time, commonly referred to here as lag-phase ( $\mathrm{t}_{\mathrm{lag}}$ ), was empirically obtained by fitting the individual traces of ThT curves. ${ }^{46,47}$

$$
Y=\left(y_{i}+m_{i} x\right)+\frac{y_{f}+m_{f} x}{1+e^{-\left(\frac{x-x_{0}}{\tau}\right)}}
$$

Utilizing GraphPad Prism 6 the initial lag-phase and plateau regions of the curves are defined by linear fits where the initial fluorescence and slope are defined by, $y_{i}$ and $m_{i}$, and the final 
fluorescence and slope as, $y_{f}$ and $m_{f}$, respectively. The time to reach the half maximum of the curve is defined by $x_{o}$ and the elongation time constant of the growth phase is defined as $\tau$. As a nonideal sigmodal function, no constraints were applied. A least squares fitting operation was then performed for a maximum iteration limit of 1000. The lag-phase time was calculated from the kinetic parameters, $t_{l a g}=x_{o}-2 \tau$. The slope of the growth phase is associated with the growth of fibrils. The slope was calculated by normalizing the ThT traces to the mean maximum response of control group (no NHSA added) within each independent experiment for comparison across experiments. To obtain the relative slope of the growth phase, $\mathrm{R}_{\text {slope }}\left(\mathrm{h}^{-1}\right)$ the linear fits of the growth phase were performed by defining the boundaries of the fit to only include the linear region between the lag-phase and the plateau region as visually determined for each ThT curve. The maximum signal of fluorescence at steady state was calculate using a linear fit over the plateau region of the sigmodal curve. This was accomplished by adjusting the starting point of the data to be fit and moving it further back to optimize the $r^{2}$ value. Initial starting point points were visually determined to be near the inflection point where the sigmoidal curve enters the plateau region. The fits were performed from these starting points to the end of the data set. Once the boundaries were defined, the average fluorescence signal within this plateau region was determined. For comparison between trials, these were converted to the relative fluorescence at steady state $\left(\mathrm{RF}_{\mathrm{ss}}\right)$ by dividing each value by the control experiment (no NHSA for that experiment). All kinetic parameters were then averaged from triplicates of independent experiments to determine the mean \pm SEM. Significance was reported as greater than $95 \%$ confidence calculated using a standard Student's T-test to determine variations in parameters across varied NHSA concentrations. 
3.2.4 Lipid Vesicle Preparation - Total lipid brain extract (TBLE; Avanti Polar Lipids, Alabaster, AL) was dissolved in chloroform at $25 \mathrm{mg} / \mathrm{mL}$ and divided into $5 \mathrm{mg}$ aliquots. Chloroform was removed in vacuo, producing a transparent film, and each aliquot was stored at $20^{\circ} \mathrm{C}$. A $5 \mathrm{mg}$ amount of TBLE was hydrated with a $20 \mathrm{mM}$ HEPES $150 \mathrm{mM} \mathrm{NaCl}$ buffer, $\mathrm{pH}=$ 7.23, and allowed to incubate for $30 \mathrm{mins}$ at $60^{\circ} \mathrm{C}$ and $1400 \mathrm{rpm}$ in a Thermomixer. Lipid samples were vigorously pipetted and scraped to remove all traces of TBLE from the walls of the centrifuge tube, after which the samples were put through 7 freeze-thaw cycles and 30 min of bath sonication at $37^{\circ} \mathrm{C}$. Lipid stocks were again heated to $60^{\circ} \mathrm{C}$ before being extruded through a $100 \mathrm{~nm}$ polycarbonate membrane filter. Resulting lipid solutions were kept at $37^{\circ} \mathrm{C}$ before being diluted into a HEPES solution at a final concentration of $0.432 \mathrm{mg} / \mathrm{mL}$ within a 96 -well plate for a protein to lipid ratio of 30:1.

3.2.5 Ex situ Tapping Mode Atomic force microscopy (TMAFM) — Incubations of A $\beta_{40}$ $(20 \mu \mathrm{M})$ were performed in a similar manner to previous ThT assays with the same concentrations and ratios of $A \beta_{40}$ to NHSA. Solutions were incubated at $37^{\circ} \mathrm{C}$ and shaken and read at the same intervals as previous ThT assays, however at the time points of $0,1,3,5,7,8,9$, 11, and $24 \mathrm{~h}$ the 96 -well plate was removed from the plate reader and two $2 \mu \mathrm{L}$ samples were taken from each solution. The experiment was done in this manner in order to track the progress of $A \beta$ aggregate formation. Once samples were taken, they were allowed to incubate for $1 \mathrm{~min}$ before being washed with $200 \mu \mathrm{L}$ of $18 \mathrm{M} \Omega$ water for one sample and $100 \mu \mathrm{L}$ of $18 \mathrm{M} \Omega$ water for the other sample of the same variable. Samples were dried with compressed air immediately after being washed. After taking samples, the plate was returned and incubated until the next time interval. Samples were imaged via atomic force microscopy (AFM) under tapping mode on a Nanoscope V Multimode (Veeco, Santa Barbara, CA) with a closed-loop vertical engage J- 
scanner. Cantilevers used for images were a diving-board-shaped silicon oxide cantilever with a resonance frequency of $\sim 300 \mathrm{kHz}$ and a spring constant of $40 \mathrm{~N} / \mathrm{m}$ (Budget Sensors).

3.2.6 TMAFM Image Analysis — Images were processed utilizing Matlab equipped with the image processing toolbox (MathWorks, Natick, MA). ${ }^{48}$ To correct for background curvature, height images were flattened using a $2^{\text {nd }}$ polynomial flattening algorithm. To aid in automatically identifying individual aggregates, AFM images were converted into binary maps after establishing a height threshold of $1.0 \mathrm{~nm}$. Individual aggregates were determined from the binary maps using a recognition algorithm. Physical features of individual aggregates (e.g., height, volume, diameter, shape factor, length, aspect ratio, length, and area covered) were measured. Average heights of fibrils were determined by measuring the fibrils along their contour length while excluding any cross over regions of overlapping fibrils. The range of fibril contour length, or the spread of fibril heights, was calculated as the interquartile range which involves taking the median of the lower and upper of a given dataset. Populations of oligomers and fibrils, along with the percent area covered by fibrils, were plotted using GraphPad Prism 6 to average across replicates and perform error analysis reported as a standard error mean (SEM).

3.2.7 Preparation of TBLE/Polydiacetylene Vesicles (PDA) - Separately $8.4 \mathrm{mg}$ of 10,12-tricosadiynoic acid (PDA) (GFS Chemicals, Columbus, OH) and $5.0 \mathrm{mg}$ of TBLE was dissolved in a 1:1 chloroform: ethanol solution. The two were combined in a glass vial at a 60:40 mass ratio of PDA to TBLE, and solvents were removed in vacuo to produce a TBLE/PDA film. This film was hydrated with $8 \mathrm{~mL}$ of the same $20 \mathrm{mM}$ HEPES $150 \mathrm{mM} \mathrm{NaCl}$ buffer, $\mathrm{pH}=7.23$, and temperature of $75^{\circ} \mathrm{C}$. The solution was probe sonicated at $180 \mathrm{~W}$ continuously for $10 \mathrm{~min}$. The resulting solution was stored protected from light in a $4{ }^{\circ} \mathrm{C}$ fridge overnight. The following day the TBLE/PDA solution was allowed to reach ambient temperature before transferring it to a 3. Acetylation of $A \beta_{40}$ alters aggregation in the presence and absence of lipid membranes 
100-mL beaker. The solution was stirred at $300 \mathrm{rpm}$ for $10 \mathrm{~min}$ under cover of a black box adapted with a TLC lamp that irradiated the solution at $254 \mathrm{~nm}$ for the full length of time. PDA assays were performed in a Costar 96 black clear flat bottom well plate with the addition of 3 $\mathrm{mm}$ borosilicate glass beads. Peptide-lipid interactions were observed fluorescently at room temperature with excitation and emission wavelengths of $485 \mathrm{~nm}$ and $560 \mathrm{~nm}$ utilizing a SpectraMax M2 Multi-Mode plate reader (Molecular Devices, Sunnyvale, CA). Data analysis was performed by averaging triplicates and performing baseline-corrections all within the GraphPad Prism 6 software suite

\subsection{Results}

3.3.1 Lysine-16 is preferentially acetylated over lysine-28. To determine the extent at which K16 and K28 were accessible for acetylation and determine experimental conditions under which the impact of acetylation on aggregation could be studied, $A \beta_{40}(20 \mu \mathrm{M})$ was exposed to

NHSA, an established agent for acetylating primary amines. ${ }^{49,50} \mathrm{~A} \beta_{40}$ was treated with varying concentrations of NHSA ranging from $0.02 \mathrm{mM}$ to $2.5 \mathrm{mM}$ (resulting in a range of peptide to NHSA molar ratios of $1: 1$ to $1: 125)$. As there are two lysines in $A \beta_{40}$ that can be acetylated (K16 and K28), $A \beta_{40}$ was digested with pepsin to generate peptide fragments containing only one of the lysines so that the extent of acetylation of each discrete lysine could be determined by MS. 
The percent of acetylated K16 (AcK16) and K28 (AcK28) was determined by comparing the abundance of these peptide fragments containing just one lysine that were acetylated or not (Figure 3.1). When no NHSA was added to $A \beta_{40}$, no acetylation of lysine was observed. At lower concentrations of NHSA, ranging from $0.02 \mathrm{mM}$ to 0.16 $\mathrm{mM}, \mathrm{K} 16$ is preferentially acetylated over K28 with K16 acetylation being 5-3 $\times$ more abundant than K28 (Figure 3.1B). With the $0.16 \mathrm{mM}$ treatment of NHSA, AcK16 and AcK28 only represented 47\% and $14 \%$ of the total $A \beta$ acetylated respectively. Effectively, these lower concentration treatments of NHSA resulted in conditions at which K16 was the predominately acetylated lysine; however, most of the available lysines (both K16 and K28) were not acetylated.
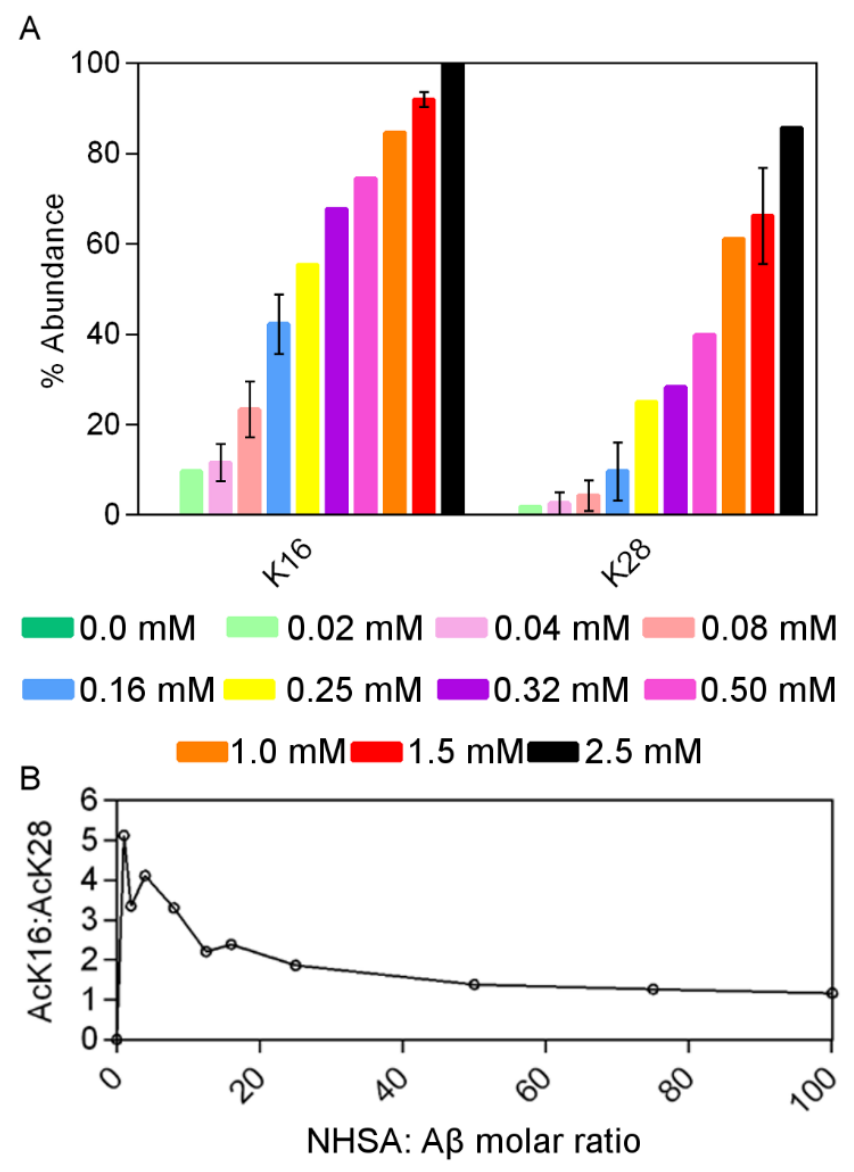

Figure 3.1. Acetylation of K16 occurs more readily than K28 (A) MS analysis of K16 and K28 specific peptide fragments reported as the percent abundance of acetylated to unacetylated lysine. (B) Ratio of AcK16 to $A c K 28$ over increasing ratios of NHSA to $A B_{40}$.

At NHSA concentrations of $0.50 \mathrm{mM}$,

$75 \%$ of K 16 was acetylated, while $35 \%$ of K 28 was acetylated, resulting in a condition in which the vast majority of $\mathrm{A} \beta$ was acetylated with AcK16 being the most abundant form $(\sim 2 \times)$. Further increasing the concentration of the acetylating agent to $1.0 \mathrm{mM}$ and $1.5 \mathrm{mM}$ produced an increase in the acetylation of $\mathrm{K} 28$ to about $60-75 \%$ and reduced the ratio of AcK16:AcK28 to 
about 1:1 at 1.5 mM NHSA. While AcK16 and AcK28 was observable with all treatments with NHSA, the NHSA concentrations of $0.02 \mathrm{mM}$ to $0.50 \mathrm{mM}$ represent a regime in which $\mathrm{K} 16$ is predominantly more acetylated than $\mathrm{K} 28$; whereas, concentrations of $1.0 \mathrm{mM}$ and above of NHSA both K16 and K28 are acetylated to similar and significant extents.

3.3.2 Acetylation of $A \beta_{40}$ extends the lag phase and extent of aggregation. Having established the extent of acetylation of K16 and K28 exposed to varying amounts of NHSA, we next determined the impact of AcK 16 and $\mathrm{AcK} 28$ on the aggregation of $\mathrm{A} \beta_{40}$. ThT assays were performed with $20 \mu \mathrm{MA} \beta_{40}$ that had been exposed to increasing concentrations of NHSA (Figure 3.2). 

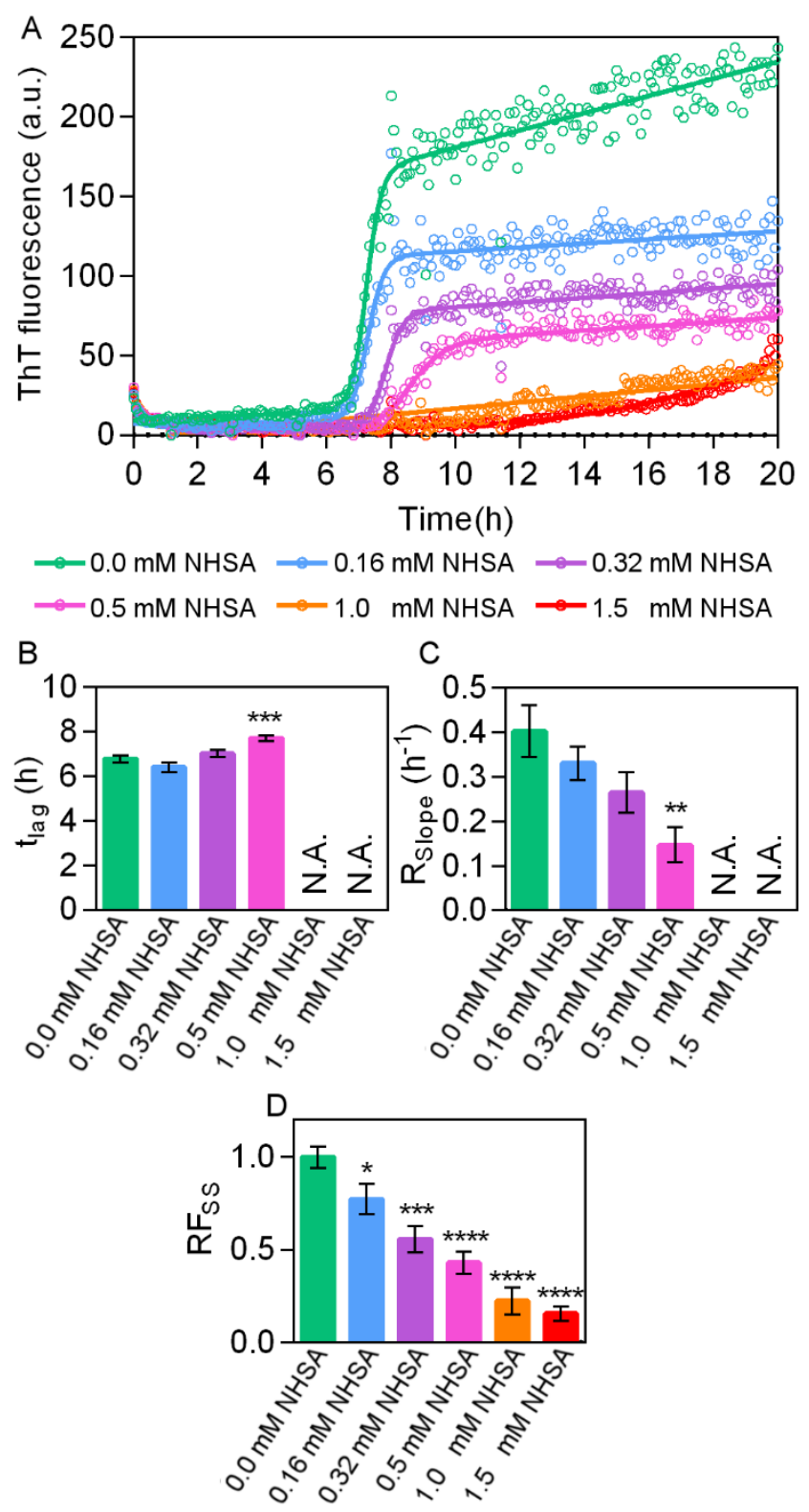

Figure 3.2. ThT assays investigating the impact or acetylation on $\mathbf{A}_{40}$ aggregation. (A) Representative ThT curves for one of three independent experiments performed at $37^{\circ} \mathrm{C}$, all at concentrations of $20 \mu \mathrm{MA} \beta_{40}$ (green), with increases in NHSA concentrations to $0.16 \mathrm{mM}$ (blue), $0.32 \mathrm{mM}$ (purple), $0.50 \mathrm{mM}$ (pink), $1.0 \mathrm{mM}$ (orange), and $1.5 \mathrm{mM}$ (red). Non-linear sigmoidal lines of best fits represented as continuous lines calculated using Equation 1. Kinetic parameters of (B) lag-phase time, $t_{\text {lag }}(h)$, and (C) slope of growth phase Slope $\left(h^{-1}\right)$ were extracted from Equation 1 for all experiments and shown as the mean \pm SEM. (D) Normalized maximum response of the steady state region of ThT curves, $R F_{s s}$, calculated by averaging the plateau region then normalizing all variables to their respective control. Data shown as mean \pm SEM of the normalized raw fluorescence signals of three independent experiments; (*) $P \leq 0.05,(* *) P \leq 0.01,(* * *) P \leq 0.001$, and $(* * * *) P \leq 0.0001$.

In general, increasing acetylation of $A \beta_{40}$ inhibited aggregation. That is, as the concentration of NHSA increased, the lag phase extended and the total extent of fibrillization decreased. The addition of $0.16 \mathrm{mM}$ and $0.32 \mathrm{mM}$ NHSA did not significantly change the lag phase associated with $A \beta_{40}$ compared to control (A $\beta_{40}$ that was not exposed to NHSA). A $\beta_{40}$ in the absence of an NHSA treatment, with $0.16 \mathrm{mM}$, or $0.32 \mathrm{mM}$ treatment of NHSA exhibited similar lag-phases of 
$6.8 \pm 0.16 \mathrm{~h}, 6.4 \pm 0.22 \mathrm{~h}$, and $7.0 \pm 0.17 \mathrm{~h}$ respectively (Figure 3.2B), and the relative slope of the growth phase, $R_{\text {slope }}\left(h^{-1}\right)$, was also not significantly changed $\left(0.40 \pm 0.058 \mathrm{~h}^{-1}, 0.33 \pm 0.037\right.$ $\mathrm{h}^{-1}$, and $0.27 \pm 0.046 \mathrm{~h}^{-1}$ respectively, Figure $2 \mathrm{C}$ ). Treatment with $0.16 \mathrm{mM}, 0.32 \mathrm{mM}$, and 0.50 $\mathrm{mM}$ NHSA reduced the total extent fibrillization as the relative fluorescent unit signal of the steady-state plateau region, $\mathrm{RF}_{\mathrm{ss}}$, of the ThT curve by $23 \%, 45 \%$, and $53 \%$ respectively (Figure 3.2D). Increasing the concentrations of NHSA to $0.50 \mathrm{mM}$ resulted in a statistically significant extension of the lag phase, $7.7 \pm 0.13 \mathrm{~h}$. In addition, the slope of the growth phase at $0.50 \mathrm{mM}$ NHSA significantly deviate from the control, $0.15 \pm 0.040 \mathrm{~h}^{-1}$ (Figure 2C), and the total extent of fibril formation (measured as relative fluorescence at steady state) was reduced by $58 \%$. Finally, treatment with $1.0 \mathrm{mM}$ NHSA and $1.5 \mathrm{mM}$ NHSA completely suppressed fibril formation over the $20 \mathrm{~h} \mathrm{ThT}$ assay; although, there is a hint of a potential fibril nucleation event after $\sim 18 \mathrm{~h}$. As such, accurate lag phase and growth phases could not be determined; however, the relative fluorescence at the end of experiment is less than $20 \%$ of the control for both conditions.

\subsubsection{Acetylation of $A \beta_{40}$ inhibits fibril formation and oligomerization. While the ThT assays} demonstrate that acetylation of lysine via exposure to NHSA reduce fibrillization of $A \beta_{40}$, these assays do not provide information concerning the potential of acetylation to promote polymorphic fibril structure or $\mathrm{A} \beta \mathrm{O}$ formation. In light of previous observations that substituting lysine in $A \beta$ with alanine results in altered fibril morphology, ${ }^{23}$ we incubated $A \beta_{40}$ under the exact same conditions as used in the ThT assays and sampled these solutions at multiple time points for AFM analysis. Beyond looking at fibril morphology, this has the added benefit of allowing for the assessment of $\mathrm{A} \beta \mathrm{O}$ formation. To analyze the population and dimensions of $\mathrm{A} \beta$ fibrils and $\mathrm{A} \beta \mathrm{O}$, criteria based on aggregate morphologies were used for automated image analysis. ${ }^{48} \mathrm{~A} \beta \mathrm{O}$ were defined in AFM images as being larger than $1 \mathrm{~nm}$ in height, having an 
aspect ratio of between 1.0 and 2.5 (indicating a non-fibrillar morphology), and occupying a surface area less than $9500 \mathrm{~nm}^{2}$. The surface area criteria were based on our observation that the smallest fibrils occupied a surface area of $\sim 10,000 \mathrm{~nm}^{2}$ and that oligomers occupied an area typically 5 times smaller than this. Fibrils were identified as aggregates that were at least $1 \mathrm{~nm}$ in height with an aspect ratio greater than 2.5 and occupying a surface area or at least 10,000 $\mathrm{nm}^{2}$. Upon solubilization, an initial aliquot of $\mathrm{A} \beta_{40}$ was sampled for all conditions (effectively time point $0 \mathrm{~h}$ ), and no aggregates were observed. 

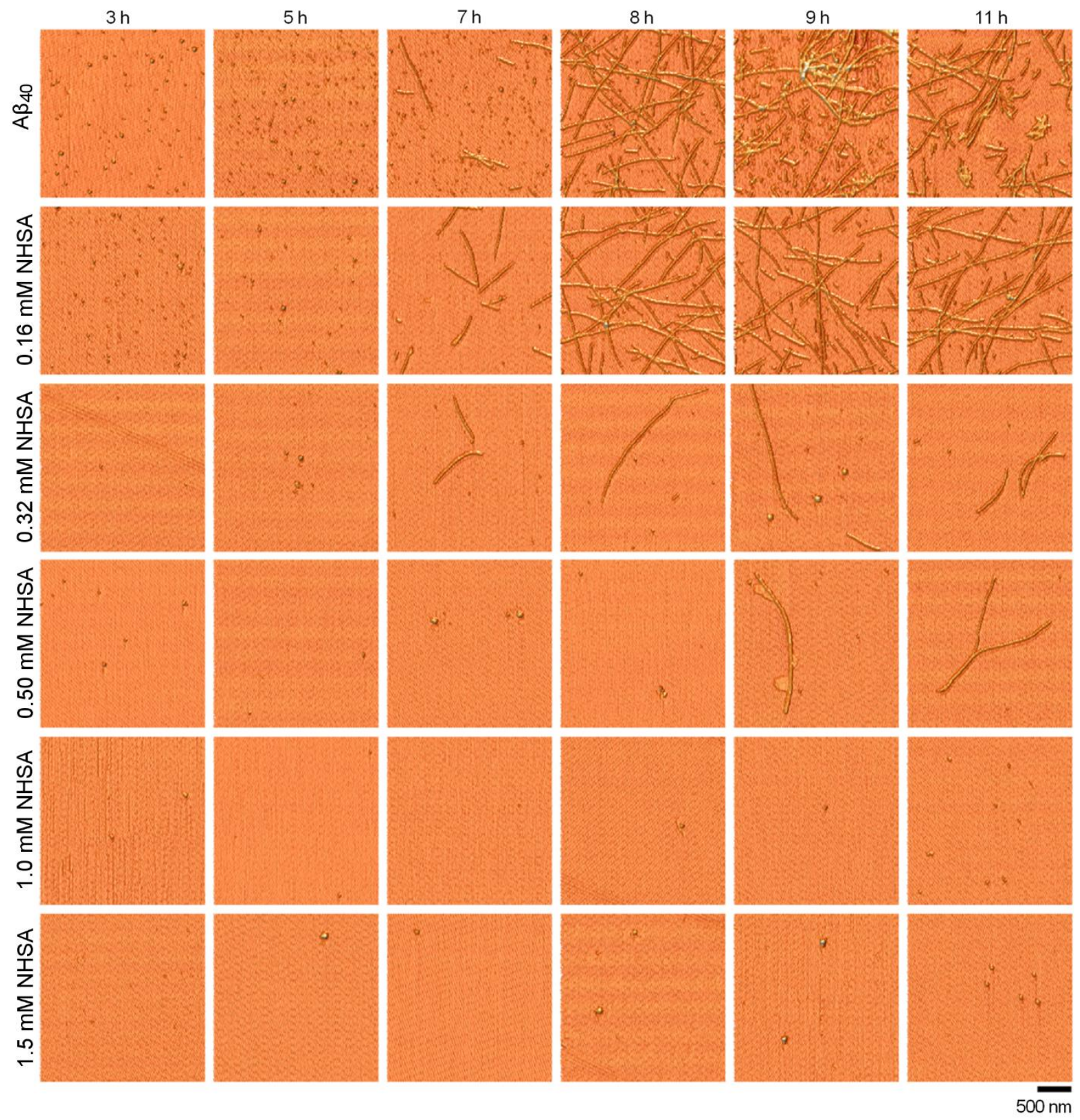

Figure 3.3. Atomic force microscopy images of $A \beta_{40}$ aggregates as a function of increasing acetylation and time. Representative ex situ AFM images sampled at multiple time points over 20 h of $A \beta_{40}(20 \mu \mathrm{M})$ at NHSA concentrations of $0.0 \mathrm{mM}, 0.16 \mathrm{mM} 0.32 \mathrm{mM}, 0.50 \mathrm{mM}, 1.0 \mathrm{mM}$, and $1.5 \mathrm{mM}$. Depositions of $A \beta_{40}$ imaged at $5 \times 5 \mu \mathrm{m}$ scan size on a mica substrate, shown here as $2.5 \times 2.5 \mu \mathrm{m}$ zoomed in images. Color scale ranges from $-5 \mathrm{~nm}$ to $10 \mathrm{~nm}$. 

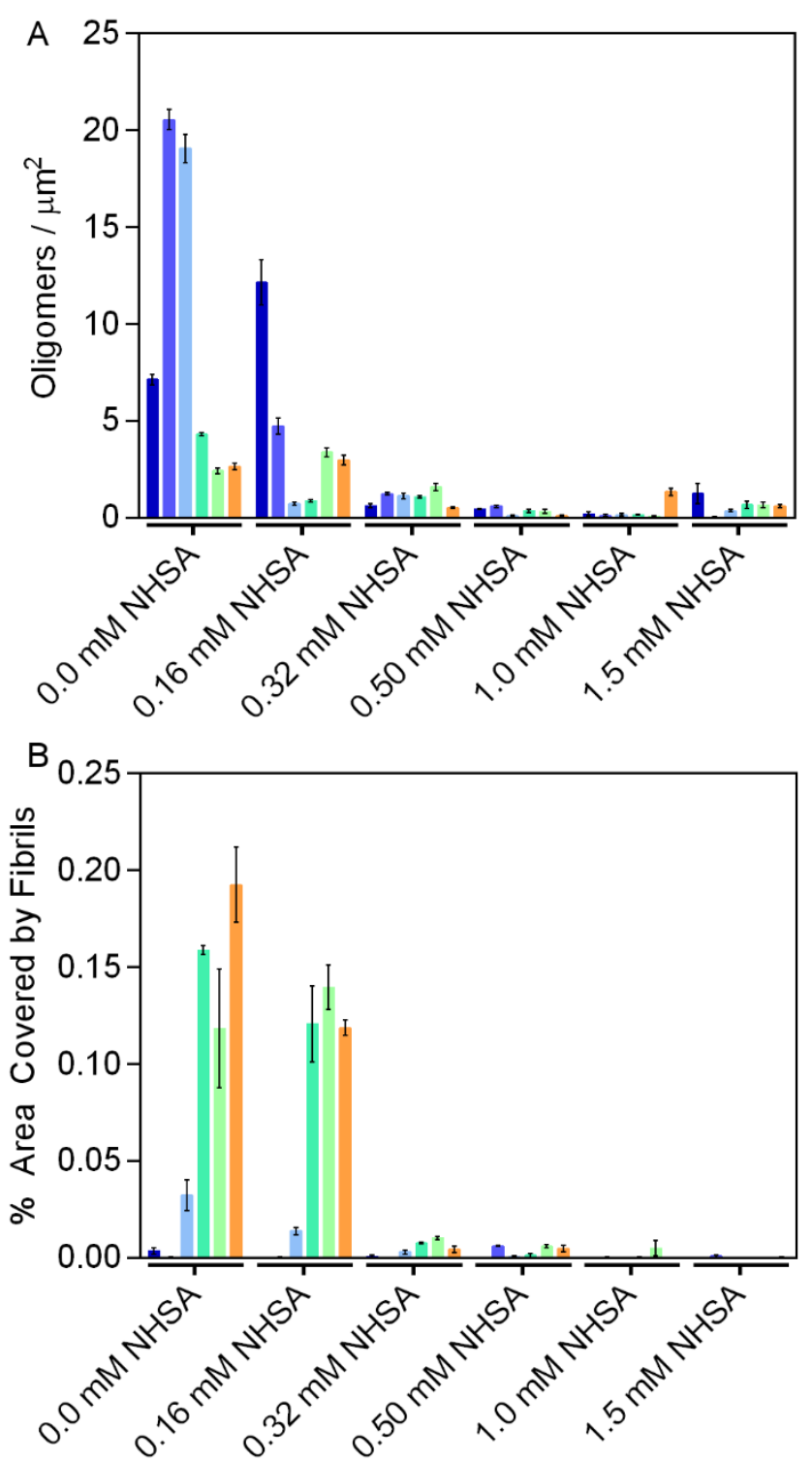

$\square 3 \mathrm{~h} \square 5 \mathrm{~h}-7 \mathrm{~h}-8 \mathrm{~h} \quad 9 \mathrm{~h} \square 11 \mathrm{~h}$

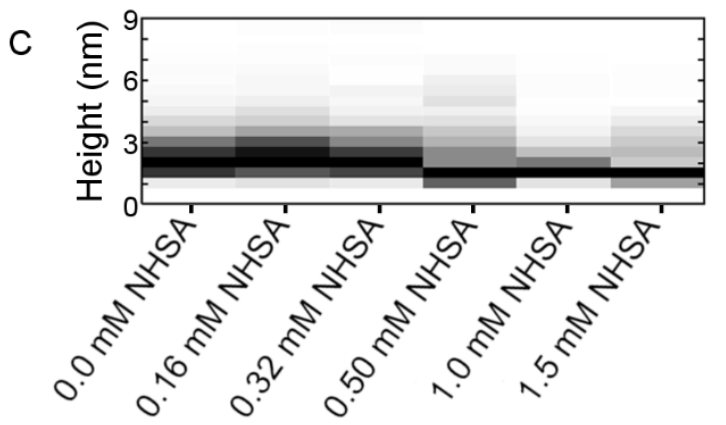

Figure 3.4. AFM image analysis of the impact of acetylation on $\mathbf{A} \beta_{40}$ aggregate populations and morphologies. (A) Population of oligomers per $\mu m^{2}$ over time determined by image analysis. Oligomer counts divided by the total area of the image analyzed. (B) Percent area covered by fibrils determined by filtering out aggregates with an area less than $95 \mathrm{~nm}^{2}$, converting images to binary maps, and dividing by the total image area. (A, B) Bar graphs shown as mean \pm SEM (C) Histogram of oligomeric heights measured over the entire $20 \mathrm{~h}$ time course of the experiment for $A \beta_{40}(20 \mu M)$ at NHSA concentrations of $0.0 \mathrm{mM}, 0.16 \mathrm{mM}$ $0.32 \mathrm{mM}, 0.50 \mathrm{mM}, 1.0 \mathrm{mM}$, and $1.5 \mathrm{mM}$. Red dashed line represents the oligomeric height of unacetylated $A \beta_{40}$ at $2.5 \mathrm{~nm}$. 
Based on AFM images and consistent with the ThT assays, increasing acetylation of A $\beta_{40}$ impaired aggregation (Figure 3.3). A $\beta O$ growth was quantified by counting the number of discrete oligomers per unit area observed on mica (Figure 3.4A); fibril growth was quantified by the percent of the mica surface covered by fibrils (Figure 3.4B). This approximation was used to quantify the extent of fibril formation due to fibril bundling and a heterogeneity in length, making it difficult to manually, or with an algorithm, determine the exact numbers of fibrils. When non-acetylated $A \beta$ was incubated, a large population of oligomers were observed within 3 $\mathrm{h}$ with a peak population appearing between 5-7 h, as measured by the number of A $\beta$ Os per unit area (Figure 3.4A). Fibrils appeared after $7 \mathrm{~h}$ of incubation, and the fibril density on the mica surface steadily increased, as measured by the \% area of the surface occupied by fibrils (Figure 3.4B). The appearance of fibrils coincided with a steady decline in the $\mathrm{A} \beta \mathrm{O}$ population.

When treated with NHSA concentrations of $0.16 \mathrm{mM}, 0.32 \mathrm{mM}$, and $0.5 \mathrm{mM}, \mathrm{A} \beta \mathrm{Os}$ also appeared after $3 \mathrm{~h}$ of incubation; however, the $\mathrm{A} \beta \mathrm{O}$ population was significantly reduced in an acetylation-dependent manner (Figure 3.3 and Figure 3.4A). With all three of these NHSA treatments, fibrils were still observed at later time points. For both $0.16 \mathrm{mM}$ and $0.32 \mathrm{mM}$ concentrations of NHSA, fibrils could be observed after $7 \mathrm{~h}$ of incubation, but fibrils were not observed by AFM for $A \beta_{40}$ treated with $0.5 \mathrm{mM}$ NHSA until after $9 \mathrm{~h}$ of incubation (Figure 3.3 and Figure 3.4B). The density of fibrils observed on mica was also decreased as a function of acetylation (Figure 3.4B). Consistent with the ThT assays, treatment with NHSA concentrations of $1.0 \mathrm{mM}$ and $1.5 \mathrm{mM}$ resulted in no observable fibrils over the $11 \mathrm{~h}$ incubation time. In addition, the number of $\mathrm{A} \beta \mathrm{O}$ s observed at any given time point was greatly reduced ( $\sim 20$ times $)$, suggesting that extensive acetylation arrests $A \beta_{40}$ aggregation at the oligomeric phase. It should 
be noted that the detection limit of A $\beta O$ s associated with this AFM analysis is likely on the order of octamers. That is, smaller A $\beta O$ s may still have formed, but would be difficult to observe with this assay. Hexameric and smaller $A \beta O$ s have been observed for $A \beta_{40}$ in which the lysines have been substituted for with alanines. ${ }^{23}$ With that being said, size analysis demonstrates that reaching a condition in which $A \beta_{40}$ is significantly acetylated results in smaller and fewer $A \beta O$ s. Specifically, AßOs formed without NHSA treatment or with NHSA treatments of $0.32 \mathrm{mM}$ or less resulted in oligomers of with a broad height distribution with a mode of $\sim 1.5-3.5 \mathrm{~nm}$ (Figure 3.4C). NHSA treatments of $0.5 \mathrm{mM}$ or greater resulted in oligomers that had a mode height of 1-1.5 nm (Figure 3.4C). As the size of AßOs observed under a specific condition did not change as a function of time and so few oligomers were observed at large NHSA treatments, the height histograms presented were compiled over all time points.

To determine if acetylation promoted unique fibril polymorphs, morphological features of fibrils grown under the different treatments of NHSA were determined by AFM image analysis (Fig 5). Height profiles were taken perpendicular to the axis of each fibril for $A \beta_{40}$ fibrils formed at NHSA concentrations of $0.0 \mathrm{mM}, 0.16 \mathrm{mM}, 0.32 \mathrm{mM}$, and $0.50 \mathrm{mM}$ (Figure 3.5A). The $1.0 \mathrm{mM}$ and $1.5 \mathrm{mM}$ NHSA condition were not analyzed as fibrils were not observed. Profiles were taken in a manner to avoid fibril crossings in order to better represent the height scale of single fibril species. The fibril height profiles of $A \beta_{40}$ at $0.0 \mathrm{mM}, 0.16 \mathrm{mM}, 0.32 \mathrm{mM}$, and $0.50 \mathrm{mM}$ NHSA concentrations all had a mode fibril heights of $\sim 2.5 \mathrm{~nm}$ (Figure 3.5A), suggesting that the fibrils formed under these conditions were not polymorphic. As fibril height can vary along the contour of the fibrils, the average height along fibril contour of every individual fibril was determined. As fibril heights did not appear to vary as a function of time, data time points of $7 \mathrm{~h}$ and beyond were compiled for each variable to produce histograms of the 
average fibril contour height (Figure 3.5B). The median fibril contour height for NHSA concentrations of $0.0 \mathrm{mM}, 0.16 \mathrm{mM}, 0.32 \mathrm{mM}$, and $0.50 \mathrm{mM}$ were $2.4 \mathrm{~nm}, 2.2 \mathrm{~nm}, 3.1 \mathrm{~nm}$, and $2.5 \mathrm{~nm}$, respectively; with an interquartile range of $1.0 \mathrm{~nm}, 0.8 \mathrm{~nm}, 0.4 \mathrm{~nm}$, and $0.6 \mathrm{~nm}$, respectively (Figure 3.5B), confirming the absence of any polymorphic fibril structures for $A \beta_{40}$ under these acetylating concentrations. 


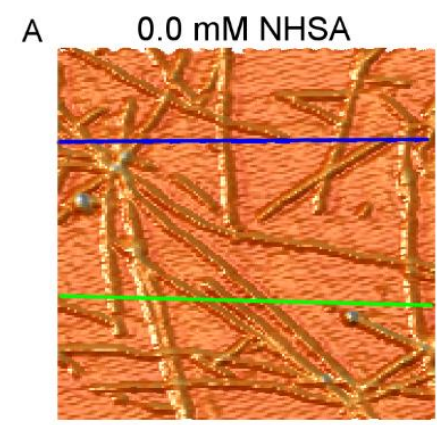

$0.16 \mathrm{mM}$ NHSA

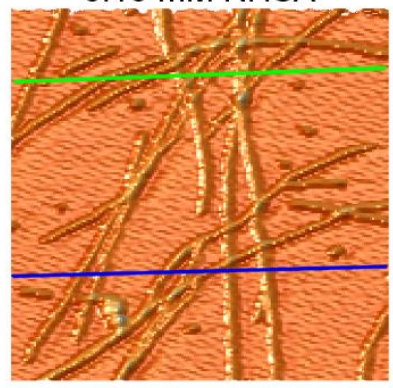

$0.32 \mathrm{mM}$ NHSA

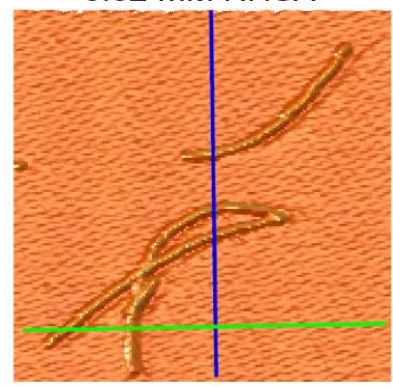

$0.50 \mathrm{mM}$ NHSA

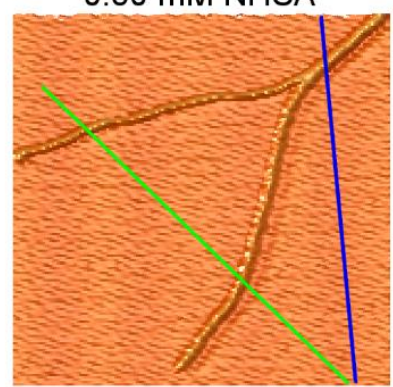

B
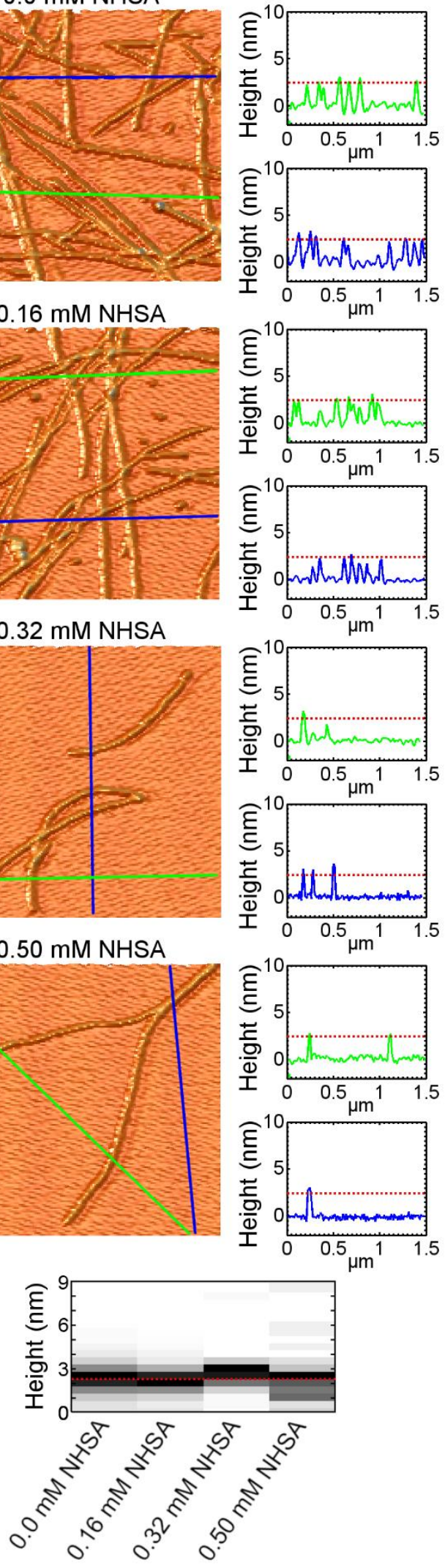

Figure 3.5. Comparison of fibril aggregates of $\mathbf{A} \beta_{40}$ as a function of acetylation. (A) Height profiles of representative ex situ AFM images of $A \beta_{40}(20 \mu \mathrm{M})$ at $0.0 \mathrm{mM}, 0.16 \mathrm{mM}$, $0.32 \mathrm{mM}$, and $0.50 \mathrm{mM}$ NHSA concentrations at $11 \mathrm{~h}$. Colored lines of images correspond to adjacent height profiles. Conditions that did not produced fibril were excluded (B) Histogram of the average fibril height as measured along the contour length of each fibril for time points of $7 \mathrm{~h}$ and greater. $(A, B)$ Red dashed-line represents height of $2.5 \mathrm{~nm}$. 
3.3.4 Exposure to TBLE membranes promotes fibrillization of acetylated $A \beta_{40}$. As the

presence of lipid membranes has been implicated as a modifier of $\mathrm{A} \beta$ aggregation, ${ }^{39,51}$ and lysines play a prominent role in peptide/lipid interactions, ${ }^{52-54}$ we next wanted to determine how the presence of lipid membranes modifies the aggregation of $A \beta_{40}$ under the various acetylating conditions. ThT assays were performed in the presence of large unilamellar vesicles (LUV) of TBLE. TBLE was chosen as a model system due to its physiologically relevant mixture of membrane lipids and its extensive use in studying $A \beta$ membrane interactions. ${ }^{7,16,55,56}$ In short, $\mathrm{A} \beta_{40}(20 \mu \mathrm{M})$ was incubated in the presence of TBLE LUVs at a lipid to peptide ratio of 30:1 (0.5 $\mathrm{mg} / \mathrm{mL}$ ) under the same experimental and instrumental conditions as the assays performed in the absence of lipids. There are examples in the literature of the presence of lipids both accelerating ${ }^{57-59}$ or slowing ${ }^{39,60} \mathrm{~A} \beta$ aggregation. While the lipid composition of the membrane plays a role, ${ }^{39,61,62}$ the preparatory history of $A \beta$ may also influence the $A \beta /$ lipid interaction. ${ }^{56}$ With the $A \beta$ preparation protocol used here, TBLE membranes slowed aggregation compared to aggregation in the absence of lipids (compare the ThT assay curves of $A \beta_{40}$ without NHSA treatment in Figure 3.2 and Figure 3.6). ${ }^{63}$ 

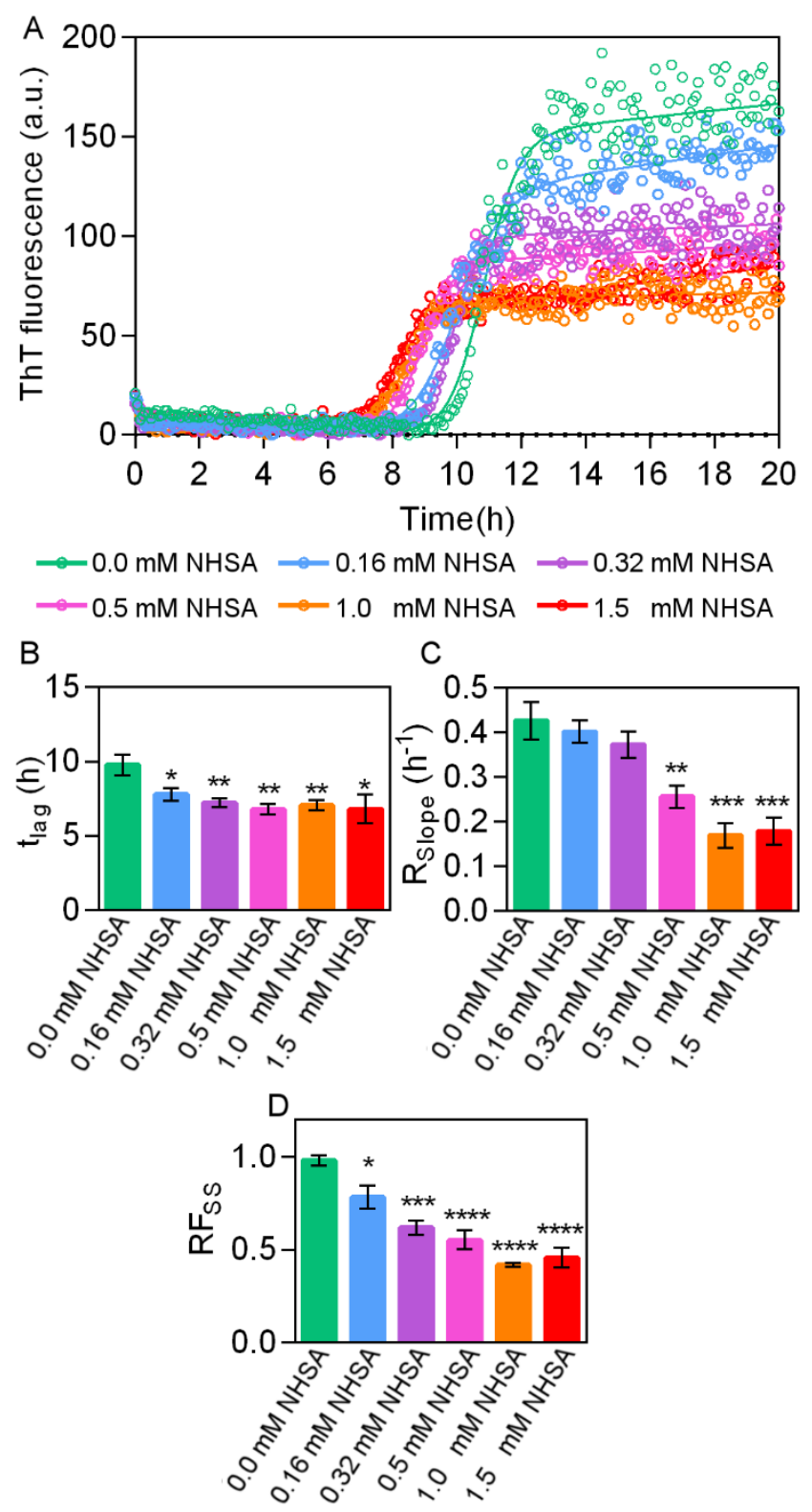

Figure 3.6. ThT assays investigating the impact or acetylation on $A \beta_{40}$ aggregation in the presence of TBLE LUVs. (A) Representative ThT curves of three independent experiments of $A \beta_{40}(20 \mu M)$ (green) in the presence of TBLE LUVS at 30:1 lipid-peptide ratio $(\sim 0.5 \mathrm{mg} / \mathrm{mL})$ at $37^{\circ} \mathrm{C}$ for all other variables. $A \beta_{40}$ was also incubated under increasing concentrations of NHSA, $0.16 \mathrm{mM}$ (blue), $0.32 \mathrm{mM}$ (purple), $0.50 \mathrm{mM}$ (pink), $1.0 \mathrm{mM}$ (orange), and 1.5 $\mathrm{mM}$ (red). Lines represent the sigmodal fit of calculated from Equation 1. Bar-graphs of kinetic parameters of the (B) lag-phase, $t_{\text {lag }}(h)$, and (C) the slope of the growth phase, $R_{\text {slope }}\left(h^{-1}\right)$, was determined for all variables by extracting values from the line of best fit. Values of tlag(h) and Slope $\left(h^{-1}\right)$ were extracted from three independent experiments plotted as the mean value. (D) Normalized maximum response of the steady state region of ThT curves, $R F_{s s}$, calculated by averaging the plateau region then normalizing all variables to their respective control. Data shown as mean \pm SEM of the normalized raw fluorescence signals of three independent experiments; (*) $P \leq 0.05$, (**) $P \leq 0.01,(* * *) P \leq 0.001$, and $(* * * *) P \leq$ 0.0001 .

For example, the presence of TBLE extended the lag phase of $A \beta_{40}$ aggregation $\sim 5 \mathrm{~h}$. While acetylation associated with NHSA treatment of $1.0 \mathrm{mM}$ or greater completely prevented fibrillization in the absence of TBLE vesicles, $A \beta_{40}$ formed fibrils under all acetylating conditions based on the ThT assay curves (Figure 3.6), and this was later confirmed by AFM images of these solutions at the end of the ThT assay (Figure 3.7). In the presence of TBLE, the lag-phase decreased with increasing acetylation, with the following lag-phase times exhibited; 
$\mathrm{A} \beta_{40}, 9.8 \pm 0.67 \mathrm{~h} ; 0.16 \mathrm{mM}$ NHSA, $7.8 \pm 0.40 \mathrm{~h} ; 0.32 \mathrm{mM}$ NHSA, $7.2 \pm 0.31 \mathrm{~h} ; 0.50 \mathrm{mM}$ NHSA, $6.8 \pm 0.34 \mathrm{~h} ; 1.0 \mathrm{mM}$ NHSA, $7.1 \pm 0.36 \mathrm{~h}$; and $1.5 \mathrm{mM}$ NHSA, $6.8 \pm 0.99 \mathrm{~h}$ (Figure 3.6B). This trend suggests that $A \beta$ acetylation promotes the formation of the critical nucleus associated with fibril initiation. This is in stark contrast to impact of acetylation in the absence of TBLE, in which the lag phase was extended. In addition to the shortened lag phase in the presence of TBLE vesicles, acetylating conditions of $0.5 \mathrm{mM}, 1.0 \mathrm{mM}$, and $1.5 \mathrm{mM}$ NHSA all exhibited a statistical significance decrease in the slope of the growth phase compared to the control; $\mathrm{A} \beta_{40}, 0.43 \pm 0.042 \mathrm{~h}^{-1} ; 0.5 \mathrm{mM}$ NHSA, $0.26 \pm 0.026 \mathrm{~h}^{-1} ; 1.0 \mathrm{mM}$ NHSA, $0.17 \pm 0.027 \mathrm{~h}^{-}$ 1; $1.5 \mathrm{mM}$ NHSA, $0.18 \pm 0.031 \mathrm{~h}^{-1}$ associated with $\mathrm{A} \beta_{40}$ acetylation in the presence of TBLE. Concomitant with this shortened lag phase, the overall $\beta$-sheet load, as measured by relative fluorescence at steady state, systematically decreased with increasing acetylated lysine content. The reduction in $\beta$-sheet formation started with $\sim 20-35 \%$ reduction at $0.16 \mathrm{mM}$ NHSA and 0.32 $\mathrm{mM}$ NHSA concentrations to $\sim 60 \%$ reduction for $1.0 \mathrm{mM}$ NHSA and $1.5 \mathrm{mM}$ NHSA (Figure 3.6D).

3.3.5 TBLE promotes unique aggregate morphologies of acetylated $A \beta_{40}$. While not resulting in unique fibril morphologies in the absence of lipids, point mutations in $\mathrm{A} \beta$ associated with familial forms of AD aggregate into unique polymorphic structures in the presence of TBLE bilayers. ${ }^{16}$ This suggests that acetylation could promote polymorphic fibrils in the presence of TBLE, despite not producing polymorphs in the absence of lipids. To determine if acetylated forms of $A \beta_{40}$ produced polymorphic fibrils, $A \beta_{40}(20 \mu \mathrm{M})$ was incubated in the presence of TBLE LUVs at a lipid to peptide ratio of 30:1. After $20 \mathrm{~h}$ samples were deposited on a mica substrate and AFM image analysis was performed for all conditions. Height profiles of fibrils 
demonstrated a fibril height of 2.5-3.0 nm (Figure 3.7A), like that observed in the absence of TBLE (Figure 3.5A). However, there are several regions along the contour of the fibrils formed in the presence of TBLE that appeared thicker. That is, the morphology along the contour of the fibril deviated to a greater extent.
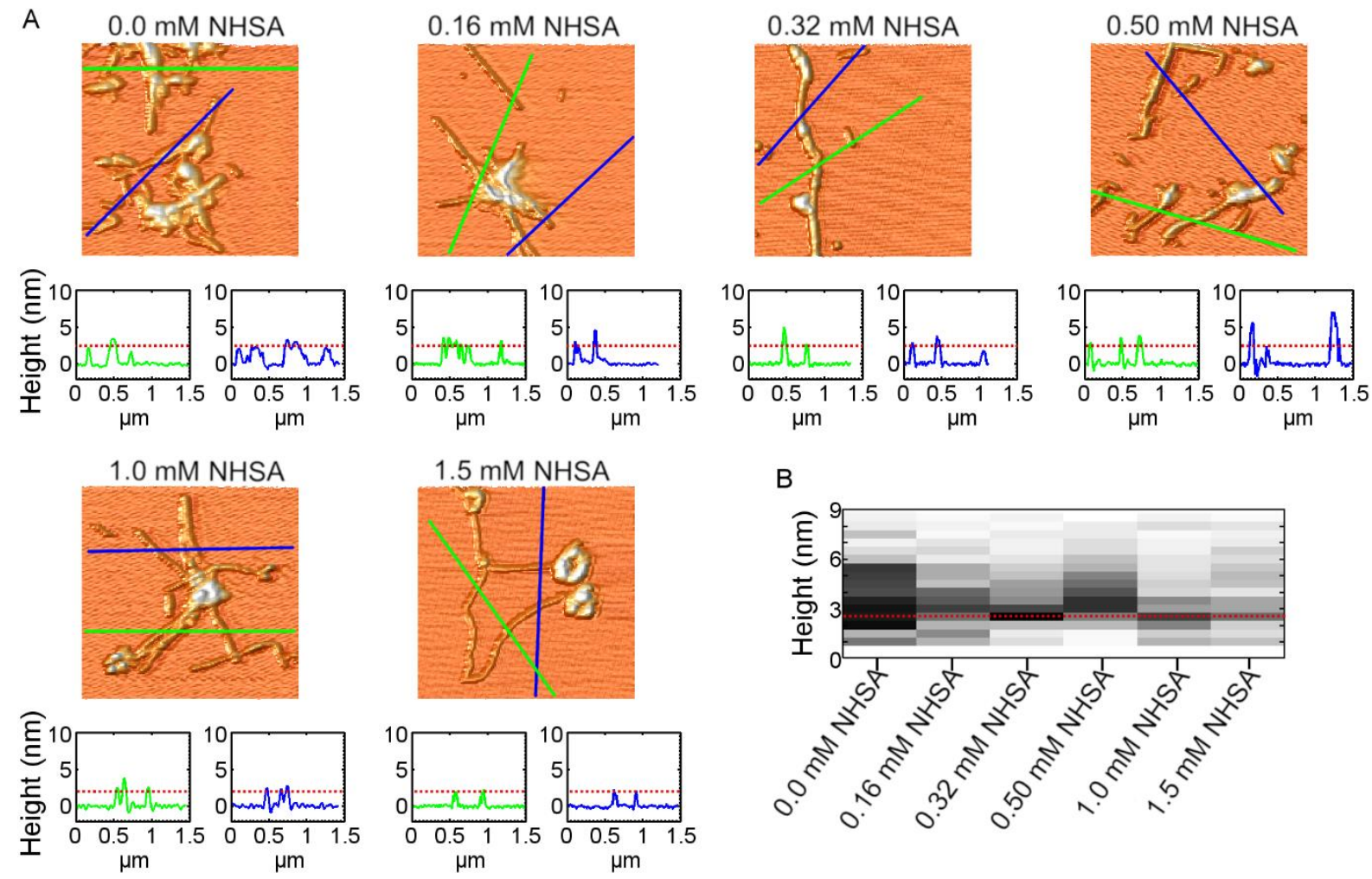

Figure 3.7 Comparison of fibril morphologies of $\mathbf{A} \boldsymbol{\beta}_{40}$ as a function of acetylation. (A) Height profiles of representative ex situ AFM images of $A \beta_{40}(20 \mu \mathrm{M})$ at $0.0 \mathrm{mM}, 0.16 \mathrm{mM}, 0.32$ $\mathrm{mM}, 0.50 \mathrm{mM}, 1.0 \mathrm{mM}$, and $1.5 \mathrm{mM}$ NHSA concentrations at $20 \mathrm{~h}$. Colored lines of images correspond to adjacent height profiles. (B) Histogram of the average fibril height as measured along the contour length of each fibril. $(A, B)$ Red dashed-line represents height of $2.5 \mathrm{~nm}$.

As a result, the height along fibril contours had a much broader distribution when compared to fibrils in the absence of lipids. Median heights of fibrils in the presence of TBLE were $3.6 \mathrm{~nm}$ (0.0 mM NHSA), $3.3 \mathrm{~nm}(0.16 \mathrm{mM}$ NHSA), $3.3 \mathrm{~nm}(0.32 \mathrm{mM}$ NHSA), $3.9 \mathrm{~nm}(0.50 \mathrm{mM}$ NHSA), $2.8 \mathrm{~nm}$ (1.0 mM NHSA), and $3.3 \mathrm{~nm}$ (1.5 mM NHSA), and the distribution of heights defined by the interquartile range were $2.6 \mathrm{~nm}(0.0 \mathrm{mM}$ NHSA), $2.0 \mathrm{~nm}(0.16 \mathrm{mM}$ NHSA $), 1.9$ 
nm (0.32 mM NHSA), $2.0 \mathrm{~nm}(0.50 \mathrm{mM}$ NHSA), $2.1 \mathrm{~nm}$ (1.0 mM NHSA), and $2.1 \mathrm{~nm}$ (1.5 mM NHSA) (Figure 3.7B). An example of this broadening can be observed for $A \beta_{40}$ and $0.50 \mathrm{mM}$ NHSA in Figure 3.8B. Collectively, it appears that TBLE does not promote a fibril polymorph in acetylated $A \beta_{40}$; however, the increased variation in morphology along the fibril contour may indicate that lipids are being incorporated into or decorating the observed fibrils. This does not appear to be dependent on acetylation. Rather, it appears to be a consequence of fibril formation in the presence of TBLE vesicles.

While the morphology of fibrils formed in the presence of TBLE did not appear to be altered by acetylation, increased acetylation promoted the formation of annular aggregates in the presence of TBLE (Figure 3.7A and Figure 3.8). For conditions of 1.0 and $1.5 \mathrm{mM}$ NHSA, a large population annular aggregates formed $\left(2.6 \pm 0.4\right.$ to $6.4 \pm 0.6$ per $25 \mu^{2}$, respectively) that were not readily observed in the absence of lipid or with lower levels of acetylation. These annular aggregates were considerably thicker than fibrils with heights ranging from $\sim 5-10 \mathrm{~nm}$ (Figure 3.8B). The inner diameter of these annular aggregates ranged from $\sim 60-200 \mathrm{~nm}$ with a median size of $\sim 114 \mathrm{~nm}$ (Figure 3.9B). Many annular aggregates appeared to be strongly associated with fibril aggregates as they were co-localized on the mica surface, with some fibrils appearing to protrude directly from annular aggregates (Figure 3.9A). 
A
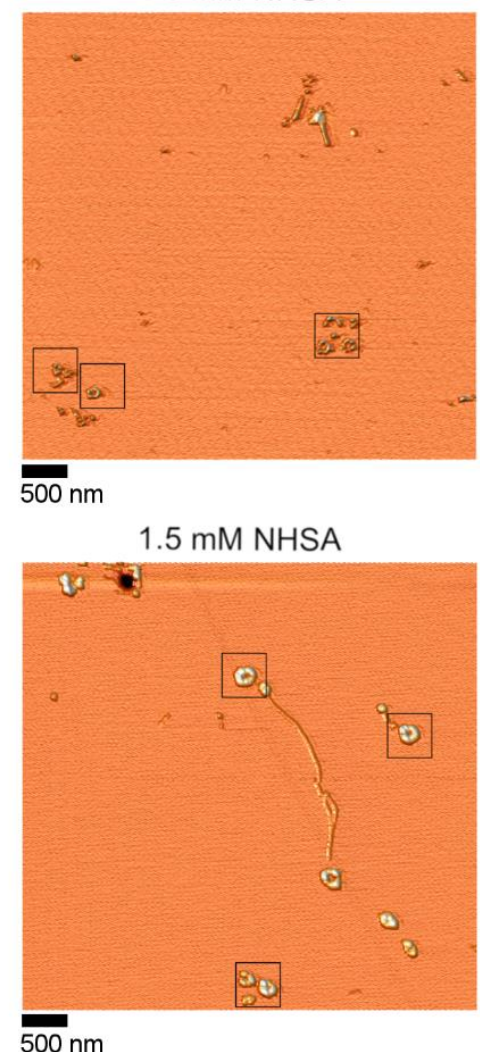

B
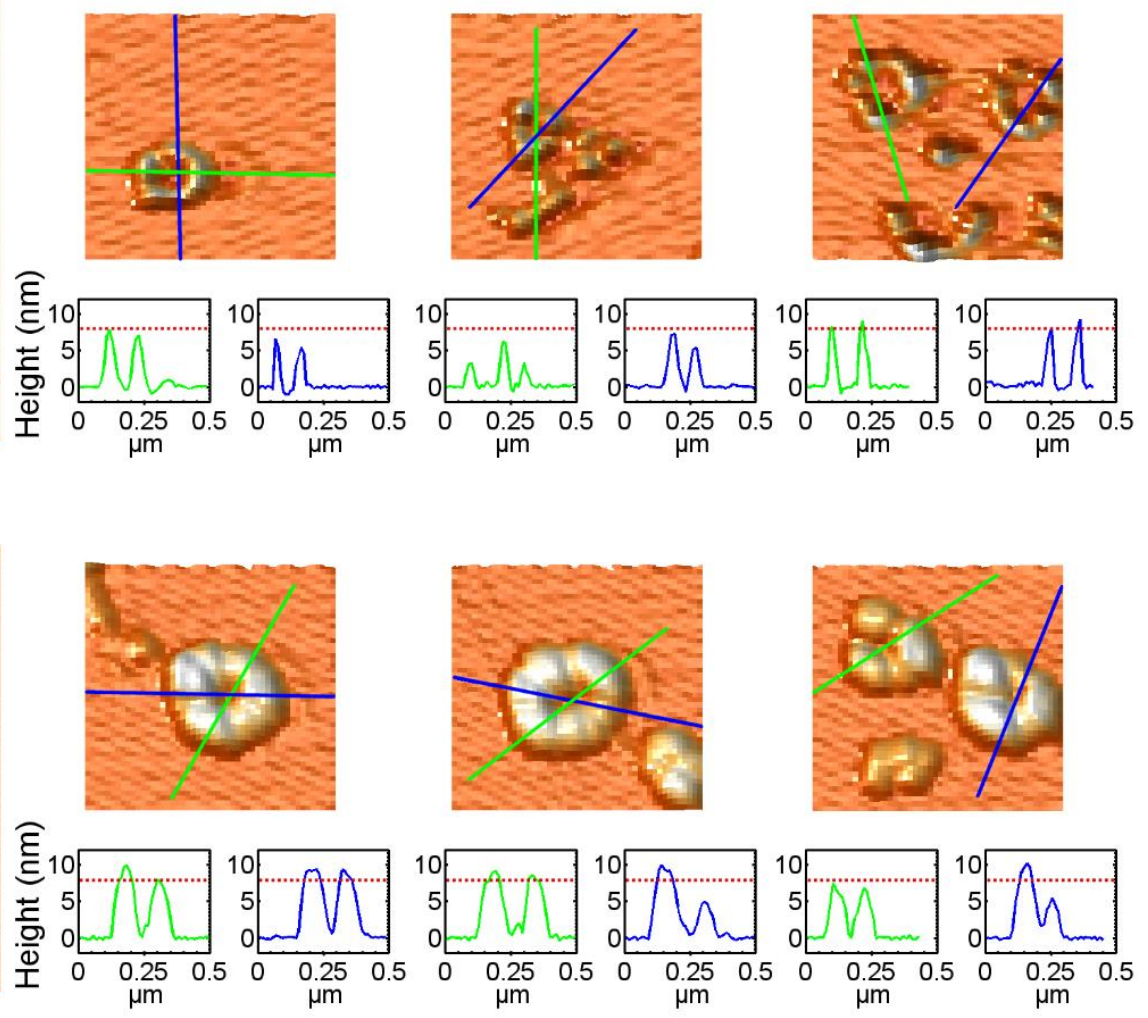

Figure 3.8 Acetylation of $\mathbf{A} \boldsymbol{\beta}_{40}$ in presence of TBLE produces annular aggregates. $(A) 5 \times 5$ $\mu \mathrm{m}$ representative ex situ $A F M$ images of $A \beta_{40}(20 \mu M)$ at $1.0 \mathrm{mMNHSA}$ and $1.5 \mathrm{mM}$ NHSA concentrations in the presence of TBLE. Boxes illustrating regions of zoomed in images (B) Zoomed in $0.5 \times 0.5 \mu \mathrm{m}$ images of annular aggregates for $1.0 \mathrm{mM}$ and $1.5 \mathrm{mM}$ NHSA. Colored lines correspond to height profiles with the red dashed line representing $8.0 \mathrm{~nm}$ height. Color scale constant for all images. 

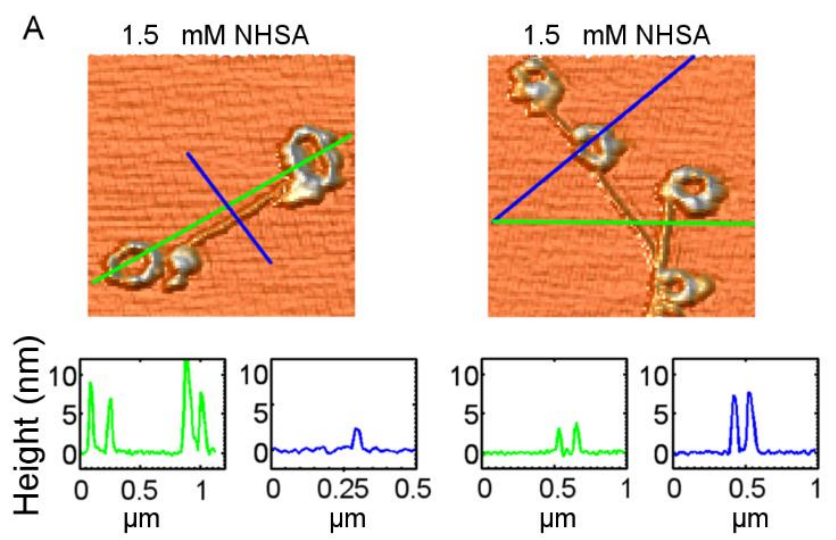

B
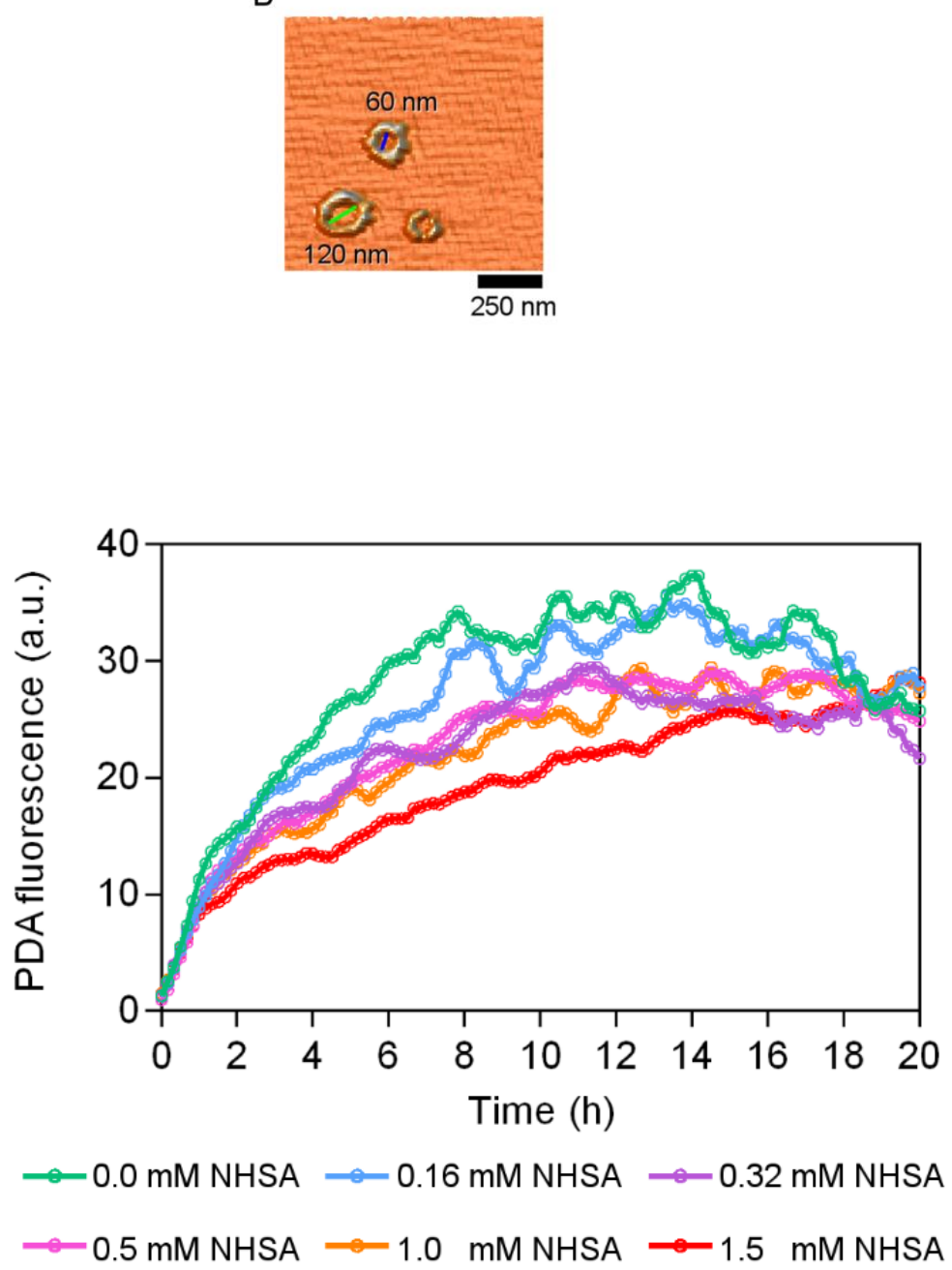

Figure 3.9. Fibrils and annular aggregates often colocalize. $(A, B)$ Zoomed in $1.0 \times 1.0$ $\mu m$ images of annular aggregates and fibrils of $A \beta_{40}(20 \mu M)$ at $1.5 \mathrm{mM}$ NHSA. (A) Height profiles of annular and fibril aggregates. Colored line corresponds to colored line of image. (B) Representative ex situ AFM image showing the range of pore sizes for annular aggregates. Color scale is the same for all images.
Figure 3.10. Polydiacetylene binding assay of $A \beta_{40}$ at increasing states of acetylation. PDA fluorescence response $\left(\lambda_{E x}\right.$ $\left.485 \mathrm{~nm}, \lambda_{E m} 560 \mathrm{~nm}\right)$ time-course of $A \beta_{40}$ (green) interacting with PDA/TBLE vesicles, incubated at $25^{\circ} \mathrm{C} . \quad A \beta_{40}$ was additionally incubated under increasing concentrations of NHSA, $0.0 \mathrm{mM}$ NHSA (green), $0.16 \mathrm{mM} \mathrm{NHSA}$ (blue), $0.32 \mathrm{mM}$ NHSA (purple), $0.50 \mathrm{mM}$ NHSA (pink), $1.0 \mathrm{mM}$ NHSA (orange), and $1.5 \mathrm{mM}$ NHSA (red).

3.3.6 Acetylation reduces the affinity of $A \beta_{40}$ for TBLE membranes. As the presence of TBLE vesicles clearly influenced the aggregation of acetylated $A \beta_{40}$, a polydiacetylene (PDA) lipid binding assay was performed to measure the total interaction between $A \beta_{40}$ and TBLE 3. Acetylation of $A \beta_{40}$ alters aggregation in the presence and absence of lipid membranes 
membranes (Figure 3.10). Polydiacetylene is a lipid moiety that is easily incorporated into vesicles and photo-crosslinked, resulting in hybrid vesicles with enhanced fluorescence in response to mechanical stress associated with peptide binding and aggregation. By monitoring fluorescence of these vesicles as a function of time, the total interaction of $A \beta$ with the TBLE/PDA vesicles can be monitored. Control experiments were performed with the various doses of NHSA, and a fluorescent response was not invoked in these control experiments. Upon exposure of TBLE/PDA vesicles to $A \beta_{40}$, the fluorescent signal steadily increases as the peptide binds and aggregates on the vesicles. As the extent of $A \beta_{40}$ acetylation was increased, the total interaction between the peptide and vesicles gradually was reduced. As binding to and aggregation on the vesicle can both induce PDA response, it is important to interpret this assay with the results of the ThT assay in mind. As the shortest lag phase for any condition was $\sim 7 \mathrm{~h}$ as determined by the ThT assay, the PDA response for the first $7 \mathrm{~h}$ is dominated by the initial binding of $A \beta$ to the membrane. It appears that acetylation reduces the overall affinity of $A \beta$ for TBLE vesicles. As the steady state phase of fibril formation is reached for all conditions by $11 \mathrm{~h}$ of incubation (as determined by the ThT assay), the total fibril load has its largest contribution to the total PDA signal. In this regard, the magnitude of the PDA decreases with increasing acetylation in a similar fashion in comparison with the ThT assay. Lastly, at $\sim 17 \mathrm{~h}$ the PDA/TBLE fluorescence signal associated with exposure to $A \beta_{40}$ that had been not been treated NHSA or treated with $0.16 \mathrm{mM}$ NHSA began to decrease instead of maintaining a plateaued maximum response. This drop-in signal eventually reaches that of the maximum response of other experimental conditions. Extensive fibrillization on lipid vesicles can lead to PDA vesicle instability leading to flocculation, and these two conditions were associated with the largest fibril 
load. As a result, this likely reflects a loss in signal to the instability of the PDA/TBLE vesicles upon prolonged exposure to late-stage aggregates that alter the colloidal suspension.

\subsection{Discussion}

Understanding how individual amino acids of $A \beta$ affect aggregation and peptide-membrane interactions are significant as it provides the possibility for focused, therapeutic targeting and may provide more effective treatment strategies. In this work, we explored the role of lysine's cationic charge in the aggregation of $A \beta_{40}$ in the presence and absence of membranes through its removal via acetylation. In summary, we demonstrate that 1) acetylation reduces the aggregation propensity of $A \beta_{40}$, eventually abolishing fibril formation; 2) acetylation impedes the formation of $A \beta O s ; 3)$ under our experimental conditions, TBLE membranes slow $A \beta_{40}$ aggregation; however, acetylation of $A \beta_{40}$ promotes aggregation in the presence of TBLE compared to control; 4) acetylation of $A \beta_{40}$ reduces the total $A \beta /$ membrane interaction; 5) the combination of acetylation and the presence of TBLE can promote the formation of annular aggregates of $A \beta_{40}$. This work suggests that the $A \beta$ aggregation process (in both the presence and absence of lipid bilayers) is highly dependent on the charge state of lysine residues and that the $A \beta$ aggregation mechanism is unique on TBLE bilayers.

Through increasing the concentration of NHSA, both K16 and K28 could be acetylated, but K16 was more readily acetylated. The preferential acetylation of K16 is consistent with structural studies of monomeric $A \beta$ demonstrating that $\mathrm{K} 16$ is solvent exposed while $\mathrm{K} 28$ is

partially protected. ${ }^{22,64}$ Our experimental conditions created two regimes of $A \beta$ acetylation: one in which AcK16 predominated ( $0.16 \mathrm{mM}$ and $0.32 \mathrm{mM}$ NHSA) and the other in which the 
abundance of AcK16 to AcK28 were similar (1.0 mM and $1.5 \mathrm{mM}$ NHSA). As the complete absence of fibrils was observed only when K28 was appreciably acetylated, it is tempting to associate K28 acetylation with this observation. However, as substitution of either K16 or K28 with alanine impacted $A \beta$ aggregation, ${ }^{23}$ it is likely that acetylation of both lysines plays a role in the observed inhibition of aggregation. There are plausible mechanisms associated with acetylation of either lysine. K16 is associated with an amyloidogenic core sequence in A $\beta$ that plays a key role in fibril formation, ${ }^{9,10}$ and as a result, altering this region is likely to impact aggregation. There is precedent for such a notion as the Flemish mutation in $A \beta$, which changes an alanine to a glycine and is at the end of this amyloidogenic core sequence, significantly reduces the fate of A $\beta$ fibrillization. ${ }^{65-67}$ Indeed, low concentration treatments of NHSA, when K28 is not appreciably acetylated, exhibited significant (although not absolute) reduction in fibril and oligomer formation. A potential mechanism for AcK16 inhibition of aggregation is provided by computational studies of $A \beta_{42}[\mathrm{~K} 16 \mathrm{~A}]$ demonstrating that the substitution of lysine results in a loss of intrapeptide contacts between the hydrophobic core and C-terminus of $\mathrm{A} \beta$, therefore, reducing the propensity of $\beta$-sheet formation required for aggregation. ${ }^{68}$ With regard to K28, acetylation would disrupt its ability to participate in a salt bridge with D23 or E22. This salt bridge is associated with the turn region of a $\beta$-hairpin observed in an $A \beta$ fibril structure. ${ }^{17}$ The removal of K28's cationic charge through acetylation would, therefore, destabilize A $\beta$ fibrils. Support for this mechanism can be seen in the success of a variety of $A \beta$ fibril inhibitors directly targeting this salt bridge. ${ }^{69-73}$ Furthermore, artificially creating the salt bridge between D23 and K28 via the addition of a lactam linker increases the rate of fibril formation by removing the entropic barrier imposed by the establishment of the salt bridge and effectively removing the lagphase. ${ }^{74}$ Changes in the net charge of $A \beta_{40}$ from -3 to -4 or -5 may also play a role in impeding 
fibril formation as increases in the solvation energy would reduce the strength of the hydrophobic collapse of $A \beta$ that is associated with the initial stages of aggregation. ${ }^{75,76}$

Beyond inhibiting fibril formation, acetylation of $A \beta$ reduces oligomerization. This finding appears to be in contradiction to the oligomerization of $A \beta_{40}[\mathrm{~K} 16 \mathrm{~A}]$, and $A \beta_{40}[\mathrm{~K} 28 \mathrm{~A}]$ which displayed similar oligomerization distributions to wild-type $\mathrm{A} \beta 40 .{ }^{23}$ However, the detection limitations of the AFM analysis used here would not allow for the detection of the small oligomers (hexamers or smaller) observed by Sinha et al. With regard to the oligomers observable by AFM, these tend to be classified as high molecular weight (HMW) oligomers, and a number of toxic HMW AßOs have been reported. ${ }^{77-80}$ The smaller, low molecular weight (LMW) A $\beta O$ s tend to be less toxic or even benign compared with their HMW counterparts. ${ }^{77,79-}$ ${ }^{81}$ Our analysis suggests that even if acetylation does not alter the formation of LMW AßOs, the more toxically-relevant HMW oligomers are reduced by acetylation. With regards to potential mechanisms for this inhibition of $\mathrm{A} \beta \mathrm{O}$ formation, molecular dynamics suggest that $\mathrm{A} \beta$ oligomerization is governed through electrostatic interactions ${ }^{40}$ and that reducing electrostatic attraction promotes smaller ordered oligomers. ${ }^{41}$ Such a scenario is consistent with our observation that high levels of acetylation resulted in fewer and smaller $\mathrm{A} \beta \mathrm{O}$, as acetylation would reduce the electrostatic attraction between $A \beta$ peptides.

The impact of acetylation on $A \beta$ aggregation suggests that targeting K16 and K28 can be an effective way to manipulate aggregation for potential therapeutic purposes. Indeed, there are several indications that such a strategy may be effective. A molecular tweezer, CRL01, that selectively binds to lysine side chains inhibits the formation of $\mathrm{A} \beta \mathrm{Os}$ and fibrils. ${ }^{82}$ Aspirin, which can act as an acetylating agent, ${ }^{83-85}$ can reduce the risk of $\mathrm{AD}^{86}$ and protects HEK239 
cells against cytotoxicity associated with exposure to $A \beta$ fibrils. ${ }^{87}$ More broadly, aspirin reduces protein aggregation in several amyloid-based, neurodegenerative diseases, ${ }^{88,89}$ and this protection was directly linked to its ability to acetylate proteins in C. elegan models of Huntington's Disease and $\mathrm{AD}{ }^{88,90}$ However, aspirin's ability to acetylate proteins is not lysine specific. ${ }^{91}$

Lipid membrane environments have been shown to influence the aggregation of a number of amyloid-forming proteins ${ }^{29,61,92-96}$ and can even induce unique aggregation pathways. ${ }^{26,94}$ Such a unique aggregation pathway would be consistent with our results with regard to $A \beta$ aggregation in the presence and absence of TBLE vesicles. While acetylation extended the lag phase A $\beta$ aggregation in the absence of TBLE vesicles, the opposite was observed in the presence of such vesicles, and $A \beta$ was able to form fibrils even after extensive acetylation associated with high concentration treatments of NHSA. Despite the shortened lag phase associated with acetylation of $A \beta$ in the presence of TBLE vesicles, the total fibril load was reduced, and polymorphic annular aggregates were observed. Collectively, this suggests that, in the presence of lipids, acetylation enhances the formation of the critical nucleus associated with initiating fibrillization but promotes secondary aggregation pathways. The enhanced nucleation could be related to enhanced diffusion along the membrane surface. That is, once bound to the lipid membrane, the removal of the cationic nature of lysine via acetylation could reduce the interaction with anionic head-groups, which may allow for freer diffusion of $\mathrm{A} \beta$ peptides along the membrane surface and increase the ability of peptides colliding and coalescing into a critical nucleus. A plausible scenario for the observed decrease in the slope of the growth phase, associated with the reduction in fibril elongation; and $\beta$-sheet load is that the inability to form a salt bridge between $\mathrm{K} 28$ and other residues increases the dissociation rate of monomers from the growing fibril ends relative to the association rate, resulting in an overall slower elongation. 


\section{References 3.5}

(1) Pilkington IV, A. W., and Legleiter, J. (2019) Challenges in understanding the structure/activity relationship of A $\beta$ oligomers, AIMS Biophys. 6, 1-22.

(2) Cline, E. N., Bicca, M. A., Viola, K. L., and Klein, W. L. (2018) The Amyloid- $\beta$ Oligomer Hypothesis: Beginning of the Third Decade, J. Alzheimer's Dis. 64, S567-S610.

(3) Sakono, M., and Zako, T. (2010) Amyloid oligomers: formation and toxicity of A $\beta$ oligomers, FEBS J. 277, 1348-1358.

(4) Goldsbury, C. S., Wirtz, S., Müller, S. A., Sunderji, S., Wicki, P., Aebi, U., and Frey, P. (2000) Studies on the in vitro assembly of A $\beta$ 1-40: Implications for the search for $A \beta$ fibril formation inhibitors, J. Struct. Biol. 130, 217-231.

(5) Stine, W. B., Snyder, S. W., Ladror, U. S., Wade, W. S., Miller, M. F., Perun, T. J., Holzman, T. F., and Krafft, G. A. (1996) The Nanometer-scale structure of amyloid- $\beta$ visualized by atomic force microscopy, Protein J. 15, 193-203.

(6) Tycko, R. (2014) Physical and structural basis for polymorphism in amyloid fibrils, Protein Sci.

(7) Yates, E. a., Owens, S. L., Lynch, M. F., Cucco, E. M., Umbaugh, C. S., and Legleiter, J. (2013) Specific domains of $\mathrm{A} \beta$ facilitate aggregation on and association with lipid bilayers, $J$. Mol. Biol. 425, 1915-1933.

(8) Enache, T. A., and Oliveira-brett, A. M. (2018) Amyloid Beta Peptide VHHQ, KLVFF, and IIGLMVGGVV Domains Involved in Fibrilization: AFM and Electrochemical Characterization.

(9) De Groot, N. S., Aviles, F. X., Vendrell, J., and Ventura, S. (2006) Mutagenesis of the central hydrophobic cluster in A $\beta 42$ Alzheimer's peptide: Side-chain properties correlate with aggregation propensities, FEBS J. 273, 658-668.

(10) W. P. $\sim$ Esler, E. R . $\sim$ Stimson, J. R. $\sim$ Ghilardi, Y. $\sim$ A. Lu, A. $\sim$ M. $\sim$ Felix, H. V. $\sim$ Vinters, P. $\sim$ W. Mantyh, J. P. $\sim$ Lee, and J. $\sim$ E. $\sim$ Maggio. (1996) Point substitution in the central hydrophobic cluster of a human $\{\beta\}$-amyloid congener disrupts peptide folding and abolishes plaque competence., Biochemistry. 35, 13914-13921.

(11) Török, M., Milton, S., Kayed, R., Wu, P., McIntire, T., Glabe, C. G., and Langen, R. (2002) Structural and dynamic features of Alzheimer's A $\beta$ peptide in amyloid fibrils studied by sitedirected spin labeling, J. Biol. Chem. 277, 40810-40815.

(12) Petkova, A. T., Leapman, R. D., Guo, Z. H., Yau, W.-M. M., Mattson, M. P., and Tycko, R. (2005) Self-propagating, molecular-level polymorphism in Alzheimer's beta-amyloid fibrils, Science (80-. ). 307, 262-265.

(13) Antzutkin, O. N., Balbach, J. J., Leapman, R. D., Rizzo, N. W., Reed, J., and Tycko, R. (2000) Multiple quantum solid-state NMR indicates a parallel, not antiparallel, organization of beta -sheets in Alzheimer's beta -amyloid fibrils, Proc. Natl. Acad. Sci. 97, 13045-13050. 
(14) Tycko, R. (206AD) Solid state NMR as a probe of amyloid structure, Protein Pept Lett 13, 229-234.

(15) Pastor, M. T., Kuemmerer, N., Schubert, V., Esteras-Chopo, A., Dotti, C. G., de la Paz, M. L., and Serrano, L. (2008) Amyloid toxicity is independent of polypeptide sequence, length and chirality, J. Mol. Biol. 375, 695-707.

(16) Pifer, P. M., Yates, E. a., and Legleiter, J. (2011) Point mutations in A $\beta$ result in the formation of distinct polymorphic aggregates in the presence of lipid bilayers, PLoS One 6.

(17) Lazo, N. D., Grant, M. a., Condron, M. C., Rigby, A. C., and Teplow, D. B. (2009) On the nucleation of amyloid $\beta$-protein monomer folding, Protein Sci. 14, 1581-1596.

(18) Petkova, A. T., Ishii, Y., Balbach, J. J., Antzutkin, O. N., Leapman, R. D., Delaglio, F., and Tycko, R. (2002) A structural model for Alzheimer's -amyloid fibrils based on experimental constraints from solid state NMR, Proc. Natl. Acad. Sci. 99, 16742-16747.

(19) Lührs, T., Ritter, C., Adrian, M., Riek-Loher, D., Bohrmann, B., Döbeli, H., Schubert, D., and Riek, R. (2005) 3D structure of Alzheimer's amyloid- $\beta(1-42)$ fibrils***, Proc. Natl. Acad. Sci. U. S. A. 102, 17342-17347.

(20) Tycko, R. (2015) Amyloid Polymorphism: Structural Basis and Neurobiological Relevance, Neuron 86, 632-645.

(21) Das, P., Murray, B., and Belfort, G. (2015) Alzheimer's protective A2T mutation changes the conformational landscape of the A $\beta 1-42$ monomer differently than does the A2V mutation, Biophys. J. 108, 738-747.

(22) Chen, Z., Krause, G., and Reif, B. (2005) Structure and orientation of peptide inhibitors bound to beta-amyloid fibrils, J. Mol. Biol. 354, 760-776.

(23) Sinha, S., Lopes, D. H. J., and Bitan, G. A Key Role for Lysine Residues in Amyloid $\beta$ Protein Folding, Assembly, and Toxicity.

(24) Strandberg, E., and Killian, J. A. (2003) Snorkeling of lysine side chains in transmembrane helices: How easy can it get?, FEBS Lett. 544, 69-73.

(25) Niu, Z., Zhang, Z., Zhao, W., and Yang, J. (2018) Interactions between amyloid $\beta$ peptide and lipid membranes, Biochim. Biophys. Acta-Biomembr. 1860, 1663-1669.

(26) Henry, S., Vignaud, H., Bobo, C., Decossas, M., Lambert, O., Harte, E., Alves, I. D., Cullin, C., and Lecomte, S. (2015) Interaction of A $\beta$ 1-42 Amyloids with Lipids Promotes "OffPathway" Oligomerization and Membrane Damage, Biomacromolecules 16, 944-950.

(27) Niu, Z., Zhao, W., Zhang, Z., Xiao, F., Tang, X., and Yang, J. (2014) The Molecular Structure of Alzheimer $\beta$-Amyloid Fibrils Formed in the Presence of Phospholipid Vesicles, Angew. Chemie Int. Ed. 53, 9294-9297.

(28) Cheng, Q., Hu, Z. W., Doherty, K. E., Tobin-Miyaji, Y. J., and Qiang, W. (2018) The onfibrillation-pathway membrane content leakage and off-fibrillation-pathway lipid mixing induced 
by 40-residue $\beta$-amyloid peptides in biologically relevant model liposomes, Biochim. Biophys. Acta-Biomembr. 0-1.

(29) Wong, P. T., Schauerte, J. A., Wisser, K. C., Ding, H., Lee, E. L., Steel, D. G., and Gafni, A. (2009) Amyloid- $\beta$ Membrane Binding and Permeabilization are Distinct Processes Influenced Separately by Membrane Charge and Fluidity, J. Mol. Biol. 386, 81-96.

(30) Bokvist, M., Lindström, F., Watts, A., and Gröbner, G. (2004) Two Types of Alzheimer's $\beta$-Amyloid (1-40) Peptide Membrane Interactions: Aggregation Preventing Transmembrane Anchoring Versus Accelerated Surface Fibril Formation, J. Mol. Biol. 335, 1039-1049.

(31) Relini, A., Marano, N., and Gliozzi, A. (2014) Probing the interplay between amyloidogenic proteins and membranes using lipid monolayers and bilayers, Adv. Colloid Interface Sci. 207, $81-92$.

(32) Connelly, L., Jang, H., Teran Arce, F., Capone, R., Kotler, S. A., Ramachandran, S., Kagan, B. L., Nussinov, R., and Lal, R. (2012) Atomic force microscopy and MD simulations reveal pore-like structures of all-d-enantiomer of Alzheimer's $\beta$-amyloid peptide: Relevance to the ion channel mechanism of AD pathology, J. Phys. Chem. B 116, 1728-1735.

(33) Chi, E. Y., Ege, C., Winans, A., Majewski, J., Wu, G., Kjaer, K., and Lee, K. Y. C. (2008) Lipid membrane templates the ordering and induces the fibrillogenesis of Alzheimer's disease amyloid- $\beta$ peptide, Proteins Struct. Funct. Genet. 72, 1-24.

(34) Ege, C., Majewski, J., Wu, G., Kjaer, K., and Lee, K. Y. C. (2005) Templating effect of lipid membranes on Alzheimer's amyloid beta peptide, ChemPhysChem 6, 226-229.

(35) Jang, H., Zheng, J., and Nussinov, R. (2007) Models of $\beta$-amyloid ion channels in the membrane suggest that channel formation in the bilayer is a dynamic process, Biophys. J. 93, 1938-1949.

(36) Sabaté, R., Espargaró, A., Barbosa-Barros, L., Ventura, S., and Estelrich, J. (2012) Effect of the surface charge of artificial model membranes on the aggregation of amyloid $\beta$-peptide, Biochimie 94, 1730-1738.

(37) Burke, K. A., Yates, E. A., and Legleiter, J. (2013) Biophysical insights into how surfaces, including lipid membranes, modulate protein aggregation related to neurodegeneration, Front. Neurol. 4, 1-17.

(38) Berthelot, K., Cullin, C., and Lecomte, S. (2013) What does make an amyloid toxic: Morphology, structure or interaction with membrane?, Biochimie.

(39) Sani, M. A., Gehman, J. D., and Separovic, F. (2011) Lipid matrix plays a role in Abeta fibril kinetics and morphology, FEBS Lett. 585, 749-754.

(40) Yun, S., Urbanc, B., Cruz, L., Bitan, G., Teplow, D. B. B., and Stanley, H. E. E. (2007) Role of electrostatic interactions in amyloid $\beta$-protein $(A \beta)$ oligomer formation: A discrete molecular dynamics study, Biophys. J. 92, 4064-4077.

(41) Urbanc, B., Betnel, M., Cruz, L., Bltan, G., and Teplow, D. B. (2010) Elucidation of

3. Acetylation of $A \beta_{40}$ alters aggregation in the presence and absence of lipid membranes 
amyloid $\beta$-protein oligomerization mechanisms: Discrete molecular dynamics study, $J$. Am. Chem. Soc. 132, 4266-4280.

(42) Burke, K. A., Yates, E. A., and Legleiter, J. (2013) Amyloid-Forming Proteins Alter the Local Mechanical Properties of Lipid Membranes, Biochemistry 52, 808-817.

(43) Quist, A., Doudevski, I., Lin, H., Azimova, R., Ng, D., Frangione, B., Kagan, B., Ghiso, J., and Lal, R. (2005) Amyloid ion channels: a common structural link for protein-misfolding disease., Proc. Natl. Acad. Sci. U. S. A. 102, 10427-10432.

(44) Yates, E. A., Cucco, E. M., and Legleiter, J. (2011) Point mutations in A $\beta$ induce polymorphic aggregates at liquid/solid interfaces, ACS Chem. Neurosci. 2, 294-307.

(45) Abdolvahabi, A., Shi, Y., Rasouli, S., Croom, C. M., Chuprin, A., and Shaw, B. F. (2017) How Do Gyrating Beads Accelerate Amyloid Fibrillization ?, Biophysj 112, 250-264.

(46) Nielsen, L., Khurana, R., Coats, A., Frokjaer, S., Brange, J., Vyas, S., Uversky, V. N., and Fink, A. L. (2001) Effect of environmental factors on the kinetics of insulin fibril formation: Elucidation of the molecular mechanism, Biochemistry 40, 6036-6046.

(47) Gade Malmos, K., Blancas-Mejia, L. M., Weber, B., Buchner, J., Ramirez-Alvarado, M., Naiki, H., and Otzen, D. (2017) ThT 101: a primer on the use of thioflavin T to investigate amyloid formation, Amyloid.

(48) Burke, K. A., Godbey, J., and Legleiter, J. (2011) Assessing mutant huntingtin fragment and polyglutamine aggregation by atomic force microscopy, Methods 53, 275-284.

(49) Markoutsa, S., Bahr, U., Papasotiriou, D. G., Häfner, A.-K., Karas, M., and Sorg, B. L. (2014) Sulfo-NHS-SS-biotin derivatization: A versatile tool for MALDI mass analysis of PTMs in lysine-rich proteins, Proteomics 14, 659-667.

(50) Mendoza, V. L., Barón-Rodríguez, M. A., Blanco, C., and Vachet, R. W. (2011) Structural insights into the pre-amyloid tetramer of $\beta$-2-microglobulin from covalent labeling and mass spectrometry, Biochemistry 50, 6711-6722.

(51) Lindberg, D. J., Wesén, E., Björkeroth, J., Rocha, S., and Esbjörner, E. K. (2017) Lipid membranes catalyse the fibril formation of the amyloid- $\beta(1-42)$ peptide through lipid-fibril interactions that reinforce secondary pathways, Biochim. Biophys. Acta-Biomembr. 1859, 19211929.

(52) Liu, A., Wenzel, N., and Qi, X. (2005) Role of lysine residues in membrane anchoring of saposin C, Arch. Biochem. Biophys. 443, 101-112.

(53) Herce, H. D., and Garcia, A. E. (2007) Cell penetrating peptides: how do they do it?, J. Biol. Phys. 33, 345-356.

(54) Yount, N. Y., Bayer, A. S., Xiong, Y. Q., and Yeaman, M. R. (2006) Advances in Antimicrobial Peptide Immunobiology, Pept. Sci. 84, 435-458.

(55) Legleiter, J., Fryer, J. D., Holtzman, D. M., and Kowalewski, T. (2011) The Modulating

3. Acetylation of $A \beta_{40}$ alters aggregation in the presence and absence

of lipid membranes 
Effect of Mechanical Changes in Lipid Bilayers Membrane Disruption, ACS Chem. Neurosci 2, 588-599.

(56) Eugene, T. C., Hall, C., Virginia, W., Box, P. O., Virginia, W., and States, U. (2014) Preparation Protocols of A $\beta(1-40)$ Promote the Formation of Polymorphic Aggregates and Altered Interactions with Lipid Bilayers.

(57) Hellstrand, E., Sparr, E., and Linse, S. (2010) Retardation of A $\beta$ fibril formation by phospholipid vesicles depends on membrane phase behavior, Biophys. J. 98, 2206-2214.

(58) Sciacca, M. F. M., Kotler, S. A., Brender, J. R., Chen, J., Lee, D. K., and Ramamoorthy, A. (2012) Two-step mechanism of membrane disruption by $A \beta$ through membrane fragmentation and pore formation, Biophys. J. 103, 702-710.

(59) Sparr, E., Chia, S., Kumita, J. R., Sanguanini, M., Vendruscolo, M., Idini, I., Bellaiche, M. M. J., Michaels, T. C. T., Dobson, C. M., Knowles, T. P. J., Galvagnion, C., Linse, S., Ruggeri, F. S., and Habchi, J. (2018) Cholesterol catalyses A $\beta 42$ aggregation through a heterogeneous nucleation pathway in the presence of lipid membranes, Nat. Chem. 10, 673-683.

(60) Malishev, R., Nandi, S., Kolusheva, S., Levi-Kalisman, Y., Klärner, F.-G., Schrader, T., Bitan, G., and Jelinek, R. (2015) Toxicity Inhibitors Protect Lipid Membranes from Disruption by A 342, ACS Chem. Neurosci. 6, 1860-1869.

(61) Matsuzaki, K. (2007) Physicochemical interactions of amyloid $\beta$-peptide with lipid bilayers, Biochim. Biophys. Acta - Biomembr. 1768, 1935-1942.

(62) Terzi, E., Hölzemann, G., and Seelig, J. (1997) Interaction of Alzheimer $\beta$-amyloid peptide(1-40) with lipid membranes., Biochemistry 36, 14845-14852.

(63) Pilkington, A. W., Donohoe, G. C., Akhmedov, N. G., Ferrebee, T., Valentine, S. J., and Legleiter, J. (2019) Hydrogen peroxide modifies A $\beta$-membrane interactions with implications for A $\beta 40$ aggregation, Biochemistry acs.biochem.9b00233.

(64) Zhang, S., Iwata, K., Lachenmann, M. J., Peng, J. W., Li, S., Stimson, E. R., Lu, Y. A., Felix, A. M., Maggio, J. E., and Lee, J. P. (2000) The Alzheimer's peptide A $\beta$ adopts a collapsed coil structure in water, J. Struct. Biol. 130, 130-141.

(65) WALSH, D. M., HARTLEY, D. M., CONDRON, M. M., SELKOE, D. J., and TEPLOW, D. B. (2015) In vitro studies of amyloid $\beta$-protein fibril assembly and toxicity provide clues to the aetiology of Flemish variant (Ala692 $\rightarrow$ Gly) Alzheimer's disease, Biochem. J. 355, 869-877.

(66) Meinhardt, J., Tartaglia, G. G., Pawar, A., Christopeit, T., Hortschansky, P., Schroeckh, V., Dobson, C. M., Vendruscolo, M., and Fändrich, M. (2007) Similarities in the thermodynamics and kinetics of aggregation of disease-related A $\beta(1-40)$ peptides, Protein Sci. 16, 1214-1222.

(67) Rousseau, F., Schymkowitz, J., Serrano, L., and Fernandez-Escamilla, A.-M. (2004) Prediction of sequence-dependent and mutational effects on the aggregation of peptides and proteins., Nat. Biotechnol. 22, 1302-6.

(68) Shuaib, S., Saini, R. K., Goyal, D., and Goyal, B. (2019) Impact of K16A and K28A

3. Acetylation of $A \beta_{40}$ alters aggregation in the presence and absence

of lipid membranes 
mutation on the structure and dynamics of amyloid- $\beta 42$ peptide in Alzheimer's disease: key insights from molecular dynamics simulations, J. Biomol. Struct. Dyn. 1102.

(69) Mithu, V. S., Sarkar, B., Bhowmik, D., Das, A. K., Chandrakesan, M., Maiti, S., and Madhu, P. K. (2014) Curcumin alters the salt bridge-containing turn region in amyloid $\beta(1-42)$ aggregates, J. Biol. Chem. 289, 11122-11131.

(70) Tian, Y., Zhang, X., Li, Y., Shoup, T. M., Teng, X., Elmaleh, D. R., Moore, A., and Ran, C. (2014) Crown ethers attenuate aggregation of amyloid beta of Alzheimer's disease, Chem. Commun. 50, 15792-15795.

(71) Ladiwala, A. R. A., Lin, J. C., Bale, S. S., Marcelino-Cruz, A. M., Bhattacharya, M., Dordick, J. S., and Tessier, P. M. (2010) Resveratrol selectively remodels soluble oligomers and fibrils of amyloid A $\beta$ into off-pathway conformers, J. Biol. Chem. 285, 24228-24237.

(72) Sinha, S., Lopes, D. H. J., Du, Z., Pang, E. S., Shanmugam, A., Lomakin, A., Talbiersky, P., Tennstaedt, A., McDaniel, K., Bakshi, R., Kuo, P. Y., Ehrmann, M., Benedek, G. B., Loo, J. A., Klärner, F. G., Schrader, T., Wang, C., and Bitan, G. (2011) Lysine-specific molecular tweezers are broad-spectrum inhibitors of assembly and toxicity of amyloid proteins, J. Am. Chem. Soc.

(73) Saini, R. K., Shuaib, S., Goyal, D., and Goyal, B. (2018) Insights into the inhibitory mechanism of a resveratrol and clioquinol hybrid against $A \beta 42$ aggregation and protofibril destabilization: A molecular dynamics simulation study, J. Biomol. Struct. Dyn. 1102.

(74) Sciarretta, K. L., Gordon, D. J., Petkova, A. T., Tycko, R., and Meredith, S. C. (2005) A $340-\operatorname{lactam}(\mathrm{D} 23 / \mathrm{K} 28)$ models a conformation highly favorable for nucleation of amyloid, Biochemistry 44, 6003-6014.

(75) Thirumalai, D., Reddy, G., and Straub, J. E. (2012) Role of water in protein aggregation and amyloid polymorphism, Acc. Chem. Res. 45, 83-92.

(76) Choudhury, N., and Pettitt, B. M. (2007) The dewetting transition and the hydrophobic effect, J. Am. Chem. Soc. 129, 4847-4852.

(77) Lacor, P. N. (2004) Synaptic targeting by Alzheimer's-Related Amyloid $\beta$ oligomers, $J$. Neurosci. 24, 10191-10200.

(78) Lesné, S., Ming, T. K., Kotilinek, L., Kayed, R., Glabe, C. G., Yang, A., Gallagher, M., and Ashe, K. H. (2006) A specific amyloid- $\beta$ protein assembly in the brain impairs memory, Nature $440,352-357$.

(79) Lacor, P. N., Buniel, M. C., Furlow, P. W., Sanz Clemente, A., Velasco, P. T., Wood, M., Viola, K. L., Klein, W. L., Pascale N. Lacor, Maria C. Buniel, Paul W. Furlow, Antonio Sanz Clemente, Pauline T. Velasco, Margaret Wood, Kirsten L. Viola, and W. L. K., Lacor, P. N., Buniel, M. C., Furlow, P. W., Clemente, A. S., Velasco, P. T., Wood, M., Viola, K. L., and Klein, W. L. (2007) A beta oligomer-induced aberrations in synapse composition, shape, and density provide a molecular basis for loss of connectivity in Alzheimer's disease, J. Neurosci. 27, 796-807.

(80) Velasco, P. T., Heffern, M. C., Sebollela, A., Popova, I. A., Lacor, P. N., Lee, K. B., Sun, 
X., Tiano, B. N., Viola, K. L., Eckermann, A. L., Meade, T. J., and Klein, W. L. (2012) SynapseBinding Subpopulations of A beta Oligomers Sensitive to Peptide Assembly Blockers and scFv Antibodies, Acs Chem. Neurosci. 3, 972-981.

(81) Ryan, T. M., Roberts, B. R., McColl, G., Hare, D. J., Doble, P. A., Li, Q.-X. Q.-X., Lind, M., Roberts, A. M., Mertens, H. D. T., Kirby, N., Pham, C. L. L., Hinds, M. G., Adlard, P. A., Barnham, K. J., Curtain, C. C., and Masters, C. L. (2015) Stabilization of Nontoxic A betaOligomers: Insights into the Mechanism of Action of Hydroxyquinolines in Alzheimer's Disease, J. Neurosci. 35, 2871-2884.

(82) Zheng, X., Liu, D., Klärner, F. G., Schrader, T., Bitan, G., and Bowers, M. T. (2015) Amyloid $\beta$-Protein Assembly: The Effect of Molecular Tweezers CLR01 and CLR03, J. Phys. Chem. B 119, 4831-4841.

(83) ALFONSO, Llyod. (2010) Does aspirin acetylate multiple cellular proteins?, Mol. Med. 2, 533-537.

(84) Roth, G. J., Stanford, N., and Majerus, P. W. (1975) Acetylation of prostaglandin synthase by aspirin., Proc. Natl. Acad. Sci. 72, 3073-3076.

(85) Xu, A. S. L., Macdonald, J. M., Labotka, R. J., and London, R. E. (1999) NMR study of the sites of human hemoglobin acetylated by aspirin, Biochim. Biophys. Acta-Protein Struct. Mol. Enzymol. 1432, 333-349.

(86) Etminan, M. (2003) Effect of non-steroidal anti-inflammatory drugs on risk of Alzheimer's disease: systematic review and meta-analysis of observational studies, Bmj 327, 128-0.

(87) Yoshiike, Y., Akagi, T., and Takashima, A. (2007) Surface structure of amyloid- $\beta$ fibrils contributes to cytotoxicity, Biochemistry 46, 9805-9812.

(88) Ayyadevara, S., Balasubramaniam, M., Kakraba, S., Alla, R., Mehta, J. L., and Shmookler Reis, R. J. (2017) Aspirin-Mediated Acetylation Protects Against Multiple Neurodegenerative Pathologies by Impeding Protein Aggregation, Antioxid. Redox Signal. 27, 1383-1396.

(89) Harris, J. R. (2002) In vitro fibrillogenesis of the amyloid $\beta 1-42$ peptide: Cholesterol potentiation and aspirin inhibition, Micron 33, 609-626.

(90) Ayyadevara, S., Bharill, P., Dandapat, A., Hu, C., Khaidakov, M., Mitra, S., Shmookler Reis, R. J., and Mehta, J. L. (2012) Aspirin Inhibits Oxidant Stress, Reduces Age-Associated Functional Declines, and Extends Lifespan of Caenorhabditis elegans, Antioxid. Redox Signal. $18,481-490$.

(91) Vane, J. R., and Botting, R. M. (2003) The mechanism of action of aspirin., Thromb. Res. $110,255-8$.

(92) Straub, J. E., and Thirumalai, D. (2014) Membrane-protein interactions are key to understanding amyloid formation, J. Phys. Chem. Lett. 5, 633-635.

(93) Vestergaard, M. (1996) Using Model Membranes for the Study of Amyloid Beta:Lipid Interactions and Neurotoxicity [Citation Wrong], J. Anat. 189 ( Pt 3, 503-505. 
(94) Butterfield, S. M., and Lashuel, H. A. (2010) Amyloidogenic protein-membrane interactions: Mechanistic insight from model systems, Angew. Chemie - Int. Ed. 49, 5628-5654.

(95) Williams, T. L., and Serpell, L. C. (2011) Membrane and surface interactions of Alzheimer's A $\beta$ peptide - Insights into the mechanism of cytotoxicity, FEBS J. 278, 3905-3917.

(96) Hamley, I. W. (2012) The Amyloid Beta Peptide : A Chemist's Perspective Role in Alzheimer's and Fibrillization. 


\section{Outlook: Future directions for advancing the understanding of A aggregation in Alzheimer's disease}

The proposed studies presented here are focused on gaining actionable information about preparatory conditions of $A \beta$ for studying aggregation, developing new tools for research of $\mathrm{A} \beta \mathrm{O}$ dynamics and structure, and exploring the role of a protective mutation on peptidemembrane interactions. By extracting trends about $\mathrm{A} \beta$ preparatory protocols, insights can be gained into environmental changes that influence the self-assembly of $A \beta$, toxic mechanisms or promote more stable forms of oligomers. This information could be used for the advancement of BODIPY based oligomer specific dyes. The development of fluorescent small molecule oligomer specific dyes would allow for real-time tracking of $\mathrm{A} \beta \mathrm{O}$ s formation, which is a current limitation in the field. The use of BODIPY oligomer specific dyes would also facilitate a high throughput methodology for screening therapeutics or stabilizing conditions for structural studies of AßOs. Also, we explore the idea of preserving isotope enriched $A \beta$ in a heterogenic oligomer with a delayed transition towards fibril structures. The success of this technique could assist in the future development of more specific fluorescent dyes and provide knowledge of the threedimensional structure of $\mathrm{A} \beta \mathrm{O}$, which is still currently unknown. Lastly, we contemplate a study designed to explore a protective mutation in $\mathrm{AD}$ and understand how its protective effects are tied to aggregation, morphology, and peptide-membrane interactions. Collectively these future projects are designed to address issues within the field and provide new tools and knowledge to advance the treatment of AD.

4. Outlook: Future directions for advancing the understanding of $A \beta$ 


\subsection{Introduction}

Alzheimer's disease is a neurodegenerative disease that currently affects 5.4 million Americans.

${ }^{1}$ The classical neuropathology of $\mathrm{AD}$ is characterized as the formation of extracellular senile plaques and intercellular neurofibrillary tangles. ${ }^{2}$ A significant amount of effort has focused on the formation of senile plaques and earlier aggregate species of $A \beta$ as the neurotoxic culprit, according to the amyloid cascade hypothesis. ${ }^{3,4}$ While there are indeed genetic links to AD, that cause early-onset $\mathrm{AD}$, these are rare and only account for $5 \%$ of all $\mathrm{AD}$-related cases. ${ }^{1}$ To date no genetic linkage or biomarkers have surfaced within the other percentage of the patient group, and the cause of $\mathrm{AD}$ still remains elusive. ${ }^{5}$ Currently, the largest risk factor for $\mathrm{AD}$ is aging, and $95 \%$ of all cases occur within the elderly demographic. ${ }^{1}$ Therapeutic strategies and clinical trials have focused on both reducing the expression of $A \beta$ and breaking up the existing aggregates within the brain. ${ }^{3}$ So far these efforts have mainly been unsuccessful, ${ }^{3,6-11}$ and the search for a common cause or mechanism of sAD is ongoing.

$\mathrm{A} \beta$ is commonly post-translationally modified in the brain tissue and cerebrospinal fluid of $\mathrm{AD}$ patients, ${ }^{12}$ As hyperphosphorylation of tau is a known trigger for tau's aggregation, it is likely that PTMs of A $\beta$ trigger and modify amyloid formation. As an experimental methodology, PTMs represent valuable tools to probe the individual roles of specific amino acids on the selfassembly and other physiologically relevant interactions of $A \beta$.

One of the most well-known PTMs of $A \beta$ is the oxidation of Met35 to its sulfoxide derivative. Due to the increase in reactive oxygen species associated with aging, oxidation of $A \beta$ is elevated in patients of $\mathrm{AD} \cdot{ }^{13,14}$ In Chapter 2, the aim was to determine how changes in the oxidative environment associated with aging affected the aggregation of $A \beta$ in the absence or presence of TBLE. This study demonstrated that exposing $A \beta_{40}$ to $\mathrm{H}_{2} \mathrm{O}_{2}$ post-translationally 4. Outlook: Future directions for advancing the understanding of $A \beta$ aggregation in Alzheimer's disease 
modified Met35 to its singly oxidized sulfoxide derivative, $\mathrm{A} \beta_{40} \mathrm{Met} 35[\mathrm{O}]$, as verified with MS and NMR. The percentage of $A \beta_{40} \operatorname{Met} 35[\mathrm{O}]$ was found to be dependent on the $\mathrm{H}_{2} \mathrm{O}_{2}$ concentration with increases in the $\mathrm{H}_{2} \mathrm{O}_{2}$ producing a higher percentage of $\mathrm{A} \beta_{40}$ Met35[O]. This post-translational modification of methionine in the absence of lipids showed reductions in the slope of the growth phase, indicating a decrease in the elongation rate of fibril ends, and a reduction in the magnitude of fibril formation, but no significant changes in the lag phase time. AFM analysis of $A \beta$ aggregation under increasing concentrations of $\mathrm{H}_{2} \mathrm{O}_{2}$ also revealed that the oligomerization of $\mathrm{A} \beta$ was not inhibited, but structural transitions towards parallel $\beta$-sheet structures were inhibited. Further evidence from the AFM also demonstrated the presence of polymorphic fibrils in the presence of $6.0 \mathrm{mM} \mathrm{H} \mathrm{H}_{2} \mathrm{O}_{2}$. However, when kinetic assays were performed in the presence of membranes, $A \beta_{40}$ exposed to higher concentrations of $\mathrm{H}_{2} \mathrm{O}_{2}$ correlated with less peptide-membrane interactions, and it was determined that the oxidation state of total brain lipid (TBLE) vesicles largely modulated the peptide-membrane interaction.

Acetylation of $A \beta$ is not a physiologically observed PTM of $A \beta$; however, the ability to chemically modify lysine makes it an attractive target for studying the role of that cationic character of lysine in $A \beta$ aggregation. $A \beta$ contains two lysine residues, $K 16$ and K28, both of which are known to form intermolecular salt bridges in $A \beta$ amyloid structures. ${ }^{15-18}$ In Chapter 3, we sought to determine how the removal of lysine's cationic charge through acetylation would alter $A \beta_{40}$ aggregation in the presence and absence of lipid membranes. Here we demonstrated that acetylation of $\mathrm{A} \beta$ readily occurs at the more solvent exposed $\mathrm{K} 16^{19}$ while $\mathrm{K} 28$ is acetylated at higher concentrations of NHSA. The acetylation of $A \beta$ was shown to increase the lag-phase of $\mathrm{A} \beta_{40}$ while also reducing the magnitude of fibril formation to the point that at $1.0 \mathrm{mM}$ NHSA and $1.5 \mathrm{mM}$ NHSA fibril formation was completely inhibited. AFM analysis of acetylated A $\beta_{40}$ 
also showed a marked reduction in the number of oligomers formed, demonstrating that fibril formation and oligomerization are both inhibited by acetylation. Morphological height analysis of $A \beta$ fibrils formed under milder acetylating conditions indicated the absence of any polymorphisms suggesting fibril inhibition may be impart due to the prevention of $A \beta$ to form salt bridges and participate in fibril formation. However, the presence of TBLE lipid vesicles promoted the aggregation of acetylated forms of $A \beta_{40}$ with a decreased lag-phase and extent of fibril formation for all acetylating concentrations. The reduction in the lag-phase compared to the control of $A \beta_{40}$ was found to arise from the decrease in the total $A \beta$-membrane interactions as assessed by PDA. Lastly, the presence of TBLE under NHSA concentrations of $1.0 \mathrm{mM}$ and 1.5 $\mathrm{mM}$ NHSA promoted the formation of a distinct annular aggregate species. Collectively the work of Chapter 3, suggested that the oligomerization and fibril formation of $A \beta$ is highly dependent on the cationic charge of lysines and that under the influence of membrane surfaces the mechanism of $A \beta$ aggregation is alter.

As there is still no treatment for $\mathrm{AD}$, continued research into the root causes of this disease are warranted. Here, several issues still facing the field will be discussed in context of the experimental results presented in this dissertation. These persisting issues in the field include: 1) the inconsistency of $A \beta$ disaggregation and preparation protocols that complicate analysis across literature reports; 2) the inability to monitor oligomer formation in real-time in a high throughput manner; and 3) unraveling the structure of oligomeric $A \beta$ species. 


\subsection{Meta-analysis of A $\beta$ sample preparation and experimental outcomes}

Preparation protocols of $A \beta$ typically involves three steps; disaggregation, reconstitution, and dilution into buffering system, but the choice in the protocol used can alter experimental outcomes. ${ }^{20}$ While several methods for the disaggregation of $\mathrm{A} \beta$ exists reproducibility across labs, manufactures, and batches of $A \beta$ is poor. ${ }^{21,22}$ To overcome this many laboratories use hydrogen bond disrupting alcohols, strong acids, strong bases, or organic solvents such as hexafluoroisopropanol (HFIP), trifluoroacetic acid (TFA), ammonia, or dimethyl sulfoxide (DMSO). Next, A $\beta$ is reconstituted in a secondary step before being diluted into a buffer. The disaggregation and solubilization protocols vary from laboratory to laboratory and complicate the ability to compare results. ${ }^{23,24}$ These differences in experimental outcomes can include changes in kinetic measurements, ${ }^{25}$ morphology, ${ }^{26,27}$ secondary structural transitions, ${ }^{28}$ membrane interactions, ${ }^{38}$ and toxicity. ${ }^{25,28}$ Ultimately, the irreproducibility of results create controversy within the field, and attempts to standardize a methodology will not be applicable to all experiments. ${ }^{29}$

In Chapter $2 \mathrm{~A} \beta$ was disaggregated with ammonium hydroxide and reconstituted with a $60 \mathrm{mM} \mathrm{NaOH}$ solution to obtain a monomeric stock of $\mathrm{A} \beta_{40}$. This was a deviation from the typical A $\beta$ preparation protocol that had been historically used in the Legleiter laboratory, which was based on the 'Stine prep' (disaggregation of A $\beta$ with HFIP and solubilizing in DMSO). ${ }^{30}$ As DMSO is a radical quencher of $\mathrm{H}_{2} \mathrm{O}_{2}$, the 'Stine prep' was not suitable for our experiments. The 'Stine prep' produces fibrils of $\sim 6 \mathrm{~nm}$ thick and exhibited accelerated fibril formation in the presence of TBLE; whereas, the protocol used in Chapter 2 and 3 resulted in fibrils that where $\sim 3$ $\mathrm{nm}$ in width, and reduced rates of fibril formation in the presence of TBLE. Furthermore, the lag phase of control $A \beta$ aggregation reactions increased in studies reported in Chapter 3 compared to 
those reported in Chapter 2. This change was the result in differences in the synthesized A $\beta$ peptides associated with different suppliers. The $A \beta_{40}$ in Chapter 3 had a counterion of TFA as opposed to $\mathrm{NH}_{4}{ }^{+}$in Chapter 2. Ultimately the problem lies in the lack of knowledge of how preparation protocols of $A \beta$ influences results. Understanding how changes in the preparation of $\mathrm{A} \beta$ alters aggregation could provide insights into how multiple conditions affect aggregation and could allow for experimental designs that would probe variations in aggregation.

A possible solution to this issue could come in the form of a combinational approach utilizing data mining and establishing a convenient method for the field to compare experimental results. To discover connections between the varied preparations of $A \beta$ and provide the ability to directly compare results across laboratories, a two-stage approach could be taken. The first stage, acquisition of data, would require the entry of research findings into a database that would catalog entries based on the preparatory steps used, kinetic parameters, toxicity results, structural observations, etc. Databases could be built by extracting relevant research articles from journal services and incorporating pdf into our own database. The biggest hurdle to overcome would be getting copyright permission from journal services as the methods sections containing $A \beta$ preparation is not freely available like abstracts, however many journals have been amenable to such studies recently. In addition, data mining could then be performed to search our databases to look for similarities in results and trends that may not be readily observable between across disciplines. This may provide useful insights into the aggregation differences between expressed or synthetic $A \beta$ and HFIP or alkaline disaggregated $A \beta$.

The second stage would be to make the data freely available to scientist via a web-based interface. This web portal would allow for scientist to search based on a broad range of experimental outcomes, preparations, cellular models, etc. In addition to providing this service, 
other scientist would be freely able to upload their results with links to their research to grow the datasets. The entries from the point of view of the scientist would be convenient/simple and would be comprised of a simple questionnaire that allows the researcher to enter in the disaggregation, reconstitution, and miscellaneous protocols used for their experiment. This would be beneficial over requiring the uploading of raw data into which can be time-consuming.

Lastly, once this information becomes more available and widely used the expansion of the database could include other amyloidogenic proteins such as $\alpha$-synuclein and Huntingtin, providing a more significant impact beyond that of just Alzheimer's disease. Many scientific databases have proven useful to the scientific community such as the Spectral Database for Organic Compounds and the Protein Data Bank. Ultimately, it is with this aggregation of data into a centralized location that would allow for the extraction of information and trends among A $\beta$ preparations that may provide actionable information that could further be experimentally tested in the laboratory.

\subsection{Real-Time tracking of A $\beta$ oligomerization}

Environmental conditions, preparation, and the presence of membrane surfaces all affect the oligomerization of $A \beta$. Atomic force microscopy (AFM) and electron microscopy (EM) provide the capability to track $\mathrm{A} \beta \mathrm{O}$ formation. In particular, AFM is a particularly useful technique in studying $\mathrm{A} \beta \mathrm{O}$ formation and morphology $\mathrm{y}^{31-41}$ as it can be operate at physiologically relevant conditions. Immunohistostaining of toxic A $\beta O$ s also appear to react with oligomerspecific antibodies like A11 (generic for amyloid oligomers in general). ${ }^{42}$ In Chapter 2 and 3 we used the state of the art technique of AFM to track oligomer formation, but our methods and others are limited by their ability to finely resolve the kinetics of $\mathrm{A} \beta \mathrm{O}$ formation. Therefore, new tools that can allow us to track the kinetics of $\mathrm{A} \beta \mathrm{O}$ in real-time would fill a current gap in 4. Outlook: Future directions for advancing the understanding of $A \beta$ aggregation in Alzheimer's disease 
understanding the dynamics of oligomer formation. A promising method for achieving real-time tracking of $A \beta O$ s is the use of BODIPY base derivatives.

Specifically in Chapter 3 AFM was also used to visualize the inhibition of A $\beta O$ formation when $\mathrm{A} \beta$ was acetylated, however our results differed from Sinha et al who observed the oligomerization of $A \beta_{40}[\mathrm{~K} 16 \mathrm{~A}]$, and $A \beta_{40}[\mathrm{~K} 28 \mathrm{~A}]$ which displayed similar oligomerization distributions to wild-type $A \beta_{40} .^{43}$ One possible reason for the discrepancy comes from detection limitations of the AFM which does not allow for the detection of oligomers smaller then hexamers, as observed by Sinha et al. In addition, using cross-linking methods, e.g. PICUP, or imaging with AFM limits the speed at which one can assess the dynamics of A $\beta O$ formation. In developing a tool that would allow for the detection of LMW and HMW A $\beta$ Os in real-time would be a vitally useful tool to all scientist studying $\mathrm{A} \beta \mathrm{O}$ formation. A promising strategy to develop this capability is using BODIPY based fluorescent dye that are selective for A $\beta$ Os.

Several straightforward spectroscopic assays are well-established to track formation and kinetic parameters of fibrils (e.g., thioflavin-T), but methods to easily track A $\beta O$ formation have been lacking. Recently, the use of 4,4-difluoro-4-bora-3a,4a-diaza-s-indacene (BODIPY) dyes have been utilized to detect the $\mathrm{A} \beta \mathrm{O}$ s in vitro fluorescently. ${ }^{44,45}$ These BODIPY fluorescent probes have high quantum yields with the capability of selectively binding to AßOs. ${ }^{46}$ Importantly, increases and decreases in the "BD-Oligo" dye fluorescence also correlated with increasing and decreasing intensities of the A11 antibody (generic for amyloid oligomers in general staining), directly relating this signal to an established method to detect $\mathrm{A} \beta \mathrm{Os}{ }^{67}$ In addition, the BD-Oligo dye can be used in parallel with ThT assays that detect fibril formation, allowing for the direct investigation of the correlation between oligomer and fibril formation. ${ }^{67}$ Rational design of BODIPY based dyes also allows for the the ability to selectivly target 4. Outlook: Future directions for advancing the understanding of $A \beta$ aggregation in Alzheimer's disease 
different aggregates of $A \beta$ or other amyloidgenic protiens. The design of a BODIPY-base dye (BAP-1) was successful in facilitating the direct visualization of $\mathrm{A} \beta$ plaques in transgenic mice, ${ }^{46}$ and rational modifications of BAP-1 also allowed for near-infrared selective detection of tau neurofibrillary tangles. ${ }^{47}$ The ability to rationally modify BODIPY dyes for fluorescent detection of specific aggregate species, the tunability of their spectroscopic properties, and their insensitivity to solvent and $\mathrm{pH}$ changes have made BODIPY dyes a recently promising avenue for high throughput studies.

Ultimately, the applications of a BODIPY dye derivative that is selective for AßOs are broad. BODIPY could replace expensive oligomeric antibodies providing the ability to stain gels, dot blots, slot blots, and tissue samples cheaply. BODIPY can also be applicable to studying the dynamics of $\mathrm{A} \beta \mathrm{O}$ formation which is limited in AFM and photo-cross-linking studies presented in Chapter 2, 3, and the work by Sinha et al. Modification of BODIPY dye derivatives may also prove useful in the application of distinguishing LMW and HMW A $\beta O$ s, though the failure to selectively distinguish these species would instead also provide an experimental overlap between HMW A $\beta \mathrm{O}$ measured in AFM studies, as presented in Chapter 2 and 3, and photo-cross-linking studies which focus more on LMW. Additionally, spectroscopic techniques such as superresolution microscopy and total internal reflection fluorescence microscope can utilized BODIPY probes to resolve accumulations of $\mathrm{A} \beta \mathrm{O}$ s at the membrane interface of cells through FRET pairing or track the dynamics of $\mathrm{A} \beta \mathrm{O}$ aggregation, transitions, and possible even trafficking and cerebral imaging in biological systems. Broadly, the development of a fluorescent molecule that selectively binds $\mathrm{A} \beta \mathrm{O}$ oligomers would be applicable to the discovering a fluorescent molecule like ThT which has proven to be a gold-standard in the development of assess $A \beta$ fibril formation, dynamics, and aggregation pathways. 


\subsection{Using reverse-phase micelles for structural studies of oligomeric Aß}

Enormous efforts have been expended in identifying the most toxic/disease-relevant $\mathrm{A} \beta \mathrm{O}$ species and the relevant underlying structure. ${ }^{48-50}$ This is a daunting endeavor due to the transient nature and extensive heterogeneity associated with $\mathrm{A} \beta \mathrm{O}$ s. ${ }^{51-53}$ It is possible that different $\mathrm{A} \beta \mathrm{O}$ species may activate different deleterious changes associated with $\mathrm{AD} ;{ }^{48-50}$ however, there may also be relatively benign $\mathrm{A} \beta \mathrm{O}$ species or even experimental artifacts. ${ }^{24,51,54}$ Unraveling the physiological activity of $\mathrm{A} \beta \mathrm{O}$ s may require separate analysis of these different species, which are

altered by preparatory protocols. ${ }^{32}$ In practice performing varied preparatory protocols can yield changes in rates of aggregation, polymorphism, and toxicity of $\mathrm{A} \beta \mathrm{Os} .{ }^{25,27,32}$

To facilitate structure/activity analysis, significant efforts have been made to obtain structural details of $\mathrm{A} \beta \mathrm{O}$ s using a variety of methods (Table 4.1). This is required to fully elucidate the modes of interaction of $\mathrm{A} \beta \mathrm{O}$ s with other, fluorescent molecules e.g. BODIPY, biomolecules, and related toxic mechanisms. ${ }^{55-60}$ Structural characterization of specific A $\beta O$ s is challenging due to their transient nature and heterogeneity. AßOs can exhibit conformational plasticity that can be heavily influenced by environmental factors, further complicating such analysis. 
Table 4.1. Methods used for analyzing A $\beta O s$.

\begin{tabular}{ll}
\hline Technique & Features of A $\beta$ Os Obtained \\
\hline Atomic Force Microscopy (AFM) & Morphology, population distributions \\
Electron Microscopy (EM) & Morphology, population distributions \\
Ion-Mobility Mass Spectrometry & Secondary structure, multimeric configurations \\
(IM-MS) & $\begin{array}{l}\text { Secondary structure, multimeric configurations, atomic } \\
\text { Nuclear Magnetic Resonance 2D } \\
\text { (NMR) }\end{array}$ \\
$\begin{array}{l}\text { Electron Paramagnetic Resonance } \\
\text { (EPR) }\end{array}$ & $\begin{array}{l}\text { Secondary structure, multimeric configurations, atomic } \\
\text { resolution structure }\end{array}$ \\
Powder X-ray Diffraction (PXRD) & Atomic resolution structure \\
Small Angle X-ray Scattering & Atomic resolution structure \\
(SAXS) & \\
Single Crystal X-ray Diffraction & Atomic resolution structure \\
(SCXD) & Size distribution of multimers \\
SDS-Page &
\end{tabular}

In Chapter 2 we observed that increasing the ratio of oxidized to unoxidized $A \beta$ had the effect of delaying the oligomer transition to protofibril or fibril species. This transition was roughly delayed by $3 \mathrm{~h}$ (Figure 2.3B). This $3 \mathrm{~h}$ window would provide ample time to perform other separation steps that would enable the isolation of $\mathrm{A} \beta \mathrm{O}$. This isolation of $\mathrm{A} \beta \mathrm{O}$ in the absence of cross-linking and covalent linkages is more advantageous as it is less likely to induce peptide structural modifications. Capitalizing on this observation, it may be possible to use a mixture of oxidized and unoxidized $A \beta$ to delay the oligomer transition to fibrils and further encapsulate them through reverse phase micelles (RM) to structurally study $A \beta$ within an oligomeric aggregate.

First, determining the ideal ratio of $A \beta_{40}$ to $A \beta_{40} \mathrm{Met}[\mathrm{O}]$ would be essential in optimizing the extension of the $A \beta O$ phase. Once established, isotope enriched $A \beta_{40}$ could be mixed with $\mathrm{A} \beta{ }_{40} \mathrm{Met}[\mathrm{O}]$ in a buffer to produce oligomeric aggregates with extended stability. While $\mathrm{A} \beta \mathrm{Os}$ are often heterogeneous in size, additional separation steps may be required to obtain more 4. Outlook: Future directions for advancing the understanding of $A \beta$ aggregation in Alzheimer's disease 
homogenous samples that are amenable to structural analysis. This can be accomplished by sizeexclusion chromatography (SEC) or a sucrose gradient and centrifugation. However, this may dilute samples below concentrations required for structural analysis, and $\mathrm{A} \beta \mathrm{O}$, given time beyond the stabilizing window provided by oxidation, may further associate producing larger aggregates. Both issues could be solved via encapsulating the AßOs in RMs, which would prevent further aggregation and allow for concentrating samples. To encapsulate $\mathrm{A} \beta \mathrm{O}$ s within our aqueous solution we first need create an emulsion of hexane and $\mathrm{H}_{2} \mathrm{O}$ to promote the formation of sodium bis(2-ethylhexyl)sulfosuccinate (AOT) RMs. ${ }^{61,62}$ After encapsulation centrifugation would be utilized to concentrate samples and be resuspended RM-A $\beta O$ s in hexane at the desired concentration. The three-dimensional structure of $A \beta$ within the $A \beta O$ structure could then be determined through solution-state NMR. Previously, encapsulation of monomeric $A \beta$ for structural studies and solution NMR structures of $A \beta$ in water-micelle environments have been effective in determining structural elements of $A \beta .^{63,64}$ By suspending the unoxidized isotope label $A \beta_{40}$ within an $A \beta O$ structure we might be able to determine the structure of $A \beta$ within an oligomer.

Due to the lack of structural information of $\mathrm{A} \beta \mathrm{O}$, insights into their structure would be paramount. This would allow for a more rational design of $\mathrm{A} \beta \mathrm{O}$ fluorescent probes e.g. BODIPY which would allow for high throughput determination of oligomer dynamics. Additionally, the $3 \mathrm{D}$ structure of $\mathrm{A} \beta \mathrm{O}$ s would also benefits computational chemistry by providing a relevant starting point for simulations overall reducing the requirement of computational resources required instead of starting with monomeric forms of $A \beta$. Finally, structural knowledge of $A \beta O s$ would also allow for the development of more effective small molecule or antibody therapeutics helping to provide a treatment option where none are currently available. 


\subsection{Protective Mutations}

In Chapter 3 we acetylated K16 and K28 to explore the role of lysine's electrostatic interactions that are associated with aggregation and membrane binding. We determined that in the absence of lysine's cationic charge oligomerization and fibrillization were inhibited, and while membrane interactions were reduced the membrane facilitated the formation of the critical nucleus promoting fibril formation alongside promoting secondary aggregation pathways. Initially we would have expected that removing the cationic character of lysine would diminish $A \beta$-membrane affinity. Instead other regions of $A \beta$, specifically the hydrophilic $\mathrm{N}$-terminus, may also be involve in the peptide-membrane interaction. However, the role of the N-terminal region of $A \beta$ in oligomerization and polymorphism has remained unexplored largely due to its unstructured nature. ${ }^{63,65}$ Recently, a structural study has propose that the $\mathrm{N}$-terminus is responsible for stabilizing the central hydrophobic core $(\mathrm{CHC})$ in its monomeric state, ${ }^{66}$ and may prevent the hydrophobic collapse of the $\mathrm{CHC}$ to the $\mathrm{C}$-terminus which may initiate the aggregation process. More recently, the charge state of the $\mathrm{N}$-terminal region is found to regulate A $\beta$-membrane interactions with the removal of anionic glutamic acid (E11) and cationic lysine's (K16) exhibiting the slowest deposition rates on POPC bilayer. ${ }^{67}$

Recently, a familial mutation in $\mathrm{A} \beta, \mathrm{A} 2 \mathrm{~T}$, has been discovered and is the only mutation known to exert a protective effect in Alzheimer's disease. Also, the A2V mutation has been discovered but instead results in early-onset Alzheimer's disease. When mixing N-terminal fragments of the 1-7 A2T variant with $A \beta$ fibrillization and cytotoxicity of $A \beta$ was reduced, however when repeated with the addition of the $\mathrm{A} 2 \mathrm{~V}$ mutation the opposite effect was observed. ${ }^{68}$ Furthermore, AFM imaging of $A \beta_{40}, A \beta_{40}(A 2 T)$, and $A \beta_{40}(A 2 V)$ fibrils in the absence of membranes have demonstrated the presence of polymorphic fibrils, ${ }^{69}$ and in the 
presence of a zwitterionic membrane, A2T fibril formation is increased compared to wild-type $\mathrm{A} \beta .^{70}$ From our experiments in Chapter 3 and these recent findings, it is possible that the polar $\mathrm{A} 2 \mathrm{~T}$ mutation will result in reduced oligomerization; whereas, the hydrophobic $\mathrm{A} 2 \mathrm{~V}$ will increase oligomerization. In addition, the A2T mutation should exhibit increased association with the membrane while disallowing the insertion of $\mathrm{A} \beta$ into the membrane; the $\mathrm{A} 2 \mathrm{~V}$ mutation should have the opposite effect due to the hydrophobic nature of valine. This could be tested experimentally using the same methods and techniques used in Chapters 2 and 3. Ultimately, this would clarify how changes in the N-terminus of $A \beta$ effect the oligomerization and membrane binding of $\mathrm{A} \beta$. If the more polar $\mathrm{A} 2 \mathrm{~T}$ mutant exhibited greater oligomerization and membrane binding but reduced membrane disruption this would show that the toxic mechanism of the A $\beta$ membrane interaction is not just connected with $A \beta$ 's association to the membrane but also requires the insertion into the membrane, a finding that would mirror toxicity studies of oxidized $A \beta$ and results of Chapter 2. ${ }^{71-73}$

\subsection{References}

(1) Alzheimer Association. (2016) 2016 Alzheimer's Disease Facts and Figures, Alzheimer's Dement. 2016 12, 1-80.

(2) Stelzmann, R. A., Schnitzlein, H. N., and Murtagh, F. R. (1995) An English translation of Alzheimer's 1907 paper, "uber eine eigenartige erkankung der hirnrinde," Clin. Anat. 8, 429431.

(3) Barage, S. H., and Sonawane, K. D. (2015) Amyloid cascade hypothesis: Pathogenesis and therapeutic strategies in Alzheimer's disease, Neuropeptides 52, 1-18.

(4) Karran, E., Mercken, M., and De Strooper, B. (2011) The amyloid cascade hypothesis for Alzheimer's disease: an appraisal for the development of therapeutics., Nat. Rev. Drug Discov. $10,698-712$.

(5) Nih, and National Institute on Aging. (2015) Alzheimer' s Disease Genetics, Fact sheet No. $15-642,1-8$.

(6) Dovey, H. F., John, V., Anderson, J. P., Chen, L. Z., De Saint Andrieu, P., Fang, L. Y., Freedman, S. B., Folmer, B., Goldbach, E., Holsztynska, E. J., Hu, K. L., Johnson-Wood, K. L., 
Kennedy, S. L., Kholodenko, D., Knops, J. E., Latimer, L. H., Lee, M., Liao, Z., Lieberburg, I. M., Motter, R. N., Mutter, L. C., Nietz, J., Quinn, K. P., Sacchi, K. L., Seubert, P. A., Shopp, G. M., Thorsett, E. D., Tung, J. S., Wu, J., Yang, S., Yin, C. T., Schenk, D. B., May, P. C., Altstiel, L. D., Bender, M. H., Boggs, L. N., Britton, T. C., Clemens, J. C., Czilli, D. L., DieckmanMcGinty, D. K., Droste, J. J., Fuson, K. S., Gitter, B. D., Hyslop, P. A., Johnstone, E. M., Li, W. Y., Little, S. P., Mabry, T. E., Miller, F. D., Ni, B., Nissen, J. S., Porter, W. J., Potts, B. D., Reel, J. K., Stephenson, D., Su, Y., Shipley, L. A., Whitesitt, C. A., Yin, T., and Audia, J. E. (2001) Functional gamma-secretase inhibitors reduce beta-amyloid peptide levels in brain, $J$. Neurochem. 76, 173-181.

(7) Hock, C., Konietzko, U., Streffer, J. R., Tracy, J., Signorell, A., M??ller-Tillmanns, B., Lemke, U., Henke, K., Moritz, E., Garcia, E., Wollmer, M. A., Umbricht, D., De Quervain, D. J. F., Hofmann, M., Maddalena, A., Papassotiropoulos, A., and Nitsch, R. M. (2003) Antibodies against ??-amyloid slow cognitive decline in Alzheimer's disease, Neuron 38, 547-554.

(8) Mangialasche, F., Solomon, A., Winblad, B., Mecocci, P., and Kivipelto, M. (2010) Alzheimer's disease: clinical trials and drug development, Lancet Neurol. 9, 702-716.

(9) Schenk, D. (2002) Amyloid- $\beta$ immunotherapy for Alzheimer's disease: the end of the beginning, Nat Rev Neurosci 3, 824-828.

(10) Vassar, R., Kovacs, D. M., Yan, R., and Wong, P. C. (2009) The -Secretase Enzyme BACE in Health and Alzheimer's Disease: Regulation, Cell Biology, Function, and Therapeutic Potential, J. Neurosci. 29, 12787-12794.

(11) Vassar, R. (2014) BACE1 inhibitor drugs in clinical trials for Alzheimer's disease, Alzheimers. Res. Ther. 6, 89.

(12) Kummer, M. P., and Heneka, M. T. (2014) Truncated and modified amyloid-beta species, Alzheimer's Res. Ther. 6, 1-9.

(13) Kuo, Y.-M. M., Kokjohn, T. A., Beach, T. G., Sue, L. I., Brune, D., Lopez, J. C., Kalback, W. M., Abramowski, D., Sturchler-Pierrat, C., Staufenbiel, M., and Roher, A. E. (2001) Comparative Analysis of Amyloid- $\beta$ Chemical Structure and Amyloid Plaque Morphology of Transgenic Mouse and Alzheimer's Disease Brains, J. Biol. Chem. 276, 12991-12998.

(14) Naslund, J., Schierhorn, A., Hellman, U., Lannfelt, L., Roses, A. D., Tjernberg, L. O., Silberring, J., Gandy, S. E., Winblad, B., and Greengard, P. (1994) Relative abundance of Alzheimer $\mathrm{A} \beta$ amyloid peptide variants in Alzheimer disease and normal aging,

Proc.Natl.Acad.Sci.U.S.A 91, 8378-8382.

(15) Petkova, A. T., Ishii, Y., Balbach, J. J., Antzutkin, O. N., Leapman, R. D., Delaglio, F., and Tycko, R. (2002) A structural model for Alzheimer's -amyloid fibrils based on experimental constraints from solid state NMR, Proc. Natl. Acad. Sci. 99, 16742-16747.

(16) Das, P., Murray, B., and Belfort, G. (2015) Alzheimer's protective A2T mutation changes the conformational landscape of the $\mathrm{A} \beta 1-42$ monomer differently than does the $\mathrm{A} 2 \mathrm{~V}$ mutation, Biophys. J. 108, 738-747. 
(17) Lührs, T., Ritter, C., Adrian, M., Riek-Loher, D., Bohrmann, B., Döbeli, H., Schubert, D., and Riek, R. (2005) 3D structure of Alzheimer's amyloid- $\beta(1-42$ ) fibrils***, Proc. Natl. Acad. Sci. U. S. A. 102, 17342-17347.

(18) Tycko, R. (2015) Amyloid Polymorphism: Structural Basis and Neurobiological Relevance, Neuron 86, 632-645.

(19) Zhang, S., Iwata, K., Lachenmann, M. J., Peng, J. W., Li, S., Stimson, E. R., Lu, Y. A., Felix, A. M., Maggio, J. E., and Lee, J. P. (2000) The Alzheimer's peptide A $\beta$ adopts a collapsed coil structure in water, J. Struct. Biol. 130, 130-141.

(20) Pearson, H., and Peers, C. (2006) Physiological roles for amyloid $\beta$ peptides, J. Physiol. $575,5-10$.

(21) Simmons, L. K., May, P. C., Tomaselli, K. J., Rydel, R. E., Fuson, K. S., Brigham, E. F., Wright, S., Lieberburg, I., Becker, G. W., and Brems, D. N. (1994) Secondary structure of amyloid beta peptide correlates with neurotoxic activity in vitro., Mol. Pharmacol. 45, 373-379.

(22) Howlett, D. R., Jennings, K. H., Lee, D. C., Clark, M. S. G., Brown, F., Wetzel, R., Wood, S. J., Camilleri, P., and Roberts, G. W. (1995) Aggregation state and neurotoxic properties of Alzheimer beta-amyloid peptide, Neurodegeneration 4, 23-32.

(23) Stine, W. B., Dahlgren, K. N., Krafft, G. a., and LaDu, M. J. (2003) In vitro characterization of conditions for amyloid- $\beta$ peptide oligomerization and fibrillogenesis, J. Biol. Chem. 278, $11612-11622$.

(24) Teplow, D. B. (2013) On the subject of rigor in the study of amyloid beta-protein assembly, Alzheimers Res. Ther. 5.

(25) Ryan, T. M., Caine, J., Mertens, H. D. T., Kirby, N., Nigro, J., Breheney, K., Waddington, L. J., Streltsov, V. a, Curtain, C., Masters, C. L., and Roberts, B. R. (2013) Ammonium hydroxide treatment of $\mathrm{A} \beta$ produces an aggregate free solution suitable for biophysical and cell culture characterization., PeerJ 1, e73.

(26) Eugene, T. C., Hall, C., Virginia, W., Box, P. O., Virginia, W., and States, U. (2014) Preparation Protocols of A $\beta(1-40)$ Promote the Formation of Polymorphic Aggregates and Altered Interactions with Lipid Bilayers.

(27) Kodali, R., Williams, A. D., Chemuru, S., and Wetzel, R. (2010) A $\beta(1-40)$ forms five distinct amyloid structures whose $\beta$-sheet contents and fibril stabilities are correlated, J. Mol. Biol. 401, 503-517.

(28) Fezoui, Y., Hartley, D. M., Harper, J. D., Khurana, R., Walsh, D. M., Condron, M. M., Selkoe, D. J., Lansbury, J., Fink, A. L., and Teplow, D. B. (2000) An improved method of preparing the amyloid $\beta$-protein for fibrillogenesis and neurotoxicity experiments, Amyloid 7 , $166-178$.

(29) Broersen, K., Jonckheere, W., Rozenski, J., Vandersteen, A., Pauwels, K., Pastore, A., Rousseau, F., and Schymkowitz, J. (2011) A standardized and biocompatible preparation of aggregate-free amyloid beta peptide for biophysical and biological studies of Alzheimers disease,

4. Outlook: Future directions for advancing the understanding of $A \beta$ aggregation in Alzheimer's disease 
Protein Eng. Des. Sel. 24, 743-750.

(30) Stine, W. B., Dahlgren, K. N., Krafft, G. a., and LaDu, M. J. (2003) In vitro characterization of conditions for amyloid- $\beta$ peptide oligomerization and fibrillogenesis, J. Biol. Chem. 278, $11612-11622$.

(31) Thibaudeau, T. A., Anderson, R. T., and Smith, D. M. (2018) A common mechanism of proteasome impairment by neurodegenerative disease-associated oligomers, Nat. Commun. 9.

(32) Yates, E. A., and Legleiter, J. (2014) Preparation protocols of A $\beta(1-40)$ promote the formation of polymorphic aggregates and altered interactions with lipid bilayers, Biochemistry $53,7038-7050$.

(33) Kowalewski, T., and Holtzman, D. M. (1999) In situ atomic force microscopy study of Alzheimer's beta-amyloid peptide on different substrates: new insights into mechanism of betasheet formation., Proc. Natl. Acad. Sci. U. S. A. 96, 3688-3693.

(34) Yates, E. a., Owens, S. L., Lynch, M. F., Cucco, E. M., Umbaugh, C. S., and Legleiter, J. (2013) Specific domains of A $\beta$ facilitate aggregation on and association with lipid bilayers, $J$. Mol. Biol. 425, 1915-1933.

(35) Pifer, P. M., Yates, E. a., and Legleiter, J. (2011) Point mutations in A $\beta$ result in the formation of distinct polymorphic aggregates in the presence of lipid bilayers, PLoS One 6.

(36) Bhatia, R., Lin, H., and Lal, R. (2000) Fresh and nonfibrillar amyloid b protein(1-42) induces rapid cellular degeneration in aged human fibroblasts: evidence for AbP-channelmediated cellular toxicity, FASEB 14, 1233-1243.

(37) Lin, H. a I., Bhatia, R., and Lal, R. (2001) Amyloid $\beta$ protein forms ion channels: implications for Alzheimer's disease pathophysiology, FASEB J. 15, 2433-2444.

(38) Lin, H., Zhu, Y. J., and Lal, R. (1999) Amyloid-b protein (1-40) forms calcium-permeable, Zn2+-sensitive channel in reconstituted lipid vesicles, Biochemistry 38, 11189-96.

(39) Rhee, S. K., Quist, A. P., and Lal, R. (1998) Amyloid b Protein-(1-42) Forms CalciumPermeable, Zn2+-sensitive Channel, J Bio Chem 273, 13379-13382.

(40) Parbhu, A., Lin, H., Thimm, J., and Lal, R. (2002) Imaging real-time aggregation of amyloid beta protein (1-42) by atomic force microscopy, Peptides 23, 1265-1270.

(41) Legleiter, J. (2011) Assessing A beta Aggregation State by Atomic Force Microscopy, in ,Alzheimer's Disease and Frontotemporal Dementia: Methods and Protocols (Roberson, E. D., Ed.), pp 57-70.

(42) Liu, P., Reed, M. N., Kotilinek, L. A., Grant, M. K. O., Forster, C. L., Qiang, W., Shapiro, S. L., Reichl, J. H., Chiang, A. C. A., Jankowsky, J. L., Wilmot, C. M., Cleary, J. P., Zahs, K. R., and Ashe, K. H. (2015) Quaternary Structure Defines a Large Class of Amyloid-beta Oligomers Neutralized by Sequestration, Cell Rep. 11, 1760-1771.

(43) Sinha, S., Lopes, D. H. J., and Bitan, G. A Key Role for Lysine Residues in Amyloid $\beta$ -

4. Outlook: Future directions for advancing the understanding of $A \beta$ aggregation in Alzheimer's disease 
Protein Folding, Assembly, and Toxicity.

(44) Teoh, C. L., Su, D., Sahu, S., Yun, S. W., Drummond, E., Prelli, F., Lim, S., Cho, S., Ham, S., Wisniewski, T., and Chang, Y. T. (2015) Chemical Fluorescent Probe for Detection of A $\beta$ Oligomers, J. Am. Chem. Soc. 137, 13503-13509.

(45) Jameson, L. P., and Dzyuba, S. V. (2013) Aza-BODIPY: Improved synthesis and interaction with soluble A $\beta 1-42$ oligomers, Bioorganic Med. Chem. Lett.

(46) Ono, M., Watanabe, H., Kimura, H., and Saji, H. (2012) BODIPY-Based Molecular Probe for Imaging of Cerebral $\beta$-Amyloid Plaques, ACS Chem. Neurosci 3, 319-324.

(47) Verwilst, P., Kim, H. R., Seo, J., Sohn, N. W., Cha, S. Y., Kim, Y., Maeng, S., Shin, J. W., Kwak, J. H., Kang, C., and Kim, J. S. (2017) Rational Design of in Vivo Tau Tangle-Selective Near-Infrared Fluorophores: Expanding the BODIPY Universe, J. Am. Chem. Soc. 139, 1339313403.

(48) Goure, W. F., Krafft, G. A., Jerecic, J., and Hefti, F. (2014) Targeting the proper amyloidbeta neuronal toxins: a path forward for Alzheimer's disease immunotherapeutics, Alzheimers Res. Ther. 6.

(49) Lesne, S. E. (2013) Breaking the Code of Amyloid-beta Oligomers, Int. J. Cell Biol. 2013, 950783.

(50) Sengupta, U., Nilson, A. N., and Kayed, R. (2016) The Role of Amyloid-beta Oligomers in Toxicity, Propagation, and Immunotherapy, Ebiomedicine 6, 42-49.

(51) Benilova, I., Karran, E., and De Strooper, B. (2012) The toxic A beta oligomer and Alzheimer's disease: an emperor in need of clothes, Nat. Neurosci. 15, 349-357.

(52) Ferreira, S. T., Lourenco, M. V, Oliveira, M. M., and De Felice, F. G. (2015) Soluble amyloid-beta oligomers as synaptotoxins leading to cognitive impairment in Alzheimer's disease, Front. Cell. Neurosci. 9.

(53) Cline, E. N., Bicca, M. A., Viola, K. L., and Klein, W. L. (2018) The Amyloid- $\beta$ Oligomer Hypothesis: Beginning of the Third Decade, J. Alzheimer's Dis. 64, S567-S610.

(54) Brody, D. L., Jiang, H., Wildburger, N., and Esparza, T. J. (2017) Non-canonical soluble amyloid-beta aggregates and plaque buffering: controversies and future directions for target discovery in Alzheimer's disease, Alzheimers Res. Ther. 9.

(55) Lesne, S., Koh, M. T., Kotilinek, L., Kayed, R., Glabe, C. G., Yang, A., Gallagher, M., and Ashe, K. H. (2006) A specific amyloid-beta protein assembly in the brain impairs memory, Nature 440, 352-357.

(56) Ono, K., Condron, M. M., and Teplow, D. B. (2009) Structure-neurotoxicity relationships of amyloid -protein oligomers, Proc. Natl. Acad. Sci.

(57) Shankar, G. M., Bloodgood, B. L., Townsend, M., Walsh, D. M., Selkoe, D. J., and Sabatini, B. L. (2007) Natural oligomers of the Alzheimer amyloid-beta protein induce reversible

4. Outlook: Future directions for advancing the understanding of $A \beta$ aggregation in Alzheimer's disease 
synapse loss by modulating an NMDA-type glutamate receptor-dependent signaling pathway, $J$. Neurosci. 27, 2866-2875.

(58) Shankar, G. M., Li, S., Mehta, T. H., Garcia-Munoz, A., Shepardson, N. E., Smith, I., Brett, F. M., Farrell, M. A., Rowan, M. J., Lemere, C. A., Regan, C. M., Walsh, D. M., Sabatini, B. L., and Selkoe, D. J. (2008) Amyloid-beta protein dimers isolated directly from Alzheimer's brains impair synaptic plasticity and memory, Nat. Med. 14, 837-842.

(59) Townsend, M., Shankar, G. M., Mehta, T., Walsh, D. M., and Selkoe, D. J. (2006) Effects of secreted oligomers of amyloid beta-protein on hippocampal synaptic plasticity: a potent role for trimers, J. Physiol. 572, 477-492.

(60) Miller, Y., Ma, B., and Nussinov, R. (2010) Polymorphism in Alzheimer A beta Amyloid Organization Reflects Conformational Selection in a Rugged Energy Landscape, Chem. Rev. $110,4820-4838$.

(61) Shuhendler, A., Regina. Gordijo, C., Staruch, R., Oakden, W., Stanisz, G., Chopra, R., and Wu, X. Y. (2010) Gadolinium-Hydrogel-Lipid Hybrid Nanoparticles Provide 'Off-On-Off'MRI Signals for Non-Invasive Thermometry, Mater. Res. Soc. Symp. Proc.

(62) Hildebrand, G. E., and Tack, J. W. (2000) Microencapsulation of peptides and proteins, Int. J. Pharm. 196, 173-176.

(63) Coles, M., Bicknell, W., Watson, R. A., Fairlie, D. P., and Craik, D. J. (1998) Solution structure of amyloid $\beta$-peptide(1-40) in a water-micelle environment. Is the membrane-spanning domain where we think it is?, Biochemistry 37, 11064-11077.

(64) Yeung, P. S. W., and Axelsen, P. H. (2012) The crowded environment of a reverse micelle induces the formation of ??-strand seed structures for nucleating amyloid fibril formation, J. Am. Chem. Soc. 134, 6061-6063.

(65) Yagi-Utsumi, M., Kato, K., and Nishimura, K. (2016) Membrane-induced dichotomous conformation of amyloid $\beta$ with the disordered n-Terminal segment followed by the stable cTerminal $\beta$ Structure, PLoS One 11, 1-10.

(66) Vivekanandan, S., Brender, J. R., Lee, S. Y., and Ramamoorthy, A. (2011) A partially folded structure of amyloid-beta(1-40) in an aqueous environment, Biochem. Biophys. Res. Commun. 411, 312-316.

(67) Morris, C., Cupples, S., Kent, T. W., Elbassal, E. A., Wojcikiewicz, E. P., Yi, P., and Du, D. (2018) N-Terminal Charged Residues of Amyloid- $\beta$ Peptide Modulate Amyloidogenesis and Interaction with Lipid Membrane, Chem. - A Eur. J.

(68) Lin, T. W., Chang, C. F., Chang, Y. J., Liao, Y. H., Yu, H. M., and Chen, Y. R. (2017) Alzheimer's amyloid- $\beta$ A2T variant and its Nterminal peptides inhibit amyloid- $\beta$ fibrillization and rescue the induced cytotoxicity, PLoS One 12, 1-19.

(69) Murray, B., Sorci, M., Rosenthal, J., Lippens, J., Isaacson, D., Das, P., Fabris, D., Li, S., and Belfort, G. (2016) A2T and A2V A $\beta$ peptides exhibit different aggregation kinetics, primary nucleation, morphology, structure, and LTP inhibition, Proteins Struct. Funct. Bioinforma. 84, 
$488-500$.

(70) Jamasbi, E., Hossain, M. A., Tan, M., Separovic, F., and Ciccotosto, G. D. (2018) Fluorescence imaging of the interaction of amyloid beta 40 peptides with live cells and model membrane, Biochim. Biophys. Acta-Biomembr. 1860, 1609-1615.

(71) Misiti, F., Clementi, M. E., and Giardina, B. (2010) Oxidation of methionine 35 reduces toxicity of the amyloid beta-peptide(1-42) in neuroblastoma cells (IMR-32) via enzyme methionine sulfoxide reductase A expression and function, Neurochem. Int. 56, 597-602.

(72) Maiti, P., Piacentini, R., Ripoli, C., Grassi, C., and Bitan, G. (2011) Surprising toxicity and assembly behaviour of amyloid $\beta$-protein oxidized to sulfone., Biochem. J. 433, 323-332.

(73) Ripoli, C., Piacentini, R., Riccardi, E., Leone, L., Li Puma, D. D., Bitan, G., and Grassi, C. (2013) Effects of different amyloid $\beta$-protein analogues on synaptic function, Neurobiol. Aging $34,1032-1044$. 